\title{
The Generalized Least Squares
}

Method (GMM) as a tool for causal

analysis of spending, budget

management and electoral results

NANDE-VÁZQUEZ, Edgard Alfredo

REYES-FONG, Teodoro

PÉREZ-CRUZ, Omar Alejandro 


\section{ECORFAN®}

\section{Chief Editor}

VARGAS-DELGADO, Oscar. PhD

\section{Authors}

NANDE-VÁZQUEZ, Edgard Alfredo. PhD REYES-FONG, Teodoro. PhD

PÉREZ-CRUZ, Omar Alejandro. PhD

Executive Director

RAMOS-ESCAMILLA, María. PhD

\section{Editorial Director}

PERALTA-CASTRO, Enrique. MsC

\section{Web Designer}

ESCAMILLA-BOUCHAN, Imelda. PhD

Web Diagrammer

LUNA-SOTO, Vladimir. PhD

Editorial Assistant

SORIANO-VELASCO, Jesus. BsC

\section{Translator}

DÍAZ-OCAMPO, Javier. BsC

\section{Philologist}

RAMOS-ARANCIBIA, Alejandra. BsC
The Generalized Least Squares Method (GMM) as a tool for causal analysis of spending, budget management and electoral results

No part of this writing protected by the Copyright Law may be reproduced, transmitted or used in any form or medium, graphic, electronic or mechanical, including, but not limited to, the following: Appointments in articles and bibliographic comments, compilation of radio or electronic journalistic data. Visit our website at: www.ecorfan.org

First edition ISBN: 978-607-8695-51-5

Editorial Seal ECORFAN: 607-8695

Control number PG: 2021-08

Classification PG (2021): 311221-0008

For the purposes of articles 13, 162, 163 section I, 164 section I, 168, 169,209, and another applicable section III of the Law of the Right of Self. 


\section{T-Books}

\section{Definition of Books}

\section{Scientific Objetives}

Support the International Scientific Community in its written production of Science, Technology in Innovation in the Research Areas CONACYT and PRODEP

ECORFAN-Mexico SC is a Scientific and Technological Company in contribution to the formation of Human Resource focused on the continuity in the critical analysis of International Research and is attached to the RENIECYT of CONACYT with number 1702902, its commitment is to disseminate research and contributions of the International Scientific Community, of academic institutions, agencies and entities of the public and private sectors and contribute to the linking of researchers who carry out scientific activities, technological developments and training of specialized human resources with governments, companies and social organizations.

Encourage the interlocution of the International Scientific Community with other study centers in Mexico and abroad and promote a wide incorporation of academics, specialists and researchers to the publication Seriate in Niches of Science of Autonomous Universities - State Public Universities - Federal IES Polytechnic Universities - Technological Universities - Federal Technological Institutes - Normal Schools - Decentralized Technological Institutes - Intercultural Universities - S \& T Councils CONACYT Research Centers.

\section{Scope, Coverage and Audience}

Books is a Product edited by ECORFAN-Mexico S.C in its Holding with repository in Mexico, is an arbitrated and indexed scientific publication. It supports a wide range of contents that are evaluated by academic peers by the Double-Blind method, around topics related to the theory and practice of the Research Area CONACYT and PRODEP, respectively, with different approaches and perspectives, contributing to the diffusion of the development of Science Technology and Innovation that allow the arguments related to the decision making and influence in the formulation of international policies in the Field of Sciences. The editorial horizon of ECORFAN-Mexico® extends beyond the academy and integrates other segments of research and analysis outside the scope, as long as they comply with the requirements of rigorous argumentative and scientific, as well as addressing issues of general and current interest of the International Scientific Society. 


\section{Editorial Board}

ROCHA - RANGEL, Enrique. PhD

Oak Ridge National Laboratory

CARBAJAL - DE LA TORRE, Georgina. PhD

Université des Sciencies et Technologies de Lille

GUZMÁN - ARENAS, Adolfo. PhD

Institute of Technology

CASTILLO - TÉLLEZ, Beatriz. PhD

University of La Rochelle

FERNANDEZ - ZAYAS, José Luis. PhD

University of Bristol

DECTOR - ESPINOZA, Andrés. PhD

Centro de Microelectrónica de Barcelona

TELOXA - REYES, Julio. PhD

Advanced Technology Center

HERNÁNDEZ - PRIETO, María de Lourdes. PhD

Universidad Gestalt

CENDEJAS - VALDEZ, José Luis. PhD

Universidad Politécnica de Madrid

HERNANDEZ - ESCOBEDO, Quetzalcoatl Cruz. PhD

Universidad Central del Ecuador 


\section{Arbitration Committee}

ESCAMILLA - BOUCHÁN, Imelda. PhD

Instituto Politécnico Nacional

LUNA - SOTO, Carlos Vladimir. PhD

Instituto Politécnico Nacional

URBINA - NAJERA, Argelia Berenice. PhD

Universidad Popular Autónoma del Estado de Puebla

PEREZ - ORNELAS, Felicitas. PhD

Universidad Autónoma de Baja California

CASTRO - ENCISO, Salvador Fernando. PhD

Universidad Popular Autónoma del Estado de Puebla

CASTAÑÓN - PUGA, Manuel. PhD

Universidad Autónoma de Baja California

BAUTISTA - SANTOS, Horacio. PhD

Universidad Popular Autónoma del Estado de Puebla

GONZÁLEZ - REYNA, Sheila Esmeralda. PhD

Instituto Tecnológico Superior de Irapuato

RUELAS - SANTOYO, Edgar Augusto. PhD

Centro de Innovación Aplicada en Tecnologías Competitivas

HERNÁNDEZ - GÓMEZ, Víctor Hugo. PhD

Universidad Nacional Autónoma de México 


\section{Assignment of Rights}

The sending of a Scientific Work to ECORFAN Books emanates the commitment of the author not to submit it simultaneously to the consideration of other scientific publications for it must complement the Originality Format for its Scientific Work.

The authors sign the Authorization Format for their Scientific Work to be disseminated by means that ECORFAN-Mexico, S.C. in its Holding Mexico consider relevant for the dissemination and dissemination of its Scientific Work by giving up its Scientific Work Rights.

\section{Declaration of Authenticity}

Indicate the Name of 1 Author and 3 Coauthors at most in the participation of the Scientific Work and indicate in extensive the Institutional Affiliation indicating the Unit.

Identify the Name of 1 Author and 3 Co-authors at most with the CVU Scholarship Number-PNPC or SNI-CONACYT- Indicating the Researcher Level and their Google Scholar Profile to verify their Citation Level and $\mathrm{H}$ index.

Identify the Name of 1 Author and 3 Coauthors at most in the Science and Technology Profiles widely accepted by the International Scientific Community ORC ID - Researcher ID Thomson - arXiv Author ID - PubMed Author ID - Open ID respectively

Indicate the contact for correspondence to the Author (Mail and Telephone) and indicate the Researcher who contributes as the first Author of the Scientific Work.

\section{Plagiarism Detection}

All Scientific Works will be tested by plagiarism software PLAGSCAN if a plagiarism level is detected Positive will not be sent to arbitration and will be rescinded from the reception of the Scientific Work notifying the Authors responsible, claiming that academic plagiarism is criminalized in the Penal Code.

\section{Arbitration Process}

All Scientific Works will be evaluated by academic peers by the Double Blind method, the Appeal arbitration is a requirement for the Editorial Board to make a final decision that will be unappeasable in all cases. MARVID ${ }^{\circledR}$ is a derivative brand of ECORFAN ${ }^{\circledR}$ specialized in providing the expert evaluators all of them with Doctorate degree and distinction of International Researchers in the respective Councils of Science and Technology the counterpart of CONACYT for the chapters of America-Europe-AsiaAfrica and Oceania. The identification of the authorship should only appear on a first removable page, in order to ensure that the Arbitration process is anonymous and covers the following stages: Identification of ECORFAN Books with their author occupation rate - Identification of the Authors and Coauthors - Detection of Plague PLAGSCAN - Review of Formats of Authorization and OriginalityAllocation to the Editorial Board- Allocation of the pair of Expert Arbitrators-Notification of OpinionDeclaration of Observations to the Author-Comparison of the Scientific Work Modified for EditingPublication. 
The Generalized Least Squares Method (GMM) as a tool for causal analysis of spending, budget management and electoral results

\section{El Método de Mínimos Cuadrados Generalizados (MMC) como herramienta para} el análisis causal del gasto, la gestión presupuestaria y los resultados electorales

NANDE-VÁZQUEZ, Edgard Alfredo†, REYES-FONG, Teodoro and PÉREZ-CRUZ, Omar Alejandro*

Universidad de Colima, School of Management and Accounting, Colima

ID $1^{\text {st }}$ Author: Edgard Alfredo, Nande-Vázquez / ORC ID: 0000-0001-6029-2242

ID $2^{\text {nd }}$ Coauthor: Teodoro, Reyes-Fong / ORC ID: 0000-0001-9542-5615

ID $3^{\text {rd }}$ Coauthor: Omar Alejandro, Pérez-Cruz / ORC ID: 0000-0003-3367-8259

DOI: $10.35429 /$ B.2021.8.1.130 


\section{The Generalized Least Squares Method (GMM) as a tool for causal analysis of spending, budget management and electoral results}

The Book will offer selected contributions of researchers that contribute to the scientific dissemination activity of the Universidad de Colima for its research area in the function of the University facing the challenges of the Knowledge Society. In addition to having a total evaluation, in the hands of the directors of the Universidad de Colima, quality and punctuality are collaborated in their chapters, each individual contribution was arbitrated to international standards (RESEARCH GATE, MENDELEY, GOOGLE SCHOLAR and REDIB ), the Book thus proposes to the academic community, the recent reports on the new developments in the most interesting and promising areas of research in the function of the University before the challenges of the Knowledge Society. 


\section{Content}

Abstract 1

Abbreviations 2

1. Introduction 3

Chapter 1. The public sector in México: characteristics of its financing and management 5

1.1. Introduction $\quad 5$

1.2. Discrete probability distributions 5

1.2.1. Types of random variables $\quad 5$

1.2.2. Probability function $\quad 5$

1.2.3. Discrete uniform distribution $\quad 6$

$\begin{array}{ll}\text { 1.2.4. Bernoulli distribution } & 7\end{array}$

1.2.5. Geometric distribution $\quad 7$

1.3 Generalized linear model $\quad 8$

Chapter 2. The public sector in México: characteristics of its financing and management 10

2.1. Introduction $\quad 10$

2.2. Legal framework $\quad 10$

2.2.1. Sources of funding $\quad 10$

2.3. The debt of states and city councils in México 13

2.3.1. Legal Framework and destination of indebtedness 13

2.3.2 Borrowing limits $\quad 14$

2.3.3 Debt ratings and subnational governments 16

2.4. The reform of the public sector in México and the new public management 21

2.4.1 The New Public Management in México 22

2.4.2 Administrative and Management Reforms 23

2.4.2.1. Means of verification 23

2.4.3 Management Modernization Programs 24

2.4.4 Government Accounting $\quad 25$

Chapter 3. Budgetary policy cycles: Theoretical framework 28

3.1. Introduction 28

3.2. The theory of public choice 28

3.3. The political economic cycles and political cycles budgets 31

3.4. Main currents of the political-economic cycles $\quad 32$

3.5. Opportunistic and Partisan Irrational Models 33

3.5.1 Rational Current of CPE's

3.5.2 The Eclectic Model 36 
3.5.4. Political Business Cycle $\quad 37$

3.6. Fiscal illusion and budgetary policy cycles 39

3.7. Agency theory 40

3.8. Creative accounting and the handling of information within the framework of budgetary policy cycles 42

Chapter 4. Model Generalized Method of Moments (GMM) applied to expenditure management and budget policy cycles (CPP)

4.1. Introduction $\quad 43$

4.2. Review of the literature $\quad 43$

4.2.1 International empirical evidence $\quad 44$

4.2.2 Empirical evidence in México $\quad 46$

4.3. Objectives and hypothesis $\quad 48$

$\begin{array}{ll}4.3 .1 \text { Objectives } & 48\end{array}$

4.3.2 Hypothesis $\quad 49$

4.4 Sample and variables $\quad 50$

4.4.1 Dependent variables $\quad 50$

4.4.2 Independent variables $\quad 50$

4.5 Methodology $\quad 51$

4.6 Analysis of results $\quad 52$

4.6.1 Results for municipalities $\quad 52$

4.6.2 Results for States $\quad 54$

4.7 Discussion and Conclusions $\quad 56$

Chapter 5 Feasible Generalized Least Squares (FGLS) applied to budget management and $\begin{array}{ll}\text { electoral results } & 58\end{array}$

5.1. Introduction $\quad 58$

5.2 Literature review and empirical evidence $\quad 58$

5.3 Objectives and Hypothesis $\quad 62$

$\begin{array}{ll}5.3 .1 \text { Objectives } & 62\end{array}$

$\begin{array}{ll}\text { 5.3.2 Hypothesis } & 62\end{array}$

$\begin{array}{ll}5.4 \text { Sample and variables } & 63\end{array}$

$\begin{array}{ll}\text { 5.4.1 Defining variables } & 63\end{array}$

$\begin{array}{ll}5.5 \text { Methodology } & 65\end{array}$

4.5.1 Model Specification $\quad 66$

$\begin{array}{ll}5.6 \text { Results } & 66\end{array}$

5.6.1 Results for Municipalities $\quad 66$

$\begin{array}{ll}\text { 5.6.2 Results for States } & 68\end{array}$

$\begin{array}{ll}5.7 \text { Discussion and conclusions } & 69\end{array}$ 


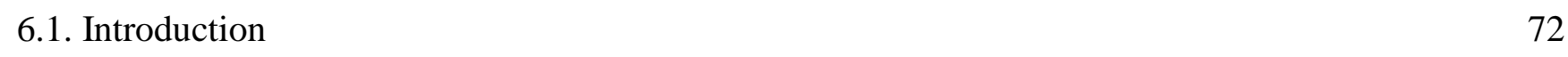

$\begin{array}{ll}\text { 6.1.1 Indebtedness and investment expenses } & 74\end{array}$

6.1.2 Indebtedness and economic and financial capacity of the entities $\quad 74$

6.1.3 Indebtedness and size of states and municipalities $\quad 75$

6.1.4 Indebtedness and CPP $\quad 76$

$\begin{array}{ll}\text { 6.1.5 Debt Limits } & 77\end{array}$

$\begin{array}{ll}6.2 \text { Objectives and hypothesis } & 79\end{array}$

$\begin{array}{ll}\text { 6.2.1 Objectives of the empirical work } & 79\end{array}$

$\begin{array}{ll}\text { 6.2.2 Hypothesis } & 79\end{array}$

6.3. Sample and variables $\quad 81$

6.3.1 Definition of Variables $\quad 81$

6.4. Methodology 82

$\begin{array}{ll}\text { 6.4.1 Model specification } & 83\end{array}$

6.4.2 Auto correlation and Heteroscedasticity $\quad 84$

6.5. Analysis of results $\quad 84$

6.5.1 Results for Municipalities $\quad 84$

5.5.2 Results for States $\quad 87$

6.6. Discussion and conclusions $\quad 89$

$\begin{array}{ll}\text { Conclusions } & 91\end{array}$

$\begin{array}{ll}\text { References } & 97\end{array}$ 


\begin{abstract}
In the different fields of science, many times, there is a need to estimate the associations between variables, as an approach to understanding the interaction of one as a function of the others. It is usually done by applying restrictive models, such as analysis of variance and linear regression. This type of analysis requires that the dependent variable be continuous, have a normal and constant distribution of the mean and variance. However, when the dependent variable is discrete or categorical, the linear model is not viable. Faced with this impediment, the theory of linear models arises and is expanded to broader categories, which have been called Generalized Linear Models. This category assumes that all distribution functions are exponential, in which the normal distribution is located. In this sense, in this research, Generalized Least Squares methods were applied in their various variants: of moments, ordinary and feasible. These models allow calculating the parameters of models in which the dependent variable has a Poisson or multinomial distribution. In such a way that the Generalized Least Squares serve as a tool to analyze the effect of the elections on public spending and its relationship with the electoral results, analyzing the variables of a budgetary nature, derived from the possibility that the government in power continues or is re-elected. For this, data related to the states and municipalities of México in the period 2007 to 2019 are used.
\end{abstract}

\title{
Linear models, Generalized least squares, Public spending and public budgetary
}




\section{Abbreviations}

\begin{tabular}{ll} 
ADEFAS & Debts from Previous Fiscal Years \\
ASF & Superior Audit of the Federation \\
IDB & Inter-American Development Bank \\
CDE & Strategic Debt Cycles \\
CONAC & National Council for Accounting Harmonization \\
CONAPO & National Population Council \\
CNVB & National Banking and Securities Commission \\
CPE & Political Economic Cycles \\
CPP & Political Budgetary Cycles \\
DOF & Official Gazette of the Federation \\
EA & Random Effects \\
EEPC & Standard Errors Corrected for Panel \\
EF & Fixed Effects \\
FENAMN & National Federation of Municipalities of Mexico \\
GMM & Generalized Method of Moments \\
INDETEC & Institute for the Technical Development of Public Finance \\
INPC & National Consumer Price Index \\
INEGI & National Institute of Statistics and Geography \\
INPC & National Consumer Price Index \\
IMF & International Monetary Fund \\
LGCG & General Government Accounting Law \\
MCGF & Generalized Least Feasible Squares \\
OLS & Ordinary Least Squares \\
NGP & New Public Management \\
NICP's & International Accounting Standards for the Public Sector \\
OECD & Organization for Economic Cooperation and Development \\
PGCM & Program for a Close and Modern Government \\
GDP & Gross Domestic Product \\
SMEs & Small and Medium Enterprises \\
SHCP & Secretary of Finance and Public Credit \\
SNCF & National System of Fiscal Coordination \\
TI & Transparency International \\
ICT & Information and Communication Technologies \\
\hline &
\end{tabular}




\section{Introduction}

In the last decade, there has been a growing interest in the problems arising from elections and their relationship with Political Budget Cycles (PBCs), and their relationship with Budget Policy Cycles (BPCs), which, as Shi and Svensson (2003) point out are a periodic fluctuation of government fiscal policies, induced by the cyclicality government fiscal policies, induced by the cyclical nature of elections. In fact, the theories about CPPs, based on the existence of information asymmetries between the electorate and the candidates, have been argued and studied in most European countries and with a tendency to countries in Europe and with an evident trend in America. This type of arguments and contrasts, analyse the existence of opportunistic manipulations in the years close to the elections, with the objective that the party in power continues to govern, observing that there are postulated the ruling party to continue governing, noting that there are positions of penalization and reward for those candidates who manipulate the budget. In this framework, politicians in power can use the politicians can use long-term indebtedness in a way that favours their intentions of continuity, in power, affecting future generations.

The literature has opposing positions, in relation to the reward or punishment of the opportunism of the government in office, that is, it is not clear if there is a reward or punishment for the candidate who increases spending and varies its composition. The works of Akhmedov et al. (2002), Veiga and Veiga (2007b), Sakurai and Menezes-Filho (2008), Drazen and Eslava (2008), Aidt et al. (2011), among others, argue that the electorate rewards fiscal actions derived from opportunism in elections, while Peltzman (1992), Brender (2003) and Brender and Drazen (2008) lean towards the penalty.

Currently, in addition to the literature on CPPs, as a support to demonstrate that governments manipulate the budget for their own benefit, information technologies also play a significant role, so that information on budget management flows every time faster, thanks to the internet and access to information. This allows taxpayers to have access to the information and that it can be used in their voting decisions.

The objective of this work is to analyse the effect of elections on public spending and its relationship with electoral results, analysing the variables of a budgetary nature, derived from the possibility that the government in power continues or is re-elected. Likewise, the factors that make it possible to explain and demonstrate the behaviour of public debt are analysed. For this, data related to the states and municipalities of México in the period 1996 to 2010 are used.

The present work is structured in five chapters, so that first the general theoretical aspects in relation to the investigation are considered and later the empirical works are carried out to contrast the delimited hypotheses. Thus, in the first two chapters we address normative and theoretical aspects, that is, the descriptive framework of the Mexican public sector, proposing its legal framework and characteristics of its financing and management, as well as the theories that support the empirical basis of the doctoral thesis.

Subsequently, in chapters III, IV and V the empirical works are collected, first addressing the chapter, "Expenditure management and budget political cycles", followed by a chapter devoted to "Budget management and electoral results", to conclude with the chapter "Explanatory factors of the level of indebtedness: the case of the states and municipalities of México". We will refer more specifically to each of these chapters below.

The first chapter presents a description of the Mexican public sector, as well as the characteristics of its financing and its management, with special emphasis on the reforms carried out in recent years within the framework of the new public management. In the second chapter we consider the main theories that have gone developing over time, showing its origin and contributions, which directly or indirectly contribute when making any type of analysis. This allows us to define the theoretical framework used in the work and the main contributions that have been made in this area. Subsequently, the empirical works are collected, where we first try to identify the effect that political budget cycles have on the increase or decrease of total public spending and its components, that is, we identify whether expenses increase or decrease in the electoral period and, what type of expenses are preferred by the ruler in power. Therefore, to support the hypotheses raised in this chapter, we begin by reviewing the existing literature and summarizing the development of Political Cycles. 
In this sense, we first resorted to the analysis of international literature, and later, we focused on the review of local literature, that is, on Mexican empirical studies, which in addition to being very scarce, are mostly focused on the level federal and state, focusing our empirical study on the states and municipalities, where this type of literature is most scarce. Once that part is reviewed, we define the objectives; the variables and specific hypotheses and we show the corresponding results for the states and municipalities of México.

In the fourth chapter, we also begin with the literature review, starting from the principles of the explanatory theories of the Political Economic Cycles (CPE) in the context of the theory of Public Choice. In this way, we study the relationship between political stimuli (change in the composition of spending) and electoral results, defining the variables used and the hypotheses to be tested.

In the last empirical chapter, we proceed to analyse which are the determining factors of the recourse to indebtedness, trying to contrast the effect of the political budget cycles and whether this recourse is based on a strategic orientation around the elections. In other words, we intend to analyse whether the evidence of CPP can be an explanatory factor for financing and subsequently for the accumulation of debt. In that sense, we first define the framework of the previous literature of our study.

Subsequently, the objectives, the sample used, which is the same as in the previous chapters, and its specific methodology are established. From this point, the hypotheses are defined, later going on to the analysis of the statistical results obtained and delimiting the main conclusions. We can highlight in this regard, as we have indicated previously, that there is no firm base of work on CPP and its relationship with the resource or accumulation of debt in our country, which makes it interesting and constitutes a novelty in our research.

The research ends with a summary of the main conclusions obtained in each of our empirical works, which constitute the main contribution of the work 


\section{Chapter 1. The public sector in México: characteristics of its financing and management}

\subsection{Introduction}

In this chapter we will address an overview of the family of linear models, from the perspective of Nelder and Wedderburn (1972), called Generalized Linear Models (GLM). This family groups both models with nominal and categorical variables, which implies considering other distributions such as: uniform discrete, Bootstrapping, Bernoulli resampling, binomial, geometric or Pascal, negative binomial, hypergeometric and Poisson.

Since the general linear model is the door to the field of study of general linear models, we will begin this section with a light exploration of the main components of this model, aspects of the general linear model.

\subsection{Discrete probability distributions}

\subsubsection{Types of random variables}

Random variables can be identified as discrete and continuous. Discrete variables acquire these characteristics when the numbers assigned to the elementary events of $E$ are isolated data. The probability of its value constitutes a set of limited or unlimited numbers. For example, if you want to calculate the flip of 6 times a coin without being loaded; the random variable $\mathrm{X}=$ "number of heads obtained in the three tosses", the values assigned to this random variable will be limited $(0,1,2,3,4,5$ and 6$)$.

On the other hand, the variables are continuous if the assigned numbers can have any value, if the value is assigned between certain intervals, that is, it can take any value of R. For example, if a random experiment is carried out where it is sought to evaluate the water level in a body of water, the random variable $\mathrm{X}=$ "water level", can take values in an unlimited way; that is, from 0 to infinity.

\subsubsection{Probability function}

The probability function of a discrete random variable $\mathrm{X}$ is called the application that associates each value of $x i$ of the variables with its probability $p_{i}$.

$0 \leq p_{i} \leq 1 p 1+p 2+p 3+\cdots+p n=\Sigma \mathrm{pi}=1$

For example, if you want to determine the probability of the distribution of the results that are obtained when rolling a die. It can be expressed like this:

Table 1 Distribution of the results

\begin{tabular}{|l|l|}
\hline $\mathrm{X}$ & $\mathrm{P}_{\mathrm{i}}$ \\
\hline 1 & $1 / 6$ \\
\hline 2 & $1 / 6$ \\
\hline 3 & $1 / 6$ \\
\hline 4 & $1 / 6$ \\
\hline 5 & $1 / 6$ \\
\hline 6 & $1 / 6$ \\
\hline
\end{tabular}

Source: Author's Own Elaboration 
And its graphic representation will be:

Figure 1 Probability function

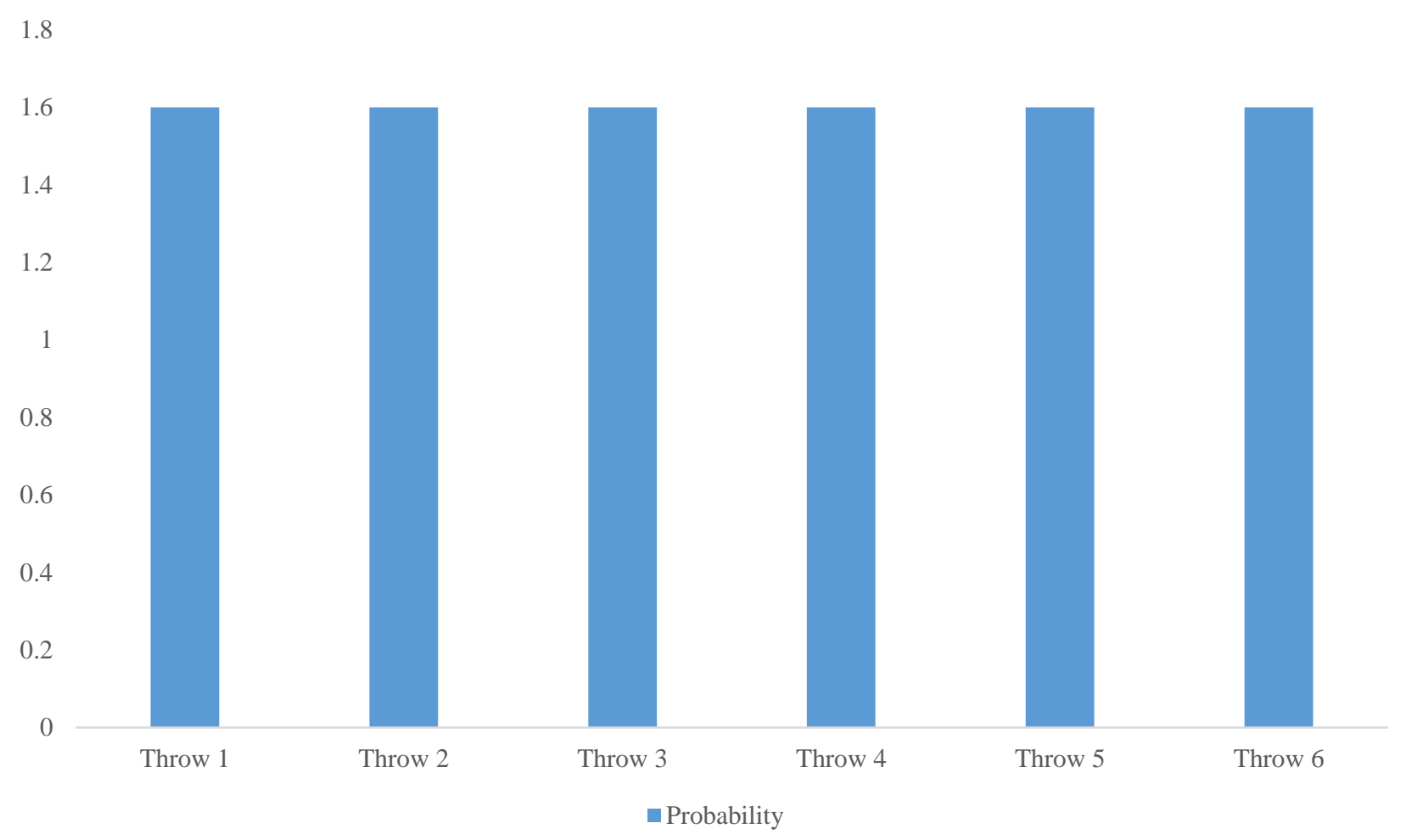

Source: Author's Own Elaboration

\subsubsection{Discrete uniform distribution}

Alonso (2019) explains that a random variable $\mathrm{Y}$ is said to have a discrete uniform distribution over $\mathrm{n}$ points $\{\mathrm{X} 1, \mathrm{X} 2, \ldots, \mathrm{Xk}\}$ if the probability function $\mathrm{P}$ associated with $\mathrm{Y}$ is:

$\operatorname{Pr}\left(X=x_{i}\right)=\frac{1}{n}$, for all $\operatorname{Pr}\left(\mathrm{X}=x_{i}\right)=\frac{1}{n}$, for all $\mathrm{i} \in\{1,2 \ldots, n\}$

Half $\mathrm{E}[\mathrm{X}]=\sum_{i=1}^{n} x_{i} \operatorname{Pr}\left(X=x_{i}\right)=\frac{1}{n} \sum_{i=1}^{n} x_{i}=\bar{x}$

Moments $p: \mathrm{E}\left[|X|^{p}\right]=\frac{1}{n} \sum_{i=1}^{n}\left|x_{i}\right|^{p}$

Variance $V[\mathrm{X}]=\mathrm{E}\left[X^{2}\right]-E^{2}[\mathrm{X}]=\frac{1}{n} \sum_{i=1}^{n} x_{i}^{2}=\frac{1}{n} \sum_{i=1}^{n}\left(x_{i}-\bar{x}\right)^{2}$

Thus, the random variable Y reproduces the characteristics of the original sample.

If the points $\{\mathrm{X} 1, \mathrm{X} 2, \ldots, \mathrm{Xk}\}$ are themselves a random sample, the practice of taking samples of the variable $\mathrm{Y}$ is called bootstrap.

In this regard, the following example 1 is presented. We want to predict the result of spinning a roulette which is divided into 6 equal sectors. If the wheel is spun randomly, what is the probability that the needle will land on a sector marked with only vertical lines? You must specify a random variable that models the result of the roll and tells its function of mass, mean and variance.

$\mathrm{X}=i$ if the number is rolled on the die roll $i$, with $i \in\{1,2,3,4,5,6\}$.

$\operatorname{Pr}(X=i)=1 / 6$, that is, all outcomes are equally likely.

$E[X]=\frac{1+2+3+4+5+6}{6}=3.5$ 
$V[X]=\frac{1^{2}+2^{2}+3^{2}+4^{2}+5^{2}+6^{2}}{6}-3.5^{2} \approx 2.9167$

$V[X]=12+22+32+42+52+626-3.52 \approx 2.9167$

\section{- $\quad$ Recursion of discrete uniform distribution}

In mathematics, the name of recursion is given to the technique of defining a function in terms of itself. Since in $\mathrm{C}$ a function can call other functions, it is allowed that a function can also call itself. Every recursively defined function must contain at least one explicit definition for some of its arguments. Otherwise the function can go into an infinite loop. When we run a recursive program, recursive calls are not executed immediately. What you do is put them in a stack until the term condition is found. Then the calls to the function are executed in the reverse order of how they were generated, as if they were being removed from the stack, therefore the order would be something like this:

$1 !=1$

$2 !=2 * 1 !=2 * 1=2$

$3 !=3 * 2 !=3 * 2=6$

$n !=n(n-1) !=\cdots 1$

\subsubsection{Bernoulli distribution}

The Bernoulli distribution is applied when the expected results are dichotomous, that is, where two response options are expected: yes or no. An example of this can be applied to the area of quality in service, where an investigation can lead to the fact that in the field of quality, a service may or may not have quality.

Thus, the values of a Bernoulli distribution can have two numerical options, 0 and 1, where 1 corresponds to a characteristic and 0 corresponds to not having that characteristic. A random variable $\mathrm{Y}$ follows a Bernoulli distribution if $\mathrm{P}(\mathrm{X}=1)=\mathrm{p}$ and $\mathrm{P}(\mathrm{X}=0)=1-\mathrm{p}$, where $\mathrm{p}$ is the probability of the presence of the determined characteristic.

Thus, the Bernoulli distribution is a discrete distribution that is in turn related to many other distributions, for example a binomial (yes-no), geometric (A and not A) and negative binomial distribution. The Bernoulli distribution expresses the dependent variable of 1 experimentation.

The Bernoulli repetition runs are the basis for generating the other distributions, where the binomial distribution calculates the number of positive responses in $\mathrm{n}$ repetitions; the geometric distribution estimates the number of failures before the first positive response and the negative binomial distribution determines the number of failures before the positive response in $\mathrm{x}$ number of times. This graph shows a binomial distribution that has 1 trial and an event probability of 0.15 . A binomial distribution with 1 trial is the same as a Bernoulli distribution.

\subsubsection{Geometric distribution}

This distribution occurs when a trial has only two possible dependent variables, this distribution is a discrete distribution that can measure the number of consecutive times necessary to obtain the expected result for the first time. Likewise, this same distribution can evaluate the number of times that occur before the first result is observed.

For example, a geometric distribution can evaluate the number of times a coin must be tossed before the first "heads" result is obtained. Similarly, if it is intended to measure the products made in an assembly line, this distribution can calculate the number of products before a defective unit is obtained. The following Figure 2 represents a geometric distribution with an event probability of 0.5. 
Figure 2 Geometric distribution

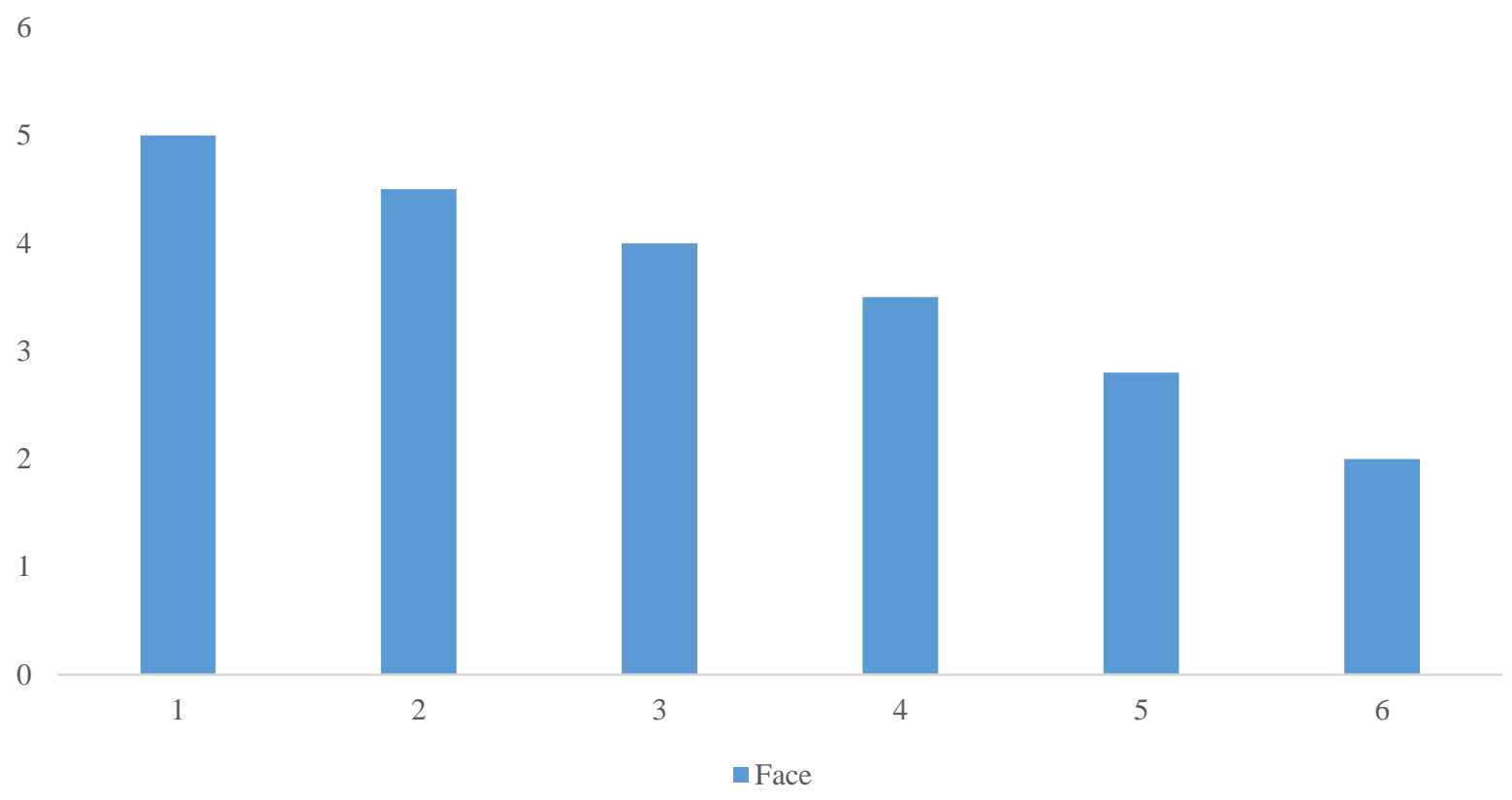

Source: Author's Own Elaboration

\subsection{Generalized linear model}

The general linear model is developed due to the need to represent quantitatively, the relationships between sets of variables, in which one is identified as a dependent or response variable and the others are called independent, explanatory or covariate variables.

In this sense, if $Y$ were a dependent variable that belongs to a family of probability distributions $\mathrm{H}$, and is explained by a set of variables $\mathrm{X} 1, \mathrm{X} 2, \ldots, \mathrm{X}$, which are designed to respond to $\mathrm{Y}$. Y value will be determined given by:

$\in\left(\frac{Y}{X_{1}, X_{2} \ldots X_{k}}=\beta_{0}+\beta_{1} X_{1}+\cdots+\beta_{k} X_{k}=\mu\right.$

Then, if we obtain a random sample of any size from this same population where $\mathrm{Y}$, and $\mathrm{X} 1, \mathrm{X} 2$, ..., Xk are linearly related, each observation in the sample can be expressed as follows:

$Y_{1}=\beta_{0}+\beta_{1} X_{i 1}+\cdots+\beta_{k} X_{i k}=\varepsilon_{i}$

Where $i=1, \ldots \mathbf{n}$ and $\varepsilon_{-} 1$ is a representation of a random error, which is inserted by default to have a causal effect of 0 , but with a constant variance $\sigma^{\wedge} 2$. Likewise, two random errors $\varepsilon_{-} 1$ and $\varepsilon_{-}\left(i^{\prime}\right)$, $\forall i \neq i^{\prime}$ can be introduced, which are not correlated with each other and can be expressed as follows:

$Y=X \beta+\varepsilon$

Where, $Y^{\prime}=(Y 1, Y 2, \ldots Y n)$ is a vector of variables, which is called a response vector of order $\mathrm{n}$; $\mathrm{X}$ is the matrix of independent variables of order $\mathrm{nx}(\mathrm{k}+1)$ and $\mathrm{B}$ the vector of unknown parameters of order $(k+1)$.

The response vector $\mathrm{Y}$ of expression (3) is made up of two components, one systematic and the other random. The first component constituted by the linear combination $\mathrm{X} \beta$, a linear predictor, which is represented as:

$n=X \beta$ 
The second component is made up of a random variable $\mathrm{Y}$, with independent variables, characterized by a distribution $\mathrm{h} \in \mathrm{H}$ with expected value $\mu$ and covariance matrix. In this way, when calculating the value of Yen (3), we have to:

$\in(Y)=X \beta=\mu$

A distinctive element of generalized linear models is that the dependent variable $\mathrm{Y}$ is expressed on a nominal scale, while the covariates can be nominal and / or categorical and that they are independent of each other. 


\section{Chapter 2. The public sector in México: characteristics of its financing and management}

\subsection{Introduction}

The public sector should be understood as a set of economic activities of a nation that directly or indirectly fall under the sphere of government action, that is, it includes all government companies and services at the three levels: federal, state and local.

Ayala (2001) considers the public sector as the formal authority to make decisions that transcend private groups and the market, which gives great power and influence over the total resources, which are available to the economy and society in your whole.

México has distinguished itself as a country with high income inequality, which, according to the OECD (2011), has recorded indicators, such as GDP, lower than the average of the affiliated countries in recent decades. There is also inequality between their regions, where the policies to overcome these irregularities have been largely compensatory, instead of focusing on boosting the growth potential of the less favoured states, thereby affecting the growth of the country.

However, in another study the OECD (2015), comments that in México legislative work has been carried out since 2012 to propose structural measures that allow improvements in competition, education, energy, employment, infrastructure, telecommunications and the tax system, where if its implementation is fully implemented, the impact of the GDP trend to 2040 will be one percentage point per year.

In this sense, the current boost to public spending on infrastructure, for example, has made it possible to strengthen investor confidence thanks to the recovery of GDP ( $0.5 \%$ in 2014), derived from the country's structural reforms, whereas conditions progress of the new management, they will improve the conditions of life of the whole country.

\subsection{Legal framework}

The legal framework of the public sector is defined in the political constitution, where the State and Municipality are defined as a legal-political unit, regulated in articles 115 and 116 respectively. In this sense, the public power of the states it will be divided for its exercise into executive, legislative and judicial, where two or more of these powers may not meet in a single person or corporation, nor may the legislature be deposited in a single individual. As regards the municipality, it will be constituted by a community of people, established in a specific territory, and has legal personality and its own assets.

\subsubsection{Sources of funding}

Among the financial resources available, both for states and municipalities, financing from own income stands out, a source that is one of the most important, especially for states and municipalities with a greater number of inhabitants. Financing from own income are mandatory contributions set unilaterally by the government through taxes, products, rights and uses.

Another resource is income from development programs, such as programs that the Federation has undertaken to strengthen sub-national governments and those that states have created to support their municipalities, regulated within the National Coordination System Fiscal (SNCF), which establishes the federal contributions as resources that the Federation transfers to the public finances of the states and, where appropriate, to those of the municipalities, conditioned on the achievement and fulfilment of the objectives that the Fiscal Coordination Law establishes.

Finally, the public debt is represented by the set of obligations contracted by a state or one of its political subdivisions, because of a credit operation that allows expanding the income available to immediately meet the demands of society, destined by regulations to investment in productive public works and improvement in the provision of public services. 
In this context, Calderón, Orozco y Villegas (2002) explain must understand that public debt represents resources that are used to finance public spending, when ordinary income is not enough. In general, the financial instruments used by state governments and municipalities are loans to the private and public banking sectors, issuance of debt or equity instruments, and financing with suppliers. The Figure 3, show this legal structure.

Figure 3 Legal Structure of the Public Sector

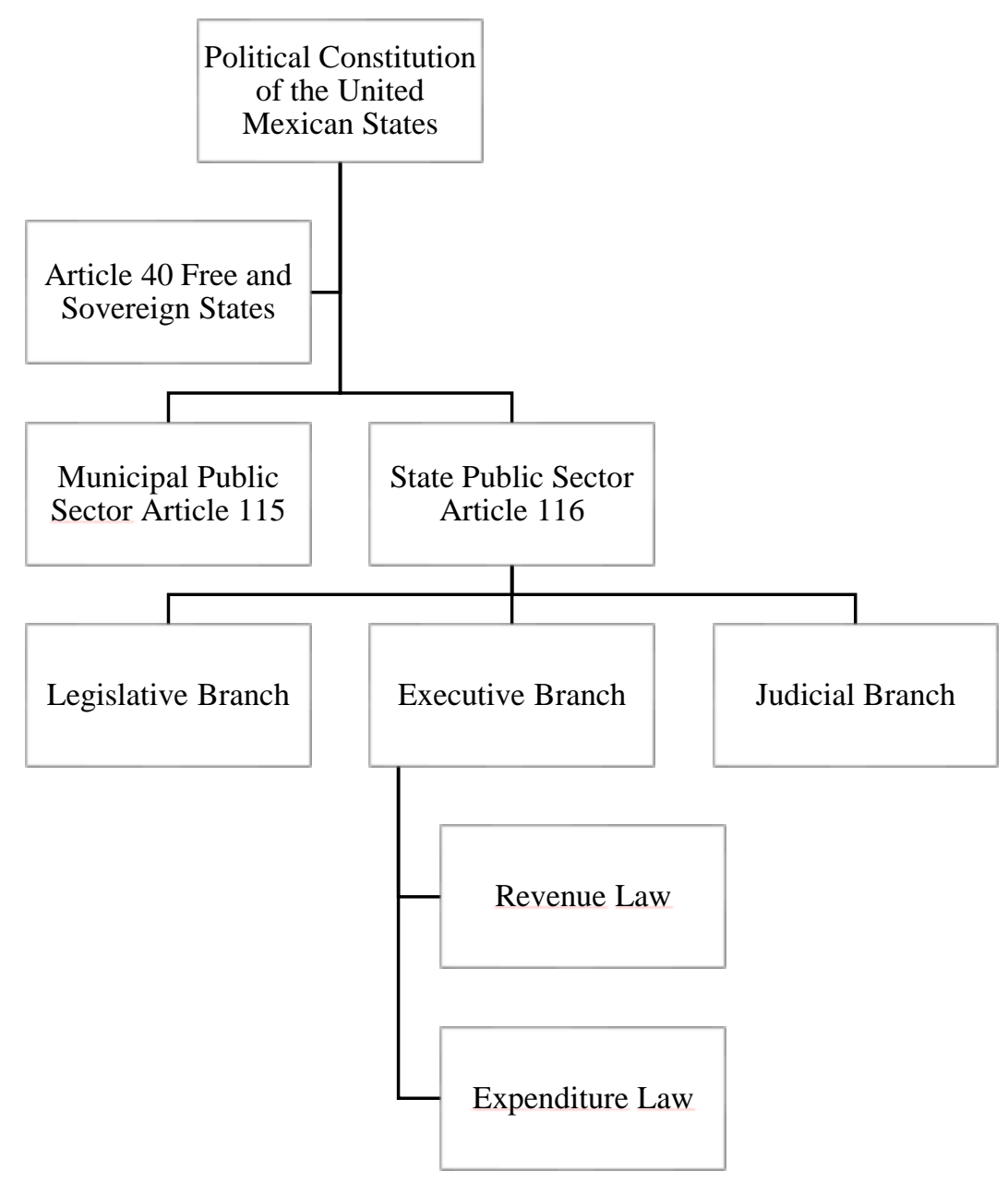

Source: Author's Own Elaboration based on current regulations

In the previous figure it was observed that in our Constitution, the principle of division of powers is established in article 49, according to which "the Supreme Power of the Federation is divided for its exercise into Legislative, Executive and Judicial". These powers carry out their functions independently and autonomously. Formally, the Legislative Power develops the legislative function (making the law), the Executive the administrative one (executing the law), and the Judicial branch the jurisdictional one (interpreting the law and imparting justice).

Now, according to the flexible division criterion, each power, from the formal point of view, performs the function assigned to it as a priority. However, from the material point of view and in a complementary manner it also carries out the other two functions, without this implying invading the matters that are the competence of the other powers.

The regulations for the payment of obligations, contained in article 9 of the Fiscal Coordination Law (DOF, 2018a), establishes that entities and municipalities will make payments of obligations in accordance with the registration mechanisms and systems established in their state debt laws and only the states should have a single registry of obligations and loans, as well as periodically publish information regarding their debt records. If there is a gap in the income-expenditure relationship of the entities, having exhausted the possibilities of obtaining resources without resorting to credit, income mechanisms can be sought through loans or bond issuance, which contribute to the execution of the works and services entrusted to the government, complementing its regular resources. 
In a recent report and within the framework of the new public management, the Ministry of Finance and Public Credit (SHCP) through the Federal Audit of the Federation, required to modernize and update the rules to make the administration of resources transparent. obtained through indebtedness, to prohibit State and local authorities contract debt, unless the resources are destined to productive public investment projects.

However, there is still the registration of contingent liabilities, financing used in contingencies, such as natural disasters, for example, inscribed in Article 2, section III, which comprise a particular scheme of public-private partnership that implies the conclusion of a long-term service contract between a dependency or entity and a supplier investor, a scheme used by governments state and municipal based on the reform of their legal framework, which are not labelled as public debt, but as current expenditure, a situation that implies the need to establish fiscal rules of prudence and responsibility to strengthen public finances.

In this context, in 2014 the SHCP reported an exponential growth in the debt of the states, where the Federal District, Nuevo León, Chihuahua, Veracruz and the State of México are headed, accounting for $49.28 \%$. In relation to the ratio of debt to GDP, it represents 9\% in Chihuahua, 7.5\% in Quintana Roo, 6.8\% in Chiapas, $6.5 \%$ in Coahuila and 5.8\% in Nayarit. The least indebted are $0 \%$ in Tlaxcala, $0.1 \%$ in Campeche, $0.5 \%$ in Querétaro, $0.9 \%$ in Tabasco and $1 \%$ in Yucatán. On the other hand, the SHCP as of 2014 reports that the indebtedness of the municipal administrations grew 9.4\%, going from 46,565 million pesos to 49,084 million in 2014.

Legal regulation of income and expenses of the state public sector and municipal to address the legal issue of income and expenses for states and municipalities, the general regulations are based on and related to the legal document issued and proposed by the federal executive called the Revenue Law, which establishes the estimate of the income that must be collected during a fiscal year. tax by concept of taxes, rights, products, benefits, issuance of bonds, loans, among other items, all to cover the expenses stated in the expenditure budget. This law must be approved by the Chambers of Deputies and Senators (DOF, 2018b)

In this sense, in each state the state executive prepares the income and expenditure budget law before December 15 of each year, which it will send to the local congress for approval and resolution. For its approval, each local legislature will examine and vote on the income and expenditure law corresponding to each state, establishing income and expenditure items like those established by the federation. For municipalities, the income and expenditure budget law originate separately, that is, the sources of financing are identified and subsequently based on this, the expenditure budget for the municipality is drawn up.

In this sense, the income law empowers the municipalities to collect the income to which they are entitled. This document is regulated from article 115 of the constitution. The draft of this law must be prepared by the municipal treasury in strict adherence to the provisions of the Political Constitution of the state, the Municipal Tax Code, the Municipal Finance Law and other current tax provisions.

Once the draft Income Law has been prepared by the treasury, it is presented to the municipal president. This is presented for its approval before the city council in a council session so that the concepts of income are discussed, as well as the determined quotas and rates. Already approved by the city council, the municipal president presents the bill to the State Congress, where it is discussed, sanctioned and approve. Subsequently, it is sent to the state executive for publication in the official state newspaper. The validity of this law is one year from its publication. This period begins on January 1 and ends on December 31 of each year.

The expenditure budget, like the income law, must be prepared by the municipal treasury, under the guidance and supervision of the municipal president, considering the amount available from the town hall income, as provided in the Municipal Organic Law of the state and the Municipal Finance Law. The criteria that each municipality must follow to prepare its expenditure budget must be determined by its specific needs, however it is very important that an elementary order be followed to elaborate it, in such a way that it is understandable and ensures proper, effective and honest management. of the resources of the municipality. 
Currently, given the limitations faced by the public treasury to attract sufficient resources that allow public spending to cover the needs expressed in its own budget, the preparation of the above documents must meet the following requirements:

1. The annual goal for the public balance is established, in congruence with the objectives of the economic policy.

2. Public revenues are estimated based on the projections of the macroeconomic variables of tax policies, prices and rates.

3. Non-programmable expenditure is calculated, an outlay destined to the fulfilment of obligations and supports determined by law, which does not finance the operation of the federal government institutions.

4. The remainder obtained determines the ceiling for the programmable expense, which is distributed according to the authorized criteria.

These requirements, given the crisis in the global context and consequently in the Mexican environment, encourage public administrations to comply with regulations and try to efficiently use their administrative, budgetary and accounting resources, to offer adequate accountability and quality in the services they offer to their citizens.

Both the income law and the expenditure budget are considered as instruments of the three government bodies (federal, state and local) to directly influence the national economy, subject to society to render accounts, in relation to the intended objectives (Perez-Cruz, 2016).

\subsection{The debt of states and city councils in México}

\subsubsection{Legal Framework and destination of indebtedness}

The public debt of the states and municipalities is legally regulated by articles 73 and 117 of the Political Constitution of the United Mexican States, summarized in figure 2, establishing that financing from public debt can only be contracted with the exclusive purpose of allocating it to productive public investment. Along these lines, credit financing is subject to the norms dictated by the Federal Political Constitution, minimum norms that states and municipalities must comply with.

In addition, the laws of the states establish in a general way that the loans or credits contracted by the governments of the states or municipalities must be used for productive public investments. In this regard, given the breadth of this concept and the justification that each federal entity gives it, it is evident that practically any state expenditure can be considered productive investment, since the concept does not distinguish between what could be considered a current expenditure and one of capital that increases the collection of physical assets of the entity for payment. These deficiencies somewhat limit the government's powers to limit the amount of indebtedness.

According to the Mexican Constitution, the limits and conditions for contracting debt must be established by the Local Congresses in their respective public debt laws. However, in practice, congresses often respond to the interests of the groups in power. The sub-national debt registry is regulated in accordance with the regulations of article 9 of the Fiscal Coordination Law (DOF, 2018a).

On the other hand, the constitution establishes the powers that local congresses have to legislate and authorize loans to states and municipalities according to their annual budgets. However, it does not specify the concept of investments that each entity will produce in relation to financing, leaving open the possibility that the states and municipalities register or not the debts that are not guaranteed with federal participations, such as short-term credits or financing contingents, the latter considered in the Public Debt law as current expenditure. The Figure 4 show this public debt. 
Figure 4 Structure of the regulatory framework for public debt in México

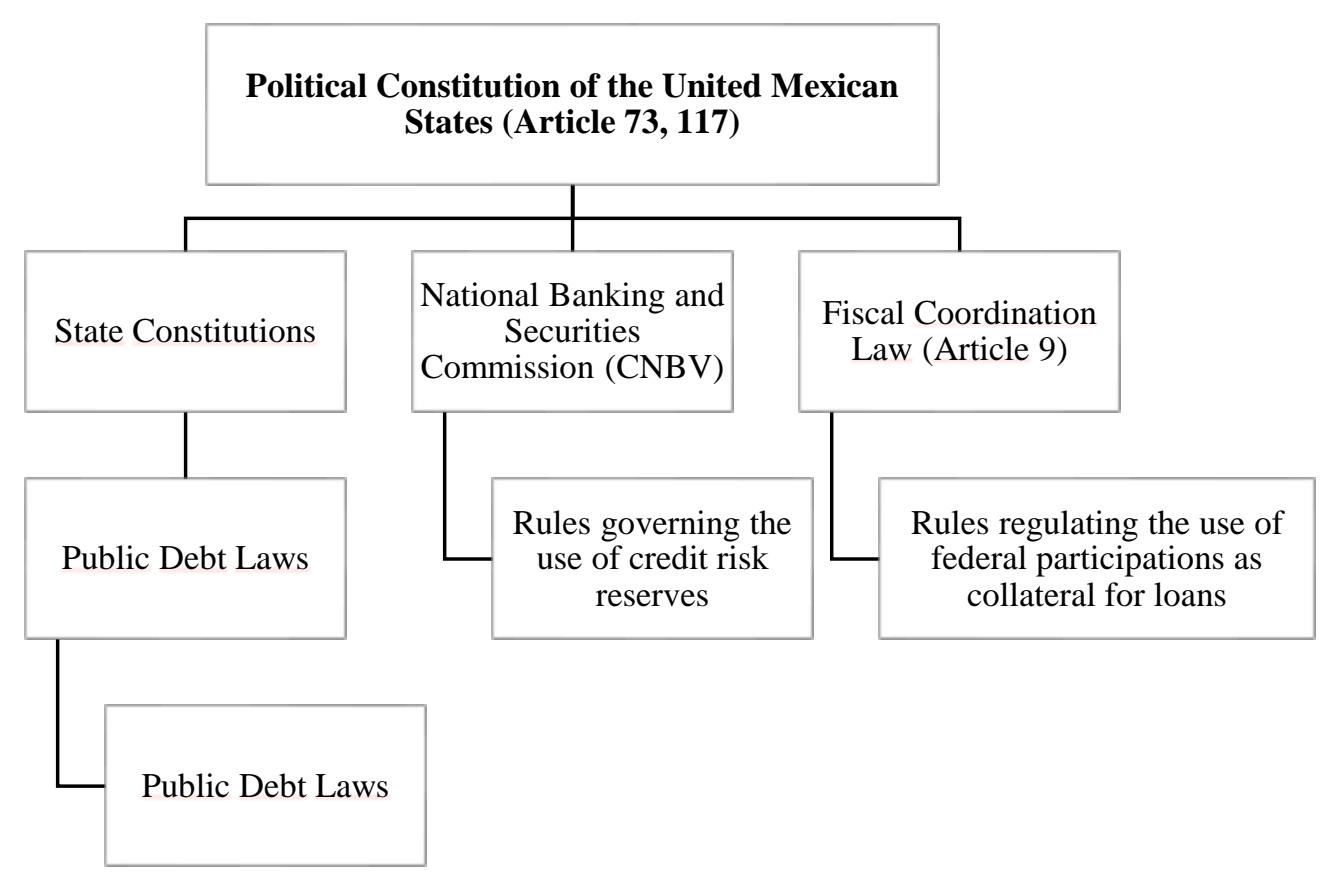

Source: Author's own elaboration, current regulations.

However, the previous structure is the base from which the norms in state and municipal matters should be designed. In this way, both the states and the municipalities have, in principle, the powers granted to them by the Federal Constitution and their powers can be expanded according to the schemes of state-municipality coordination that each state determines, regulated in the Fiscal Coordination Law.

\subsubsection{Borrowing limits}

According to the legal framework, the authorization of the public financing of the states for the fiscal year in question corresponds to the local Congress in use of its powers to approve the financial programs of the state government and, in some cases, to set restrictions on the indebtedness as a function of type variables fiscal and financial.

In this sense, due to the repercussions that excess indebtedness has on state and municipal public finances, and the possibility of financial insolvency, some local legislatures established in their law's limits to indebtedness, associated in some cases with their disposable income, in others are equal to a percentage of your budget, or to federal revenue shares. Other limits only applied to municipalities and for short-term financing whose maturities did not exceed 180 calendar days. On the other hand, according to the Superior Audit of the Federation (ASF, 2011) of all the states, only 17 legislated to establish locks that limit public financing, which included their municipalities.

With the administrative modernization, in February 2015 the reform of the Constitution in matters of financial discipline of the federative and municipal entities was approved, collecting new limits for the authorization of the contracting of debt, highlighting the powers of the local Congresses to approve loans, superior oversight and the principle of transparency and accountability, as well as new provisions for contracting debt by municipalities and state. That is, it establishes that states and municipalities may not contract obligations or loans but when they are used for refinancing or restructuring, which must be carried out under the best market conditions.

In addition, local legislatures must authorize, with the vote of two-thirds of their members present, the maximum amounts to contract said loans and obligations, after analysing their destination, payment capacity and the granting of a guarantee or the establishment of the source of payment. The constitutional reform also establishes that states and municipalities may contract obligations to cover their short-term needs, without exceeding the maximum limits and the conditions provided by the general law issued by the Congress of the Union. Table 2 summarizes the evolution of public debt, and the and Figure 5, shows the tendency of this public debt, as a percentage of public spending in México. 
Table 2 Evolution of public debt in México

\begin{tabular}{|l|r|}
\hline Date & Total debt (M.Dlls) \\
\hline 2020 & 656.877 \\
\hline 2019 & 676.884 \\
\hline 2018 & 656.138 \\
\hline 2017 & 626.868 \\
\hline 2016 & 612.184 \\
\hline 2015 & 618.692 \\
\hline 2014 & 643.443 \\
\hline 2013 & 585.119 \\
\hline 2012 & 512.228 \\
\hline 2011 & 506.516 \\
\hline 2010 & 444.341 \\
\hline 2009 & 394.551 \\
\hline 2008 & 474.004 \\
\hline
\end{tabular}

Source: Author's own elaboration based on Dates Macro (2020)

Figure 5 Evolution of public debt in México as a percentage of gross domestic product (GDP)

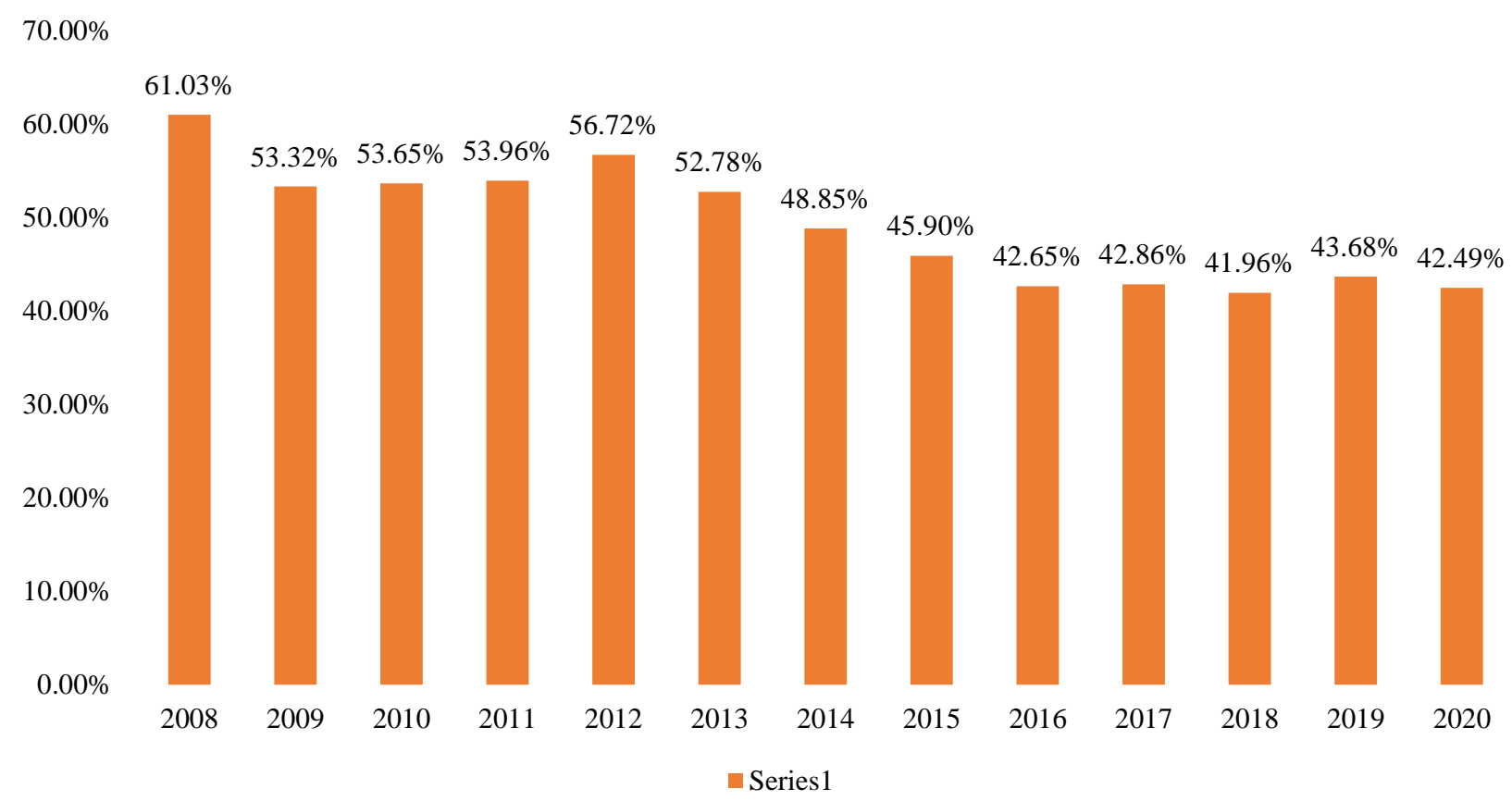

Source: Author's own elaboration based on Dates Macro (2020)

The level of debt of the Mexican public sector has evolved in recent years in line with the financing limit and the deficit authorized in each legislature locally and federally, so it is important to maintain the debt level recommended by the International Monetary Fund [IMF] (2012a, b) which indicates that a level of public debt risk in emerging markets is $60 \%$ percent of GDP, a much higher figure registered in the country.

It also points out that according to its article IV of the IMF (Constitutive Agreement, the level of debt in México is moderate and will remain stable in the medium term. In this context, the fact of not keeping a debt limit, can lead to serious financial difficulties that they can take years to recover (Blaug, 1985), which can harm their debt status in the short term. Figure 6 shows public debt as a percentage of gross domestic product (GDP). 
Figure 6 Public debt per capita

6

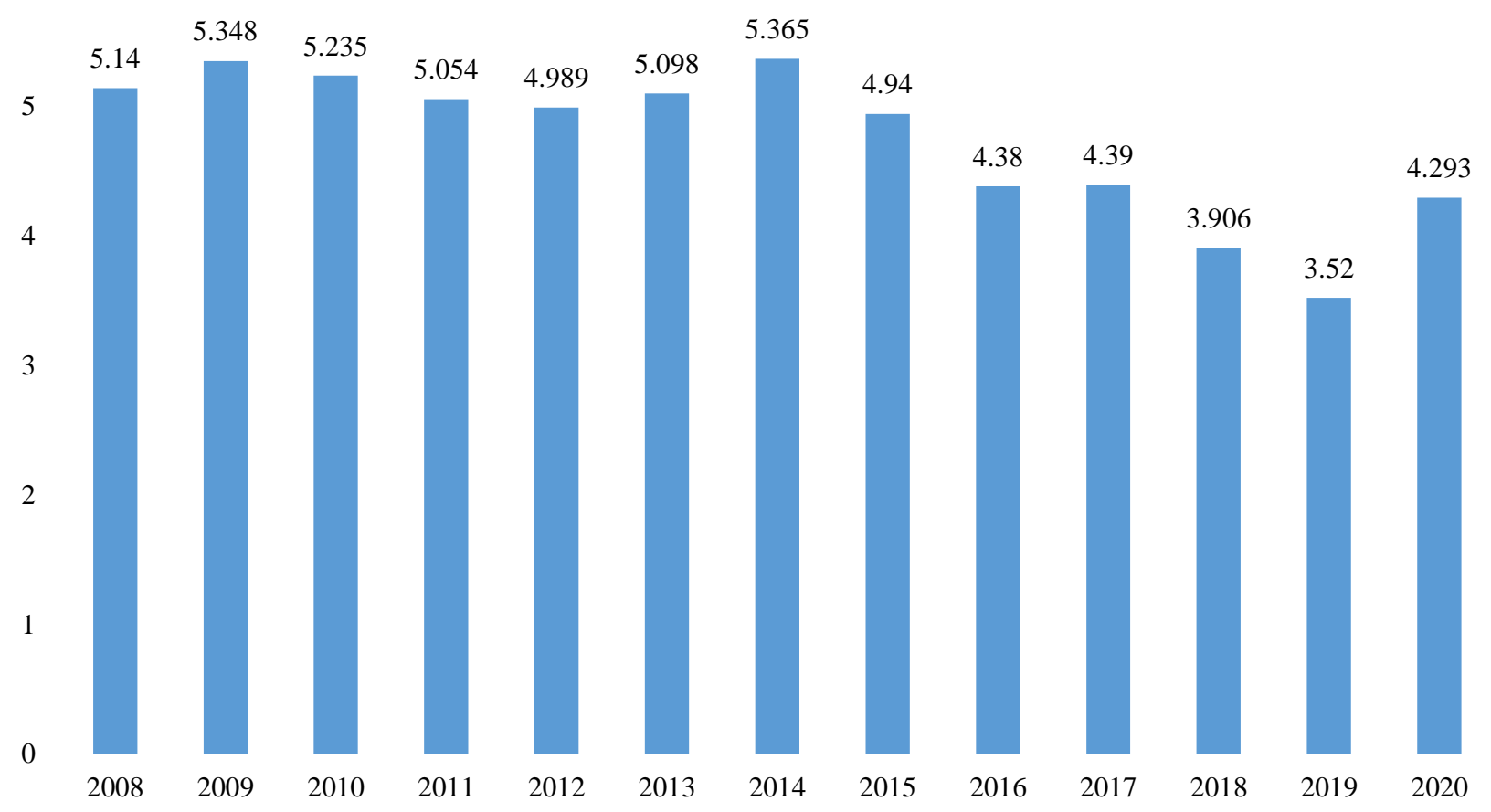

Source: Author's own elaboration based on Dates Macro (2020)

Faced with this situation, the legislators approved the constitutional reform in matters of fiscal responsibility and financial discipline of states and municipalities, which establishes principles, controls and guidelines that promote the orderly and sustainable use of financing for federal entities and their municipalities, as well as, avoid the incorrect use of financing for public debt, highlighting in transitory article 8 , that the debt of states and municipalities must be contracted through public bidding, for ensure the best market conditions and the strengthening of transparency.

\subsubsection{Debt ratings and subnational governments}

State and local governments in México today have a complex economic and financial situation that could put their credit quality to the test in the future, due to various internal and external factors. These types of factors can be classified in relation to the upward trend of the crisis in a global context, a deficient limit in the regulations on the recourse of debt, cuts in federal transfers to states and municipalities, a decline or stagnation in the generation of own income and the continuous pressures derived from permanent operating expenses, conditioned by an excessive payment of wages and salaries. According to data from the SHCP (2014), the evolution of the debt grew exponentially due to budgetary and financial factors, mainly in relation to higher shares in federal income, as the main source of payment and guarantee of contracted financing, with some characterizing notes of the situation. 
Figure 7 Debt payment of feder tarnsfers by state in 2020

$140,000,000,000$

$120,000,000,000$

$100,000,000,000$

$80,000,000,000$

$60,000,000,000$

40,000,000,000

$20,000,000,000$

0

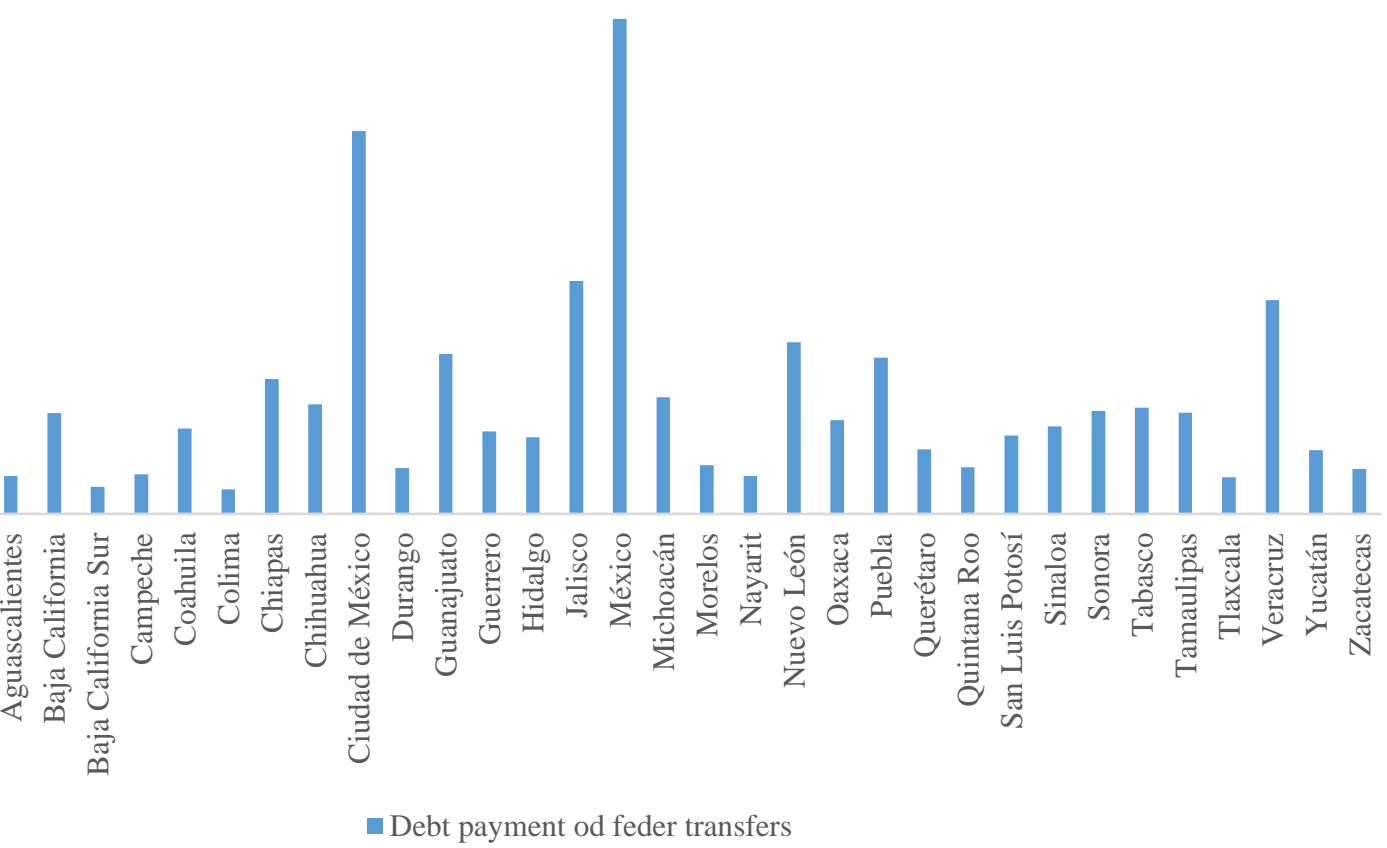

Source: Author's Own Elaboration

In addition to mounting deficits, the growth of the credit market, falling interest rates and the incursion of local governments in issuing debt securities in the stock markets, the issuance of debt has led to the emergence of credit ratings. , which translates into better financial conditions when contracting a loan, which is why it is convenient for local governments to qualify themselves and know their financial solvency as well as being a regulatory requirement to have access to the various debt markets.

Figure 8 Debt payment of state institutions by state in 2020

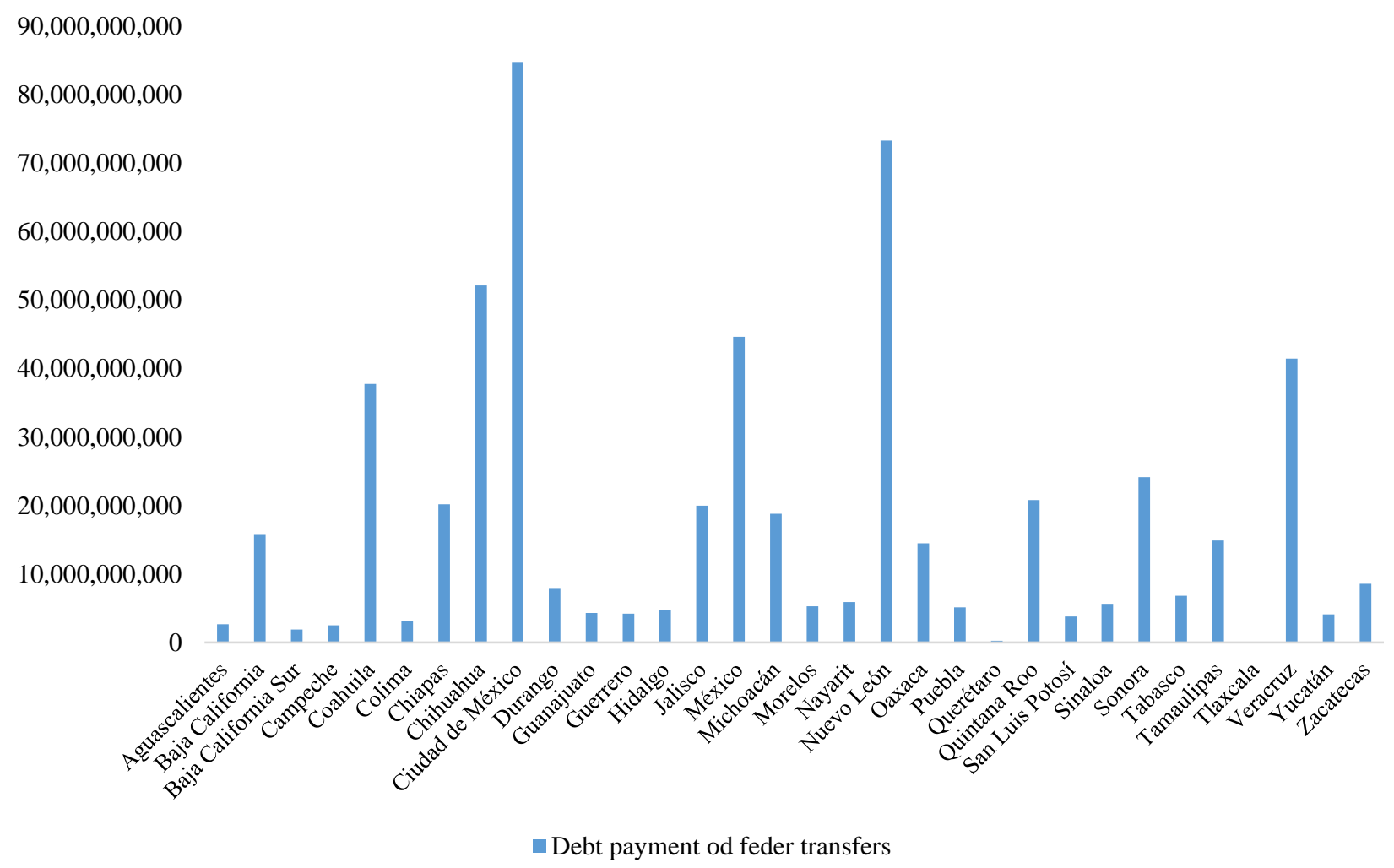

Source: Author's Own Elaboration 
In this sense, both quantitative and qualitative factors that determine the credit rating in local governments, generally speaking, tend to be the average maturity of the debt as well as the interest rate. Figures 9 and 10 show these data.

Figure 9 Average maturity of debt and interest rate

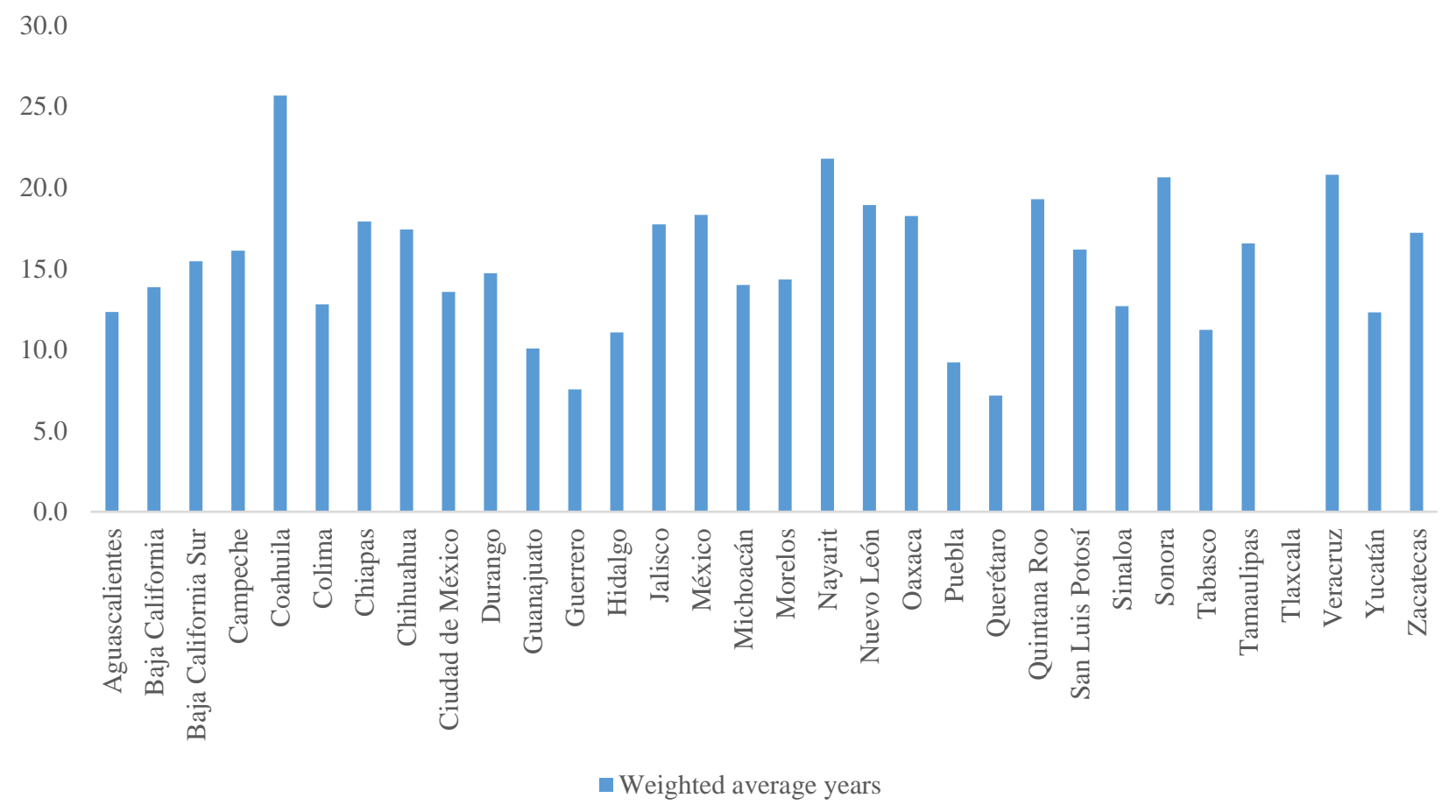

Source: Author's Own Elaboration

Figure 10 Average cost of debt

10.00

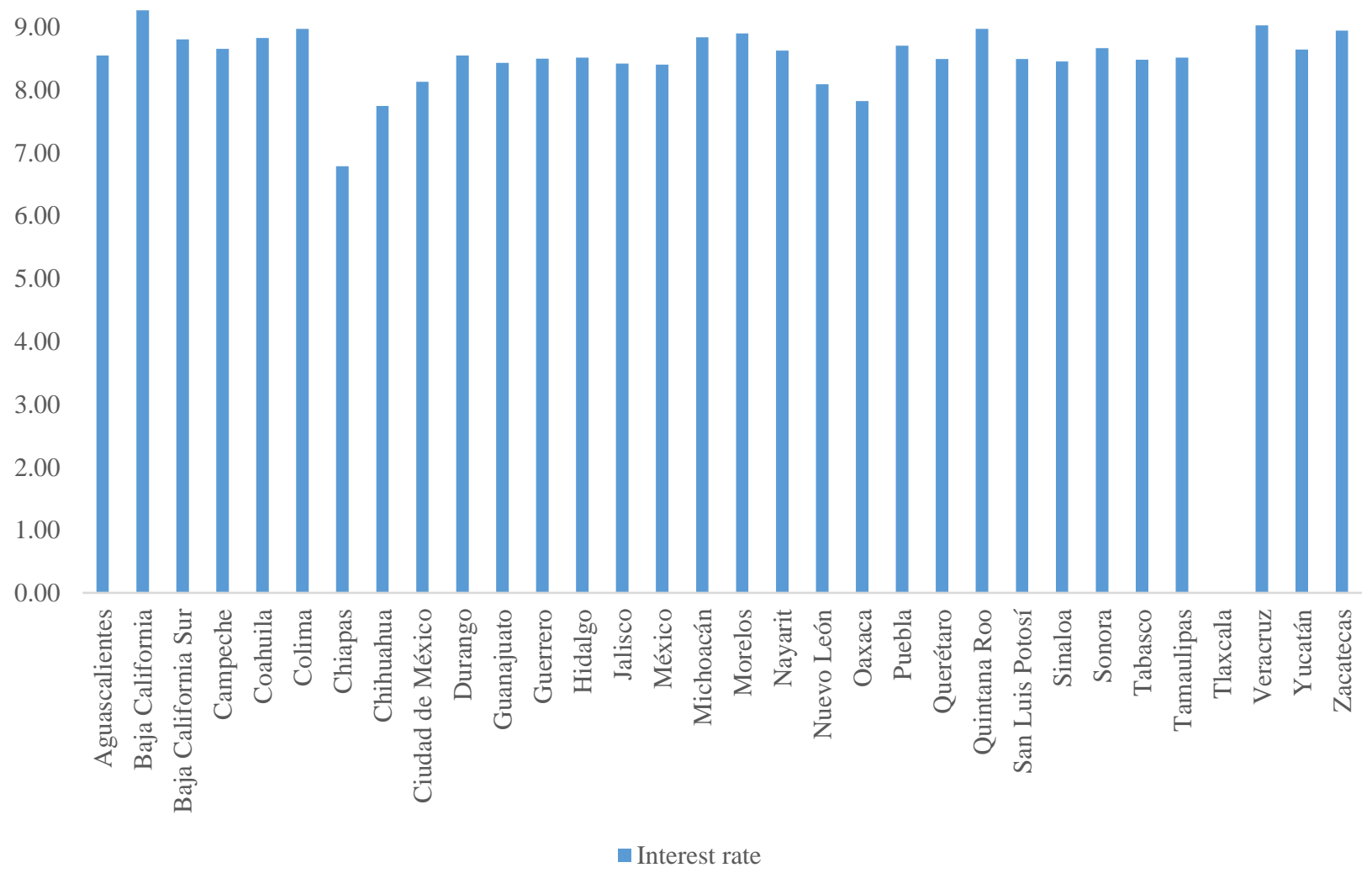

Source: Author's Own Elaboration 
According to Moody's (2008) are: the operating environment, the institutional framework, the financial situation and performance, the debt profile, economic fundamentals, government practices and management. In that sense, the operating environment and institutional framework are based on systemwide circumstances, while the other four are specific to local government. Figure 11 shows these factors:

Figure 11 Moody's investors services

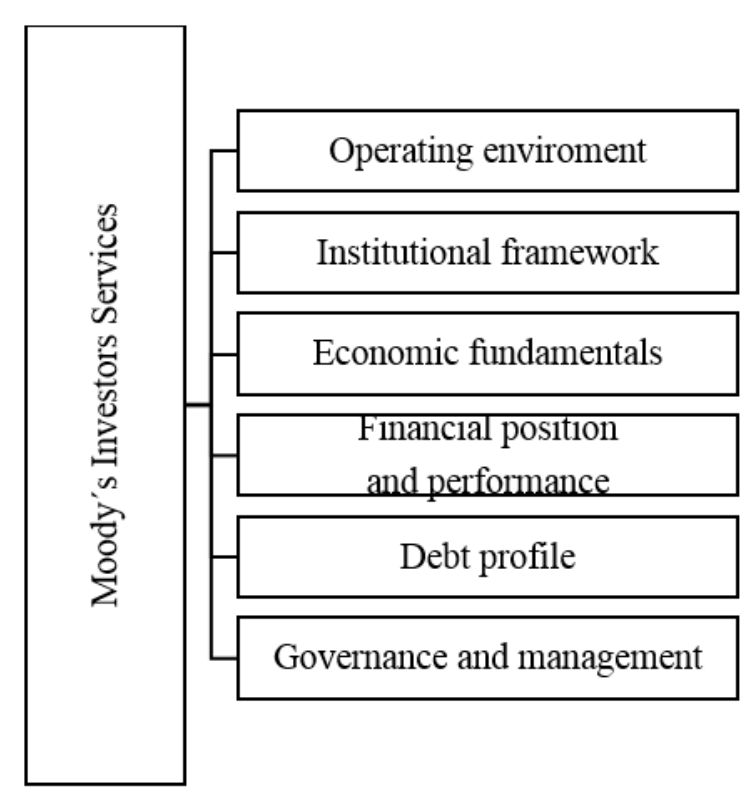

Source: Author's Own Elaboration

For its part, Standard and Poor's (2018), analyses the quantitative and qualitative factors that are relevant to determine the credit quality of governments in México. These factors include economic indicators, institutional aspects, financial management, financial flexibility, budget performance, liquidity and debt management, debt level, and contingent liabilities. Figure 12 shows these factors:

Figure 12 Standar and Poors rating factors

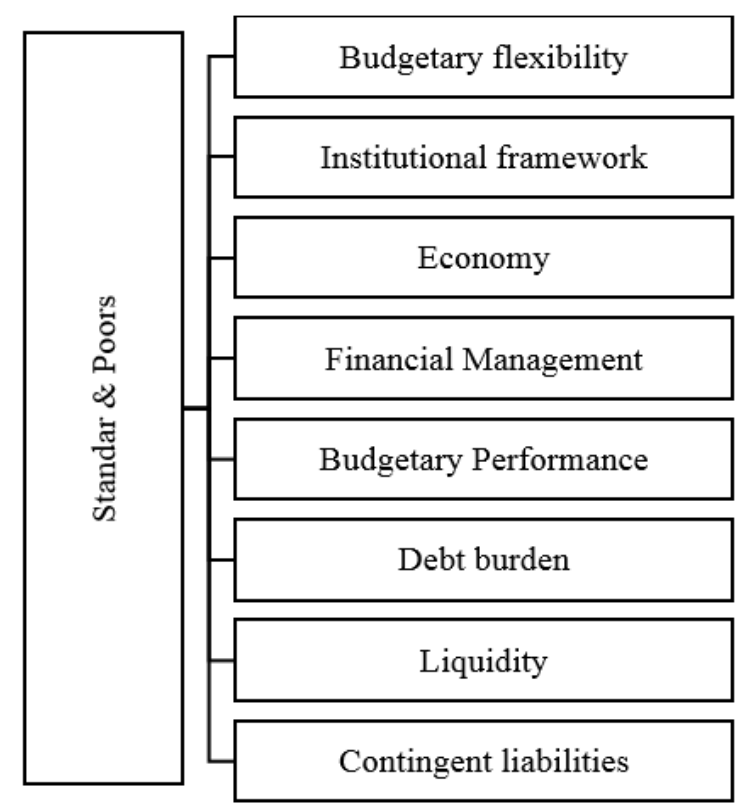

Source: Author's Own Elaboration

Fitch (2021) analyses the economic and institutional scenario in which federal and state governments operate, measuring their performance in four main indicators: debt and long-term liabilities; finance; management and administration; domestic economy. The institutional setting frames the context in which the government operates according to the four factors indicated. Figure 13 shows these factors: 
Figure 13 Fitch's factors in credit rate subnational governments

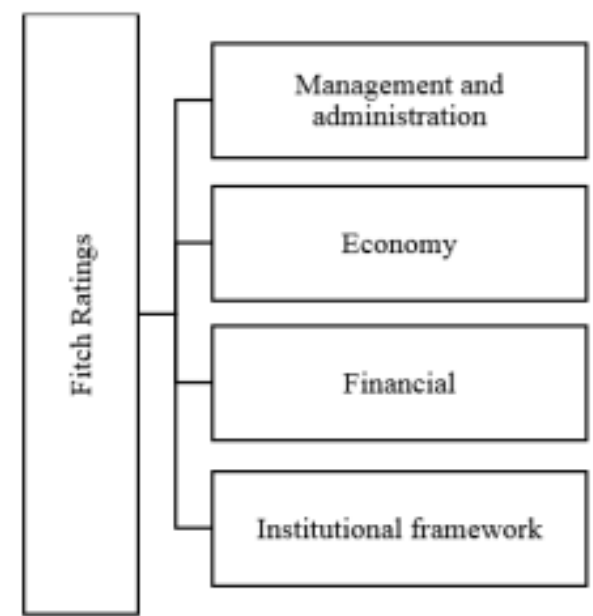

Source: Author's own elaboration based on Fitch (2021)

As can be seen, there are similarities and differences between the rating methodologies used by the three main international credit rating agencies to determine the credit quality of subnational governments. The credit rating methodologies of these three major internationals are summarized below. Figure 14 shows these factors:

Figure 14 Comparation of credit rating agencies

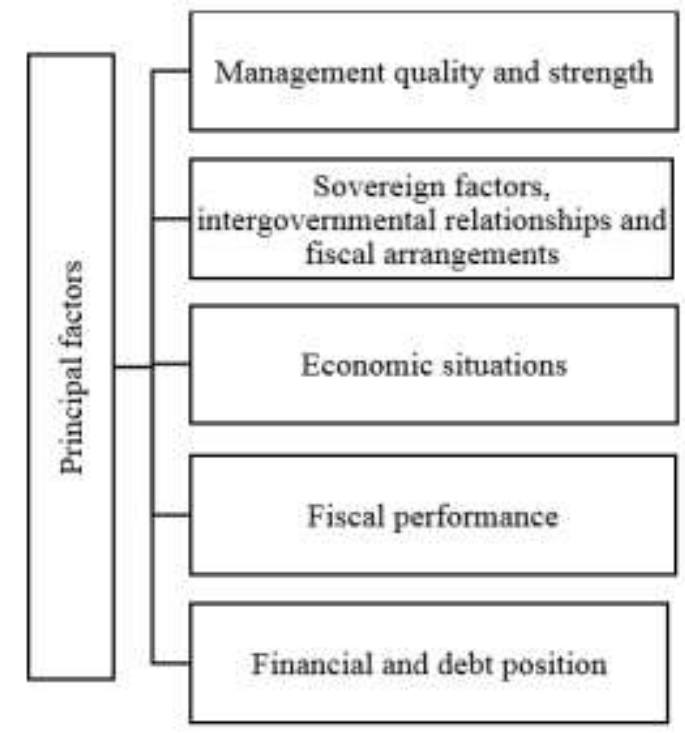

Source: Author's own elaboration based on Fitch (2021); Standars and Poors (2018) and Moody's (2008)

In México, the low per capita economic production and periodic events of economic instability in states and mainly in municipalities, suggest that these risks may be more severe, conditioning negative credit consequences. However, there is interest on the part of all states and some municipalities, mostly metropolitan, to have a credit history that guarantees their administration to be subject to financing credit instances and this leads to the generation of public works.

In this sense, Nuñez (2010) in his article published by the Institute for the Technical Development of Public Finance (INDETEC), analyses the credit conditions of 108 municipalities, mostly metropolitan and urban, that had been rated, which it represents a little more than $4.4 \%$, reflecting with it, a low participation in the rating of the municipalities. Currently, according to the Fitch Ratings website (2015), the number of qualified municipalities has decreased, being only 65 and 52 respectively, which represents $2.66 \%$ and $2.13 \%$ of qualified municipalities. In this context, same author, concludes that many rural, semi-rural, small urban municipalities and a part of the middle urban ones are entities that have not considered requesting to be qualified in terms of financial risk, due to the high cost to be qualified or likely, because they do not have the skills and professional staff required to carry out these actions. 
According to Fitch Ratings, the credit quality of Mexican states and municipalities ranges from a high credit quality "A + " to a good credit quality "BBB" with positive (+) high and negative (-) indicators in low, meaning notifications to investors of a probability of a rating change. Under this scheme, in the states the credit rating oscillates between "AAA" and "BB", which is due to the orderly performance and the strengthening of state finances in recent years, which is characterized by a high generation of domestic savings and due to an improvement in the levels of leverage and sustainability.

In line with the above, the 31 states of the republic show rigid cost structures and a high dependence on federal revenues, which mostly come from participations, allowing limited financial flexibility. In this context, the 52 municipalities classified with "A" and "BBB" in 2013 account for $60 \%$ of the debt. Regarding the debt service ratio, entities rated with the "BBB" parameter have a higher service ratio due to two factors: access to less favourable terms and conditions, and the limited generation of free cash flow. of operations. Along these lines, the firm Fitch Ratings indicates that the debt of the states and municipalities could rise between 10 and $15 \%$ at the end of 2015 .

In 2015, derived from the reform that tries to discipline the federal and municipal entities for debt contracting, the rating company Standard and Poor's (2018) points out that the new reform must be well implemented, as it could avoid problems of over-indebtedness and bad management of the finances that some states and municipalities currently face. Likewise, Smith (2015) would contribute to strengthening and transparency in accountability, as well as promoting better conditions in the contracting of local government debt.

In this sense, the rating agency estimates that between 2015 and 2016 the debt of the states and municipalities will increase between 10 and $15 \%$ as estimated by Ratings Fitch (2015), however, that the ratings for these years will depend on how they spend based on of the approved reform, warning that the elections will be a point of reference that can be determined in 2015 and in the face of a restrictive scenario in 2016, negative conditions in the debt ratings.

\subsection{The reform of the public sector in México and the new public management}

In México, constant reforms and administrative improvements have been promoted. From successive administrative reform programs have been implemented in the nineteenth century, structural changes, administrative modernization and implementation and adaptation of the government accounting model, where except for the latter the results have been unsatisfactory.

However, governance indicators show that we are well below the countries of the Free Trade Agreement (FTA), the OECD and some of America Latin. The Transparency International Corruption Perceptions Index (TI) corresponding to México show that the indices are not satisfactory, which has focused on implementing new management and administrative reform models. The result of the transparency indicator is shown in the following Table 3.

Table 3 Rating and place occupied by México among 178 rated countries

\begin{tabular}{|c|r|r|}
\hline \multicolumn{1}{|c|}{ Year } & Place & Rating \\
\hline 2006 & 59 & 3.3 \\
\hline 2007 & 21 & 3.7 \\
\hline 2008 & 57 & 3.6 \\
\hline 2009 & 64 & 3.6 \\
\hline 2010 & 64 & 3.6 \\
\hline 2011 & 65 & 3.5 \\
\hline 2012 & 70 & 3.3 \\
\hline 2013 & 72 & 3.5 \\
\hline 2014 & 72 & 3.6 \\
\hline 2015 & 89 & 3.3 \\
\hline 2016 & 98 & 3.1 \\
\hline 2017 & 100 & 3.0 \\
\hline 2018 & 105 & 3.4 \\
\hline 2019 & 106 & 3.4 \\
\hline 2020 & 103 & 3.5 \\
\hline
\end{tabular}




\subsubsection{The New Public Management in México}

In recent decades, the appearance of the New Public Management model tries to respond to the need for new instruments that allow the analysis of a reality that is constantly evolving. At present, many countries have implemented this type of measure, the which are mainly aimed at replacing the traditional bureaucratic model with that of a philosophy within the framework of New Public Management (NPM). In this sense, the NPM is a measure aimed at increasing the value of the services offered, evaluating the economy, effectiveness, efficiency and social impact of public services (Cortés, 2003). This economic phenomenon that has occurred in recent decades has substantially modified the design and the structure of the public administration. However, Pollitt (2002) considers that despite the reforms being promoted in each country, they currently differ among them, classifying the main innovations in three points: personnel policies, modifications in the organizational structure and improvement of financial and techniques of control. The Figure 5 show this NPM

For de la Cruz (2004), the new public management in México requires democratic and structural changes that allow a true functionality of the services offered by the government, a difficult situation due to the excessive increase in poverty and inequality that exists in the country. In this context, optimizing the NPM philosophy in any country implies structural changes in the public sector and the relationship between government and society, summarized in four basic principles indicated by Losada (1997):

1. From an Expansive Administration to a Balanced Administration.

2. From an Administration Closed to a Relational Administration.

3. From a Neutral Administration to a Competitive Administration.

4. From an Indifferent Administration to a Responsible Administration before society.

These principles intend that the institutions manifest better flexibility, decentralizations, outputs, better accountability and transparency in the information culture. In this sense, changes in institutions involve processes and phenomena that affect the entire functioning of administrations. Figure 15 shows the elements of these NPM:

Figure 15 Philosphy of New Public Management

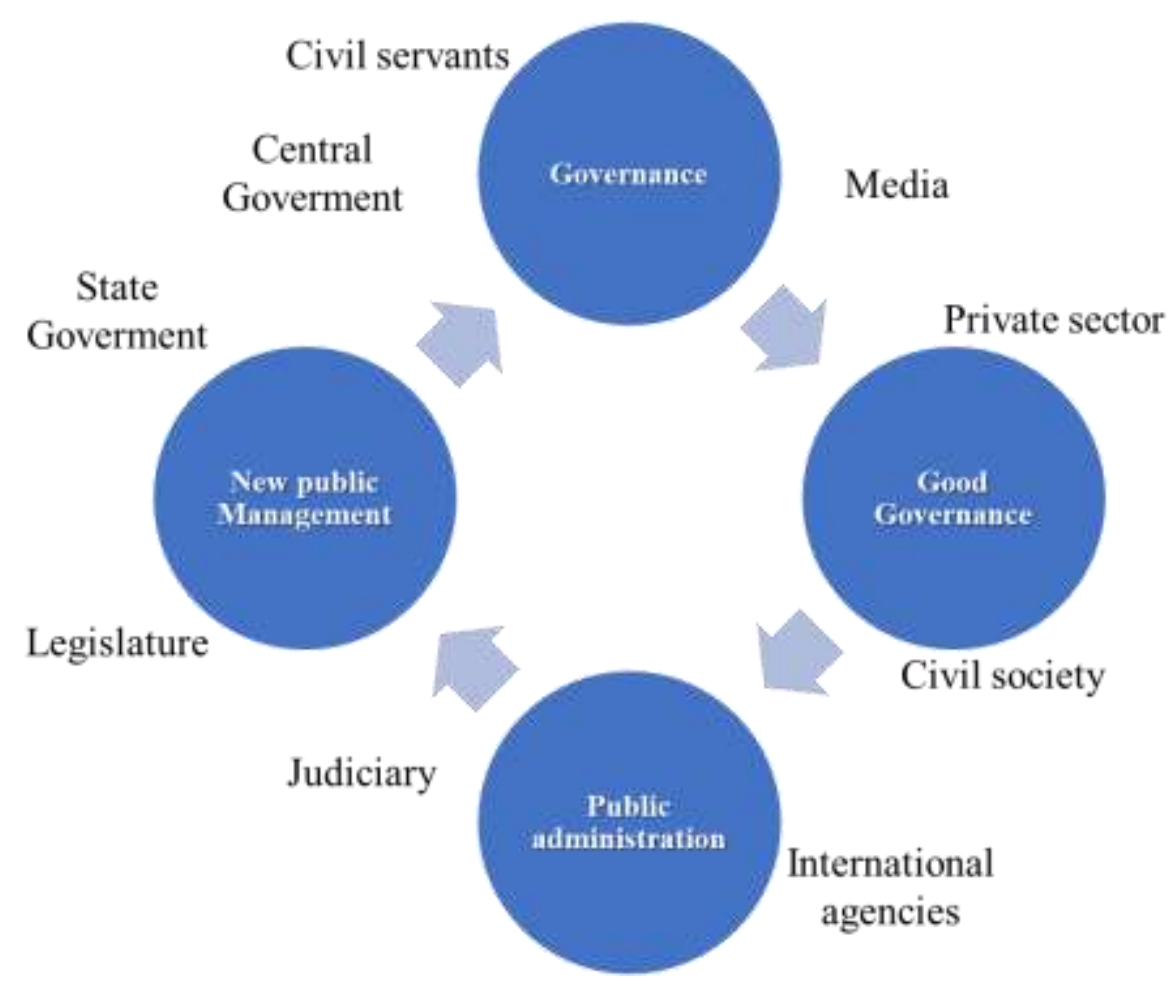

Source: Author's own elaboration based on Cortés (2003) 
Currently, the public administration in México seeks that this philosophy is implemented, subject to the new demands of the state and society, trying to offer better economic expectations of efficiency and effectiveness for the citizen.

Along these lines, different processes of transformation of public institutions have been implemented, specifically implementing administrative reforms that modify public administration to try to offer better well-being for citizens. However, there is still a long way to go in the field of transparency and e-government, as is the case in most Latin American countries (Caba et al., 2010).

In this context, with the objective of demonstrating the modernization of public management in México's public administration, the most relevant actions of its administrative programs for the new government management are analysed.

\subsubsection{Administrative and Management Reforms}

According to Samuelson y Nordhaus (1992), administrative reform is a permanent process, which seeks to increase the effectiveness and efficiency of the administrative and governmental apparatus in the achievement of all the objectives of the State. In this sense, administrative reform is the response to a changing situation, which is currently characterized by severe fiscal crises, causing consequences such as the reorientation of public spending and the implementation of macroeconomic policies aimed at achieving greater stability and economic growth.

In México, the strengthening of democracy has also made progress meaningful, that is, the mechanisms aimed at achieving better accountability accounts of the governmental apparatus towards society and the promotion of greater social participation, have been strengthened.

In 2011, for example, the Audit Superior of the Federation (ASF), implemented a strategic plan for the period 2011-2017, seeking to contribute to the improvement of government action and this way to generate the trust of society. In addition, with this plan it allows audited institutions have an objective diagnosis of their performance, offer to society a technical and objective overview of resource management public. principles:

The reforms have also been aimed at promoting development under a pact based on four basic

a) Superimpose the interests of the country and those of the Mexicans to any party or individual interest.

b) Keep the word pawned.

c) Deepen transparency; and

d) Act under strict adherence to the Constitution and the laws that emanate from it (Pacto por México, 2013).

\subsubsection{Means of verification}

According to National Council for the Evaluation of Social Development Policy [CONEVAL] (2018) these correspond to the information sources used to calculate the indicators and should allow anyone who wishes to estimate the indicators and verify the information. Said means can be official documents, documents or internal reports generated by the program, processed databases, among others. The information presented was analysed with the intention of determining the main source of information to build the indicators, and five types were established:

- Information generated by CONEVAL

- Information generated by the National Institute of Statistics and Geography (INEGI)

- Information from international institutes

- Information generated within the unit

- Others 
The results are shown in graph 8.11 Likewise, it is highlighted that $7 \%$ of the indicators do not have means of verification, that is, it is not possible to re-estimate 28 indicators or, at least, to know the sources of information with which were built.On the other hand, the information media for most of the indicators are internal sources of the entity in charge of monitoring the indicators (53\%). It is preferable that these are constructed based on external sources, in such a way that the independence of the information is verified, or that the internal information sources used are very clear.

\subsubsection{Management Modernization Programs}

Within the evolution of change towards New Public Management in México, it was created in 2008 a special management improvement program, which included the period 2008-2012. One of the relevant topics of this management program was to establish control bodies and guidelines to regulate the management operation in the Federal Public Administration. This Program was published on September 10 of 2008 and actualized in 2021 in the Official Gazette of the Federation (DOF, 2021).

The program influenced and modernized the day-to-day operation of government institutions through various strategies aimed at improving processes and public services that are provide to citizens. In this program the Federal Government undertook the zero-based regulation strategy, issuing nine administrative manuals1 for improve government management. The objective of this new implementation was to eliminate 10,486 administrative regulations from the 14,579 that existed until 2008.

From this reform, the institutions of the federal public administration directed their efforts to improve their management, to try to fulfil their goals as far as possible, implementing different strategies for the execution of the new management plan. This plan was based on the consolidation of results, modernization and improvement of management, simplification of processes, simplification or elimination of regulations, procedures and services, obtaining savings due to efficiency and effectiveness in the administrative operation by electronic government (Pérez-Cruz, 2018).

The results were evaluated by the Management for Results Index, carried out by the InterAmerican Development Bank (IDB) since 2010 (García and García, 2010). This institution evaluated five fundamental pillars for public administration, highlighting planning for results, budgeting for results, financial management and audit, program and project management and finally monitoring and evaluation.

This study included 25 countries in Latin America and the Caribbean, and México ranked fourth in the region, concluding that although there is significant progress in the Public Management reform for the country, México still faces a great challenge in its performance and government efficiency.

Within the current administration, in 2013 the "Program for a Close and Modern Government (PGCM) 2013-2018" (DOF, 2013), where its objectives are measured through strategies and specific lines of action, that is, evaluated based on performance indicators in the framework of good governance practices, issued by the Ministry of Finance and Public Credit and of the public function.

The purpose of the program is to promote a government with policies and programs framed in a results-oriented public administration that is efficient and with evaluation mechanisms that improve its performance, that optimizes the use of public resources, that simplifies government regulations and procedures, that it is accountable in a clear and timely manner to the public and that it uses the new Information and Communication Technologies (ICT) (Pérez-Cruz, 2018).

In addition, the program evaluates and recognizes the actions that generate the results that are required to meet the most pressing needs of the country, implementing improvement actions and redirecting resources to generate a greater impact on the society. This new scheme integrates five objectives, 28 strategies and 207 lines of action based on the areas of opportunity detected, after a diagnosis made by the academic sector and civil society, based on the National Development Plan (PND) 2013-2018 (DOF, 2013b). Opportunity areas, objectives and justification are described in Table 4.

1 The manual for auditing, procurement, internal control, public works and services, financial resources, human resources, material resources, information and communication technologies, and transparency and accountability. 
Table 4 Areas of opportunity, objectives and justification of the PGCM

\begin{tabular}{|l|l|l|}
\hline \multicolumn{1}{|c|}{$\begin{array}{c}\text { Area of } \\
\text { Opportunity }\end{array}$} & $\begin{array}{l}\text { Objective } \\
\text { Promote an open government that } \\
\text { strengthens accountability in the } \\
\text { APF. }\end{array}$ & $\begin{array}{l}\text { Its implementation encourages any interested party } \\
\text { to access the use of information generated by the } \\
\text { government. }\end{array}$ \\
\hline Trasparency & $\begin{array}{l}\text { Strengthen results-based budgeting } \\
\text { results-based budgeting of the } \\
\text { APF, including federalized } \\
\text { federalized spending }\end{array}$ & $\begin{array}{l}\text { Aims to promote efficiency } \\
\text { efficacy and economy in the allocation of } \\
\text { resources, seeking to that the budget is managed as } \\
\text { a tool as a tool to increase operational efficiency } \\
\text { and effectiveness of effectiveness of public } \\
\text { spending. }\end{array}$ \\
\hline Open budget & $\begin{array}{l}\text { Improve government public } \\
\text { management in the APF. }\end{array}$ & $\begin{array}{l}\text { It is intended to improve management seeking the } \\
\text { consolidation of a } \\
\text { productive, efficient and effective government. }\end{array}$ \\
\hline Management & $\begin{array}{l}\text { Establish a strategy digital speed } \\
\text { insertion of Mexico in the society of } \\
\text { Information and knowledge. }\end{array}$ & $\begin{array}{l}\text { Search through ICT modernization of the functions } \\
\text { of the government counting on } \\
\text { digital enablers and a adequate legal framework for } \\
\text { such effects. }\end{array}$ \\
\hline Digital strategy & \multicolumn{2}{|c|}{}
\end{tabular}

Source: Author's Own Elaboration based on National Development Plan (NDP) 2013-2018

From this program, different lines of action are contemplated for the transversal programs that allow the achievement of the strategies, such as: coordination, referring to those actions that will be implemented by the agencies or entities in charge of coordinating the policy in each matter; general, that all agencies and entities must incorporate in their respective sector programs; or specific, which will be mandatory for one or more agencies or entities through their respective programs.

\subsubsection{Government Accounting}

The reform of public management has also affected government accounting and at this time there is an international trend to modernize public accounting systems that encompasses all Latin American countries, as evidenced in Caba and Hernández (2007). In the specific case of México, in compliance with the Mexican Constitution, on December 31, 2008, the General Government Accounting Law (LGCG) (DOF, 2018c) was published, by which the three levels of government. After this law, the National Council for Accounting Harmonization was created, which is made up of the federation, states and municipalities (Carrasco, 2011).

In this context, the correct application of the LGCG is mandatory today for all public sector entities in México. Legally, this obligation is based on article 1 of the law itself, which indicates, among other things, that both the executive, legislative, and judicial powers, the states, municipalities, parastatal entities and autonomous bodies, are subject to the provisions of this law., which, within the framework of the new public management, facilitates the implementation of accounting systems that contribute to the efficiency and effectiveness of the planned objectives within its own administrative organization.

The new Accounting Law, in addition, motivates some fundamental aspects, such as, the strict accounting record in congruence with the budgetary information; that accounting systems allow accrualbased records for the integration of financial information; a register and inventory control of movable and immovable property; that the basic postulates of government accounting will be the basic support for the accounting methods, procedures, and practices to report clear, concise, timely and truthful information to any entity.

Likewise, it is intended to carry out in specific accounts of assets, movable and immovable property intended for public service, including computer equipment and vehicles and that financial, programmatic, budgetary and accounting that emanates from the system, is the basis for the issuance of reports. In this context, Table 5 presents a comparative analysis of the previous situation and that existing with the NPM. 
Table 5 Comparative analysis of the evolution of governmental accounting

\begin{tabular}{|c|c|c|}
\hline $\begin{array}{c}\text { Area of } \\
\text { Opportunity }\end{array}$ & Objective & Justification \\
\hline $\begin{array}{l}\text { Rules of } \\
\text { information } \\
\text { financial }\end{array}$ & $\begin{array}{l}\text { - It has not worked in a effective the State Council } \\
\text { of Accounting Harmonization. } \\
\text { - } \quad \text { Low level of diffusion and training, regulations } \\
\text { approved. } \\
\text { - } \text { Insufficient classification of entry and exit. } \\
-\quad \text { Non-existent or deficient control patrimonial. } \\
-\quad \text { Non-existent control of assets of public domain. } \\
-\quad \text { Insufficient disclosure of liabilities } \\
-\quad \text { Laboral and prosecutors, among others. } \\
-\quad \text { Failure to register with based on the accrual } \\
\text { principle. } \\
-\quad \text { Inaccurate registration depreciation. } \\
-\quad \text { Direct charge to results. }\end{array}$ & $\begin{array}{l}\text { - Application of basic postulates, } \\
\text { general and specific rules. } \\
\text { - Consolidation of information } \\
\text { financial according to the National } \\
\text { Council of Accounting } \\
\text { Harmonization. } \\
\text { - Accounting accrual. } \\
\text { - Recognition of the operations of } \\
\text { income, expenses, assets, liabilities } \\
\text { and equity. } \\
\text { - Valuation and registration of } \\
\text { provisions. } \\
\text { - Control of movable property and } \\
\text { real estate and inventory. }\end{array}$ \\
\hline Budget & 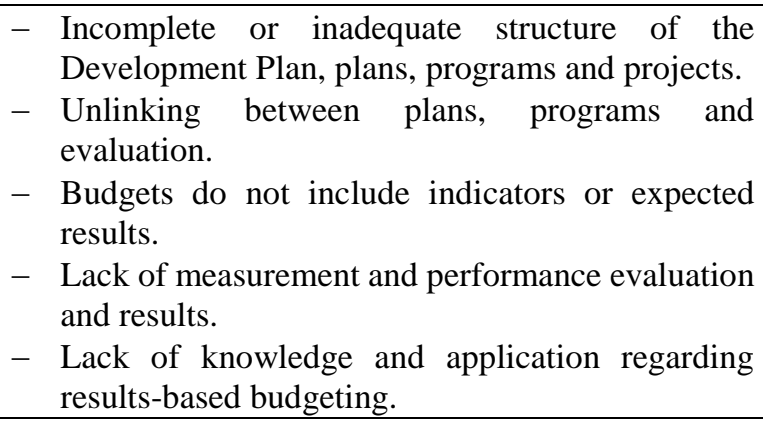 & $\begin{array}{l}\text { - } \text { Budget based on results. } \\
- \text { Budgetary stages (income and } \\
\text { expenses); accounting moments. } \\
-\quad \text { Automatic integration of the budget } \\
\text { year with the accounting operation. } \\
-\quad \text { Performance evaluation. }\end{array}$ \\
\hline $\begin{array}{l}\text { Comprehensive } \\
\text { financial information } \\
\text { system }\end{array}$ & $\begin{array}{l}- \text { Lack of a comprehensive system. } \\
- \text { Breach of real time. } \\
- \text { Unlinking between accounting and budget } \\
\text { records. } \\
-\quad \text { Inefficient control of income by register and } \\
\text { accounts receivable. } \\
- \text { Tax enforcement, if it exists, is unrelated to the } \\
\text { comprehensive system. } \\
-\quad \text { Inadequate infrastructure for the operation of the } \\
\text { systems. } \\
-\quad \text { No sharing of resources between the State and } \\
\text { municipalities. } \\
-\quad \text { Inadequate security elements. }\end{array}$ & $\begin{array}{ll} & \text { Standards and processes } \\
- & \text { Real-time information } \\
- & \text { Single registration and automatic } \\
& \text { allocation; event accounting } \\
\text { - } & \text { IT solution }\end{array}$ \\
\hline Accountability & $\begin{array}{l}\text { - The public account is not automatically derived } \\
\text { from the accounting system } \\
\text { - Lack of uniformity in its content } \\
\text { - Lack of consolidation } \\
\text { - Various periods and moments of presentation } \\
\text { - Does not include additional information, } \\
\text { explanations or comments } \\
\text { - Does not include indicators or elements for } \\
\text { evaluating results. }\end{array}$ & $\begin{array}{l}\text { - Integration of the public account } \\
\text { - Periodic publication of financial } \\
\text { information }\end{array}$ \\
\hline
\end{tabular}

Source: Author's Own Elaboration based on Farías (2009)

The National Council for Accounting Harmonization, in coordination with the SHCP, therefore intends that transparency and accountability today constitute fundamental elements of the relationship between government and society. In that context, it is strictly assumed that both the federal, state and local governments accept the modernization process of the accounting technique with the highest levels of quality in accordance with national and international standards.

In addition, the deadlines for the formulation of the public finance account have been established so that the legislatures corresponding to each state, in coordination with the Superior Audit of the Federation, carry out the processes of inspection and review on the execution of the income law, the exercise of the expenditure budget and the evaluation of the approved programs. 
Likewise, article 54 of the LGCG states that the budgetary and programmatic information that is part of the public account must include the results of the performance evaluation of federal, state and municipal programs. The Figure 16 exhibits the aggregate revenue of the state:

Figura 16 Aggregate Revenue of the state

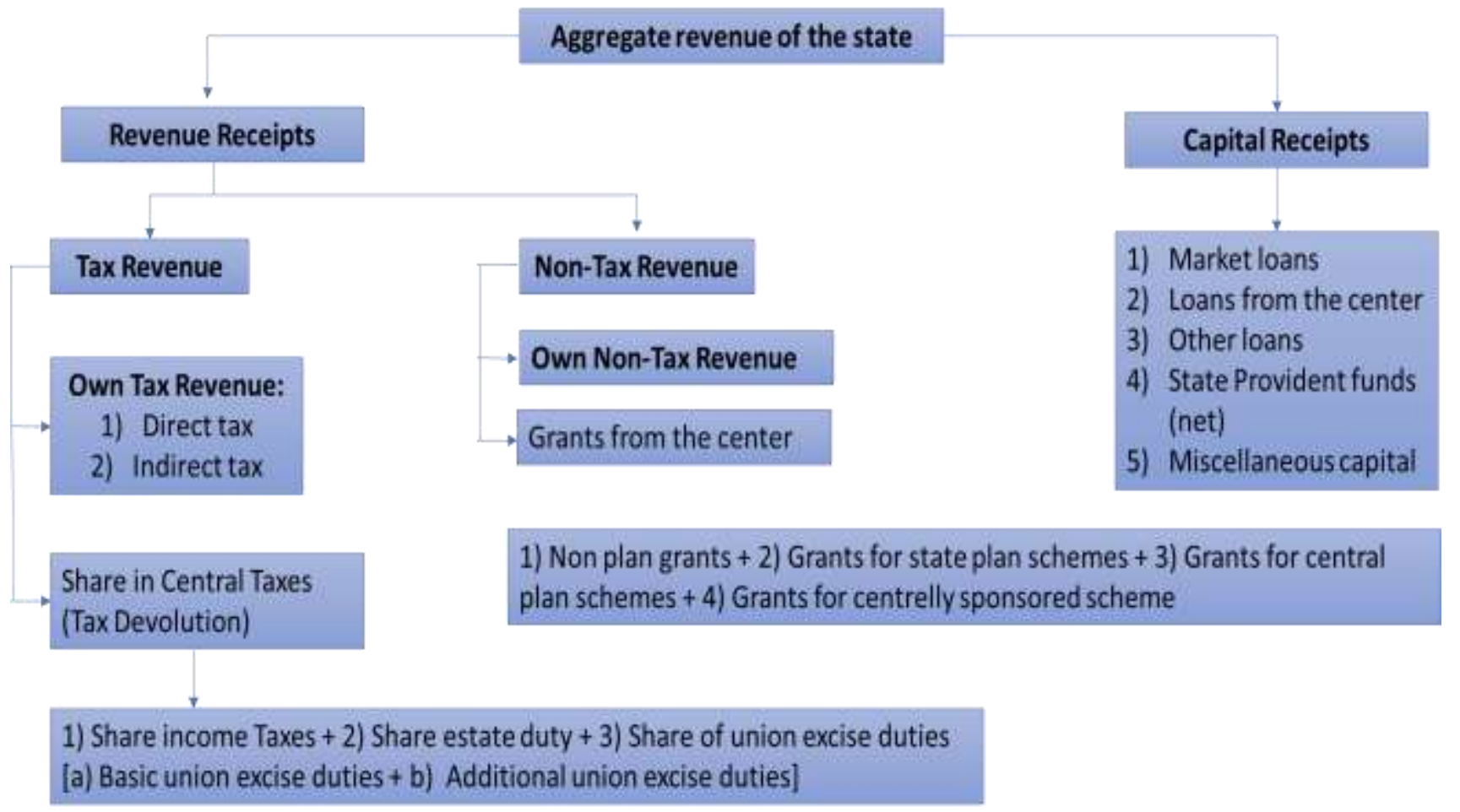

Source: Manjhi and Mehra (2019)

In this framework, the implementation of management indicators that make it possible to measure the results achieved (Carrasco et al., 2011) should play a very important role. The implantation of analytical accounting systems that allows to support the processes of decision norms is pending (Carrasco et al., 2006).

The evolution towards changing the new schemes has not been easy, however, the interest and willingness of all public entities to want to meet the objectives of the regulations has been a very positive factor in the search for efficiency and effectiveness on the responsible management of public resources. 


\section{Chapter 3. Budgetary policy cycles: Theoretical framework}

\subsection{Introduction}

The study and development of political economic cycles (CPE) emerged from the 1940s, with the studies of Kalecki (1943), with two phases having been differentiated. The first, started in the 1970s, with traditional macroeconomic models that allowed governments to stimulate in a way that artificial economic variables in the post-election period. Later in the second phase, developed in the eighties, the study of political cycles incorporated rational expectations of the voters, that is, they assumed that the voter could identify a large amount of data that could expand his expectation about the level of competition that would exist in the elections.

In this sense, the literature that we intend to explain in the following section is developed from macroeconomic models as part of the explanatory theories of CPEs. One of its variants that emerged in the 1970s, and with much presence today, is the political budget cycle (CPP), a recent model that emerged from the changes in the CPE, which is based on the manipulation of instruments of fiscal policy influenced by the rulers' opportunists in electoral periods who intend to continue in power.

Both models are framed from the school of Public Choice, which analyses the connection between politics and economics, from the point of view of alteration of economic variables over time, which in turn are caused by the actions of economic agents of the public sector. Thus, the definition of CPE is based on two approaches that complement each other and that we cannot isolate from the public sector, the economy and politics. In line with the above, the economic concept can be conceived as a recognized heterodox approach in the 1940s. This approach can be described as a reasoning that shows the autonomy in the actions of the state, with respect to the economic powers.

In this logic, the Theory of the Economic Cycle developed in the work of Kalecki (1943) can be mentioned, influenced by the Socio-Political Theory of Marxism, emphasizing neoliberal aspects of the last decades of the 20th century, offering a description of the socio-political dimension of the class conflict in an evolutionary moment from the heterodox model to the orthodox approach.

In this context, the work of Kalecki (1943) marked a strong influence on the evolutionary process of economic theory, motivated by neoliberal aspects of the analysis of political-economic interdependence, which originated a significant change in the afore mentioned model.

This work was considered as a pioneer of the opportunistic models of the economic cycles of political origin, arising from the Theory of Public Election, stating that both the heterodox and orthodox approaches rest on conceptions of capitalism, characterized by two phenomena: the extension of the right to vote and the quantitative and qualitative growth of the presence of the State in economic life.

The CPP, as Shi and Svensson (2003) point out, is the periodic fluctuation in the government's fiscal policies induced by the electoral period, constituted as a tool of opportunistic behaviour by the rulers in power.

\subsection{The theory of public choice}

The Theory of Public Choice, emerged at the end of the fifties of the twentieth century, acquiring a significant weight among the critical currents, founded on Keynesian thought on economic policy. In this sense, among the pioneering works we can consider those of Arrow (1951), Downs (1957a), Black (1958), and Buchanan and Tullock (1962). For example, Arrow (1951) shows the phenomenon of cyclical majorities, as a sequence of comparisons that would generate pairs of continuous cycles without equilibrium or stopping point. This work was much debated among the thought of economists and political scientists, influencing ideas for later studies.

Downs (1957), for his part, manifests the role of ideologies in democratic politics, where political parties are elected in an electoral system by relative majority, so that they will rationally move their motives towards the preferred point of the median voter. 
Black (1958) showed a current of study based on the theories of various mathematicians of the 18 th century, on voting processes. The author analyses the policy applied by governments in democratic states to consider the opinion of the voters, starting from the idea that politicians, bureaucrats and civil servants in general act according to their own interests.

Buchanan and Tullock (1962), in their book The Calculus of Consent, make a contribution of a two-level structure in collective decision-making: differentiating between what could be called "ordinary politics" (that corresponding to decisions made, often by majority vote, in legislative assemblies) and "constitutional policy" (corresponding to decisions made with respect to the set of rules of the framework within which ordinary politics is allowed to function). A considerable contribution that is currently manifested in most countries. The following Figures 17 and 18 are shown, from the point of view of the politician and politician-voter.

Figure 17 Elements of economics decisions I

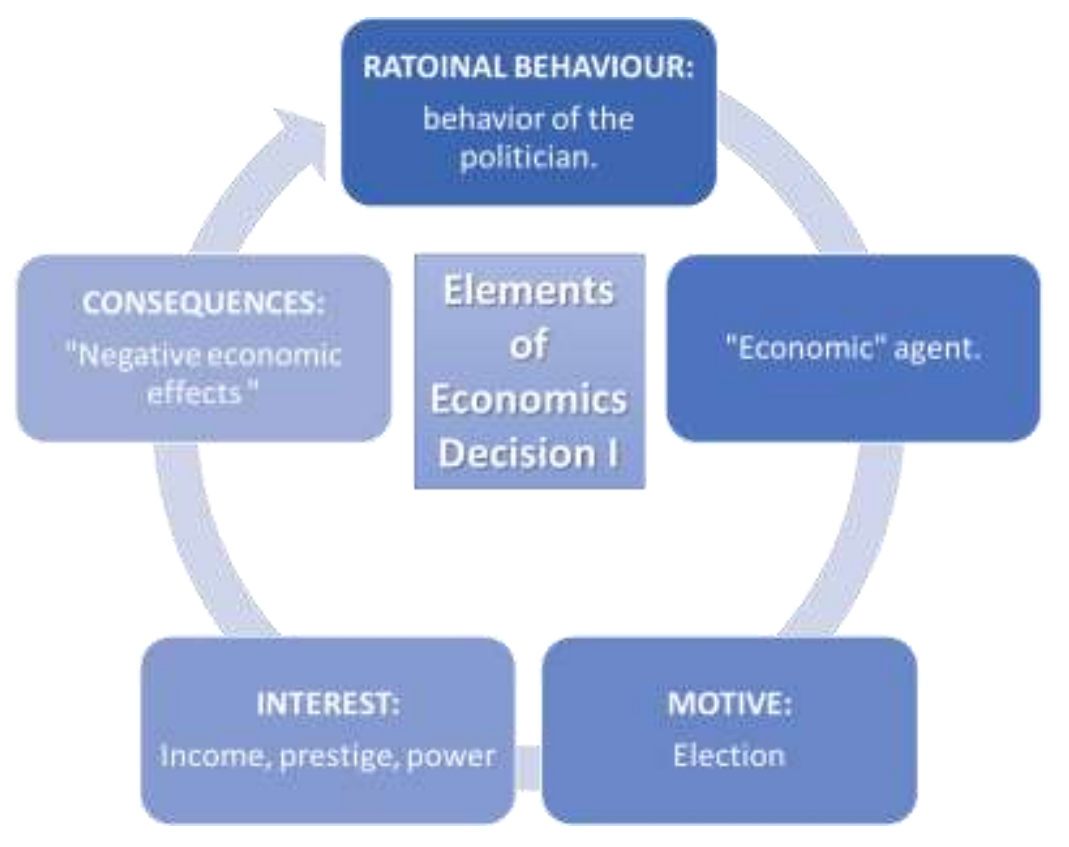

Source: Author's own elaboration based on Downs (1957)

The above scheme indicates that individuals participate in political life exclusively for selfish motives. In this sense, "each political party is a team of men who want their positions with the sole purpose of enjoying the income, prestige and power that the leadership of the governmental apparatus supposes" (Downs, 1978). Under this context, the economic consequences fall on the public entity.

In this way, economic agents behave based on the particular and selfish interest of these agents in political decisions. In figure 18 there is a rational behaviour between two agents (voters and politicians) giving efficient results in their economic policies, that is, all the agents of the model, both Voters and politicians behave rationally, so that rationality and selfishness are inextricably linked (Downs, 1957a).

Mueller (1976) defines public choice as the economic study of decision making, or simply the application of economics to political science. In this regard, Downs (1957 y 1978) in his axioms analyses the adoption of economic decisions considering first the line of politicians in their economic interest, to later analyses the rational interests of voters and politicians, from the individual motivations of the agents, highlighting two points of view, regarding the relationship between voter turnout and politicians. In this sense. 
Figure 18 Elements of economics decisions II

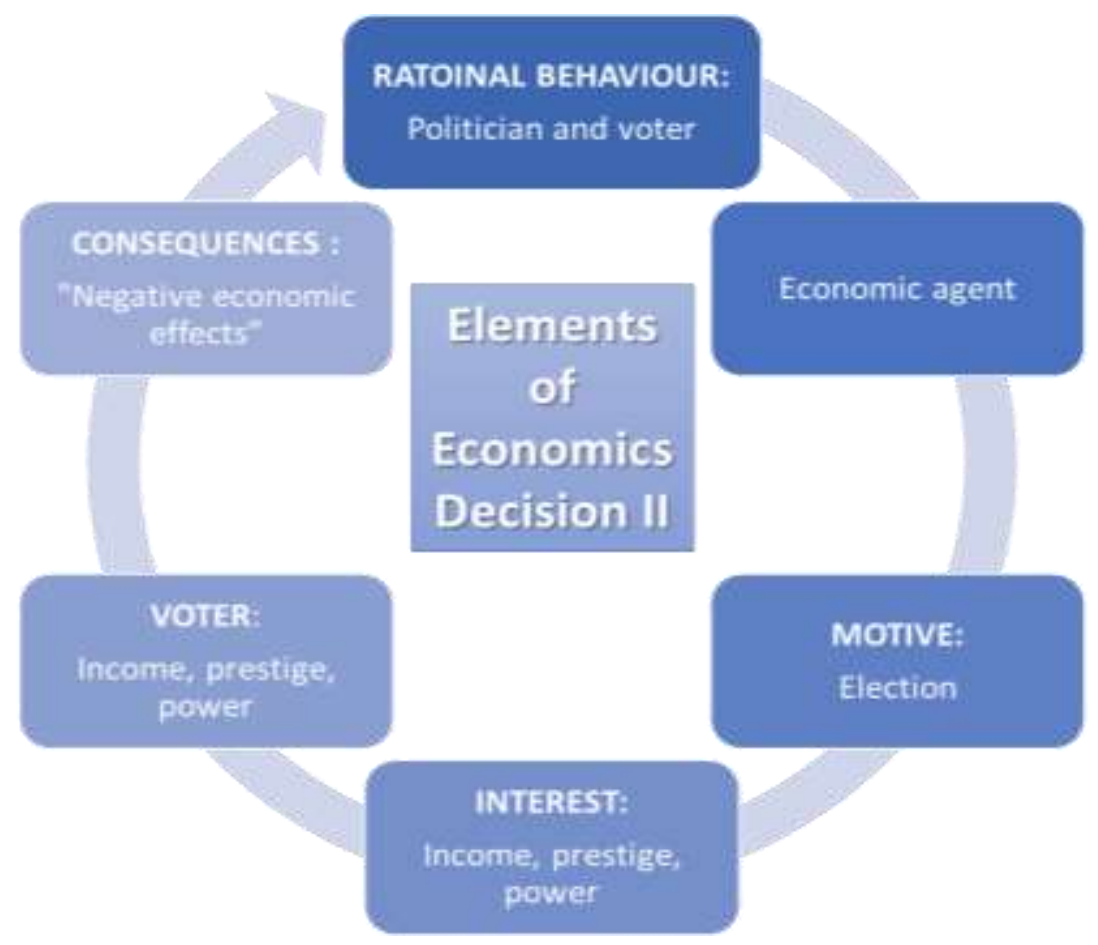

Source: Author's own elaboration based on Downs (1957)

The above figure indicates the egoism that prevails on the part of the politician, manifests his manipulation of the rational behaviour of the voter, so that the performance of politicians in democracy is oriented exclusively to the capture of votes, where the point of view of the politician widens his margin of being re-elected in a next governmental period. This approach presides over the political-economic models developed at the origin of the Public Choice Theory and used in the neoclassical approach to political-economic interdependence.

In this context, Frey and Schneider (1988) carry out a formal analysis of interdependence between politics and economics that characterizes the relationship between the two, stating that the essential elements in this relationship, government and voters, are dependent on each other, requiring each of them the motivation of your arguments to obtain an answer.

In the model proposed by Frey and Schneider (1988, 1981 and 1978) there are two approaches: the one that relates the Economy-Voters-politics (Relationship 1) and on the other hand the approach between Politics-Government-Economy (Relationship 2).

- Relationship 1, Voters-Economy-Politics (demand side) assumes that voters attach great importance to the economic performance of the Government when assessing its management, that is, the existence of the so-called economic vote is assumed.

For relation 2, Politics - Government - Economy (supply side): there is the thesis that the Government, in a context in which the parties compete for power, manipulates the economy to facilitate their electoral triumph and to maximize its usefulness in pursuit of its ideological goals.

The Figure 19 exhibits these elements: 
Figure 19 Elements of economics decisions

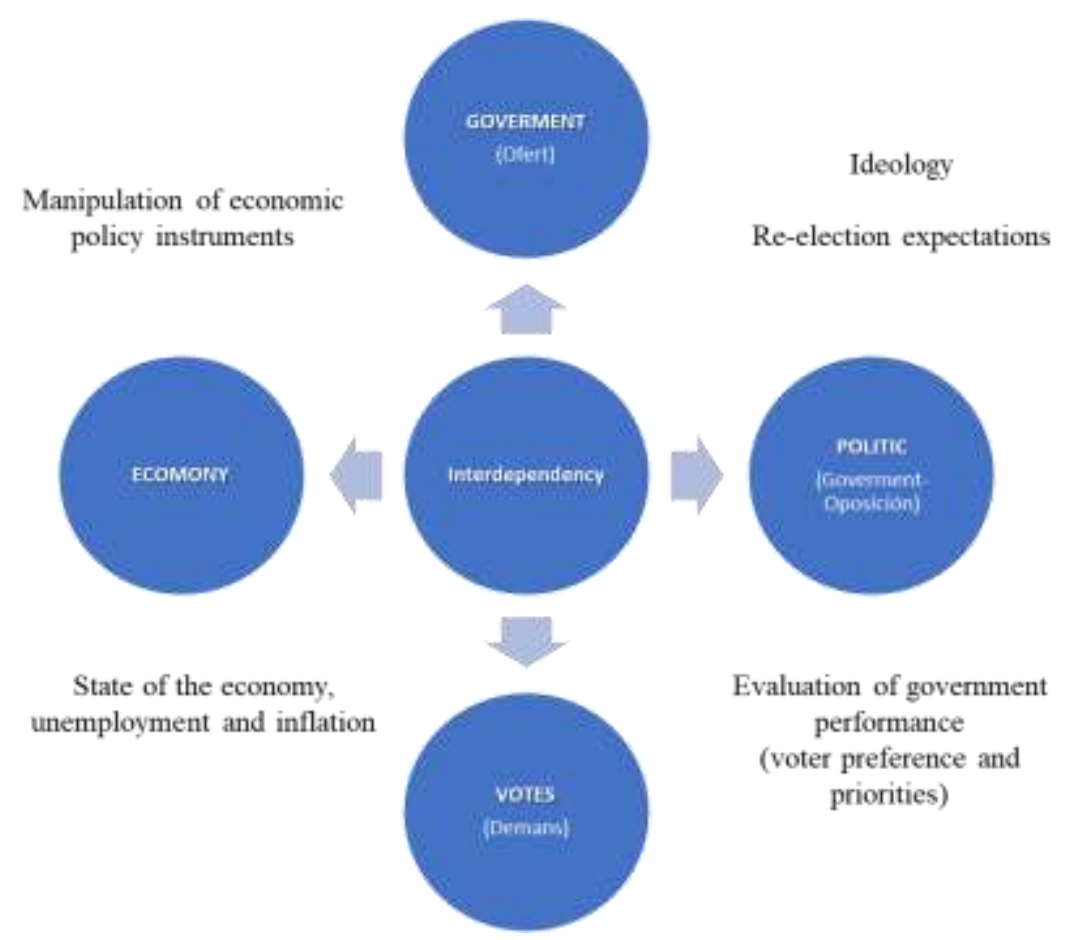

Source: Author's own elaboration based on Frey and Schneider (1988)

The previous models allow us to make an approximation to the characteristics of the approach of the political-economic models, developed within the framework of the Public Choice Theory and focused on the political-economic interdependence.

\subsection{The political economic cycles and political cycles budgets}

The development of the CPE and its derivation as CPP arise from the manipulation of fiscal policy instruments, exercised in the electoral year by the rulers who intend to continue in power. This opportunistic model for the ruler highlights the manipulation of instruments such as taxes, transfers, public spending, financing, among others, trying to influence the decision of the voter in his aspiration to continue governing.

The CPP as a recent model stands out with greater force from the eighties and nineties, with studies by Rogoff and Sibert (1988) and Rogoff (1990), which pointed out opportunistic behaviors on fiscal policy instruments based on information asymmetries in relation to the voter. In this context, in studies of the past decade, the works of Drazen (2000), Brender and Drazen (2003, 2005), Shi and Svensson $(2000,2003,2006)$ can be highlighted, where in addition to studying opportunistic behaviours, they highlighted that such behaviour occurs with more force in developing countries in the electoral period, that is, the manipulation of fiscal policy instruments is exercised with more intensity in that period.

In this context, this trend, as a variant of the CPE, is a phenomenon of the new democracies, since as Brender and Drazen (2005) point out, the CPP is characterized in these democracies by spending expansions in the electoral period and with it, an increase in the public deficit in the year after the election. The economic cycles of political origin and their influence on the economy originate from the political stimuli derived from an election of representatives through a vote. In this sense, these motivations have developed in different models and different stages, these are shown in the Figure 20. 
Figure 20 Economy Cicle

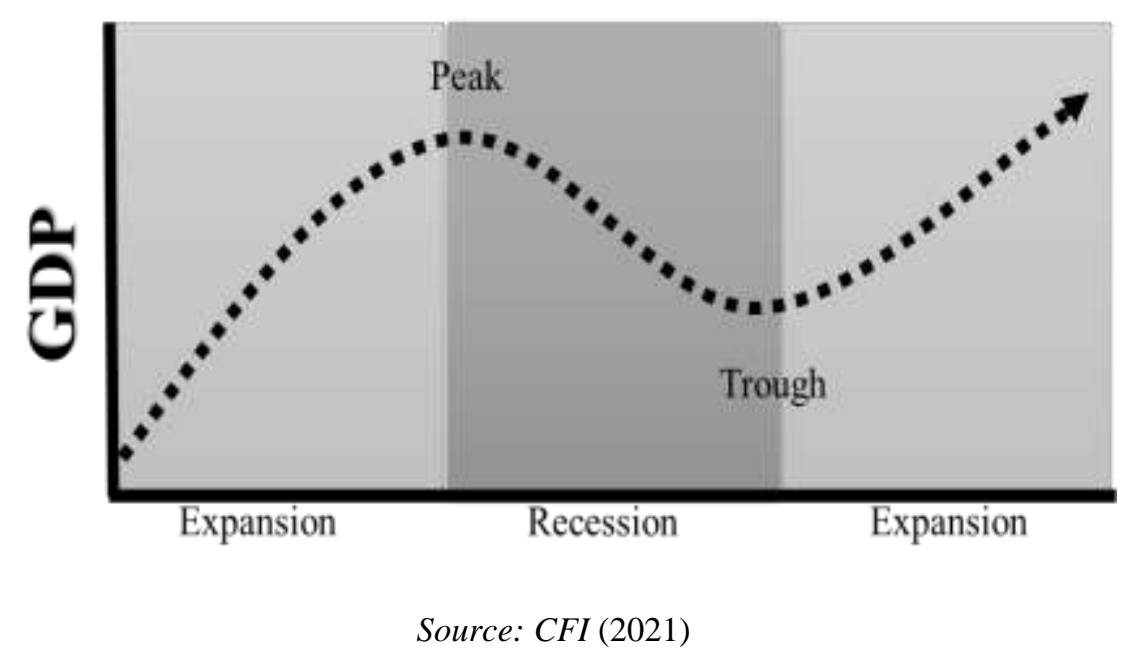

Chronologically the first generation of models of Economic cycles of political origin start from opportunist and partisan models within the 1970s. These models are characterized by reasoning with adaptive expectations, arising from a theoretical context characterized by the Orthodox Keynesian dominance. At this stage, it was considered that the rulers generated economic cycles on income, inflation and unemployment in the electoral period, factors that were supposed to motivate the voter, who only perceived the evolution of the government as a good economic situation and with this, they would support the party in power (Perez-Cruz, 2016).

In the second stage, which emerged in the mid-eighties, the business cycle models incorporate rational opportunistic expectations, with the government paying more attention to macroeconomic variables on the influence of the cycle and the economic cycle, effect on the intention to vote, representing opportunistic behaviour and partisan behaviour.

In this sense, opportunistic models maintain the assumption that politicians in power try to maximize their popularity, and thereby try to increase their probability of continuing to govern. In partisan models there is the collectively, that is, different political parties represent different segments of the electorate. However, there is also the eclectic current, which is between the two previous currents, attending adaptive and rational expectations, weighing the weight of the different objectives depending on the popularity of the ruling party in the pre-electoral period in the sense of Pérez-Cruz, NandeVázquez and Martínez-Verdugo (2021).

Finally, the strategic debt cycles, oriented under the assumption of the fiscal smoothing theory, which represents a normative reference from which the political economy models are derived (Barro, 1979; Lucas and Stokey, 1983).

In this sense, according to Perez-Cruz, O., Nande-Vazquez, \& Martines-Verdugo (2020), the empirical studies that have been carried out to determine the existence of cycles as much as possible are ambiguous, although the empirical evidence has been worth the CPP more than the CPE.

\subsection{Main currents of the political-economic cycles}

The development and origin of the theories of economic cycles spread from the work of Kalecki (1943), although it is from the seventies when his study was more evident and significant, taking force the opportunistic model of the CPE. At this stage the works of Nordhaus (1975), Lindbeck (1976), MacRae (1977) and from a budgetary point of view Tufte (1980), constitute the basis of the literature on CPE. All these studies emerge in the first generation of economic models. In this sense, these authors share the same vision around the object of our study, characterized by the objective of politicians in the opportunistic context and the expectations of voters, which in general terms we could call "non-rational", emerged in a second generation with Cukierman and Meltzer (1986), Rogoff-Sibert (1988), Rogoff (1990), Persson and Tabellini (1990), Price (1997), among others. 
In this sense, the objective pursued by the rulers based on rational and non-rational models is to raise the number of votes in an election either for him or for his party's candidate. In the following Table 6 , the main currents are collected from the rational and irrational theories, classified according to the theory or model, type of expectation of the voters and author:

Table 6 Theory voter's

\begin{tabular}{|c|c|c|}
\hline Theory or model & Voter's expectation & Author \\
\hline $\begin{array}{l}\text { Opportunistic Theory of the Irrational } \\
\text { Political Cycle }\end{array}$ & Adaptive & $\begin{array}{l}\text { - } \quad \text { Nordhaus (1977) } \\
\text { - Nordhaus et. al. (1989) } \\
\text { - MacRae (1977) } \\
\text { - Tufte (1978) }\end{array}$ \\
\hline $\begin{array}{l}\text { Partisan Theory of the Irrational Political } \\
\text { Cycle }\end{array}$ & Adaptive & $\begin{array}{l}-\operatorname{Hibbs}(1992,989, \quad 1987 \quad \text { and } \\
\text { 1977) }\end{array}$ \\
\hline $\begin{array}{l}\text { Opportunistic Rational Theory of the } \\
\text { Political Cycle }\end{array}$ & Rational & $\begin{array}{ll}- & \text { Cukierman y Meltzer } \\
- & (1986) \\
- & \text { Rogoff-Sibert (1988) } \\
- & \text { Rogoff(1990) } \\
- & \text { Persson y Tabellini (1990) } \\
- & \text { Persson y Tabellini (2002) } \\
- & \square \text { Drazen y Eslava (2005) }\end{array}$ \\
\hline $\begin{array}{l}\text { Rational Party Theory of the Political } \\
\text { Cycle }\end{array}$ & Rational & $\begin{array}{l}\text { - } \quad \text { Alesina (1987) } \\
\text { - } \text { Alesina y Sachs (1988) } \\
\text { - } \quad \text { Price, } 1997\end{array}$ \\
\hline Eclectic Model & $\begin{array}{l}\text { Adaptative } \\
\text { Rational }\end{array}$ & $\begin{array}{l}\text { - Frey y Schneider (1988), } \\
\text { - (1981) and (1978). }\end{array}$ \\
\hline Strategic Debt Cycles (CED) & $\begin{array}{l}\text { Adaptative } \\
\text { Rational }\end{array}$ & $\begin{array}{ll}\text { - } & \text { Barro (1979) } \\
\text { - } & \text { Lucas y Stokey (1983) } \\
\text { - } & \text { Alessina yTabellini (1988) } \\
- & \text { Aghion y Bolton (1990) } \\
- & \text { Milesi-Ferreti }(1995) \\
- & \text { Escudero (2002) } \\
- & \text { Benito y Bastida (2005) } \\
- & \text { Pascual } \text { et al. }(2008) \\
- & \text { Vila i Vila }(2011,2010) \\
- & \text { Sánchez Mier }(2011)\end{array}$ \\
\hline
\end{tabular}

Source: Author's own elaboration based on study of CPE

The previous theories and models are classified according to their chronological order into irrational models and rational models. These currents in turn represent opportunistic behaviours and partisan behaviours shown in the following epigraphs.

\subsection{Opportunistic and Partisan Irrational Models}

Within the opportunist irrational scheme, the work of Nordhaus (1975) states that governments interested in maximizing their number of votes should adapt macroeconomic policy to improve the probability of being re-elected, basing their study on the manipulation of economic policy instruments2, capable of from affect the behaviour of voters and thus exercising a choice between present and future possibilities of well-being.

In addition, Nordhaus (1975) predicts the existence of two variables that can affect the increase in votes, on the one hand, high growth in the economy and, on the other, low unemployment, increasing inflation in election periods and a recession post-election without considering the political orientation of the government in power. He also acknowledges the possible inconsistency of this assumption, as 50\% plus 1 would suffice to win. The following Figure 18 illustrates an electoral cycle of unemployment and inflation.

\footnotetext{
${ }^{2}$ In terms of inflation, unemployment, production, public debt, deficit, expenses or income.
} 
Figure 21 Ejemple of electoral cycle of unemployment and inflation

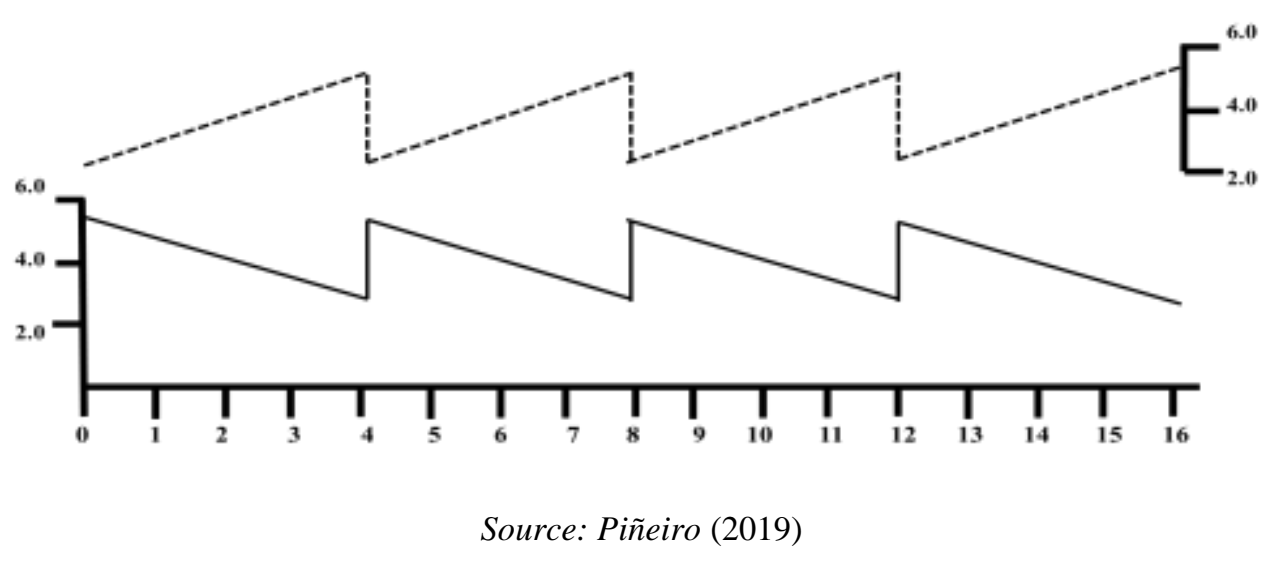

For the irrational party model, the game of ideas and different forms of behaviour between parties prevail, that is, they interact between politics and economics (Frey and Schneider, 1988), choosing from them within the Phillips curve the different combinations between inflation and unemployment (Hibbs, 1992, 989, 1987 and 1977). In this sense, the foundation of these studies shows that political parties do not always coincide in their policies, which is applied in different governmental contexts, contradicting the vision of Downs (1957b) in his rational axioms within the theory of public election. The next Figure 22 illustrates the partisan conflict in the U.S. economy.

Figure 22 US Partisan conflict that comes with growing wealth gaps 1970-2020

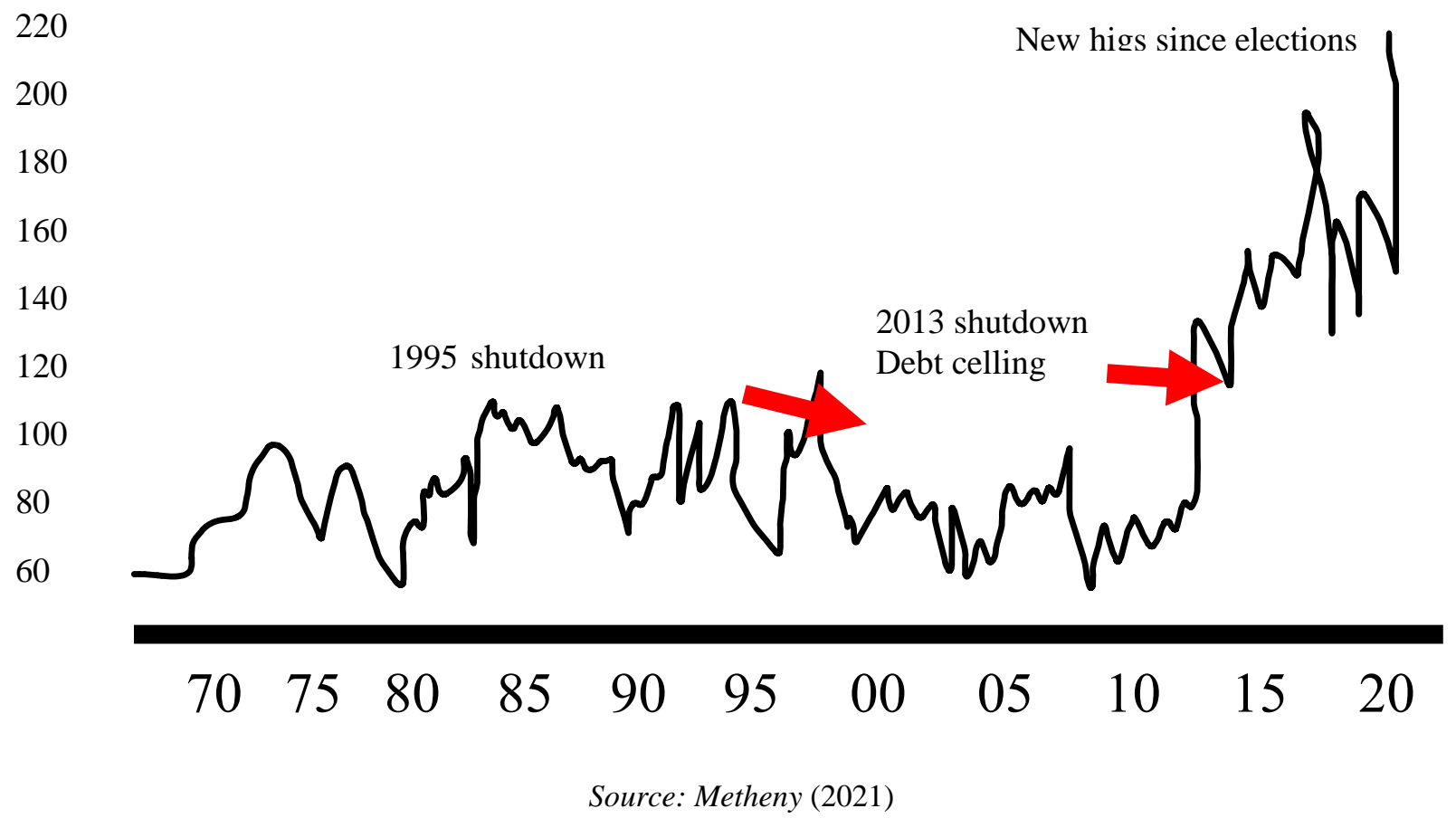

Given all the above, party theory show in the Figure 23, predicts the existence of a cycle derived from the alternation of parties of different signs in power, and in each of them exercises the economic policy most appropriate to their interests, that is, governments on the left prefer greater production, thus controlling unemployment, while those on the right take a stance based on concern about rising inflation (Alesina et al., 1999). 
Figure 23 The development of political business cycle theories

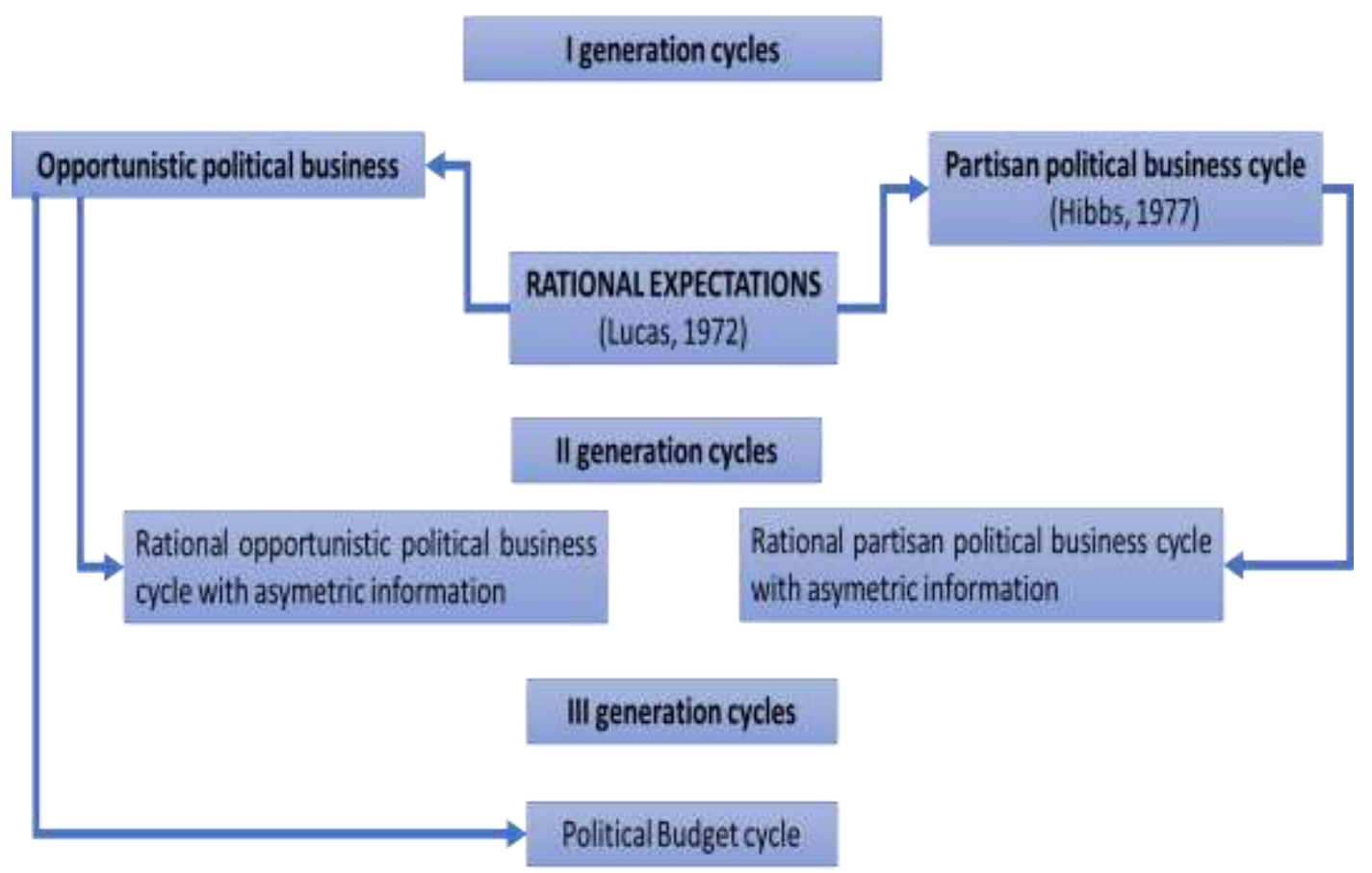

Source: Author's own elaboration based on Frey and Schneider Petreikyté (2013)

In this sense, two important assumptions can be derived from party theory: the first, that different parties follow different rules to define their optimal policies, and that their actions will be influenced by the achievement of their objectives, ideological, and the second, that both the objective variable (inflation - employment) and the instruments of economic policy fluctuate over time according to the alternation of the parties in power.

A final theoretical conception related to the economic political cycle is that developed by Frey and Schneider (1978), who argue that politicians interfere in the world of economics when their chances of re-election are seriously viewed, threatened by economic problems, damaging their level of popularity with the electorate.

\subsubsection{Rational Current of CPE's}

This trend emerged in the late eighties with CPE models with rational expectations, with contributions from Cukierman and Meltzer (1986), Alesina (1987), Rogoff and Sibert (1988), Rogoff (1990), Alesina, Cohen and Roubini (1992), Price (1997), Persson and Tabellini (1990), Shi and Svensson (2003; 2006), among others. With these manifestations, the rational current makes the aspect of voting behaviour more coherent with the behaviour of the politician in office, that is, the variable of rational behaviour is manifested and is part of the knowledge of the voter within the economic cycle, considered in studies above by Frey and Schneider (1988) and Pérez-Cruz (2015).

On the other hand, Shi and Svensson (2003), as part of this option of CPE models, highlight the role of information asymmetries, an aspect considered by politicians in power, highlighting the CPP as the periodic fluctuation in fiscal policies of the government induced by the electoral calendar. However, the authors disagree with some implications of the signalling models used by Alesina et al. (1998), since they comment that the signs of verifiable implications are unclear, where only the politician in office is capable of distorting economic policy in the supposed political opportunism.

From the previous models of the CPE for voters, the manipulation of the vote with opportunism has decreased thanks to the rational behaviour of the voter, leading to a better position to choose a ruler that best suits the self and collective interest. 


\subsubsection{The Eclectic Model}

The Eclectic Model was developed by Frey and Scheneider in 1978, in a theoretical conception that has electoral behaviour as a basic element or conditional variable, which allows to approach the basic characteristics of economic political models in relation to an analysis of the interdependence between economy and politics. Likewise, this model incorporates two assumptions of popularity, the high and low level, shown in the electoral cycle.

The first assumption is below the standard that would allow the party to continue governing, that is, it would be applying expansionary measures if the problem were unemployment or contractionary if there is inflation. On the contrary, the second assumption would leave a margin of manoeuvre to achieve re-election and its current it would be entirely ideological, even though it represents a certain political cost. In this context, the model brings together the possibility of connecting ideological and opportunistic stimulations in the same scheme, with the purpose that both possibilities influence the re-election of the rulers.

This theory led to at least two conclusions, first, that the ruling parties will not try to influence economic variables, unless they judge that these reach critical levels that require the adoption of some type of economic intervention, and on the other hand, that the attention of the party in power changes with respect to economic objectives, in harmony with the behaviour of the voters.

It is likely that by adopting this model in the sense of opportunistic behaviour, reputation will pay off its results, that is, if the ruler were to win even after manipulating economic policies, they would affect both his ability to act during the next term and his chances of succeeding. re-election, which would be minimal in the future, its reputation being the main social cost of the re-elected party.

This theoretical current, according to Fernández de Mantilla and Flores (2008), tries to find an intermediate and interdisciplinary approach between the sociological trend (social, economic and demographic) and psychological paradigm, seeking an approach for analysis and research in expansive or restrictive policies and their way of manipulation in the different economies of the public context.

\subsubsection{Strategic debt cycles}

The models of strategic debt cycles (CDE), arise from the electoral cycles, also considered as part of the political economy. These models are considered independent of currents with adaptive and rational expectations; however, their validity is still significant within electoral periods in developed and developing countries. In relation to the CED, some studies, such as those by Persson and Svensson (1989), Aghion and Bolton (1990), Milesi-Ferreti and Spolaore (1994) and Milesi-Ferreti (1995), among others, have indicated that the model originates between bipartisan systems a different variation of opinion on the level of public spending and the CED, that is, governments of the right prefer low levels of spending, contrary to those of the left, in addition to preferring to borrow and thus limit the next government, trying in what possible to influence the election outcome and voter preferences.

In this sense, within electoral cycles, Escudero (2002) comments that where indebtedness has acquired the greatest role has been in the so-called strategic debt cycles (CED), whose models depart from traditional models that we observed in previous sections. This current assumes that the governments in power create limitations for future governments through the resource of indebtedness, also assuming that the volume will be greater when there are two-party systems, competition between left-right parties or when there is a risk of continuity in power. According to the author, this type of phenomenon is difficult to observe evidence, for which it is possible to resort to proxy variables whose construction could be considered arbitrary.

In this context, this current originates from a representative agent and the government, which acts and makes the most of the utility of this agent, that is, both have the same horizon but not the same ideas, with the government being the main manipulator of the economic variables of his administration, explained from the fiscal smoothing. The Figure 24, exhibit this theory, which explains that the budget deficit and surplus are optimally used to minimize the distorting effects of the system, that is, deficits will occur when expenditures are temporarily high, and surpluses when they are low. 
Figure 24 Strategic debt cycles

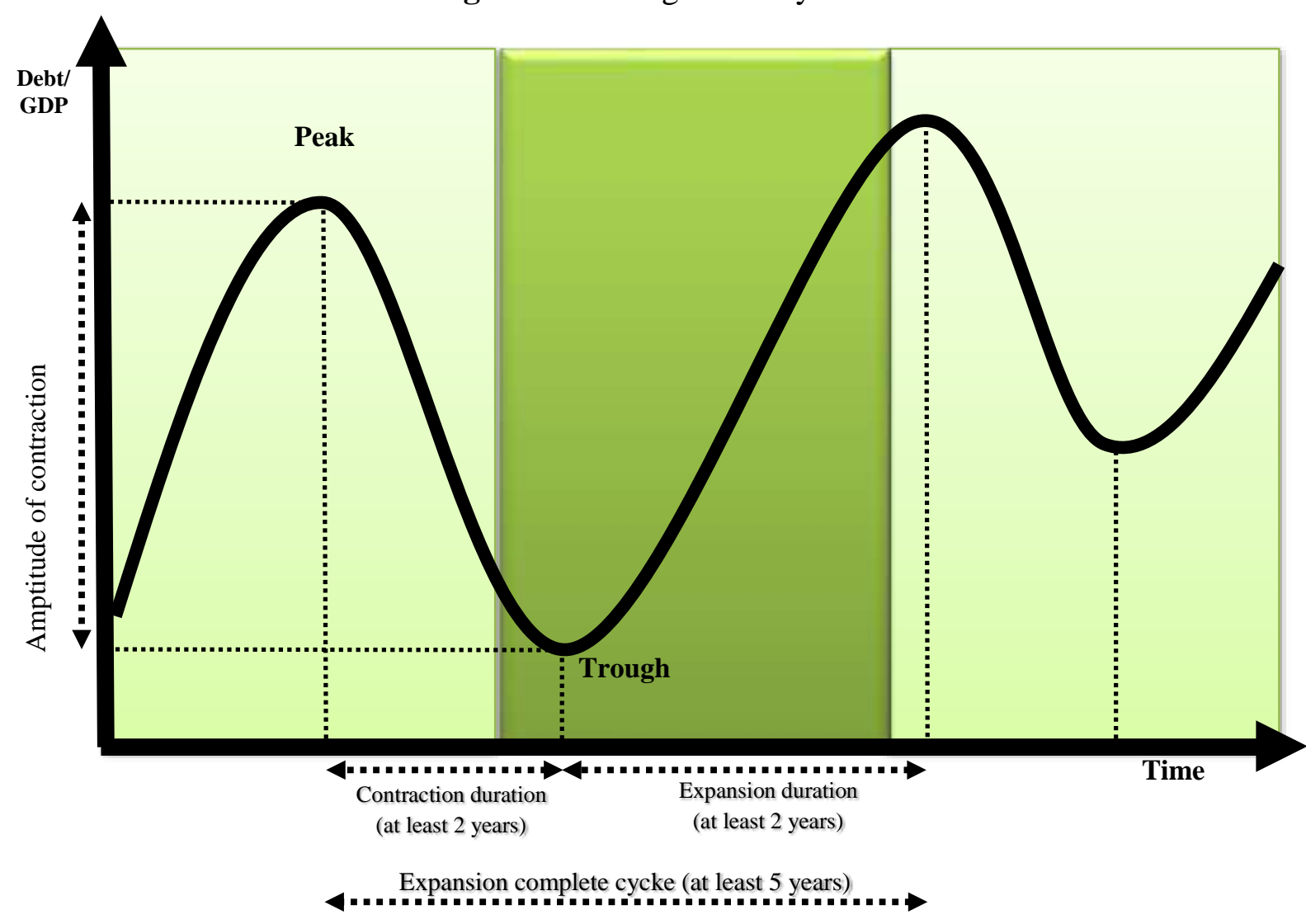

Source: Poghosyan \& Akitoby (2015)

In addition, from the point of view of income, this theory explains that due to the economic cycle there will be cyclical fluctuations in fiscal income, which implies deficits during recessions that will be offset by a surplus at the time of expansion, discussed in the Escudero's work (2002).

Benito and Bastida (2005) in their study conclude that the orientation of the government's political party does not influence debt levels or respect for limits on indebtedness. However, electoral cycles do influence, stating that strategic debt is influenced by non-financial budgetary outcome variables, capital expenditures, and capital inflows.

Pascual et al. (2008), in their work on the stock of outstanding debt per capita of the town councils of the Navarra community, verify that the debt is applied to investment expenses, this component being one of the main determinants of the use of strategic debt in the municipal level. In addition, they deduce that the greater availability of tax resources favours greater indebtedness as there is a greater capacity to face the financial burden, Vila i Vila (2010), add some novelties to this type of study in Spain. They confirm that legal limits are effective in limiting indebtedness, but in turn this may have consequences on the level of investment and by extension on the anti-cyclical work of the local treasury, discarding the hypothesis of a different behaviour in the face of indebtedness, because of the colour ideological nature of the local government, but not in view of the majority or coalition nature of the government.

Sánchez-González (1998) points out that the main difficulty of this model lies in the empirical verification of its hypothesis in relation to the governments' expectations of being defeated in the following elections, something that is not directly observable and that forces them to choose proxy variables which can have an arbitrary construction.

\subsubsection{Political Business Cycle}

Drazen and Eslava (2003) carried out a verification work for the Colombian case of the model known as the Political Business Cycle. In this work, the cyclical behaviour of GDP was examined for the national level and the departmental level, as well as its relationship with the variables of economic policy (specifically fiscal) and the periods of elections of local leaders, finding significant relationships between the total spending of territorial entities and the level of GDP. 
Later, in 2004, the authors presented another work that showed how political cycles can take the form of changes in the composition of government spending and not in its amount. Furthermore, in this model, voter-preferred spending increases before the election, while other types of spending decrease to reduce the effect on the total budget and thus balance its composition. In this way, the politician in power tried to indicate a coincidence of his fiscal preferences with those of the voters.

In 2005 they presented a model for two election periods in Colombia, trying to differentiate the behaviour of a politician in power and an opposition politician. In this model, politicians in power use the composition of spending to attract votes, unlike the opponent, which is a clear example of information asymmetry evidenced at the time by Rogoff and Sibert (1988) and Rogoff (1990), demonstrating that the proportion of votes received by a politician in the exercise of his functions increases with the increase in capital spending in the election period.

Within the approach of this model, Perez-Cruz, Nande-Vazquez and Martines-Verdugo (2020) explain a very reasonable approximation is made towards the preferences of the politician in power. In other words, this approach was based on the different evaluations that voters give to different types of spending, where politicians act by modifying the composition of spending, which in many cases is not observed by voters, nor by competitors in the process. In this way, they change the composition towards those expenses preferred by the voters, implying high post-electoral levels and consequently, a greater present utility for the voter, which would translate or result in more votes for the politician in power.

In this model capital expenditures and current expenditures were called focused expenditures and unfocused expenditures respectively. The model expects targeted spending to increase its level in total spending, and this would serve as a signal for voters to attract their vote. In addition to this type of increase, the model also predicted that the rest of the expenses should decrease, thus achieving a budget balance.

In this sense, the Drazen and Eslava (2008, 2005 and 2003) models are part of a theoretical formulation, in which the cycles of fiscal policy suggest manipulations in the composition of spending, without the need to alter the total amount of the budget or the deficit. In addition, the authors conclude that the recomposition of spending with a view to increasing the probability of re-election (of the ruling party) is focused on cutting current spending and increasing expenses related to the development of infrastructure projects. For Álvarez and Delgado (2006), this model presents a similar scheme to that used by Rogoff (1990), in relation to the economic classification that this work originates. Those similarities occur when:

1. They examine how the agents behave, in relation to the maximization of the objectives sought by the voter and for his part, the politician.

2. The postulates of rational behaviour and asymmetric information between the agents derive imbalances of separation and confusion.

3. The opposing interests of agents are shaped by varying a portion of spending, so that their behaviour derives a different utility for the voter than it does for the politician.

The Figure 25, exhibit the political transition business cycle in México. 
Figure 25 The Political-Transition Business Cycle in México

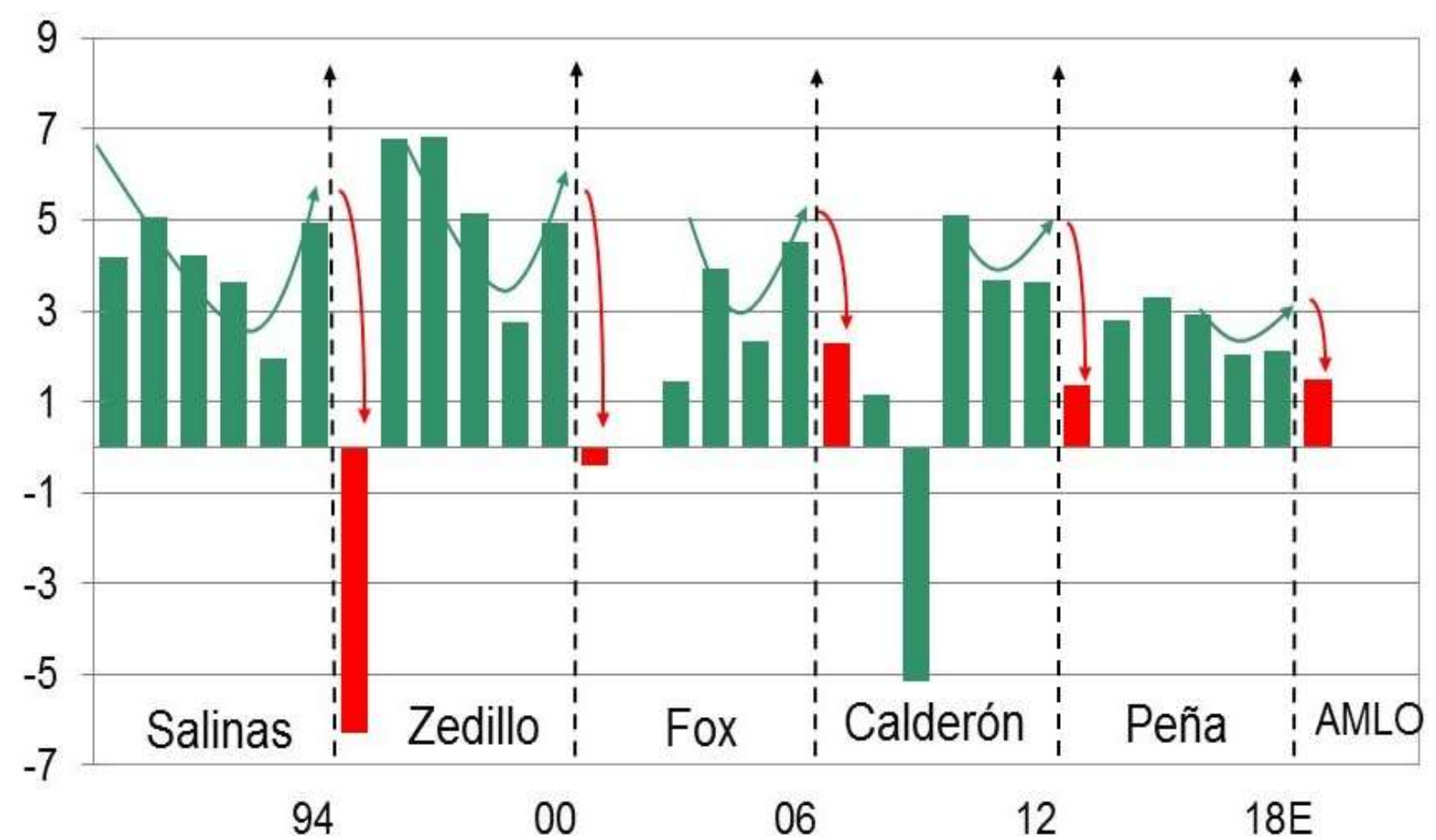

Source: Coutino (2018)

The previous figure shows the fiscal policy cycles of the 5 previous presidential terms. The variable suggests that in all periods, in the election year the composition of spending was manipulated. In addition, it is observed that the reconfiguration of spending is committed to reelection (of the ruling party). It is also observed that the spending variable decreases at the beginning of each presidential term and they focus on cutting current spending.

\subsection{Fiscal illusion and budgetary policy cycles}

In the context of the search for explanations and the analysis of the growth of public sector budgets and its relationship with the public deficit, the concept of fiscal illusion arises. This approach, as Hernández (2011) points out, when governments do not have constitutional restrictions on indebtedness leads to a fiscal illusion when thinking that the cost of public services provided using a source of financing are lower than if they were financed by taxes, generating a wrong parameter of the services offered, which leads in the short term to a budget deficit.

For the Latin American Institute for Economic and Social Planning [ILPES](2004), the fiscal illusion means that voters do not fully integrate the government's inter-temporal restriction. That is, when a spending program financed with a larger deficit is proposed to them, voters overestimate the advantages of these expenditures, and they underestimate the weight of future taxes, so opportunistic politicians take advantage of this situation to increase spending more than income.

At present, empirical analyses on fiscal illusion have taken the form of studies of public spending or of jobs that use demand functions for public goods and services. In this context, the studies by Buchanan and Wagner (1977) argue that deficit financing allows a higher level of spending, due to the existence of fiscal illusion. For their part, Brennan and Buchanan (1980) suggest that in a Leviathan-type government, higher taxes in the present entail higher expenses in the future.

Barro (1979) and Peacock and Wiseman (1979) state that spending increases in the present tend to be followed by tax increases in the future. Other authors support the hypothesis of interdependence between income and expenses, initially raised by Wicksell (1896) and reformulated by Musgrave (1966) and Meltzer and Richard (1981), predicting that decisions about both variables are made by the same groups, so they will be adopted jointly and interdependently. One of the most important lines of research in relation to tax illusion is the complexity that exists with the collection mechanisms. In other words, an increase or decrease in its level would generate a positive or negative movement in the tax price received from public goods. 
In that sense, Wagner (1976) establishes that as the tax system becomes more complex in time (financing through debt), in space (various collection administrations) and in the diversification and complexity of collection mechanisms, the cost of obtaining information for voters.

Other authors such as Clotfelter (1976), Pommerehne and Schneider (1978), Baker (1983), and Breeden and Hunter (1985) included the concept of "visibility" of taxes, in the sense that the less visible they are, the more degree of fiscal illusion they will generate.

The results of empirical studies in most cases show and support the hypothesis of fiscal illusion; however, there are no studies that harmonize the work of the countries in this regard. In this context, some critics argue that the basic assumptions that have been used for these studies are not very consistent, and there are other explanations for the relationships detected.

Gemmell et al. (1999) point out that although the evidence obtained in the empirical work is consistent with the hypothesis of the existence of fiscal illusion, via the invisibility of taxes, it is also consistent with the idea that governments finance spending increases using taxes marginally more. efficient, which tend to be the least visible.

In this sense, Wagner (1976) affirms, "possibly a quite different interpretation of the empirical results could be offered, where it could be maintained that the choice of an income structure is made in order to minimize the excess of taxation produced by the collection system".

In México, the application of the fiscal illusion as such is scarce, however, at present the different programs have tried to reduce the deficit levels in public finances, in the sense of promoting growth with equity, they suggested that at be considered a fiscal pact, there would be a lack of reciprocity between paying taxes and an improvement in spending efficiency (Pacto por México Program, 2013).

\subsection{Agency theory}

The concept of agency theory begins to develop with the approaches and conflicts of interest that take place between the various agents in a company (Jensen and Meckling, 1976), in this case, owners and managers. In this sense, this type of conflict occurs specifically in large organizations and to a lesser extent in medium and small (SME's). In a political scenario, the agency theory could be applied in the politician-voter relationship, where the politician in power seeks the maximization of his own well-being that implies the maximization of votes to favour his re-election or the maximization of the privileges that can result from their job (Buchanan and Tullock, 1962), where it is assumed that economic agents (the principal as voters and the agent as elected politician), are rational agents and wish to maximize their own interest (Jensen and Meckling, 1976 and Zimmerman, 1997).

This theory generically analyses formal and informal contracts through the principal, who is the owner, entrusting another person to defend the interests, called the agent (administrator), delegating in this, decision-making power. In addition, this theory is characterized by having an orientation towards the context of organizations. For his part, Downs (1978) presents the following assumptions of rationality economic in voting decisions:

1. Individual voters are motivated for economic interests, which can be material such as tax reduction, or immaterial, such as the psychological gratification that the preferred candidate is the chosen one.

2. Individual voters should consider when making their decision the probability that your vote will determine the outcome of the election.

3. The politicians are motivated by the desire to obtain and remain in power; and

4. For to be successful, politicians must make decisions that are perceived by a coalition dominant of the voters in their own interest. Therefore, the tendency of a voter is to vote for the person who he believes will provide the best interest and utility high.

Which can be represented in Figure 26 
Figure 26 Voter \& politician relationship

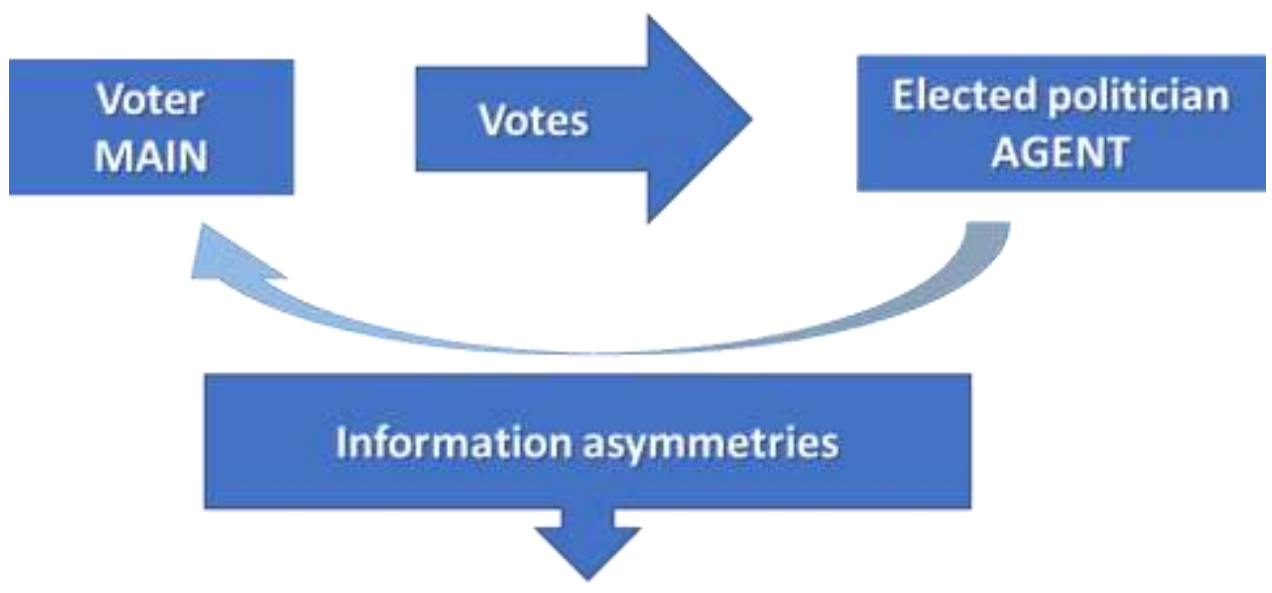

\section{Opportunism}

Source: Author's own elaboration based on Buchanan y Tullock (1962); Jensen y Meckling (1976); Zimmerman (1997)

The agency problem arises when there are information asymmetries, it is that is, when the agents have more and better information than the principal, leading to another problem, opportunism, since the agent can take advantage of the ignorance of the principal as an excuse to supply suboptimal levels of effort (Przeworski, 1998).

In that sense, to try to lessen the difficulties between the principal and the agent, Przeworski and Stokes (1995) indicate a list with the information that citizens as the principal can use in their evaluation's retrospectives of the governments that the agent is, which includes:

1. The motivations of politicians.

2. Sources of financial support from parties and campaigns electoral.

3. The private finances of politicians.

4. All conditions objective observed by governments; and

5. The causal relationships between policies and results.

In addition to the previous list, the solutions proposed in the agency theory to control government actions are, equal opportunities of access to information using performance evaluation systems, financial performance and clear determination of objectives (Vargas, 2005).

Trying to respond to these needs, the theory of New Public Management (NPM) emerged, which arises from the new cultural, informational, and economic circumstances, since the beginning of the eighties. Suleiman (2000) points out that the reforms carried out by the OECD countries have placed the accent on organizing the government into groups of agencies and departments, on the adoption of strategic and results-oriented decisions, on the use of management objectives, output, performance indicators, positions in relation to results and quality improvement measures, in cutting expenses, improving efficiency in the provision of public services, in promoting competition and between public sector organizations, which also allows deducing procedures according to the economic situation that favours transparency and accountability for better decision-making.

This type of reform prioritizes a series of transformations within the state (Oszlak, 1999), supported by ideas from management sciences, whose legitimacy originates as a source of proposals to improve the performance of the public sector, which in turn time finds support in the experience of the private sector over the last few years. 


\subsection{Creative accounting and the handling of information within the framework of budgetary policy cycles}

In the literature on the manipulation of financial information there are various conceptions that refer to this concept. For example, Healy and Wahlen (1999) consider that the manipulation of financial information takes place when managers make use of the discretion and subjectivity inherent in their position in the preparation of financial statements, with the objective of inducing the error in their interpretation of users.

Within this idea of manipulating financial information, creative accounting arises, which as Naser (1993) points out, is a process of manipulating accounting to take advantage of the gaps in accounting regulations and the possible choices between different valuation practices. and accounting that it offers, observing this term as a form of manipulation, since it transforms the annual accounts from what they must be to what they prefer it to be, in order to highlight the results that are best for the public entity.

In this sense, Monterrey (1997) and Blasco (1998) argue that creative accounting is the product of the manipulation of accounting, making use of the flexibility, imprecision or non-existence of accounting standards that are used, individually or together, to obtain and present desired values. Monterrey (1997) highlights that societies have a natural tendency to adopt accounting procedures that minimize any unfavourable economic effect and highlight those they consider most favourable.

Griffiths (1988) explains that creative practices represent skills that do not violate the rules of the game or accounting standards, giving it a certain relationship of legitimacy and legality, to define creative accounting as the manipulation of the reality of the company to present falsified information that reflect a desired situation and not the actual situation.

Some theoretical works, such as that of Dye (1988), show that manipulation practices constitute an optimal solution to the problem of agency between shareholders (principal) and manager (agent). In the field that concerns us, the representatives of the entities know the accounting information before the citizens, which manifests an asymmetric information argued in the works of Rogoff and Sibert (1988) and Rogoff (1990), having consequently in many cases the possibility of carrying out the interpretation of accounting principles for their common benefit.

On the other hand, for the public sector, manipulable financial information is captured based on two perspectives: first, the benefits of the political actors in power who work to retain and use one more period of government, and second, the benefits citizens who receive such information and will make their interpretation.

At present, to avoid manipulation of accounting information in public and private entities, accounting regulations have been issued in different countries. Mention may be made, for example, of the International Accounting Standards for the Public Sector (NICPs), elaborated based on the private sector standards, which aim for governments to improve both the quality and comparability of financial information presented by public sector entities. all over the world.

In México, López (2013) highlights some aspects related to debt and the manipulation of information, which are derived from the malfunctioning of some subsectors of the private sector. According to López (2013), these problems have increased the public sector debt, since if the private sector debt is added to the public one, it would be higher than the published debt. And on the other hand, the budget of spending reduces the room for manoeuvre of economic policy, worsening the monetary outlook.

The same author recognizes that in México, low deficits are not a reflection of healthy public finances, this is due to creative practices, makeups, and manipulations, which if not corrected will cause further deterioration in public finances and in the economy of all Mexican entities. 


\section{Chapter 4. Model Generalized Method of Moments (GMM) applied to expenditure management and budget policy cycles (CPP)}

\subsection{Introduction}

The literature on budgetary political cycles arises due to the interest of the ruler in the manipulation of fiscal and budgetary variables, because of an asymmetry of information originated in the benefit of the rulers in power. This phenomenon is evidenced in the works of Rogoff and Siber (1988) and Rogoff (1990), who maintained the assumption of asymmetries of Nordhaus et. Al. (1989), but from an imperfect information approach, where governments are heterogeneous in their competitiveness and Voters deduct their vote based, among other reasons, on their economic performance.

At present, the growing interest of the media to disclose financial information in the context of democracies increases the dissemination of those variables that motivate the manipulation or advantage of the ruler, which contributes to the knowledge and reasoning of users about performance government for better decision making. Said media, such as the web, print media, radio, television, etc., today are supported and regulated by the different legal regulations on access to and knowledge of public information in most of the countries. However, the investigations that analyse the transparency and use of information as a means of control for the voter to regulate are still limited. the actions of politicians in government (Brusca and Montesinos, 2006; Benito et al. 2013).

In this context, the literature like Seitz (2000) and Selume (2007) has echoed different consequences, as is the case of creative accounting, where governments use the possibilities at their disposal to balance budgets based on the increase or decrease in financial costs expenditure components. Similarly, a line of research on political cycles tries to show whether politicians use the instruments at their disposal to maximize the chances of being re-elected.

According to the positivist theory of accounting, formulated by Watts and Zimmerman (1978), accounting practices can be analysed from two different perspectives: the opportunistic approach and asymmetric information, originated by attitude and aptitude, that is, politicians They deliberately distort the financial statements because they have reasons and, in addition, they have the necessary technical capacity to do so, which generates a change in the composition without affecting other variables in the budget (Cano, 2001).

With the evolution of voter reasoning, new economic and financial strategies were incorporated to gradually exclude the limitations of traditional models of political budget cycles. In this sense, Gámez and Amarillas (2011) showed that one of the changes to exclude the limitations was to move from the analysis of the outcome variables (outcome), citing inflation, GDP growth and unemployment, to the socalled variables instrumental, which originate the tools of monetary policy (money supply, interest rates) and fiscal policy (taxes and public spending). That is, both the object of study and the methodology are modified.

In this context, this chapter aims to analyse the effect of elections on budget management, that is, we will try to show what type of expenditures are chosen by the government in power to try to maximize their chances of continuing in government or be re-elected.

\subsection{Review of the literature}

The literature on Budgetary Political Cycles is developed in two periods, first with irrational macroeconomic models that emerged in the mid-seventies, and later with rational models in the eighties, contributing and evolved in later investigations with expectations formulated from the behaviours of previous studies. Therefore, the CPP as an evolutionary part of the CPE has been studied and evidenced by numerous researchers, motivated by the events and conditions arising in the economy and the biases that limit it. Next, we refer to the different works carried out and the results obtained, to highlight what it can contribute to us to develop this first empirical work. In this sense, literature is divided into two sections, international and México. 


\subsubsection{International empirical evidence}

The empirical evidence on CPPs in the international arena presents divergent results, that is, the literature shows trends in both directions in relation to the spending variable, its composition and signalling in the periods before and after the elections Barber y Sen (1986).

In Spain, Escudero (2002) carried out an analysis for 86 Catalan municipalities with a population greater than 10,000 inhabitants during the period 1988-1999. He concluded that there is an expansion of spending in the year prior to the election and a contraction of it in the electoral and post-election year, also conditioning an increase in the debt variable.

For their part, Drazen and Eslava (2003) analysed the national and regional level in Colombia. For the first, they considered the period 1974-2000, while for the second, the period analysed is 19841998. The authors concluded that at the national level there is no evidence of a political cycle in the monetary aggregates or in the exchange rate. However, the evidence for a political cycle in total spending or tax collections was ambiguous. In addition, they found strong evidence of an expansion of government investment before the elections. At the regional level, they observed a significant increase in total public spending, with an increase in investment spending before the elections. The study concludes that in both levels there is an increase in the investment spending variable prior to the election.

Along these lines, Khemani (2004), focusing on India, analysed 14 states from 1960 to 1996. This work observed significant increases in capital spending in electoral periods targeting specific locations and specific groups of citizens. Furthermore, she argues that the pattern of evidence is inconsistent with the predictions of the Asymmetric information models and myopia of voters.

Brender and Drazen (2005) consider in their research the period 1960 to 2001, with a sample that covered 107 countries, differentiated between old and new democracies. The authors use the GMM estimator in differences of Arellano and Bond (1991), and Arellano and Bover (1990), where, first, the regression is estimated including the total number of democracies, then for new democracies, later new democracies excluding economies in transition and, finally, the old democracies. The study concluded that the new democracies showed a strong increase in spending before the elections, which also explains the significant increase in the public deficit in electoral years. Furthermore, these findings suggested that fiscal manipulation is stronger in new democracies than in old ones.

Eslava (2005) analysed the local level, that is, 1,100 Colombian municipalities from 1987 to 2000. He found that the head of each local government increases capital expenditures as an optimal strategy to favour continuity in power, reflected in the development of projects. related to infrastructure.

Shi and Svensson (2006) focused their analysis on a base of 85 countries during the period 1975 1995. They reviewed the relationship between fiscal policy and elections. The evidence found is that public spending increases before the elections, while on the contrary income is reduced, giving rise to a larger deficit. In addition, they showed that the evidence is stronger in developing countries than in developed countries.

In the study by Álvarez and Delgado (2006), the base included the Argentine provinces from 1983 to 2002, analysing the variations in total spending and its components. This work concluded that capital and current expenditures increase in the electoral year between 15 and $20 \%$ for the former and up to $6 \%$ for the latter. In addition, they showed that the population variable positively influences capital spending, reflecting the trend effect of spending on the increase shown by this variable.

Drazen and Eslava (2008) analysed a panel of data that included 1,100 Colombian municipalities from 1987 to 2002 in Colombia. The authors find evidence of CPP in the pre-election year, where investment spending increases and current spending contracts. The authors used the GMM procedure suggested by Arellano and Bover (1990), a standard approach for estimating dynamic data models, since the differentiation presented endogeneity problems. 
On his part, Vergne (2009), in his analysis of the composition of public spending, used data from 42 developing countries from 1975 to 2001, evidencing the electoral impact on the allocation of public spending. Their results show that in the election year current spending is more visible than capital spending. In addition, it suggests that governments prefer the option of changing the composition of spending, without increasing total spending and, therefore, raising their public deficit.

Brusca et al. (2010) for Spain, considered 162 Valencian municipalities with a population of more than 1,000 inhabitants, with budgetary data from 1994-2005. This work used GMM by Arellano and Bond (1991), showing in their results an increase in investment spending and a contraction in current spending in the electoral period. In addition, the study deduces that the population maintains a positive relationship with total spending and tourism indices and negative economic activity, which indicates that the municipalities with greater economic activity and a high tourism index require less spending. Regarding investment spending, these increased in the year prior to the election, showing that this spending is preferred and visible to citizens. The paper concludes that government incumbents prefer capital spending to try to impress the voter in the years leading up to the election.

Sakurai and Menezes-Filho (2011), for Brazilian municipalities, demonstrated the existence of a pre-electoral shift towards the heading of current spending together with a decrease in capital spending. This study considered the period 1989-2005. Aidt et al. (2011) analysed political, financial and economic variables in 278 Portuguese municipalities from 1979 to 2005 . Their study concluded that public spending increased before the elections, thus showing the CPPs.

Sedmihradská et al. (2011) examined CPPs at the municipal level in the Czech Republic, using data from 205 municipalities from 2001 to 2007. This study presented evidence of capital spending manipulation in the year of the elections and the year before the elections. Their results confirmed a significant increase in capital expenditures and a decrease in current expenditures in 2002 and 2006. Furthermore, the authors show that the manipulation of capital expenditures did not increase the probability of re-election of incumbents in the municipalities of the Republic Czech.

Katsimi and Sarantides (2012) contrasted that the elections shift public spending towards current spending, that is, before the elections there is an increase in current spending mainly due to its immediate visibility. This work analyzed a sample of 19 countries belonging to the OECD from 1972 to 1999.

In another study at the local level, Cioffi et al. (2012) proved the existence of CPPs in Italian municipalities under the GMM difference model, by Arellano and Bond (1991). This work considered 8,100 municipalities in a period of nine years (1998-2006) and focused its analysis on the opportunistic behaviour of politicians with municipal spending, taking total spending and capital spending as the dependent variable, and electoral year, population, budget variables, political affiliation, and education as explanatory variables. The conclusion shows that any increase in total spending is explained by the increase in capital expenditures, which increases the chances of re-election of the incumbent in the government. In addition, they deduce that the CPP is notorious in the municipalities with the largest population.

Suharnoko et al. (2013), also for the local level, analysed the CPPs in Indonesia. This work considered the period from 2001 to 2009 and used total expenditure, current expenditure and other expenses as dependent variables. For the independent variables they used variables of population, urbanization, and electoral periods.

The results of this work indicate the strategic use of spending in electoral years, with differences between direct and indirect elections, so that the CPPs in other expenses are produced only in the direct election and said increase is due to the organization of the elections themselves.

For their part, Benito et al. (2013) applied the difference model proposed by Arellano and Bover (1990), to analyse the 97 largest municipalities in Spain in the period 1999 to 2009 and observe the effect of financial transparency on the magnitude of the CPP. They use as dependent variables the total expenditure, expenditure of capital and taxes, in relation to the number of inhabitants. In the independent variables electoral, political and transparency variables were used. The conclusions regarding the increase in total spending and capital spending indicate that both increase in the year prior to the elections, which suggests an adjustment after the elections. 
Vicente et al. (2013) considered in their work a sample of 132 local entities in Spain, with a population greater than 50,000 inhabitants for the period 1995-2009. The study analysed the application of the new Budget Stability Law and influence on CPPs. This work pointed out that the variables analysed, such as the deficit, investment spending and current spending, before the entry of the new law, they suggested opportunistic expansions both in the year before the elections and in the electoral year. However, with the new regulations, a smaller increase in these variables was observed in the year in which there are elections.

In addition, in their conclusion they argued that if the law is of general application throughout the electoral period. There should be a penalty clause that contains incentives for politicians to manipulate budgetary variables in electoral years to favour their re-election.

\subsubsection{Empirical evidence in México}

The empirical literature on the existence of CPP in México is relatively new and mostly oriented towards the federal and state levels. In this context, the literature for Mexican municipalities is scarce. The following is a review of the published works and their results on the existence of CPP in the Mexican economy.

The CPP evidence was approached from the eighties by Gámez and Botello (1987), who carried out an analysis on the relationship between the presidential cycle in México and the variables of consumption, investment, exports, imports, spending public and aggregate income.

Figure 27 Annual Rates of Inflation 2000-2020

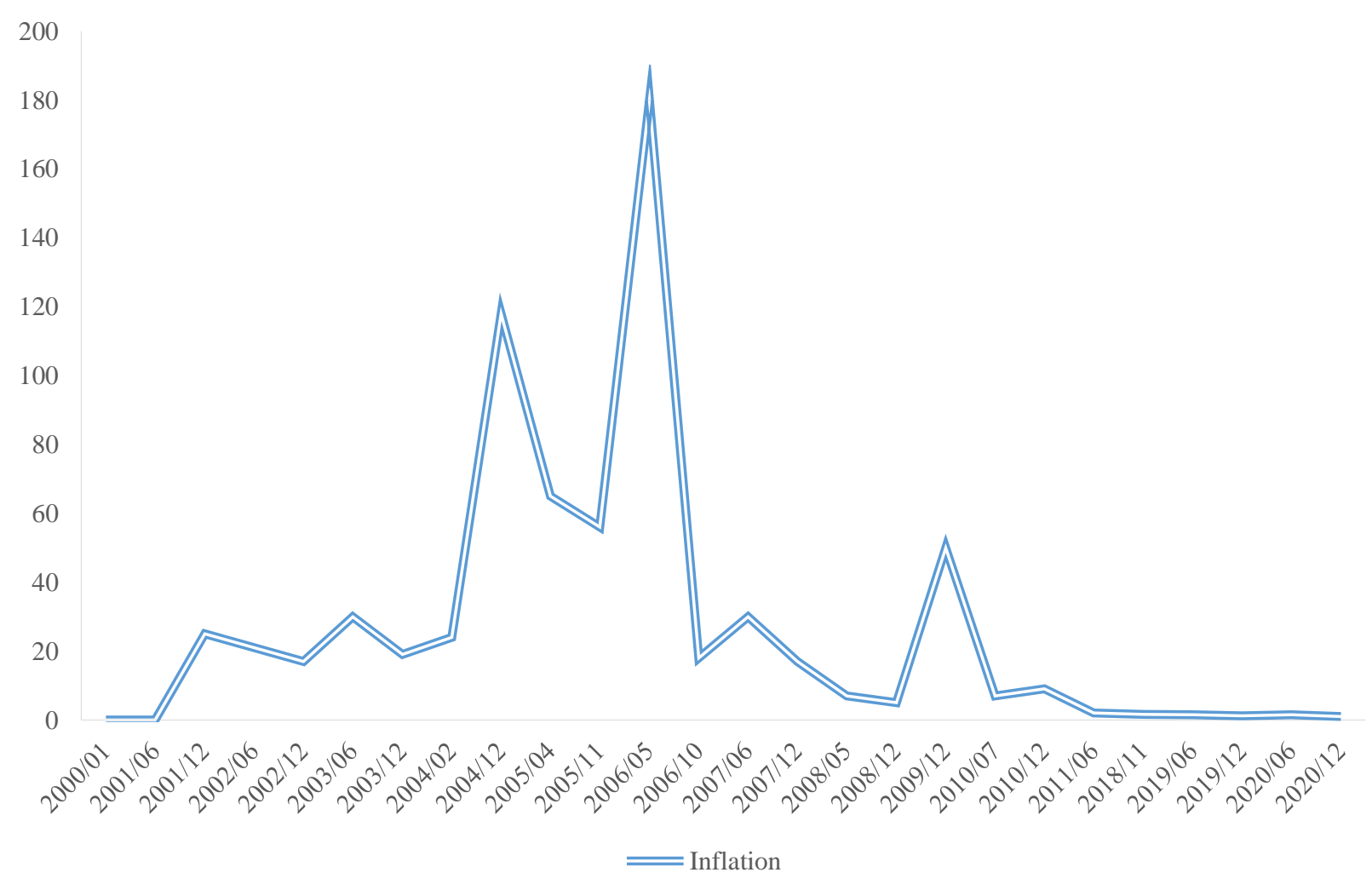

Source: Carrasco (2011)

This study was integrated from five presidential administrations, from Ruiz Cortines to López Portillo (1953-1982). The evidence in the Figure 24, confirmed that the presidential cycle has a significant influence on the behaviour of public spending, exports and aggregate income. In a later study, Magaloni (2000) examined the influence of the political cycle on the Mexican economy in the period 1970-1998 and divided his study into two subsamples. On the one hand, the so-called "populist governments", related to a political culture of the regimes of Presidents Luis Echeverría (1970-1976) and José López Portillo (1976-1982), who preferred to stimulate economic growth, at the cost of increasing inflation. 
And on the other hand, the "technocratic or neoliberal parties", considered in the governments of Miguel de la Madrid (1982-1988), Carlos Salinas de Gortari (1988-1994) and Ernesto Zedillo Ponce de León (1994-2000), who they opted for macroeconomic stability, at the cost of growth. The evidence showed in the Figure 28, significant increases in public spending, private consumption, and economic growth before the elections. Furthermore, his study found that governments postpone economic adjustments on private consumption and economic growth, observing a contraction in economic activity after each election.

Figure 28 Inflation trends in México \& U.S. 1990-2020

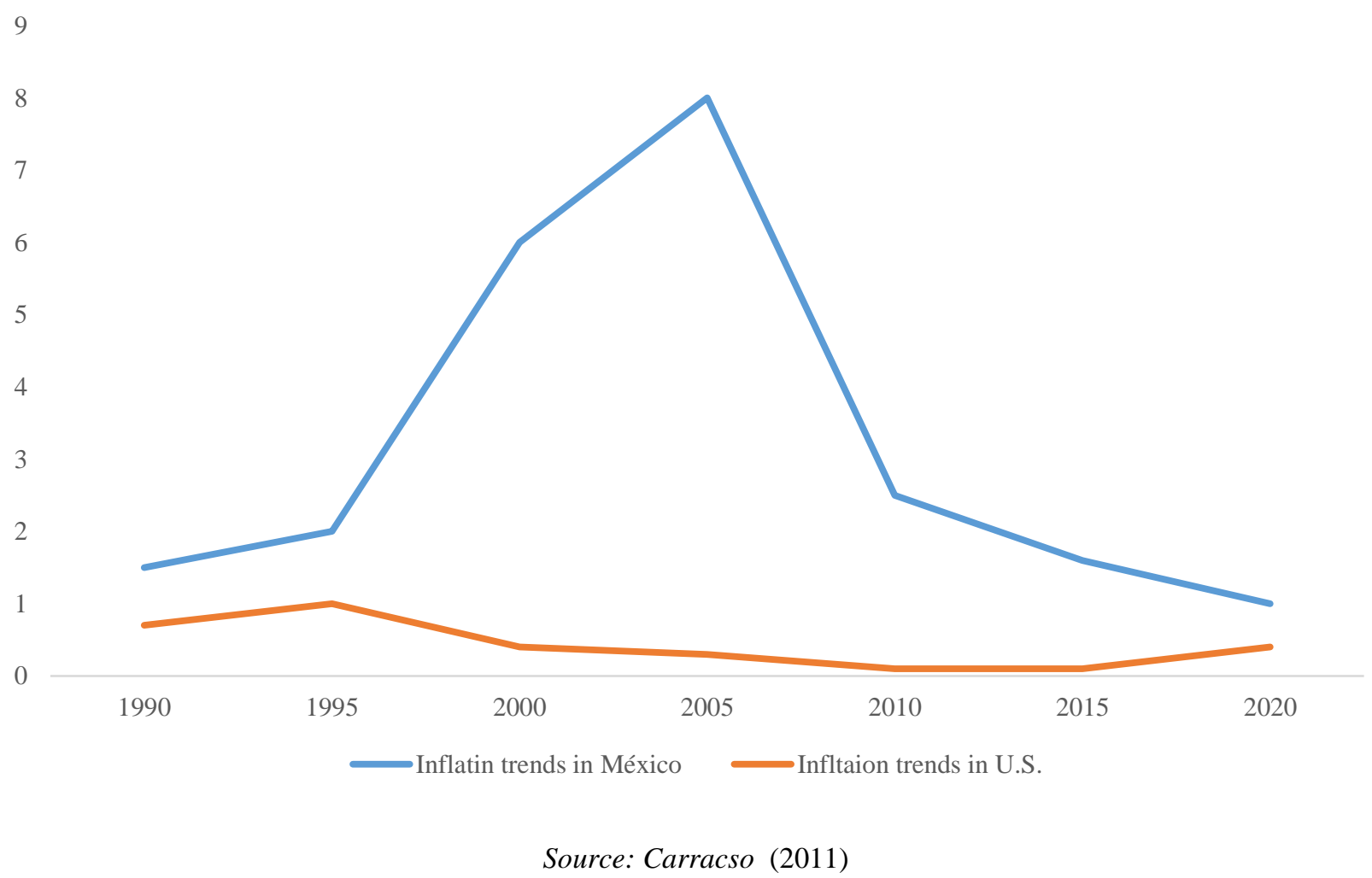

González (2012, 2002 and 2000) conducted an analysis at the federal level and used in his two studies a simple econometric model, calculated for México's fiscal policy between 1957 and 1997. The estimate reveals the government's strong systematic use of public spending, which shows CPPs in infrastructure and current transfers as a means of winning votes.

Moreno (2007), in his work for municipalities in México, applied the statistical method of fixed effects, considering as dependent variables investment spending and current spending, and as independent variables, budgetary variables, ideological variables, electoral and population variables for the period 1990-2001.

The conclusions showed that spending on public works is highly political, that is, it not only increases significantly in electoral years, but is also a useful means for the actions of municipal governments to be more visible to the population, mainly when they come from Party ranks different from those of the state governor.

Furthermore, the authors consider that the political nature of spending on public works does not necessarily represent a disadvantage, since it can provide municipalities with an important incentive to generate charitable social projects. However, it is also possible that municipal governments, to obtain immediate political recognition, choose projects with short-term results, even though their quality is not optimal and expected by the voter.

For their part, Gámez and Ibarra-Yúnez (2009) analyse the influence of the political cycle on the composition of state public spending in México. This work considered in its database annual information on income and expenses of the states from 1997 to 2004. The study concluded that there is a CPP in public spending at the state level since it detects an increase in subsidies in the years before the election and a contraction in the year following the election. 
However, the study showed an increase in investment spending in electoral years. Likewise, the population variable maintains a positive and significant relationship with all expenses, which shows the effect of this variable on the demand for services, public works and infrastructure. The study also allowed us to observe if the governments of different parties have different behaviours in the management of public spending.

Gámez $(2006 ; 2010)$ in his two works measured the influence of the CPP in the Mexican economy for the national and state government in the period 1934-2007. Specifically, he analysed the influence of political cycles on economic activity, aggregate demand, public expenditures, and the exchange rate. The results show the influence of the political cycle on general economic activity, sectoral activity, aggregate demand, public expenditures and the real exchange rate.

At the state level, he showed that there is a significant increase in public spending in electoral years, as well as an increase in public salaries in the years following the elections. In this sense, he adds that in the last 11 six-year terms there was a slowdown in the economy in the first year of the new sixyear term. In this regard, the author explains that everything is due to a learning curve that the new administrations must face, reflecting a lower rate of activity and spending in the first months of each administration, which is transmitted to the other levels of government.

Along the same lines, Gámez and Amarillas (2011) analyse the federal and state government. For the federal level they considered the period from 1986 to 2010 and for the state level between 1989 and 2006. The study for the federal level showed that capital spending manifests itself with greater intensity at the beginning of the electoral year followed by contractions after the election. For the statements, the results were limited to explaining only the total expense, due to the lack of disaggregated information on the entities.

In this sense, the results showed a significant increase in total spending before the election. Therefore, the work concludes that there is a CPP in total public spending and investment in the state and federal governments in the last year of each administration, followed by contractions in the first months after the elections, which suggests that public spending it is handled as an electoral weapon and not as a means of social welfare. In addition, they questioned the operation of the institutional control systems, which, in principle, should ensure that such deviations do not occur, and that spending is destined to meet citizen needs.

Ramírez and Erquizio (2012) in their work for 31 states of the republic from 1993 to 2009, and using the GMM model, pointed out an opportunistic behaviour of the tax authorities before the elections, that is, they confirm that total spending it increases in the year before the elections. The conclusion points out that the rulers of the 31 state entities practice a political management of the public budget to maintain their positions and increase their probability of electoral victory.

These authors generally propose that the analysis should be extended to the municipal level, in line with the work carried out in Colombia by Drazen and Eslava $(2003 ; 2008)$, in Portugal by Gonçalves and Veiga (2007), in Italy by Cioffi et al. (2012), in Indonesia by Suharnoko et al. (2013) or in Spain by Benito et al. (2013), since the literature in México is scarce, an aspect that will be addressed in this investigation in order to cover said gap.

\subsection{Objectives and hypothesis}

\subsubsection{Objectives}

The objective of this work is to analyse the effect of elections on budget management, to show whether there are political budget cycles aimed at maximizing the chances of governments being re-elected. In this context, the behaviour of spending in the vicinity of the elections will be studied to look for evidence susceptible to manipulation in the management of state and municipal spending. In this regard, the international literature indicates that the fiscal policy instruments of local governments are limited in relation to state governments, so the CPP is less intense (Brusca et al. 2010). Considering the previous results obtained in the literature of this line of research, this empirical work is carried out with the following specific objectives: 
1. Analyse if there is a change in spending that is associated with the electoral period.

2. Examine what type of spending is used to reveal to the electorate the ruler's supposed preferences and that his party continues in power.

3. Observe if the increase in population increases total spending and how it affects its composition, since its increase generates demand for services, public works and infrastructure.

\subsubsection{Hypothesis}

Drazen and Eslava (2005) point out that the manipulation of expenses consists of altering the composition of total expenses in favour of those expenses that reveal to the electorate the supposed fiscal preferences of the incumbent in office. Therefore, the spending analysis indicates whether the decisions that the ruling party makes regarding spending are influenced by the proximity of the electoral process.

In this context, the hypotheses that we intend to contrast, in line with the previous literature analysed, are the following:

- $\quad \mathrm{H}_{1}$. The per capita spending of the states and municipalities increases in the period before the election.

- $\quad \mathrm{H}_{2}$. Investment spending is preferred by ruling parties to influence the voter in the run-up to the election.

- $\quad \mathrm{H}_{3}$. Current spending decreases in the pre-election period in response to the increase in investment spending.

- $\quad \mathrm{H}_{4}$. The population has a positive impact on the composition of public spending.

In this sense, if the electoral variable is positive, and significant, it would imply that the type of expenditure taken as the dependent variable increases the corresponding periods, that is, we would be facing a visible expenditure in the Rogoff model (1990) or against a preferred expenditure in the model of Drazen and Eslava (2005). Now, if this variable has a negative coefficient, we would be concluding the opposite. Therefore, we estimate that in our model the sign for total and investment spending should be positive and negative for current spending. On the other hand, if the population presents a positive and significant sign, we would be confirming that the population has a positive impact on total spending and investment spending, that is, we could affirm the evidence from Brusca et al. (2010) and Vicente et al. (2013). The Figure 29 shows the hypothesis and the expected sign.

Figure 29 Hypothesis and the expected sign to expenditure management

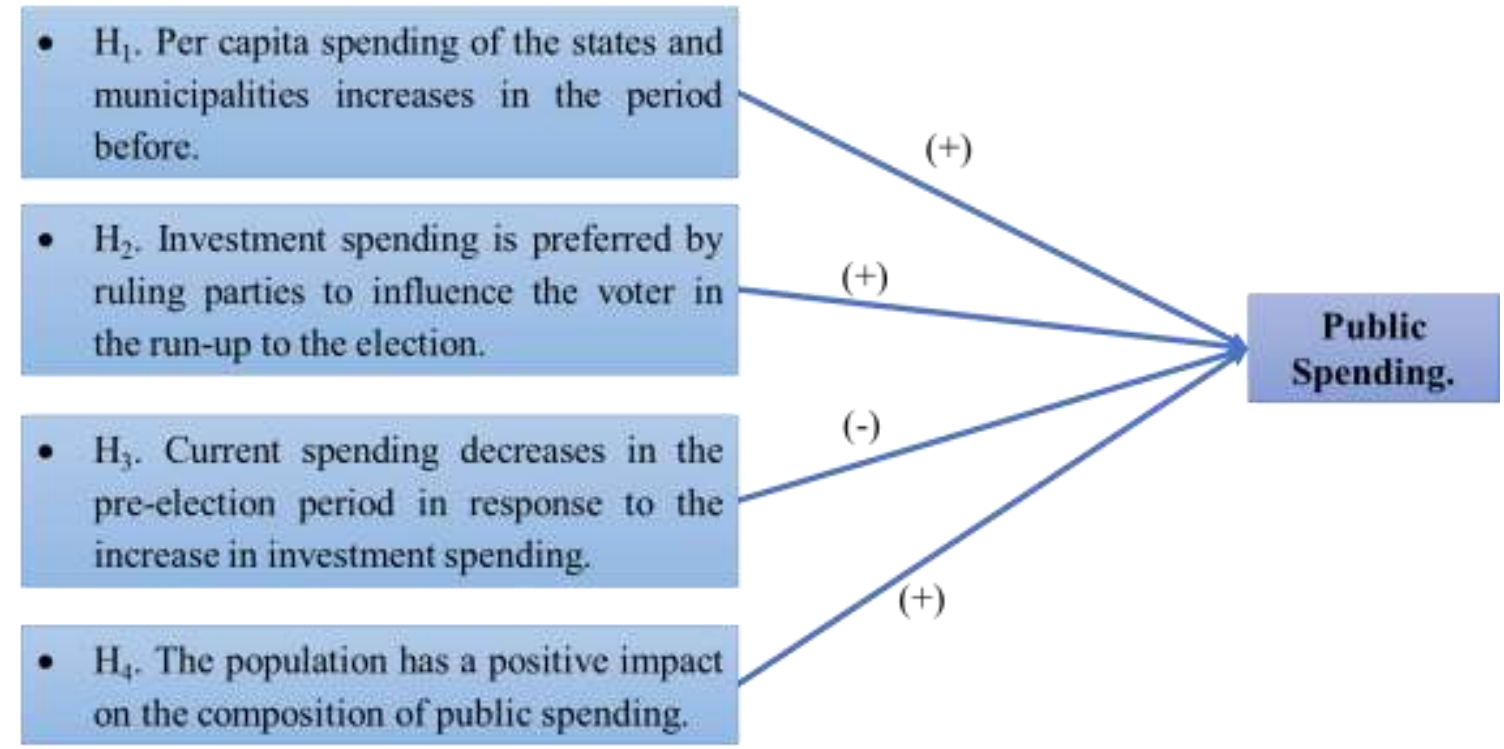




\subsection{Sample and variables}

The empirical analysis is carried out with two panel-type databases that integrate information from the 31 states and 127 municipalities from 1996 to 2010. Therefore, the base includes 430 observations for the states and 1,525 for municipalities with a population greater than 50,000 inhabitants. We have had to eliminate entities at the municipal level of less than 50,000 inhabitants, since we have detected an important restriction of the estimator if the full base was used, verified by the Arellano and Bond (1991) test for autocorrelation and the Sargan (1964) test for overidentification, instruments (Montero, 2010).

For the estimation of the statistical model, variables of a budgetary nature, electoral and population variables were used, obtained from the National Institute of Statistics and Geography [INEGI] (2015), from the website of the respective federative entities, from the electoral institutes of each state and from the National Council of Population [CONAPO] (2015). The budget information is reported in nominal pesos. The original data were deflated using the National Consumer Price Index (INPC), prepared by Banco de México, to be expressed in constant 2015 pesos.

\subsubsection{Dependent variables}

We use three dependent variables that are intended to reflect the level of manipulation of total spending, investment spending and current in each entity. In accordance with the afore mentioned, the variables were taken in line with the works of Cioffi et al. (2012), Brusca et al. (2010) and Brender and Drazen (2005), that is, the variable total expenditure in relation to the number of inhabitants, investment expenditure and current expenditure in relation to total expenditure.

In this sense, the disaggregation of spending will allow us to specify the effect of the elections on spending in both concepts, that is, it will allow us to observe the probable existence of manipulation of the investment spending and current spending variables. In Table 7 we show the description of the dependent variables and their calculation.

Table 7 Definition and calculation of dependents variables

\begin{tabular}{|l|l|l|}
\hline Dependent Variables & Description & Variable Calculation \\
\hline Total expenditure & TE_A & Total expenditure/number of habitants \\
\hline Investment spending & IS_A & Investment expenditure/total expenditure \\
\hline Current spending & CS_A & Current expenditure/total expenditure \\
\hline
\end{tabular}

Source: Author's Own Elaboration

\subsubsection{Independent variables}

Regarding the explanatory or independent variables, we use electoral and population variables to show and argue those variables that offer greater explanatory power on the manipulation of the corresponding preferred instruments. These variables are the following:

Lagged variable of total spending, investment spending and current spending determined with respect to the Arellano and Bond (1991) model. Based on these, for each model, we measure the influence of the explanatory variable on the dependent variable and consider the persistence of decisions on fiscal policy from the previous year, since in the budget framework inertia exerts a significant influence and predetermines the behaviour of successive years.

Electoral variable, with which we measure the level of influence of the choices in total spending and its composition. We construct a dummy variable considering that spending manipulation could occur one year before the election.

Population variable, which will make it possible to control the effect that the increase in population can have on total spending and on its composition. calculation.

Specifically, in Table 8 we show the description of the independent variables and their 
Table 8 Definition and calculation of independents variables

\begin{tabular}{|l|l|l|l|}
\hline Independents Variables & & \multicolumn{1}{c|}{$\begin{array}{l}\text { Sign } \\
\text { expected }\end{array}$} \\
\hline Delayed total spending & $\mathrm{TE}_{\mathrm{t}-1}$ & \\
\hline Delayed investment spending & $\mathrm{IS}_{\mathrm{t}-1}$ & & \\
\hline Delayed current expenditure & $\mathrm{CS}_{\mathrm{t}-1}$ & & $\begin{array}{l}\mathrm{TE}(+) \\
\mathrm{IS}(+) \\
\mathrm{CS}(-)\end{array}$ \\
\hline $\begin{array}{l}\text { State and municipal electoral cycle } \\
\text { dummy }\end{array}$ & $\mathrm{EL}_{-} 1$ & $\begin{array}{l}1 \text { year prior to election } \\
0 \text { other case }\end{array}$ & $\begin{array}{l}\text { Increase in population with respect to the } \\
\text { previous year }\end{array}$ \\
\hline Population increase & $\mathrm{POB}$ & $(+)$ \\
\hline
\end{tabular}

Source: Author's Own Elaboration

Figura 30 Expected signs for the variables of GMM model

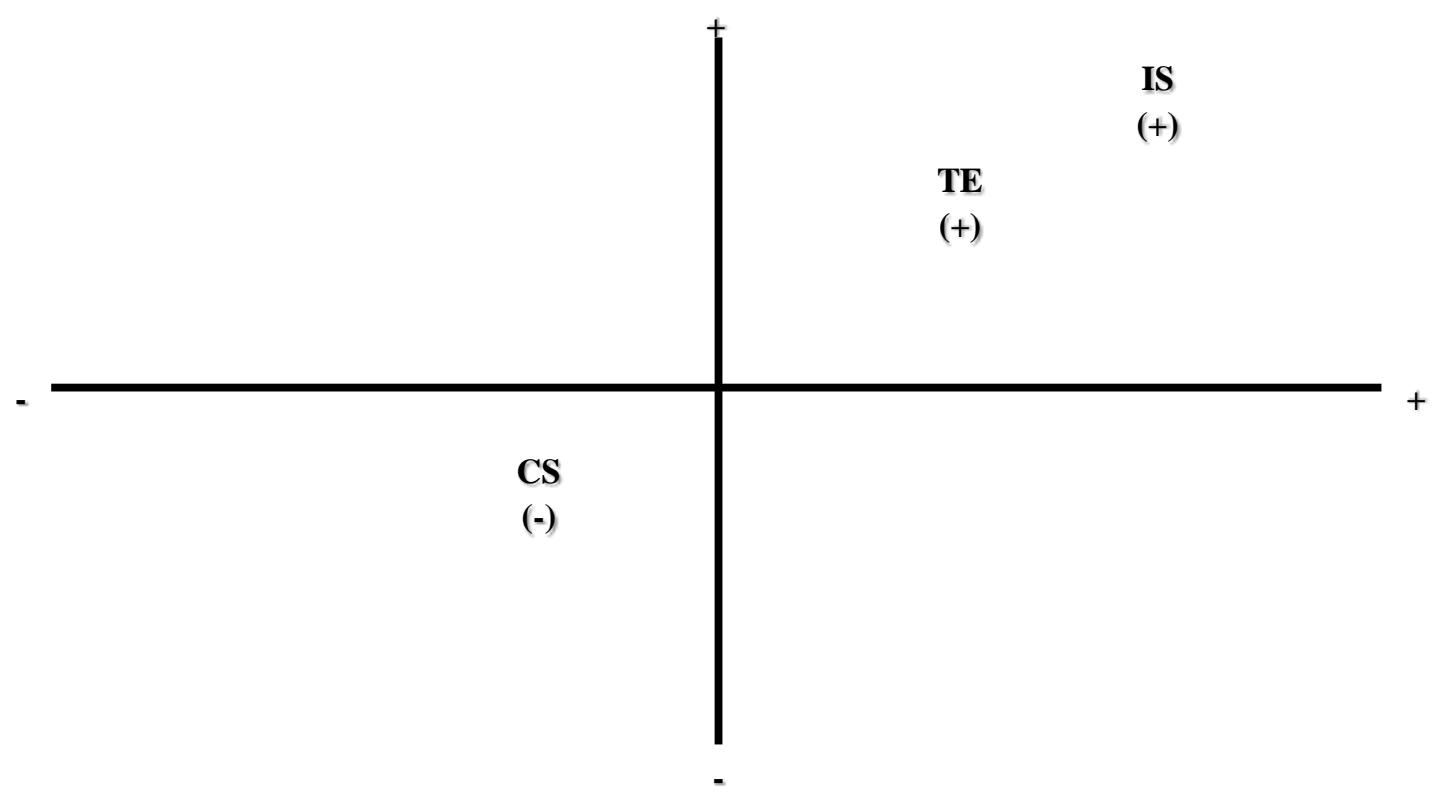

Source: Author's Own Elaboration

\subsection{Methodology}

In this first empirical work, we used the panel data methodology (OLS; EF; EA), to make estimates on investment spending and current spending; furthermore, we introduce a dummy variable to identify the year prior to the election and to control the influence of the electoral period in each regression.

Likewise, we include as a variable $x_{i t}$ the population increase, which, it will determine whether it affects the increase in total expenditure and its composition due to the demand that its increase generates in services, public works and infrastructure. In addition, the model incorporates the vector $y_{i t-1}$ which aims to improve the efficiency of the results and, therefore, represents the inertia in the allocation of the composition of public spending. In this sense, the general model for panel data used is the following:

$\gamma_{i t}=\alpha_{i}+\beta+x_{i t}+E L 1+\varepsilon_{i t}$

This autoregressive model that we propose did not present for our analysis the robustness and reliability in the results to control the individual character of each state or of each municipality, causing errors in the estimates due to the unobservable effect that the suggested model presented, this, due to the delays dependent variable.

To correct this problem, Arellano and Bond (1991) propose an estimator based on the Generalized Method of Moments (GMM), which uses instrumental variables based on lags and differences of all the variables in the model. In this sense, the proposed model was expressed as follows: 
$\gamma_{i t}=\beta \Delta \gamma_{i t-1}+\Delta x_{i t}+\Delta E L_{-} 1+v_{i t}$

Using $y_{i, t-s-1}$ as instruments of de $\Delta y_{i, t-s-1}$ y $y x k_{, i, t-s}$ as instruments $\Delta x k_{i, t-s}$ where 1 vector $v_{i t}=\Delta \varepsilon_{i t}$, guarantees the validity of the instruments. In addition, Arellano and Bond (1991) observed that there are many valid instruments available and that they do not exploit all the information in the database. In that way, the GMM approach can build a more efficient estimator for the dynamic panel data model, where it includes strictly exogenous and predetermined regressors, including the lagged variable of the dependent variable, and endogenous regressors correlated with the unobservable individual effect $v_{i t}$.

It is important to comment that, in this econometric analysis, state and municipal electoral periods are governed by heterogeneous calendars, that is, elections take place in different years and months, depending on the local legislation of each entity, considering in the empirical models the electoral variables as constant during each year of each period, until the next election begins.

The 15 years covered by the study include two constitutional elections for the states. For some municipalities, due to their heterogeneous periods, in some cases it covers four elections and, in others, up to five.

\subsection{Analysis of results}

Once the method has been analysed and explained in this first empirical work, the results of the estimates according to the model proposed by Arellano and Bond (1991) are presented in this section; in Tables 9, 10 and 11 for municipalities and in tables 12,13 and 14 for states.

All the tables show the coefficients of each regression of the explanatory variables, in addition to the standard error and the Arellano and Bond (1991) tests to detect auto-correlation and test the validity of the instruments through the Sargan test. In this sense, based on these tests, we will be able to verify if in each the model accepts or not the null hypothesis, that is, if the errors are not serially correlated, and then show that the instruments used in each regression are valid. This type of test, both for this first group of regressions and for the second, they will give greater support to the results of the estimation of the dynamic model in differences.

\subsubsection{Results for municipalities}

Tables 9, 10 and 11 show the statistical models obtained for the estimates of total expenditure, investment expenditure and current expenditure respectively.

Table 9 GMM Model, dependent variable total expenditure (TE_A)

\begin{tabular}{|l|r|r|r|}
\hline Independent variables & Coeficient & Err. Std. & $P$ \\
\hline TE$_{\mathrm{t}-1}$ & 0.6361 & 0.0018 & $*$ \\
\hline EL_1 & 136.1913 & 2.1728 & $*$ \\
\hline POB & 0.0043 & 0.0000 & $*$ \\
\hline Constant & -443.5389 & 13.8253 & $*$ \\
\hline Test Abond & 0.1447 & & \\
\hline Test Sargan & 0.1833 & & \\
\hline Number of observations & 1525 & & \\
\hline Levels of significance: & $*$ Significant to 1\%. \\
& $* *$ Significant to 5\% \\
& $* * *$ Significant to 10\% \\
\hline
\end{tabular}

Source: Author's Own Elaboration 
Table 10 GMM model, dependent variable Investment spending (IS_A)

\begin{tabular}{|l|r|r|r|}
\hline Independent variables & \multicolumn{1}{c|}{ Coeficient } & Err. Std. & \multicolumn{1}{c|}{$\boldsymbol{P}$} \\
\hline $\mathrm{IS}_{\mathrm{t}-1}$ & 0.3035 & 0.0085 & $*$ \\
\hline $\mathrm{EL}_{-} 1$ & 0.0106 & 0.0010 & $*$ \\
\hline POB & 0.0121 & 0.0069 & $* * *$ \\
\hline Constant & 0.0389 & 0.0831 & \\
\hline Test Abond & 0.3290 & & \\
\hline Test Sargan & 0.3234 & & \\
\hline Number of observations & 1525 & & \\
\hline Levels of significance: & $*$ Significant to 1\%. \\
& $\begin{array}{l}* * \text { Significant to 5\% } \\
\text { *** Significant to } 10 \%\end{array}$ \\
\hline
\end{tabular}

Source: Author's Own Elaboration

Table 11 GMM model, dependent variable current spending (CS_A)

\begin{tabular}{|l|r|r|r|}
\hline \multicolumn{1}{|c|}{ Dependent variables } & \multicolumn{1}{c|}{ Coeficient } & \multicolumn{1}{c|}{ Err. Std. } & \multicolumn{1}{c|}{$\boldsymbol{P}$} \\
\hline $\mathrm{CS}_{\mathrm{t}-1}$ & 0.3213 & 0.0108 & $*$ \\
\hline EL_1 & -0.0095 & 0.0012 & $*$ \\
\hline POB & -0.0286 & 0.0088 & $* * *$ \\
\hline Constant & 0.8429 & 0.1072 & \\
\hline Test Abond & 0.3012 & & \\
\hline Test Sargan & 0.2180 & & \\
\hline Number of observations & 1525 & & \\
\hline Levels of significance: & $*$ Significant to 1\%. \\
& $\begin{array}{l}* * \text { Significant to 5\% } \\
\text { ** Significant to } 10 \%\end{array}$ \\
\hline
\end{tabular}

Source: Author's Own Elaboration

First, we observe that the three models for municipalities present non-significant values in the Arellano and Bond tests for autocorrelation and Sargan for heteroscedasticity. The first test by Arellano and Bond shows that in the proposed models there is no autocorrelation, while the Sargan statistic checks that the equations are adequate and are correctly over-identified. These results confirm the efficacy of the two models used, and at the same time, that the instruments for estimating the equations are adequate. The lagged variable is positive and significant in the three regressions, which confirms that there is an incidence of the variables from the previous exercise. As Veiga and Veiga (2007a), Drazen and Eslava (2005) and Brusca et al. (2005), this variable tries to consider the persistence of decisions on the fiscal policy of the previous year, since in the framework of the budget inertia exerts a significant influence and predetermines the fiscal expenditure of subsequent years.

Regarding the explanatory variables of the models, there are significant differences in their behaviour, that is, a significant increase in total per capita spending is first observed, which affects the increase in spending related to investment in the year prior to the election and, on the other hand, a contraction in the level of current spending, although in all cases the level of significance is $1 \%$.

Regarding the first model of the total expenditure variable, it can be observed that the electoral dummy variable has a positive and significant sign in its coefficient, which indicates an expansion of total expenditure per inhabitant before the election.

This result supports the hypothesis of the existence of CPP in the increase in total spending per inhabitant, showing that local governments in México try to impress the electorate with expansive spending before the election.

This result is like that obtained by Cioffi et al. (2012) and Benito et al. (2013), who stated in their works that the increase in total spending is due in part to the increase in investment spending, an expansionary fiscal policy that the rulers use before the election. On the other hand, for the population increase variable, its coefficient has a positive and significant sign at 1\%, which confirms the hypothesis we propose, that is, the population increase has a positive impact on the composition of public spending by part of the government. 
This result confirms what was indicated by Brusca et al. (2010) and Vicente et al. (2013) which showed that the population has a positive influence on total spending, which indicates that large local entities have higher spending than smaller ones.

Likewise, this result also confirms that indicated by Escudero and Prior (2002), Cioffi et al. (2012), Benito et al. (2013) and Suharnoko et al. (2013) who observed a positive influence on the population variable in relation to total spending, suggesting that total spending increases as the population increases because of its generational increase.

In the second model of the regression of investment spending in relation to total spending, the dummy variable is significant and presents a positive coefficient. This result verifies the hypothesis raised, where investment spending is indicated by the ruler to try to influence the voter in the election.

In this sense, it is observed that there is an increase in investment spending, indicated by the rulers who consider that the electorate values the public works and infrastructure positively before the election. This result confirms that of the works by Drazen and Eslava (2005), Álvarez and Delgado (2006), Brusca et al. (2005) and Vicente et al. (2013), who obtain that spending on public works is preferred and indicated by government operators, that is, the politician in power expands public spending with works and infrastructure to try, as far as possible, to retain the power.

However, the studies by Cioffi et al. (2012) and Vicente et al. (2013) for local governments in Italy and Spain respectively, found that the effect of elections on capital spending has been reduced, reducing the effect of the CPP on spending in investment, due to the introduction of the new budgetary regulations in Italian municipalities and the new Budget Stability Law in Spanish municipalities.

For the population variation variable, the coefficient is positive and significant at $10 \%$, so in principle we can affirm that the population increase increases the need for investment spending.

This result confirms that of Brusca et al. (2010), who pointed out that in the largest municipalities there is a need for greater investment spending, contrary to the study by Cioffi et al. (2012), where the largest Italian municipalities only increase total spending, as a consequence of the new budgetary rules discussed: in this case, the demand for spending has an origin also based on the age of the population, for example the smaller population and long-lived, it requires more spending on social services and not so much the demand for investment.

In the current spending model, as we expect, the dummy variable indicates that it decreases in the year prior to the election, which reiterates that local governments prefer to indicate investment spending and, in contrast, reduce current spending. This confirms our hypothesis, that is, current spending decreases in the period prior to the election of the ruler.

In the variable population variation, the coefficient has turned out to be significant and with a negative sign, which indicates that the ruler, by increasing the population, increases investment spending and decreases current spending.

\subsubsection{Results for States}

For the study of the states, we have used the same procedure as in the municipalities, that is, we calculated three regressions with the difference model of Arellano and Bond (1991).

The following are presented in Tables 12, 13 and 14 results of the dependent variables total per capita expenditure, in investment over total expenditure and current expenditure with respect to total expenditure for the state level. 
Table 12 GMM Model, dependent variable total expenditure (TE_A)

\begin{tabular}{|l|r|r|r|}
\hline Independent variables & \multicolumn{1}{c|}{ Coeficient } & Err. Std. & $\boldsymbol{P}$ \\
\hline $\mathrm{TE}_{\mathrm{t}-1}$ & 0.9597 & 0.003 & $*$ \\
\hline $\mathrm{EL} 11$ & 0.6885 & 0.1726 & $*$ \\
\hline POB & 2.3816 & 0.3123 & $*$ \\
\hline Constant & -29.3423 & 4.3923 & $*$ \\
\hline Test Abond & 0.9488 & & \\
\hline Test Sargan & 0.2712 & & \\
\hline Number of observations & 430 & & \\
\hline Levels of significance: & * Significant to 1\%. \\
& $\begin{array}{l}* * \text { Significant to 5\% } \\
* * \text { Significant to 10\% }\end{array}$ \\
\hline
\end{tabular}

Source: Author's Own Elaboration

Table 13 GMM model, dependent variable investment spending (IS_A)

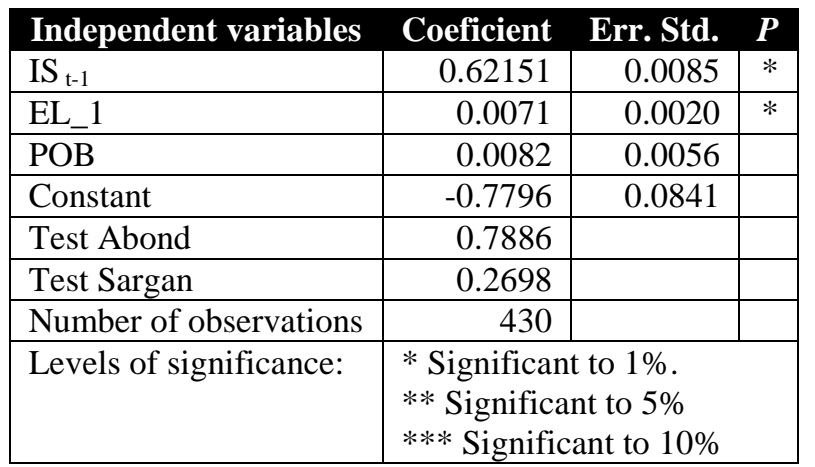

Source: Author's Own Elaboration

Table 14 GMM model, dependent variable current spending (CS_A)

\begin{tabular}{|l|r|r|r|}
\hline Independent variables & Coeficient & Err. Std. & \multicolumn{1}{|c|}{ P } \\
\hline $\mathrm{CS}_{\mathrm{t}-1}$ & 0.7066 & 0.0144 & $*$ \\
\hline $\mathrm{EL} \_1$ & -0.0098 & 0.0018 & $*$ \\
\hline POB & -0.1188 & 0.0048 & $* *$ \\
\hline Constant & 0.4333 & 0.7601 & $*$ \\
\hline Test Abond & 0.8429 & & \\
\hline Test Sargan & 0.2822 & & \\
\hline Number of observations & 430 & & \\
\hline Levels of significance: & * Significant to 1\%. \\
& ** Significant to 5\% \\
& $* * *$ Significant to 10\% \\
\hline
\end{tabular}

Source: Author's Own Elaboration

As can be seen in the tables, there are also significant differences in the behaviour of the variables analysed, showing that the coefficients of the explanatory variables are mostly significant. The lagged variable for the three models is positive and significant, which indicates, as in the municipalities, stability, and inertia in the composition of total spending.

In the specific model for total expenditure, all the variables are significant. In this sense, the dummy variable that represents the year prior to the election, in addition to being significant, shows a coefficient with a positive sign, which indicates an expansion of total expenditure per inhabitant before the election, as in the case of the town halls. However, the CPP is weak, that is, it presents a lower value than that of the municipalities.

This result obtained for the states of México is comparable with that of Brusca et al. (2010) for Spanish entities and that of Cioffi et al. (2012) for Italians, where the CPP has decreased due to the introduction of the new budgetary management rules, supported by better control and supervision that implies improvements in the government's management of spending. 
As regards the variable population variation, as can be seen, it shows a significant and positive coefficient, that is, its increase conditions the need for an expansion of total expenditure per inhabitant. The estimate corresponding to investment spending over total spending only presents two significant variables, the lagged variable and the dummy variable that represents the year prior to the election. In this sense, the dummy variable is significant and presents a positive coefficient, indicating that investment spending increases significantly with respect to total spending before the election year, showing the existence of CPP reflected in the increase in public works and infrastructure.

This suggests that the state governments, to try to impress the voter, and thereby increase the probability that the candidate of their party will continue to lead the Government, in addition to increasing their total spending, focus their spending on investments. This result confirms those obtained by Rosenberg (1992), Kneebone and McKenzie (2001), Drazen and Eslava (2003), Khemani (2004), Álvarez and Delgado (2006), Brusca et al. (2010) and Cioffi et al. (2012) who considered that spending on public works is preferred by operators, that is, the politician in the government expands public spending with works and infrastructure to retain his power as much as possible.

In this sense, in the three regressions of the local and state level, the evidence shows us the existence of CPP in total spending and investment spending, which is in line with the postulates of the opportunistic model. On the other hand, in line with the studies from México, our findings confirm those obtained by Gámez and Ibarra (2009), Gámez (2006; 2010), Gámez and Amarillas (2011) and Ramírez and Erquizio (2012), who developed models with pooled statistical approaches, fixed effects, random effects or the Arellano and Bond (1991) model, and in all investment, spending increases in the years prior to the election.

In addition, the results show the influence of the political cycle on the economic activity of the states, where they indicate that there is opportunistic behaviour by the authorities that govern the states and a management with a political tendency to maintain or increase their probability of remaining in government.

In this sense, our results follow the same guideline, with an opportunistic behaviour in the period prior to the election and confirm the manipulation of the composition of spending in favour of investment. For the variable population variation, although its coefficient is positive in the case of investment spending, it is not significant, so in principle, we could not affirm that the increase in population indicates a positive relationship with the generation of public works in states, that is, the population does not affect the greater investment spending ratio.

For the model that represents current spending, its results show that the current spending variable decreases in the year before the elections, contrary to the increase in investment spending, which is logical in relation to the balance that both represent on the total spending of each entity, which shows that state governments prefer to increase investment spending and decrease current spending.

This result confirms those obtained in previous studies in México, such as Gámez and Ibarra (2009), Gámez (2006; 2010), Gámez and Amarillas (2011) and Ramírez and Erquizio (2012), who determined disaggregated spending as a dependent variable. current, that is, they evidenced it by specific line of current spending, but the result in most of them showed a negative sign in its coefficient, a clear contraction due to the increase in investment spending.

The lagged variables for the previous regressions were positive and significant, which shows stability in the composition of spending, and the results evidenced support the inertia that suggests that there is some continuity in spending at the state and municipal level.

\subsection{Discussion and Conclusions}

This work offers an overview of the effect that elections have on budget management, which has evidenced the existence of political budget cycles in total spending and its composition, both in the states and in the municipalities of México during the period of 2007 to 2019.

The results were derived in a specific context, that is, 31 states of the Mexican Republic and 127 municipalities with a population greater than 50,000 inhabitants were considered. 
We conclude that in México, at the state level, elections cause increases in total spending per inhabitant, as well as investment spending and a contraction of current spending compared to total spending. For municipalities with more than 50,000 inhabitants, the evidence of the political budget cycle was like that of the states, that is, there is an increase in total spending, investment spending and a contraction in current spending in relation to total spending.

This leads us to discuss some questions, such as: Is total spending used to impress the voter before the election? Is investment spending used by ruling parties to influence the electorate? Does investment spending increase in the electoral period? Or does the need for works and services in municipalities with larger populations influence the composition of spending? The results obtained show us some aspects that help us to answer these questions.

Recent works from México, such as Gámez y Amarillas (2011) or Ramírez and Erquizio (2012), and international ones, such as Drazen and Eslava (2005; 2008); Brusca et al. (2010), Cioffi et al. (2012), Benito et al. (2008) complement what has been reflected: the budgetary political cycle suggests increases in investment spending during the year prior to the elections, which means that it should be to increase the well-being of its citizens. However, such an increase - in some cases - is used as a weapon to attract votes and maintain or retain power.

The results are similar in our research and suggest for the two levels analysed an expansion of total per capita spending, spending on public works and infrastructure, while there is a contraction in current spending, trying to seek benefits for the party in power thus, signalling their policies.

The foregoing supposes for both a pattern of opportunistic behaviour on the myopia of the voters, who, according to Gámez and Amarillas (2011), have little retrospective memory, and allows the ruling party to execute opportunist policies successfully. The authors conclude that voters in México only consider current information and present adaptive expectations based on the information available from government operators.

In our work, the results at the local level confirm the hypotheses raised: public spending is used to impress the electorate, that is, total spending increases, as well as the ratio of investment spending to the total and, consequently, the current decreases, varying its behaviour in relation to the period of the electoral cycle.

Regarding the variation of the population, our results seem to have a greater influence on the municipalities, since in the states its coefficient is lower, which suggests that in the states the variation in population has less impact.

The scope of this first work was to verify the presence of political budget cycles at the state and municipal level, and our conclusion points to the evidence presented of the existence of CPP in investment expenditure and current expenditure for the two levels analysed.

In general terms, the results evidenced are in line with the approaches of the opportunist model, although with some differences that could be myopia related to the experience in electoral processes or the media that make the voters aware of the opportunist policies of the parties in power (Gámez and Amarillas, 2011).

Finally, we consider it important that in subsequent studies we can analyse the CPP in a disaggregated manner in relation to the budgetary programs that make up spending by programs, especially regarding social and education expenditures, to test a possible relationship in these variables of study. 


\section{Chapter 5 Feasible Generalized Least Squares (FGLS) applied to budget management and electoral results}

\subsection{Introduction}

The introduction of an electoral system in which citizens can elect their political representatives is typical of democracy and tries to guarantee the functioning of political systems, although it has some barriers. As Downs (1957) points out, the decision to vote has an eminently prospective, since the objective of any rational voter is to maximize the expected utility of him, choosing the best of the candidates.

The problem of maximization or expected profitability arises when the voter does not have perfect information and, therefore, is forced to use information from the past, to form their expectations about the economic future of the country, where the rational expectation is affected by this fact. The works of Kuklinski and West (1981), Lewis-Beck and Skalaban (1989), Fearon (1999) and Farnham (1985) relied on the rational expectations model to explain the final decision of the voter. In addition, the previous authors stated that the economic vote also has a character prospective and that the elections not only produce accountability but are also an instrument to select the best of the candidates.

In this context, participation in elections within democracy has been based on the theory of public choice, specifically on the assumption of rationality of the voter, based on the works of Black (1948) and Arrow (1951), which has provided the methodological foundation for understanding behaviour rational of the voter in the elections within a democratic system.

On the other hand, the literature has evidenced the rationality of the citizens' vote in relation to the application of the fiscal policies of management of the party in power, which can condition the continuity of the party, arguments recognized and indicated by Rogoff and Sibert (1988) and Rogoff (1990), who have led us to fundamentally analyse the case of the states and municipalities of México.

Some studies, such as that of Peltzman, S. (1992). showed that the electorate penalizes those governments that increase public spending and thereby condition the deficit. Likewise, there are works that affirm the opposite, for example the works de Akhmedov and Zhuravskaya (2004), Veiga and Veiga (2007a), Sakurai and Menezes Filho (2008) and Aidt et al. (2011), who consider that the increase in public spending before the elections the possibility of re-election of the rulers increases.

On the other hand, Drazen and Eslava (2005) and Eslava (2005) pointed out that the voter values better the investment spending made by the incumbent, while current spending does not influence voters' decisions. Therefore, the evidence obtained in the previous chapter gives us the opportunity to develop this work to contrast the effect of electoral cycles on budget management.

In the first place, we will carry out a review of the literature and empirical evidence, to analyse the theoretical arguments that bring us closer to the model that we are going to propose, trying to show the influence on the number of votes of the increase or decrease of different variables of a budgetary nature, to try to contrast the empirical results that the literature offers.

\subsection{Literature review and empirical evidence}

In this section we intend to review the literature to analyse the theoretical and empirical arguments on the influence of management budget in the electoral results, based on the evolution of the political economy and elections.

The literature on budget manipulation and its relation to results elections is framed within the works evidenced by the CPP models, that is, in other words, the management of the governments' economic policies are influenced by the electoral periods from a vision of fiscal illusion and its relationship with the voter irrationality.

In this context, from the 1940s on, the literature on CPE, as a predecessor of the CPP's, it gains strength in the works of Kalecki (1943), which proposed an alternative analysis of political-economic interdependence from a heterodox approach towards the orthodox. 
Later in the 1970s, Nordhaus et. al. (1975), proposed a simple model of the relationship between economic cycles of political origin and elections, showing that the results of elections are linked to opportunistic behaviours of economic policy, that is, Voters are retrospective, and their discount factor over past periods is high, they have short memories and only remember the policies of recent periods.

From that moment on, the literature contains different approaches to analyse the extent to which voters should value total public spending and its composition, that is, spending on government programs, spending on its consequences expansionary and/or spending due to contractionary consequences of the economy, a common fact, known as an increase or decrease in spending in first world economies or emerging economies, indicated in a certain way as a fiscal illusion that favours the actions that the government undertakes to try as much as possible retain power.

The importance of the arguments of Rogoff and Sibert (1988), and Rogoff (1990), on the conditioning of the vote is evident, focusing on the electoral motivations that the rulers have as a source of the CPP, arguing that the interaction between the rulers and Voter's lead to a set of spending signals. That is, voters only appreciate a part of the projects or works undertaken by the government (visible expenses), ignoring the problems that the increase and expansion of spending can cause, for example, accumulation of debt and therefore an increase in the deficit, which they harm the actions and conditions of the voter's generational future and the work of the next government. This type of evidence was also pointed out in the works of Alesina and Tabellini (1990), which also indicate that the government in power can unbalance its accounts to improve its probability of remaining in power.

These hypotheses have been considered in the works of Block (2002), Galli and Rossi (2002), González (2002), Khemani (2004), Drazen and Eslava (2005), Sakurai and Meneses-Filho (2008), Aidt et al. (2011), Balaguer and Brun (2013) and Vásquez-Ruiz (2013), some of which only limit themselves and focus on analysing the CPP, while others, in addition to showing the political cycle, verify the opportunistic effect on the possibility that the party in power continues to govern, which demonstrates the punishment or reward of the voter in relation to the budgetary variables or adjustments of the economy in the period prior to an electoral competition.

Brender (2003), in a study focused on Israeli governments, analysed the effect of local governments' fiscal policy on electoral results, concluding that the electorate penalizes the government with its vote, which expands fiscal spending and thereby increases the deficit. In addition, in this work they obtain evidence that a greater percentage of votes obtained in the previous election, positively affects the re-election of the rulers. Likewise, the work tried to measure the influence of the election from the two electoral rounds established by this country, where, if none of the candidates obtains more than $40 \%$ of the votes in the first round, it proceeds to a second with the candidates. with the most votes. In this way, the author includes a dummy variable to control and therefore distinguish between the candidates with the most votes elected in the first and second rounds, thus indicating the support obtained by the party that is running for re-election.

Along these lines, Eslava (2005) analysed the fiscal preferences of voters and the dynamics of fiscal policy around elections in Colombia, explaining how the fiscal policy of spending affects the opportunity of the politician in power to continue governing. This work concluded that the voter rewards the increase in investment spending and punishes the officials who raise the deficit before the election.

Brender and Drazen (2005) considered 106 countries on a basis that divided the old and new democracies in the period 1960-2001, however, that the data for many countries the periods are shorter. This work collected data related to the electoral period, total expenses generated, total income, and subsidies, showing that the voter responds to the increase in spending and consequently to the increase in the deficit in the electoral period, manifested mainly in countries with new democracies, which, reduces the possibilities of the ruler who intends to repeat in power.

For their part, Cerda and Vergara (2005) carried out a study in Chile in the period 1989-2000, in which they estimated the effect of monetary and in-kind subsidies on the electoral result of the party in the municipal government. They demonstrated in their work the reaction of the electorate by increasing subsidies to improve their electoral results. Their results indicated that the higher the government spending (measured by the percentage of the population that receives the subsidy), the higher the votes in favour of the incumbent. 
Drazen and Eslava (2005) considered a panel of electoral results comprised in the period 19872000 trying to see their relationship with the state budget data. This study presented a high level of disaggregation of expenses, that is, it allowed to distinguish the different types of expenses for a better analysis of the electoral results. The results showed a positive relationship between electoral results and investment spending and a negative one on current spending, that is, there is a positive assessment of the increase in the variable of spending on public works. However, the percentage of votes obtained by the politician in power decreases with the level of deficit, which shows that well-informed voters punish the fact that spending is increased indiscriminately, without having resources to finance it, or in other ways. In other words, it appears the voter would be averse to the deficit.

In this sense, Shi and Svensson (2006) in their work for 85 developed and developing countries during the period from 1975 to 1995 allowed them to study how elections affect the behaviour of fiscal variables and they assumed that voters did not they can perfectly monitor the budget, specifically, it is difficult to observe the behaviour of the deficit, which would result in a fiscal expansion before the election. Likewise, they show that the magnitude of the cycle is greater in developing countries than in developed ones.

For their part, Veiga and Veiga (2007a), in their two studies for Portugal, considered a base of 275 municipalities for the periods 1979-1989 and 1979-2001. In these works, they showed different evidence, that is, first they show that opportunism leads to a greater number of votes, while in the second work, the Opportunism does not have the same effect on electoral results, which could suggest a significant difference in the behaviours manifested by the voter.

Álvarez and Delgado (2006) in their work for Argentine provinces, during the period 1983-2002, look for evidence of electoral manipulation of public spending before the elections and its effect on the elections. The results in the regressions for the variables of total expenses and their composition in no case showed significant coefficients in their results, which indicates that the manipulation of total and investment expenses does not affect the voting decision in the same sense of Schneider, (2003).

Eslava (2006) pointed out that voters penalize fiscal conservatism with their vote. In that sense, the fiscal conservatism of the voters only translates into fiscal prudence in the most transparent systems, as Peltzman, (1992) points out in his work for US governments showing that voters are fiscal conservatives, expressing an aversion towards increasing fiscal spending and thereby motivating a lower vote.

Along the same lines, there are other studies that revealed aversion to deficit, among which we can name Alesina et al. (1998), Brender (2003), Eslava (2006), Arvate et al. (2009), Klomp and Haan (2009), Schipper, (1989), Schuknecht, (1996), which highlighted that voters, in addition to preferring austere governments, have an aversion to the deficit, which could be one of the causes of the decline in votes in elections, due to high public spending and consequently, an increase in this type of variable.

Brender and Drazen (2008) analysed a sample of 74 countries that includes developed countries, developing countries, countries with presidential or parliamentary systems of government, countries with proportional or majority electoral systems, and countries with different levels of democracy, for the period 1960-2003.

This study demonstrated in its results that in countries considered as old democracies, the deficit reduces the probabilities of continuing to govern, supporting the hypothesis of voter fiscal conservatism, while in new democracies voters favour spending expansion with their vote. Given this result, the authors suggest a positive electoral effect of the deficit, which may be consistent with the political cycle found in new democracies.

Drazen and Eslava (2008), reconsidering their 2005 study and with arguments that confirm that voters do not like the deficit and the high spending generated, obtain two basic predictions in their models: 
1. Before elections, fiscal manipulation can take the form of changes in the composition of spending and,

2. There is an impact on voters of changes in the composition of spending before the elections, also considering some aversion to the deficit.

In this way, their model showed that specific expenditures such as infrastructure, road construction, construction of power plants and water, increase before the election, however, they also generate contractions in other categories, reflecting the spending preferences of the ruler. In addition, they pointed out how the action of the vote responds to changes in the composition of spending, that is, the voter's resistance to high spending and, therefore, to a significant deficit, negatively valued by the voter and contrary to the government in functions.

In this sense, the authors show that the increase in votes is more significant when investments are increased and the deficit does not increase, suggesting that voters penalize the ruling party for increasing this variable, supporting the hypothesis of fiscal conservatism.

Sakurai and Menezes-Filho (2008), analysed a sample of 2,000 Brazilian municipalities, examining the elections in the period 1988-2000. This study suggested that mayors who spend more during their mandate increase the possibility of their own re-election or of a successor to the same party, showing high spending of capital in the pre-election years. These results suggest that Brazilian voters value capital investment positively in election years.

On the other hand, there are studies that suggest the opposite, indicating that governments do not obtain benefits from the manipulation of expenditures before the elections (Alesina et al. 1998; Brender 2003; Cerda and Vergara 2007 and 2008; Klomp and Haan 2009).

Aidt et al. (2011), using 278 Portuguese municipalities for the period 1979-2005, propose a work with a test that explored the bidirectional relationship on the implication of the victory of the party in the government and the magnitude of the distortion opportunistic of budgetary variables. The empirical results supported his hypothesis, that is, fiscal opportunism is worth it, since higher spending generated in the election year leads to a greater difference in votes between the incumbent and his opponents.

Likewise, they showed that opportunistic distortion is greater when the margin of advantage of the politician in power is smaller in relation to his opponents.

For their part, Balaguer and Brun (2013), in a study focused on the Valencian Community, analysed a sample of 183 municipalities in the period 2000-2007. This work tried to explain the probability of re-election in relation to the increase in public spending. This study shows that the electorate values investment spending in a positive way, while current spending does not influence voters' decisions, concluding that higher municipal public spending has a positive effect on the possibility that the government be re-elected.

Vásquez-Ruíz et al. (2013), in a study for the Dominican Republic in which they analyse the three most important political parties of the 1978-2012 period, conclude that the voter values capital spending positively in electoral periods.

In summary, the findings manifested by the different works mostly coincide that in pre-electoral periods public spending expands, practices of manipulating the budgets that are punished or penalized on occasions and rewarded in others.

However, this type of practice indicates significant differences in the management of the composition of spending that each country presents, which could suggest that the tendency of new democracies is to imitate the behaviour of old democracies in the short or medium term. that is, to use as an electoral weapon the rational behaviour of the vote in relation to the actions, practices and management of its fiscal policies that the government in power undertakes, giving rise to the model of rational behaviour discussed in the works of Kuklinski and West (1981), Lewis-Beck and Skalaban (1989), Fearon (1999), Rogoff and Sibert (1988) and Rogoff (1990). 


\subsection{Objectives and Hypothesis}

In this section we try to delimit the objectives and hypotheses raised in our empirical work, in which we intend to contrast the response expressed by the voter from the increase or decrease of the budgetary variables, trying to analyse their impact on the electoral results. considering that voters perceive in a concrete way the actions of the government and its attempts to manipulate public spending.

\subsubsection{Objectives}

The general objective of this work is to verify if the fiscal policy followed by the state and municipal governments in power, specifically in the composition of spending and deficits, influence the electoral result, to check whether those governments that have manipulated budget variables get better results.

These objectives are intended to apply to both the states and municipalities of México for the period 2007 to 2019. To do this, we focus on the impact of the behaviour of the budgetary variables to see whether or not the results found in other countries can be confirmed.

\subsubsection{Hypothesis}

As we have previously commented, the literature obtains different results on the effect of budget management on electoral results. While in some cases a positive effect is observed, other authors point out that voters are slow to respond with their votes for the purposes of budget management.

Thus, the works of Drazen and Eslava (2005), Eslava (2005), Sakurai and Menezes-Filho (2008), Aidt et al. (2011) and Vásquez-Ruíz et al. (2013) point out that the voter values investment spending positively, while current spending influences in the opposite way. The empirical results of these studies show that the electorate rewards the ruler when he points to investment spending as a strategy to stay in power.

In the case of the deficit, following the works Alesina et al. (1998), Drazen and Eslava (2005), Eslava (2017; 2006), Arvate et al. (2009), Klomp and Haan (2009) and Kalendiene \& Petreikyte (2013), we try to verify the aversion to this variable, and therefore, to what extent the voter values the deficit negatively.

If the results were different, a positive electoral effect of the deficit would be evidenced, consistent with the results of the new democracies, where voters cannot monitor said variable, and therefore it is not relevant to determine the electoral results (Shi and Svensson, 2006; Brender and Drazen, 2008). In line with this, we define the following hypotheses:

- $\quad$ H1. The electorate rewards those governments with the highest investment spending, increasing the probability that the party in power will continue to govern.

- $\quad$ H2. The electorate rewards those governments with the highest current spending.

- $\quad$ H3. The electorate negatively values the deficit, motivated by the increase in fiscal spending, which has a negative impact on the electoral results.

In this context, it is expected that the government in power by stimulating budget variables, and specifically investment spending, current spending and deficit, would be signalling to the electorate its fiscal preferences in the electoral period, which would translate into an increase in the probability that the government will continue to govern. 
Figure 31 Hypothesis of votes from the previous election

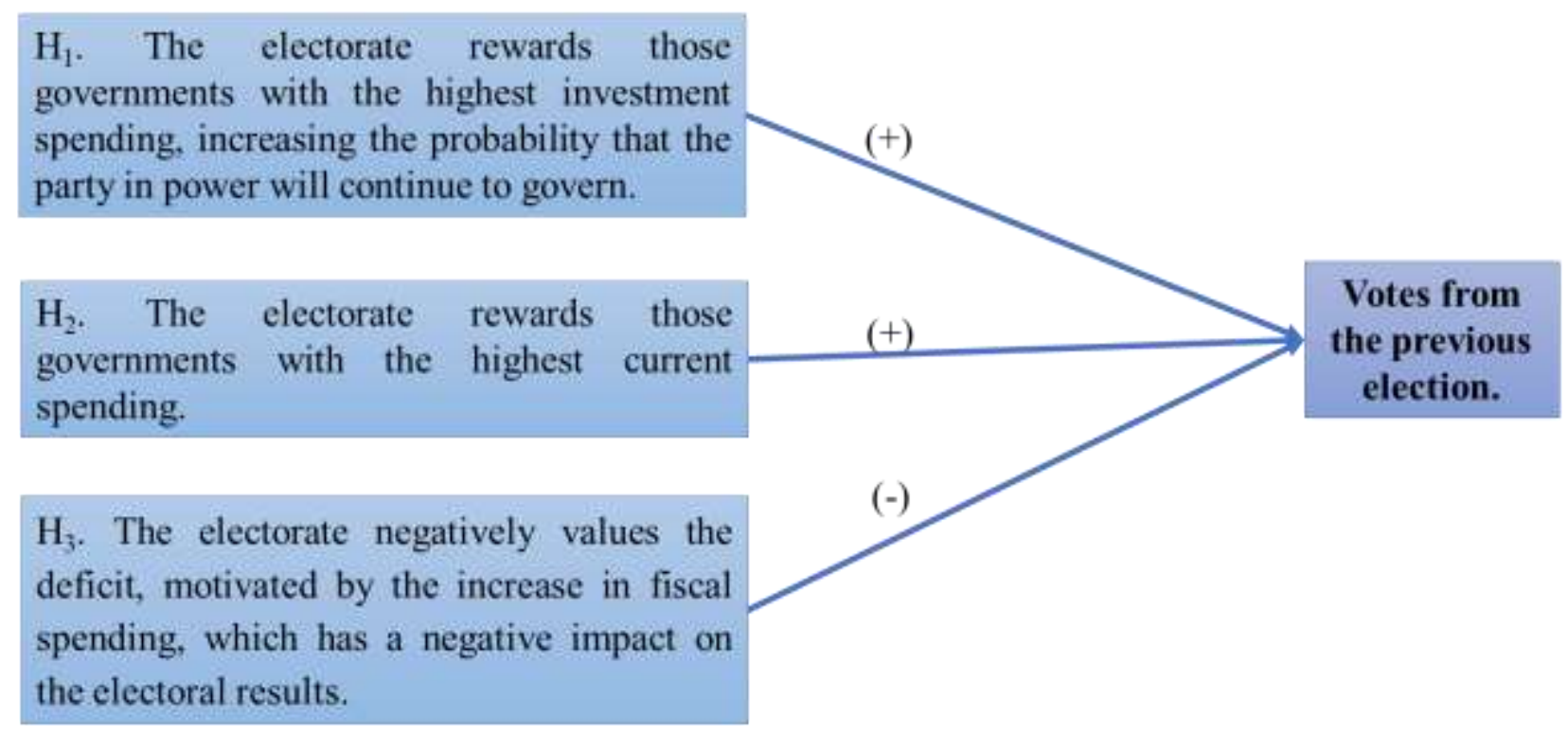

Source: Author's Own Elaboration

\subsection{Sample and variables}

In this chapter, we use a database that contains information for 1,949 city councils and 31 states. The base includes 9,747 elections for city councils and 63 for states in the period 1996-2010. These two bases specifically include for the dependent variable the number of votes obtained by the winning candidate and for the explanatory variables, the budgetary variables by city council and by states.

The sample is reduced only to the electoral years of each city council and state, which do not coincide for the whole group because they have heterogeneous calendars to elect their representatives, so that each observation unit is not observed in the same years. However, there could be the possibility of capturing some fixed effect through the intersection of a dummy variable, with the aim that it can help to determine less complex analysis groups. Specifically, for this work the budgetary variables that reflect the effect of the fiscal policies of the ruler in power were considered, starting from the interaction with the variable dummy coin 1 , as explained later.

\subsubsection{Defining variables}

The analysis takes as a dependent variable the number of votes obtained in the elections by the party in power (VOT_EL). As independent variables, we take as representative variables of spending, investment spending (GI_A) and current spending (GC_A) in the election year, in addition to the effect of the per capita deficit (DEF). Table 15 contains the description of the dependent variable.

Table 15 Dependent variables used in the estimates

\begin{tabular}{|l|l|l|}
\hline \multicolumn{1}{|c|}{ Description } & \multicolumn{4}{c|}{ Variable Calculation } \\
\hline VOT_EL & $\begin{array}{l}\text { Votes obtained by the } \\
\text { winning party in the } \\
\text { current election. }\end{array}$ & $\begin{array}{l}\text { The value of the variable corresponds to the number of votes } \\
\text { obtained by the winning candidate (p) in the state or } \\
\text { municipality (i) in period }(\mathrm{t})\end{array}$ \\
\hline
\end{tabular}

Source: Author's Own Elaboration

Following the works of Brender (2003), Veiga and Veiga (2007b), Drazen and Eslava (2005; 2008) and Aidt et al. (2011), the variables investment spending, current spending and deficit will be intercepted with a dummy coin- 1 variable, a dichotomous variable that takes a value of 1 if the party in power governed before the election and 0 if it was not, expecting that the intercepted variables show the advantage or disadvantage of the party in power when manipulating budget items. 
In short, in this way we try to incorporate into the analysis that the candidate of the party in power facing an election will try to modify the composition of spending in favour of those that allow him to increase the possibility of continuing to govern.

In this sense, the intercepted variable investment spending is expected to have a positive sign, that is, we expect its coefficient to verify the hypothesis of the benefit that the candidate of the party in power obtains from spending in investment. On the contrary, for the intercepted variable current spending, a negative sign is expected, since the electorate may consider that there is an excess of spending that will raise their taxes above what is desirable.

On the other hand, for the deficit a negative sign is expected while the hypothesis we have defined that the voter values this variable negatively. Table 16 contains the description of the independent variables, their sign and their calculation.

Table 16. Independent variables used in the estimates

\begin{tabular}{|c|c|c|}
\hline Independent variable & Description & Variable Calculation \\
\hline VOT_ELA & Votes from the previous election. & $\begin{array}{l}\text { Votes of the winning party of the previous } \\
\text { election. }\end{array}$ \\
\hline IS_A & Investment spending in election year & $\begin{array}{l}\text { Investment expenditure/ number } \\
\text { inhabitants of the state or municipality }\end{array}$ \\
\hline CS_A & Current spending in the election year & $\begin{array}{l}\text { Current expenditure / number of inhabitants } \\
\text { of the state or municipality }\end{array}$ \\
\hline PCD & Per capita deficit & $\begin{array}{l}\text { Total income (-) Total expenses/number of } \\
\text { habitants }\end{array}$ \\
\hline IS_PA & \multirow{3}{*}{$\begin{array}{l}\text { Variables that reflect the effect of the fiscal } \\
\text { policies of the ruler in power, based on the } \\
\text { interaction with the dummy variable "coin } 1 " \text {, } \\
\text { which takes the value of: } \\
-\quad 1 \text { if the party is in power before the } \\
\text { election, and } \\
-\quad 0 \text { otherwise }\end{array}$} & Investment expenditure $*$ coin -1 \\
\hline CS_PA & & Current Expense $*$ coin -1 \\
\hline DEF_PA & & Deficit $*$ coin -1 \\
\hline
\end{tabular}

\section{Source: Author's Own Elaboration}

The following figure shows the expected signs for the variables described in the table above.

Figura 32 Expected signs for the variables of FGLS model

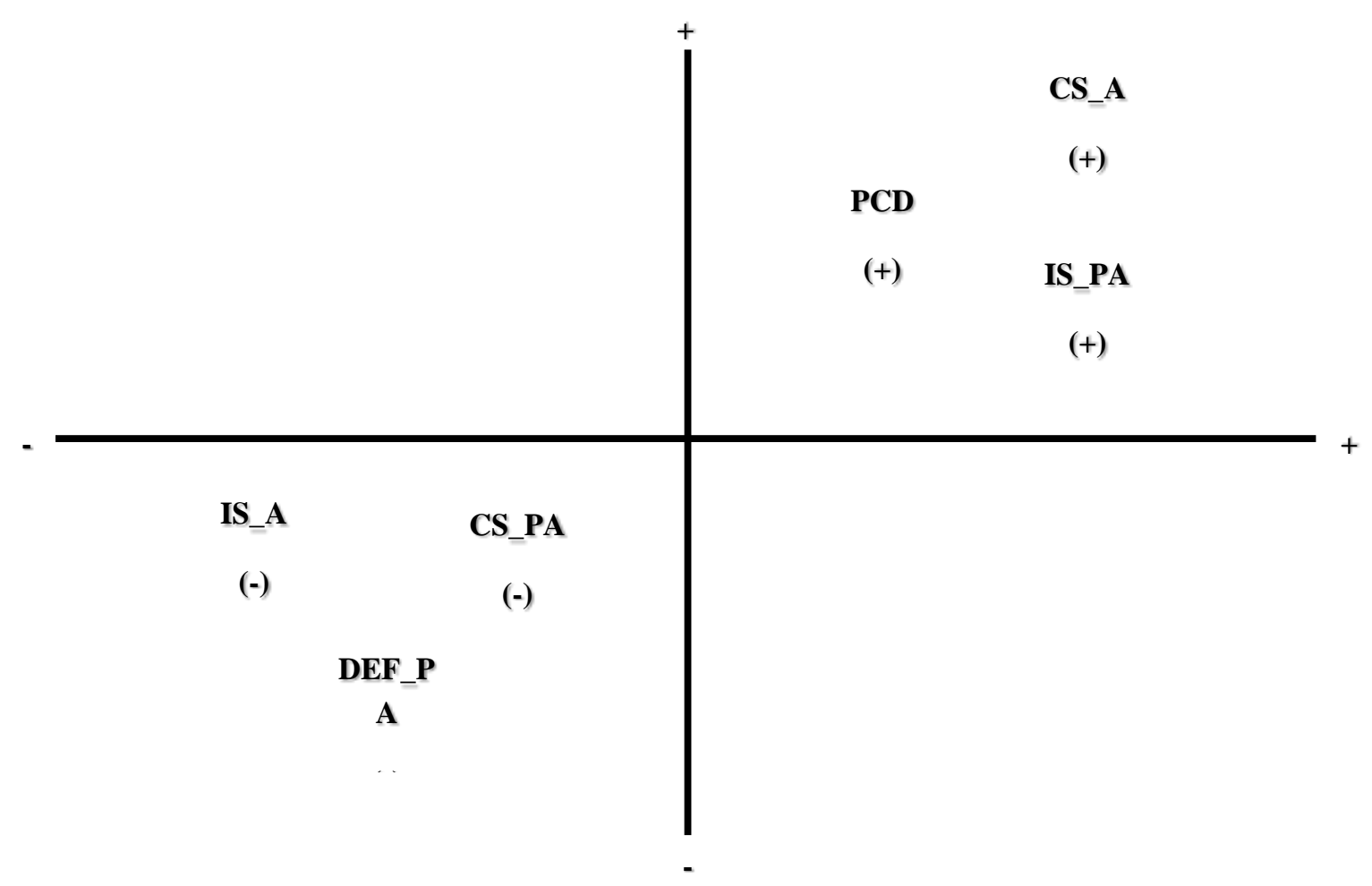




\subsection{Methodology}

To contrast the hypotheses raised, a statistical panel-type data model is estimated, which will improve the reliability of the estimates by working together with the information from all municipalities and states over time. The program used is Stata.

At first, the statistical model applied in this work corresponds to the grouped regression method OLS (ordinary least squares), a simple approach to analyse panel-type data, omitting the space and time dimensions of the grouped data, being a methodology studied and analysed in the works of Álvarez and Delgado (2006) and Drazen and Eslava (2005; 2008).

In addition, since the nature of the bias of the variables that are not identified is not known, the Breusch-Pagan/Cook-Weisberg test will be used to verify the absence of heteroscedasticity, where, if the test is significant, we will proceed to calculate the estimator of Feasible Generalized Least Squares (MCGF), an option that allows us to correct the heteroscedasticity problem of the model for states and municipalities.

In this context, the basic model of OLS panel data linear regression analysis is expressed as follows:

$Y_{i t}=\alpha+\beta_{1} X_{1 i t}+e_{i t}$

Where $i$ takes the values $i=1,2 \ldots, N$ and indicates the unit of cross section, $t=1,2 \ldots, T$ in line, we interpret the vectors of the model as follows:

Table 17 Definitions of vectors of the model

\begin{tabular}{|l|l|}
\hline Vector & \multicolumn{1}{c|}{ Concept } \\
\hline$\gamma$ & Reflects the dependent variable in each year t, in each local government \\
\hline$\alpha$ & Constant term \\
\hline$\beta_{1}$ & Vector of parameters to be estimated \\
\hline$X_{1 i t}$ & Value taken by the independent variables for each municipality i in period $\mathrm{t}$ \\
\hline$e_{i t}$ & I term error or random disturbance of the regression \\
\hline
\end{tabular}

Source: Author's Own Elaboration

However, although the estimation model can be consistent and efficient, there are other effects that derive from the previous model that are frequently used in econometrics, that is, derivations with disaggregation of the random error into two terms, originating the random effects models and fixed effects.

However, it is important to comment that the random effect estimator (AR) or fixed effect (FE) is not used in this work, since there are commented restrictions that reduce the calculation only to electoral years, limiting that each observation unit is not perceived in the same years, as occurs in the works of Drazen and Eslava (2005; 2008).

In addition, since the nature of the bias of the variables that are not identified is not known, the Breusch-Pagan/Cook Weisberg Test will be used as we said before to verify the absence of heteroscedasticity. In this regard, if Ho is accepted then the same STATA will allow in a simple way to influence the estimators to be consistent and unbiased using the Feasible Generalized Least Squares (MCGF) estimator model.

However, there is the possibility that the estimation model presents endogeneity problems, due to the existence of many more elements that determine the difficulty in any election scenario, where hypothetically if a candidate has been involved in corruption scandals, if he has had social problems, if his management has been deficient, etc., then it could be said that the candidate of the party in power faces a complex scenario, facing a greater degree of difficulty. In these circumstances, most of these types of difficulties are very difficult to measure and compare, so that the measurement of the commented variables implies, in any of the scenarios, numerous problems and risks in estimation biases. 
Likewise, the omission of these types of difficulties could also imply a significant bias in the estimation of the regression since the omitted variables would present a negative correlation with the dependent variable and positive with one of the explanatory variables (composition of expenditure).

This type of problem has been addressed by Levitt and Snyder (1997) for the case of the United States, who show that faced with the risk of not being elected, the candidate of the party in power makes a greater effort to obtain more federal funds and since this type of effort is difficult to measure, it suggests a bias of the estimator due to the omission of variables.

However, this type of problem can be solved with the use of instrumental variables. For example, in a study focused on Chile, Cerda and Vergara (2005) solve this problem by means of instrumental variables correlated with the subsidies, but not correlated with the errors of the initial estimate, which eliminates the endogeneity problem.

For their part, Drazen and Eslava $(2005 ; 2008)$, in their model do not consider the supposed problem of endogeneity, they only estimate the effect that the change in the composition of spending has on the results obtained by the party candidate in the government, which has been used as a reference to calculate our model, as we propose in the next section.

\subsubsection{Model Specification}

According to the above, the estimated linear model to be able to contrast the hypotheses raised is the following:

$$
\begin{aligned}
& V O T_{-} E L_{p i t}=\alpha_{0}+\alpha_{1} V O T_{-} E L A_{p i t-1}+\alpha_{2} I S_{-} A_{i t}+\alpha_{3} C S_{-} A_{i t}+\alpha_{4} P C D_{i t}+\left(\beta_{1} I S_{A_{i t}}+\beta_{2} C S_{A_{i t}}+\right. \\
& \left.\beta_{3} P C D_{i t}\right)+* \operatorname{coi}_{p i t-1}+\varepsilon_{i}
\end{aligned}
$$

The time indices $t$ refer to electoral periods, so $t$ is the current election and $t-1$ after election. $V O T_{-} E L_{p i t}$ are the votes obtained by party $\rho$ in city council or state $i$ in election $t$. We also have the budgetary variables that correspond to the year of the election; investment expenditure $\left(I S \_A_{i t}\right)$, current expenditure $\left(C S_{-} A_{i t}\right)$ and deficit per cápita $(P C D)$, calculated in relation to the number of inhabitants. A dichotomous variable $\left(c i_{p i t-1}\right)$ discussed above is also considered, and its error or random disturbance $\left(\varepsilon_{i}\right)$.

For the interpretation of the coefficients considered key in our work, it is expected that $\beta_{1}, \beta_{2}$ they reflect the impact of the spending made by the ruling party with respect to its competitor, if investment spending should increase votes and reflect a positive sign and that the current expenditure should contract them, indicating a negative sign. For the vector $\beta_{3}$ we expect a negative sign, derived from the increase in spending before the election and the supposed aversion that the voter manifests towards this variable. Regarding the term, we intend to capture the part of the Voter behaviour that the politician cannot predict, these decisions being based on random events, which will be calculated automatically by the statistical program.

\subsection{Results}

In this part, we first present the estimation of models for municipalities and later for states, to identify the results obtained in each model and whether or not the hypotheses can be confirmed.

\subsubsection{Results for Municipalities}

When calculating the regression under the grouped procedure, the results were optimal, however, in the Breusch-Pagan / Cook-Weisberg test the $\rho$ value was significant, indicating that the null hypothesis of constant variance should be rejected, as it presents significant heteroscedasticity problems. The result of this test is presented in Table 18. 
Table 18 Heteroscedasticity test for municipalities of the pooled model (OLS pooled)

\begin{tabular}{|c|c|c|}
\hline Test & Test Statistics & P values \\
\hline Breusch-Pagan/Cook-Weisberg test for heteroscedasticity & Chi $_{2}(1)=32168.35$ & Prob $>$ chi $2=0.0000$ \\
\hline
\end{tabular}

Source: Author's Own Elaboration

To solve this problem, we calculate the MCGF estimator that corrects these types of problems. Table 16 shows the results of the regression.

The results shown in the estimate indicate that the $\mathrm{R}^{2}$ of the estimate is 0.4832 , which shows that the explanatory power of the model we propose is $48.32 \%$. In this sense, the $F$ statistic indicates that the null hypothesis of global non-significance is not rejected. The Table 19 show the results of the MCGF Estimation for municipalities.

Table 19 MCGF Model, dependent variable Votes from the previous election (VOT_EALA)

\begin{tabular}{|l|r|r|r|}
\hline Independent variables & \multicolumn{1}{c|}{ Coeficient } & \multicolumn{1}{l|}{ Err. Std. } & $\boldsymbol{z}$ \\
\hline VOT_ELA & 0.8026 & $*$ & 12.13 \\
\hline IS_A & -0.1796 & $* *$ & -2.09 \\
\hline IS_PA & 0.1986 & $* *$ & 1.99 \\
\hline CS_A & 0.1009 & $* * *$ & 1.93 \\
\hline CS_PA & -0.1191 & $* *$ & -1.98 \\
\hline PCD & 0.5880 & & 0.96 \\
\hline DEF_PA & -0.4862 & & -0.73 \\
\hline Constant & 2638.904 & $*$ & 10.39 \\
\hline R-cuadrado & 0.4832 & & \\
\hline Chi-cuadrado & 0.0000 & & \\
\hline Number of observations & 9747 & & \\
\hline Levels of significance: & $*$ Significant to $1 \%$. \\
& $* *$ Significant to 5\% \\
& $* * *$ Significant to $10 \%$ \\
\hline
\end{tabular}

Source: Author's Own Elaboration

Regarding the results observed in the regression, the variable votes of the previous election (VOT_ELA), appears significant at 1\%, which should not be understood as an inertia or because of it, but as evidence of the relevance of the Candidate votes in the last election.

Regarding the variables that interact with the dummy variable, specifically investment spending (IS_PA) and current spending (CS_PA), the former presents a positive and significant coefficient at 5\%, which confirms the incidence of this spending on the number of votes obtained by the party in power. On the other hand, the variable of current spending registers a negative and significant coefficient also at 5\%, thus confirming that the votes negatively value increases in current spending. This confirms our two hypotheses, that is, the electorate values with their vote the management of the economic policies of investment spending and therefore, rewards with their vote.

These results confirm those obtained by Drazen and Eslava (2005; 2008) and Eslava (2006), who distinguished a positive relationship in the interception of investment spending and a negative one in current spending. Specifically, in our study investment spending when made by the party in power shows a positive sign and is also significant, which suggests that the electorate values the increase in this spending, increasing the probability of the party in power to continue governing.

This result confirms those of the works by Sakurai and Menezes-Filho (2008), Aidt et al. (2011) and Balaguer and Brun (2013), where they state that the electorate rewards governments that increase investment spending, which suggests a positive effect on the possibility of the government being reelected. 
Regarding the deficit (DEF_PA), it presents a coefficient with a negative sign, however, it is not significant. In that sense, it could be assumed that the level of the deficit appears to be irrelevant to voters. In this case, we could argue that although voters do not value the deficit, they do not have aversion to it, so our hypothesis was not confirmed, that is, we cannot affirm that the electorate values the deficit negatively. To some extent, we assume that voters do not try to monitor the deficit, which would result in a fiscal expansion before the election, as indicated by Shi and Svensson (2006).

Ultimately, our result suggests that voters do not use this information to penalize the ruler, contrary to the evidence indicated in the works of Alesina et al. (1998), Brender (2003), Arvate et al. (2009), Drazen and Eslava (2008) and Klomp and Haan (2009), which highlighted that voters, in addition to preferring austere governments, have an aversion to the deficit, which reduces the votes in the election, and therefore, reduces the possibility of remaining in power.

These results reflect a greater probability that municipal governments that increase investment spending in México continue to govern, due to their intrinsic reward for the increase in public works and infrastructure and in contrast to the negative assessment of current spending by the electorate. In this sense, the results in municipalities reflect that the electorate rewards municipal governments with their vote for the increase in investment spending and thus increases their probability of continuing to govern.

\subsubsection{Results for States}

In the case of the states and following the same methodological procedure as in the municipalities, we first calculated the regression with the grouped OLS model, to later apply the Breusch-Pagan / CookWeisberg test, to verify the possible existence of heteroscedasticity. The result of this test is presented in Table 20.

Table 20 Heteroscedasticity test for states of the pooled model (OLSpooled)

\begin{tabular}{|c|c|c|}
\hline Test & Test Statistics & P values \\
\hline Breusch-Pagan/Cook-Weisberg test for heteroscedasticity & Chi $_{2}(1)=0.05$ & Prob $>$ chi $_{2}=0.8225$ \\
\hline
\end{tabular}

Source: Author's Own Elaboration

As can be seen, the Breusch-Pagan heteroscedasticity test for states presents different results to municipalities, that is, it indicates that the null hypothesis of constant variance should not be rejected, as it does not present problems significant heteroscedasticity.

Given the previous condition, the OLS statistical model for states is adequate, since it does not present heteroskedasticity problems, proceeding to comment on the results obtained in this model and which are collected in Table 21.

The results of the OLS estimation for states present, as we can see in table 18 , an $\mathrm{R}_{2}$ of 0.5345 , which shows the $53.45 \%$ explanatory capacity of the model we propose. In this sense, the $\mathrm{R}_{2}$ as we observe is higher than in the case of the municipalities, as it has greater explanatory power. The $F$ statistic also indicates in the regression that the null hypothesis of global non-significance is not rejected.

Regarding the dependent variables of Table 21, we must observe that the regression results show that the variable votes of the previous election (VOT_ELA), appears significant at 1\%, which should not be understood as an inertia, but as evidence of the relevance of the candidate's votes in the last election, as we discussed in the case of municipalities. 
Table 21 OLS estimation results for states

\begin{tabular}{|l|l|l|l|}
\hline Independent variables & Coeficient & Err. Std. & $\boldsymbol{z}$ \\
\hline VOT_ELA & 0.7159 & $*$ & 8.7 \\
\hline IS_A & -132.0771 & $* *$ & -2.15 \\
\hline IS_PA & 74.6324 & $* * *$ & 1.78 \\
\hline CS_A & 0.6010 & & 0.08 \\
\hline CS_PA & -21.2575 & $* *$ & -2.6 \\
\hline PCD & 262.4453 & & 0.67 \\
\hline DEF_PA & -77.0428 & & -0.95 \\
\hline Constant & 325391.8 & $*$ & 8.3 \\
\hline R-cuadrado & 0.5345 & & \\
\hline Chi-cuadrado & 0.0000 & & \\
\hline Number of observations & 63 & & \\
\hline Levels of significance: & $\begin{array}{l}* \text { Significant to } 1 \% . \\
\text { * Significant to 5\% }\end{array}$ \\
& \begin{tabular}{l} 
*** Significant to $10 \%$ \\
\hline
\end{tabular} \\
\hline
\end{tabular}

Source: Author's Own Elaboration

Regarding the variables considered key in this section, that is, the variables of investment spending and current spending (IS_PA and CS_PA) that interact with the dummy variable, the first one presents a positive and significant coefficient at $10 \%$, which suggests an advantageous position when acting on investment spending.

On the other hand, current spending registers a negative and significant coefficient at 5\%, which confirms a negative effect of this variable on the electoral result, verifying, as was the case in municipalities, that in the states, budget management can increase the probability that the state government will continue to rule. The results indicated, as in the municipalities, confirm what was obtained by Drazen and Eslava (2005; 2008), Eslava (2006), Sakurai and Menezes Filho (2008), Aidt et al. (2011) and Balaguer and Brun (2013), confirming our first two hypotheses, that is, the voter values the vote based on the management of public works, and therefore, rewards this action.

As for the deficit, the same is confirmed as in the municipalities, that is, the expected sign is obtained, however, it is not significant either. In this sense, also for the states it seems that the level of deficit is irrelevant to the voter, a trend that in México is found for both levels of government, assuming in both cases that voters do not try to monitor the deficit, which could lead to an expansion in total spending in the short term, demonstrated in the work of Shi and Svensson (2006).

The evidence presented in this work reflects, as in the case of municipalities, that the probability that state governments continue to govern also depends on the increase in public works and infrastructure. This justifies that it is the object of interested attention of the politicians in power, affecting for its benefit the decision of the voter that supposes a reward for the management done. However, for the deficit the hypothesis was not confirmed, that is, it is not significant. This assumes that the voting decision is only affected by the effect that the elections have on investment spending and that the politician in power tries to increase it.

\subsection{Discussion and conclusions}

In this paper we offer a vision of the effect that budget management, and specifically spending and deficit policies, has on electoral results, to show whether those governments that have manipulated budget variables obtain better results.

The results evidenced in this second empirical chapter were deduced considering the database that integrates information on the number of votes and information of a budgetary nature in the elections of city councils and states, in the period 1996-2010.

The studies specifically included, for each model, as a dependent variable the number of votes obtained by the winning candidate by city council and state and the relevance of spending and deficit as independent variables. 
The results obtained at the two levels indicate that higher spending on public works and government infrastructure can have a positive effect on their ability to remain in power, thus showing that there is a positive assessment of spending on electoral results, that is, the electors of the states, and of the municipalities, reward the governments that increase investment spending, and therefore contract current spending before the election.

This type of evidence leads us to discuss some questions that arise from the hypotheses that were made at work, such as: Is the economic and fiscal management of the ruler rewarded by the voter ?; Does the electorate reward those governments that increase investment spending ?; Does increased investment spending increase the likelihood that a government will remain in power ?; Does the fiscal effect of the deficit condition the government's continuity in power?

The behaviour shown in the results at the two levels responds to the above questions, that is, the results of both states and municipalities indicate that the management in relation to the increase in investment spending carried out by the government is positively valued by the voter, while current spending is shown as non-preferred spending, which justifies an inertia of decline before the election.

The two results of the analysed models are considered as a tangible effect on the politician in two scenarios, that is, increasing the probability of continuing to govern, or that his party in government remains in power.

Regarding the deficit, the results of the two regressions show a negative sign, however, it is not significant, confirming that the effect it represents in the two models is irrelevant and it seems that it does not affect the relationship with the number of votes, indicating that in México, the deficit is not a variable that compromises continuity of the politician at the head of the government.

The commented results confirm the trend observed in other democracies, that is, citizens reward and value the different types of spending, showing little interest in the deficit, contrary to the results observed by Kraeemer (1997), Alesina et al. (1998), Brender (2003), Brender and Drazen (2005), Drazen and Eslava (2005; 2008) Arvate, Avelino and Tavares (2009), Brender and Drazen (2008), Klomp and Haan (2009), Aidt et al. (2011) and Balaguer and Brun (2013), who show that governments are penalized by the negative fiscal effect of the deficit on electoral results and that voters prefer austere governments. On the other hand, the results obtained in our models confirm what was obtained by Eslava (2006) and Drazen and Eslava (2005; 2008), who showed in their argument that the number of votes increases in relation to the increase in investment spending and citizens are receptive to this type of action, as is sample in a work for Brazil carried out by Sakurai and Menezes-Filho (2008).

The conclusion of this chapter suggests that in México the voter has a special interest in the management carried out by the ruler, so that by increasing investment spending an effect on the election can be achieved, since it is perceived as an increase in their standard of living by the population.

In addition, the results justify that the increase in spending indicated by the government and valued positively by the voter, is a constant practice that the governments of the states and municipalities of México carry out each election period. In short, it is a phenomenon that represents positive dividends in the period of analysis so that the party in power continues to govern.

The scope of this second work was to verify that with the presence and existence of the CPP at the state and municipal level evidenced in the first empirical chapter, the politician can have a real electoral effect. The results confirm that the expenditure valued and awarded by the voter in the elections is the investment expenditure for the two levels, thus reconciling the results obtained in the previous empirical chapter.

In general terms, the results show that both the increase in investment spending and the contraction of current spending comply with the assumption suggested in the political budget cycles.

Subsequent studies intend to analyse other factors to try as much as possible to improve the results and include the effect of a difficult political scenario, where the politician can react in certain spending, with expansionary policies, for example, the increase in subsidies for improve their electoral results, as shown in Cerda and Vergara (2005). 
On the other hand, this would allow dealing with endogeneity problems, that is, problems that lie in the existence of many more elements that determine the difficulty in any election scenario, for example, corruption, poor management problems, among others. These options offer a consideration for future work, an important area of opportunity to improve our models and therefore the results, in the face of increasingly interesting scenarios to analyse. 


\section{Chapter 6. Model Panel Corrected Standard Errors (PCSE) applied to level of indebtedness}

\subsection{Introduction}

In recent years, the alternative of recourse to debt has experienced accelerated growth in state and municipal governments, with the risk of the sustainability of public finances, which today requires a transparent system of its commitments and control of operations carried out, in most cases destined for investment operations.

One of the government levels with the most problems is that of the municipalities, without ignoring those also expressed by the states, where frequently the own resources that enter and administer are insufficient to meet the commitments acquired, and almost always depend on financing to assume the inherent functions and meet citizen demands. In this context, the Superior Audit of the Federation (ASF, 2012), in its annual report, defines five causes of public debt, in relation to the increase and dependence observed in recent years:

1. High dependence on resources of federal origin and weakness of the income obtained from own collection.

2. Limited collection powers and capacities of the governments of the federative entities and municipalities.

3. Local spending policy with growing budget and primary deficits.

4. Weak, insufficient and imprecise regulation of public debt.

5. Opacity and almost zero accountability on the use of resources obtained through financing, especially from municipalities.

To a certain extent, indebtedness reflects the financial needs of the authorities of state governments and city councils when managing their finances, which due to their economic capacity and administrative conditions complicate development economic and compliance with financial obligations. Ayala (2001) points out that public debt implies an obligation for the government to pay a monetary amount, as well as a yield, to those who legally possess the debt documents. For their part, Dornbusch $e t$ al. (1988) indicate that public debt is made up of medium and long-term securities, in circulation, and some aspects stand out:

1. Public debt represents an obligation established by the government (borrower) with those who buy government securities (lenders).

2. Public debt is a commitment that implies an obligation in a specific period and with the corresponding interest at the time the accrual occurs.

3. The relationship between the government and holders of public securities is of an inter-temporal nature since the government becomes the nexus through which future generations will have to pay off the debt to the lenders when the terms expire.

In the current context, it is difficult for disposable income to be sufficient or exact to cover spending needs, which is why debt operations are used to fully assume the respective functions and meet, as far as possible, the demands of the governed.

In México, recourse to public debt, both in states such as municipalities, grew permanently and requires in each period greater income and financing for investment goods and, therefore, well-being before the citizens.

The Ministry of Finance and Public Credit (SHCP) points out that in México in 2014 the public debt, between states and municipalities, represented an amount of 489,643.4 billion pesos, which constitutes a 7.30-fold increase in relation to 2005, as can be seen in Figure 33. 
Figure 33 Evolution of the debt of federal entities and municipalities

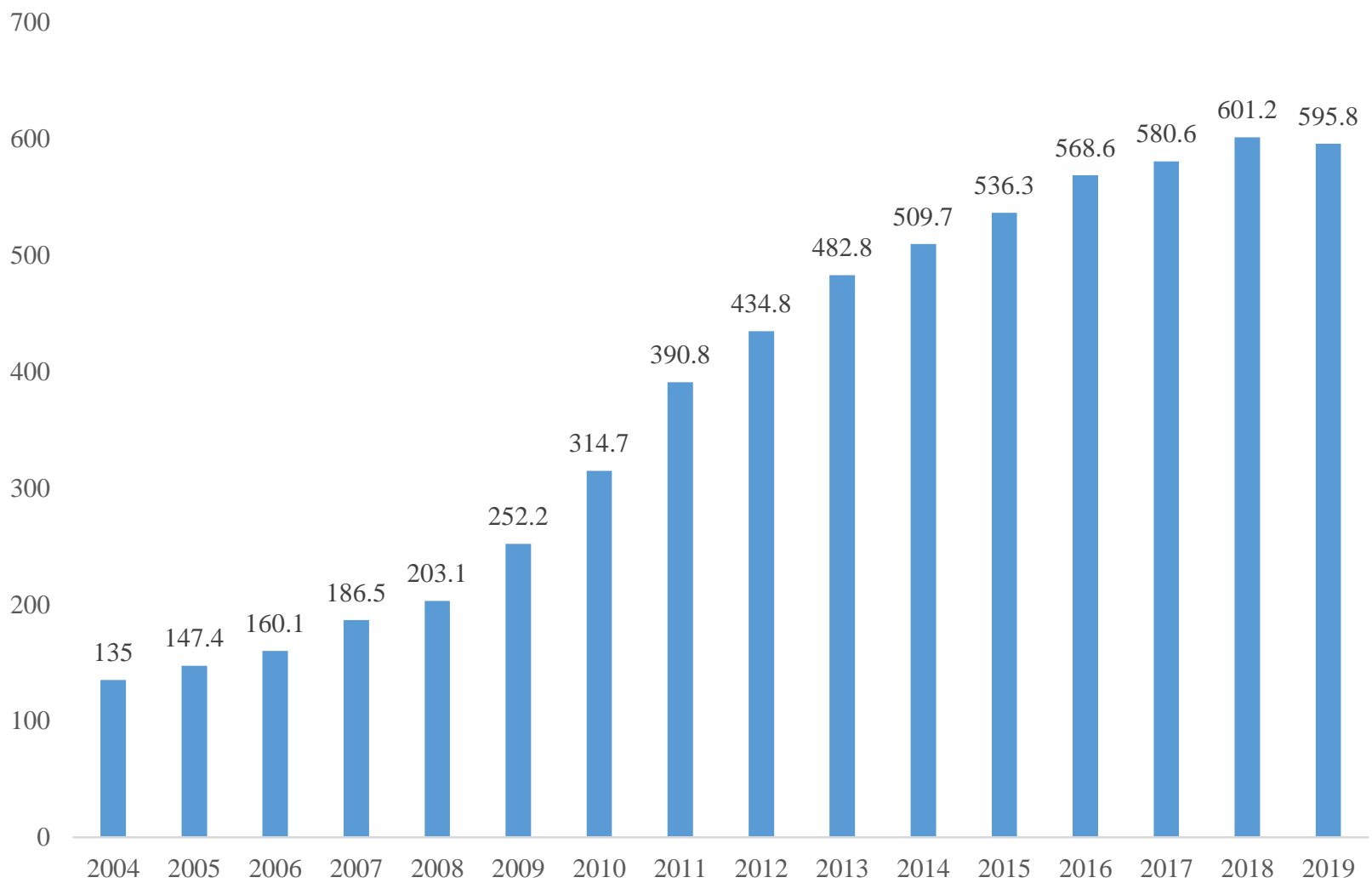

Note: million pesos.

Source: CEFP (2019)

However, it should be noted that in the federative entities and municipalities, the registration in the SHCP began in 2005, and from that year on, the methodology of public debt statistics and its registration with that body changed, in addition to trying to centralize the information. for the control and analysis of this magnitude. The change in the statistical methodology indicated includes the bank and stock exchange debt reported to the SHCP by the states, in addition to the municipal debt guaranteed and not guaranteed by the state governments.

As can be seen, at the state level its increase was 300 times. However, as a percentage of the total debt in 2019. However, the evolution of the debt shows an upward trend, without ups and downs or setbacks. For example, although during the last year, the amount of debt increased in a monetary sense, going from 575 thousand 827.7 million pesos in 2018 to 579 thousand 709.4 million pesos in 2019. In percentage terms, the debt was under $3.7 \%$. Additionally, if the period of the last quarter of these same years is analysed, the debt fell both in economic and percentage terms, having a decrease in the first case of 21 thousand 508.9 million pesos and in the second of -7.8 percent.

Faced with such a scenario, the debt resource must be used responsibly, since the payment commitment is passed on to future generations. In this paper we analyse the factors that explain the behaviour of the state and municipal public debt, to obtain more evidence on the variables that condition the level of indebtedness in México. Likewise, the following paragraphs review the theoretical framework in which the relationship between the indebtedness and political budget cycles.

\section{Previous literature}

Studies related to the financial and fiscal situation of state and local entities have been a priority in many conferences and exhibitions by international specialists in recent years. Specifically, some of them have studied public debt and the factors that can explain it, using different variables, such as investment spending, economic capacity, size of the entity, debt limits or CPP, among others.

In this context, in the following sections we will try to analyse the studies that can be considered an important reference for our work, grouped according to the factors analysed as determining factors for debt. 


\subsubsection{Indebtedness and investment expenses}

Each year the states and municipalities present their spending budget, with their own characteristics and the distribution of public resources by programs and projects. The legal framework for indebtedness in México is based on Article 117 of the Constitution, so that resources from debt in both states and municipalities must be used for productive public investment. In this sense, the international and local literature shows us a general panorama showing that one of the most relevant factors is investment spending.

For example, Benito and Bastida (2005), in their analysis of city councils in the Valencian Community, for the period 1994-2000, pointed out that the variables that best explain the use of debt are the non-financial budgetary result, capital expenditures and capital income.

Pascual et al. (2008), focusing on the stock of outstanding debt per inhabitant of the municipalities of the Autonomous Community of Navarra, found that debt is applied to investment expenses, this component of spending being one of the main determinants of municipal debt. In addition, the work concludes a positive relationship between income and indebtedness and a negative relationship between net savings and capital transfers with respect to outstanding debt.

On the other hand, Brusca et al. (2010) showed that in the years prior to the elections, governments tend to increase their recourse to debt, which is due to the intensification of investment spending and greater financing is used.

Vila i Vila (2012) analysed the causes of indebtedness in Valencian municipalities with an empirical approach to the factors that motivate indebtedness for the period 1992-2006. The results indicated that capital spending, financial autonomy and saving are the variables that best explain the behaviour of the debt, showing an indication of a cycle generated by a greater investment effort in the years prior to the election.

Zafra-Gómez et al. (2009), in their study for 1,309 municipalities in Spain from 2003 to 2008 , found that financial variables are those that explain the level of debt to a greater extent. Specifically, this work concluded that financial magnitudes, specifically capital expenditures, present a positive and statistically significant coefficient, which significantly increases indebtedness.

Pérez et al. (2013) in their study on the factors that condition that Spanish municipalities present a certain level of debt in periods of economic crisis, used a base of 1,238 municipalities in the period 2008-2011, and concluded that the capital expenditure variable influenced positively in debt.

In a more recent study, Kinto (2014) contrasted different economic, financial and institutional hypotheses to explain the contracting of new public debt by state governments in México from 2007 to 2012. This work confirmed that to the extent that investment spending increases, increases indebtedness. In addition, the results showed an increase in dependence on federal resources, which was measured in relation to the share of guaranteed federal income with respect to total state income.

\subsubsection{Indebtedness and economic and financial capacity of the entities}

Numerous studies have been carried out at the European level to analyse public debt based on the economic and financial capacity that it can explain. For example, Brusca and Labrador (1998) analysed a sample of municipalities in Catalonia and took the variation and increase in debt at the end of each year as the dependent variable and the number of inhabitants, annual per capita income, net and gross savings as independent variables, the annual expenditure per inhabitant, and finally, the budget surplus per inhabitant. This work found that annual per capita spending and gross saving are the ones that have a considerable influence on the level of per capita debt.

Escudero and Prior (2003) analysed 86 local entities in Catalonia with a population greater than 10,000 inhabitants. This work shows that the local entities with greater decentralization are those that maintain the highest level of debt. 
Furthermore, the variables as a tourist level, the per capita income, and to a lesser extent the population, gross savings and the relationship of taxes with current income, were the variables that originated in this work important differences in the debt levels of the municipalities studied. In addition, their results reinforce the role of the fiscal illusion, that is, governments to increase their possibility of remaining in power increase the level of spending using instruments to reduce the cost perceived by the voter (debt), which decreases the prominence of taxes within the financing of expenses.

Benito et al. (2004) analysed the debt of the Spanish Autonomous Communities in the period 1994 to 1999, using variables of an economic, budgetary and institutional type. By introducing all these variables in the model, a multicollinearity problem appeared, for this reason, they chose to build a model for each of the independent variables and then, on the set of variables, thus, only the variables that presented lower correlation index.

Their results indicated that the Communities with greater powers have higher levels of debt. Furthermore, that GDP and the expenditure generated for transfers seem to be variables that cause differences in the level of debt of the different Communities.

Brusca et al. (2012) analysed the possible relationship between indebtedness and levels of decentralization of public services for Catalan and Valencian municipalities with a population greater than 20,000 inhabitants.

Their results confirmed the existence of a positive relationship between the level of debt and decentralization in management, which implies the need to question the representativeness of the current local accounting information presented on an unconsolidated basis. That is, they showed that those entities that have greater gross savings and therefore greater capacity to borrow, show higher levels of decentralization.

Pérez et al. (2013), in their study on the factors that condition Spanish municipalities to present a certain level of debt in the 2008-2011 period, concluded that the variables of the net savings index and subsidies were significant, noting that in periods of crisis the relationship with indebtedness does not differ as a boom time.

Pérez et al. (2014) also analysed the impact of the creation of agencies, public companies, and outsourcing of services and the political and financial aspects of the entity. This work used the statistical regression model using fixed effects, observing a panel of 1,517 Spanish municipalities for the period 2003-2008. The results showed that the subsidy index is the variable with the greatest explanatory power of the level of indebtedness, while the political factors do not have a clear influence on the debt.

Likewise, they show the incidence of the forms of management employed; verifying that the outsourcing of public services presents a negative relationship with the level of indebtedness, and that the municipalities that present a greater number of outsourcing and participation in consortiums obtain a lower level of debt.

\subsubsection{Indebtedness and size of states and municipalities}

The increase in public spending and its application to meet the demands of citizens suggests an increase in debt related to the size of the entity. For this reason, the increase in indebtedness is derived, in part, from the adjustment in the services and public works required by states and municipalities based on their characteristics. In this sense, there are significant factors that condition indebtedness: the size of the population, the economic inequality between municipalities and its accelerated growth. In particular, population growth would be a factor in increasing debt, since the resources collected and generated by state entities and municipalities are not sufficient, so state and local entities have to increase the use of the debt resource to generate more public works.

In this sense, Escudero and Prior (2003) analysed 86 local entities in Catalonia, pointing out that the population has a significant influence on the levels of debt in the municipalities studied. 
Benito and Bastida (2005), in their analysis of the municipalities in the Valencian Community, for the period 1994-2000, pointed out that the variables that best explain the use of debt are the nonfinancial budgetary result, capital expenditures, income capital and population. This work stated that the size of the population has a significant influence on indebtedness, relating this result to those obtained by Mitchell (1967) and Pogue (1970), which suggested that the greater the increase in population, the level of debt of the entities studied increases. Likewise, this work shows that the ideology of the local government intervenes within the political cycle, and that the parties try to influence the vote for the next cycle, leaving an automatic reflection of debt within their finances, which are inherited by the next government.

Guillamón et al. (2011), taking as a reference Spanish city council with more than 1,000 inhabitants in 2008, analysed variables of a social, economic, ideological and gender nature to determine those that best explain indebtedness at the local level. This work concluded that the variables population, percentage of immigrants, economic level, transfers and taxes are those that positively affect the level of debt per capita. On the other hand, for political variables, such as political strength, they found that the weakest governments are those with the lowest level of per capita debt.

Zafra-Gómez et al. (2010), in their work for 1,309 municipalities in Spain in a period of 5 years (2003-2008), found that the population has a positive influence on indebtedness.

\subsubsection{Indebtedness and CPP}

The political budget cycles suggest the possible existence of a strategic relationship between the political cycle and the level of indebtedness. The literature suggests that in electoral cycles, governments increase their indebtedness and, therefore, generate a CED that can be considered in the CPPs.

It is also possible to propose a model in which governments increase debt as a strategy to limit its use to the next administrations in a polarized electoral scenario and, therefore, with little possibility that the party in power continues to govern.

The works of Aghion and Bolton (1990), Milesi-Ferreti (1995) and Milesi-Ferreti and Spolaore (1994), indicate that governments strategically manage their debt to influence the outcome of elections, trying to influence preferences electoral, apply the debt resource as a political instrument for the ruler in his aspiration to be reelected or increase his possibility of continuing in power. Other studies such as Shadbegian (1999), Feld and Kirchgässner (2001a; 2001b), Allers et al. (2001) and Galli and Villani (2011) obtained conclusions where indebtedness increases at the end of the political budget cycle.

On the other hand, Akhmedov et al. (2004), found that in the regional governments of Russia, public indebtedness increases in the electoral year due to transfers and payment of salary arrears, which could lead to governments in functions manipulate fiscal policies.

Sánchez Mier (2011) contrasted the hypothesis of the existence of a political budget cycle based on data from Asturian municipalities through a panel referring to the 2001-2008 period. In this research, he tried to build a model that delved into the factors of indebtedness, estimated in the form of variation of financial liabilities and considering two electoral periods. The results of this study do not corroborate a trend towards greater indebtedness in progressive governments, nor in governments made up of coalitions.

Likewise, the increase in public debt in the years before and during the election is an argument rejected in the study's estimates. Basically, it shows that in the main Asturian municipalities, indebtedness is directly related to financial autonomy, and to a lesser extent with the structure of assumed public spending, capital expenditures and investments on the one hand and "rigid" or "captive" expenses, of ordinary character, on the other.

Considering the empirical literature of México, the contributions are still scarce, and the study by Ramírez (2003) can be highlighted, which used a database of 2,412 municipalities for the period 19891999 , relating municipal public finances with political variables and its effect with political cycles such as determinants of indebtedness. This study indicated that the indebtedness of the municipalities increases in the year after the election. 
For their part, Ramírez and Erquizio (2012), in their study for the 31 states of the 1993-2009 period, linked the political cycle with public spending variables and its influence with indebtedness. This work confirmed the presence of the political cycle in total spending as a determining factor in the increase in debt in the states of México.

Carpizo (2012) for state entities in the period 2003-2010, estimated several econometric models, taking as a dependent variable the total debt (direct debt + agency debt) and additionally, the two debt measures based on state GDP. For the independent variables, he considered divided governments, political parties, financial dependence, per capita collection, and lagged variables of the population and GDP of the states.

The results concluded that debt decisions are conditioned by the environment of political competition of each entity, that is, political pressure exerts greater incentives on governors to finance public works more actively. Furthermore, the level of intensity of political competition is key to understanding the incentives that the different actors have when negotiating the amounts of state indebtedness in each political budget cycle.

\subsubsection{Debt Limits}

For the analysis of the empirical evidence on debt limits we refer basically to studies that have tried to analyse the effect of limitations or restrictions found in the recourse to indebtedness by public administrations because of legal regulations.

In this context, the theoretical scheme of the analysed works shows us that it is possible to use instruments that reduce the control to which they are subjected. public entities, such as the creation of entities with special purposes to finance debt through the issuance of bonds.

Specifically, the studies of the last decades carried out in the United States make significant contributions to the study of the rules and regulations on debt limits and how they directly or indirectly affect public debt.

In this sense, some studies criticized the effectiveness of the limitations to indebtedness (Bennett and Dilorenzo, 1982; Blewett, 1984; Bunch, 1991; Von Hagen, 1991; Metcalf, 1991), while others admitted the effects on cuts in levels of public services (Pogue, 1970; Farnharm, 1985; Kiewiet and Szakaty, 1996).

For example, Pogue (1970), analysed the effect of legal limits on recourse to indebtedness in two different years for 48 states and 173 metropolitan areas of USA. His results indicate that state boundaries have the effect to restrict the use of debt financing, although they may also have some unwanted effects, that is, the author suggests that the limit of debt not only reduces local spending, but also aggregate state spending, in such a way that Thus, lower levels of debt may appear associated with lower levels of public services.

However, Bennett and Dilorenzo (1982) concluded that debt constraints have not achieved their objectives, that is, governments have changed their structure to be able to skip them. For this study they used the variable long-term unsecured debt term, which is issued by decentralized entities. Similarly, Blewett (1984) accepted that debt limitations have caused municipalities to divert its debt to the agencies to bypass the limitations imposed by the government.

Farnham (1985), for his part, pointed out that the proliferation of government units and the growing use of unsecured debt are consequences derived from the imposition of limits on the indebtedness of local governments. This work analysed a sample of 2,087 entities with a population equal to or greater than 10,000 inhabitants in the period 1976-1977.

The conclusions of this study indicated that the limits on local debt imposed by the states have a negative effect on the levels of gross debt per capita, thus reducing both the guaranteed debt and the unsecured debt, however, it detects some substitution of the debt. first type of debt for the second in those communities subject to stricter limits. 
Bunch (1991) in his work analysed that the permanence of a party (Democrat or Republican) in power, and how this constancy can circumvent the limitations on indebtedness through the issuance of unsecured debt, exempt from limitation.

This work concluded that the permanence of the same party in power for several years, supposes a greater creation of public entities that issue unsecured debt, therefore, they circumvent the limit of their unsecured indebtedness.

Von Hagen (1991) made comparisons between states that have debt limits and those that do not have for the period 1975 to 1985 . This study indicated that per capita debt ratios are higher in states without limitations. His main conclusion was that fiscal restrictions induce the restriction of debt instruments of the states analysed.

Metcalf (1991) using the fixed effects model (EF) analysed a sample of 185 North American entities from 1978 to 1988 . This work tried to verify to what extent the fiscal policies of the federal government limit the acquisition of financial assets and liabilities by municipalities, concluding that fiscal policies influence the level of debt held by municipalities.

The work of Kiewiet and Szakaty (1996), as well as that of Bunch (1991), tried to verify to what extent the limitations of indebtedness are circumvented through the issuance of unsecured debt, and if these limitations cause a transfer of debt state-to-local level debt in the United States. In this work, the authors applied the panel-type data methodology, considering 50 states from 1961-1990.

The conclusion highlights that the per capita income and the political sign positively influence the level of indebtedness, that is, the conservative parties maintain lower levels of debt and better comply with the legal limits of indebtedness imposed by the central government. Where in addition, that the level of existing debt in a period depends on the type of limit established.

For their part, Feld and Kirchgässner (2001a) carried out an analysis on the behaviour of indebtedness in 134 Swiss entities in 1990, whose population ranged between 300,000 and 400,000 inhabitants. This work observed that fragmentation in government, the rules regarding the debt limit and its restrictions are aspects that increase the deficit, further accentuating the crisis and therefore, increasing the debt accordance with Pérez-Cruz (2015).

García et al. (2011), analysed a sample of 148 Spanish municipalities with a population greater than 50,000 inhabitants in the period 1998-2008. The results show that during the electoral year, politicians behave opportunistically, which leads to a significant increase in public debt in relation to municipal revenues, although parties with a progressive ideology try three times greater than those involved. conservatives.

In addition, Tellier (2006) and Vallés (2002) explain governments conservative locals tend to significantly attenuate this behaviour in the years before the elections, while left-wing parties do not. Likewise, it was observed in this study that the partisan and electoral cycles have been mitigated since 2002 with the entry into force of the Budget Stability Law, which imposed limits on the indebtedness that local administrations can assume. In addition, the empirical evidence obtained in this work highlights the need to improve internal and external control mechanisms to avoid the rupture of the stability policy and the risk of debt unsustainability, achieving greater budgetary discipline.

Vila i Vila (2012) analysed a sample of Valencian municipalities with a population equal to or greater than 5,000 inhabitants for the period 1994-2009. The results indicate that minority or coalition governments are more likely to resort to borrowing than majority single-party governments. It also observed that a significant number of municipalities did not allocate all their long-term loans to financing investments, worsening their solvency and economic situation. This work concluded that recourse to debt does not seem to respond to a differentiated ideological behaviour, or to a strategy to win elections, and that coalitions appear more prone to using debt as a source of financing. The authors also indicate that governments on the right are less respectful of legal limits, taking advantage of this situation to benefit from greater transfers than those on the left. 


\subsection{Objectives and Hypothesis}

In this last empirical work, we intend to carry out an analysis of the factors that explain the behaviour of the use of state and municipal public debt, based on the theoretical framework and previous literature analysed.

\subsubsection{Objectives of the empirical work}

The general objective of this empirical work is to analyse the factors that can explain the behaviour of the use of state and municipal public debt in México. To do this, we will use the states and municipalities of México in the period 1996 to 2010, conducting an individualized study based on the relationship between debt and other explanatory variables. Specifically, we intend to answer the following analysis questions:

- To what extent does the investment spending that the entities make influence the recourse to indebtedness?

- How do the capital transfers received affect the recourse to debt?

- What is the effect of the per capita economic level measured in relation to per capita GDP on the recourse to debt?

- To what extent does the gross savings generated through current income contribute to the decrease in financing and their need to resort to debt to cover the basic needs of the citizen?

- Does the financial autonomy of the states and municipalities have an effect on the recourse to debt?

- $\quad$ Does the period before the elections increase the debt resource of the states and municipalities?

\subsubsection{Hypothesis}

To answer the previous questions and considering the previous literature analysed in the points addressed in the first part, in this work we intend to contrast the following hypotheses:

- $\quad \mathrm{H}_{1}$. The greater the effort in generating public works and investment in states and municipalities, the greater the recourse to indebtedness.

The increase in indebtedness for financing public works and investment finds its justification in part, in the transfer of the cost to future generations, since they will benefit in the medium and long term (Cabasés et al., 2007; Letelier, 2010). Therefore, it is expected that there is a positive relationship between debt and investment (Vallés, et al. 2005). This same argument was also used by Benito and Bastida (2005), Sánchez Mier (2011), Pérez et al. (2014) and Kinto (2014).

- $\quad$ H2. Entities with a higher level of capital transfers will require a lower level of indebtedness.

Capital transfers are aimed at financing investments, and as they grow, states and municipalities will resort to less debt. These arguments were used in the studies by Levaggi and Zanola (2003), Benito and Bastida (2005) and Lago-Peñas (2008), who confirm the existence of an inverse relationship between both variables.

- H3. The increase in population increases the recourse to indebtedness of the states and municipalities. 
In this sense, like other authors in the literature, we consider that the population maintains a positive and significant relationship with the level of state and municipal debt, as indicated by Mitchell (1967), Benito and Bastida (2008), Guillamón et al. (2011) who argue that the larger the population requires more debt; This can be justified by the impact that the increase in spending acquires as the population increases, derived from the services offered by both the states and the municipalities.

H4. The recourse to indebtedness for states and municipalities is conditioned by the percapita GDP.

Some authors such as Benito et al. (2004) and Benito and Bastida (2005), consider GDP per capita from two perspectives: first, it could be expected that a higher GDP per capita requires less debt, since the capacity to generate income would be greater. However, it can also happen that the greater the wealth of an entity, the greater the needs of the citizens and therefore there are difficulties in meeting them without resorting to debt. Therefore, we consider two important situations: first, the expected sign in this variable will be uncertain in principle. Second, we consider that this variable is a good indicator of the capacity to generate income in the states and municipalities.

- $\quad$ H5. Institutions with lower gross savings have a greater need to resort to borrowing.

Gross saving indicates the ability to generate resources for new investments or to face indebtedness, so there may be a negative relationship between the financing capacity and the recourse to indebtedness, so the sign expected is negative. This variable has been considered in the works of Mceachern (1978), Brusca and Labrador (1998), De Mello (2001), Benito and Bastida (2004), Fernández de Mantilla and Flores (2008), and Guillamón et al. (2011).

- $\quad$ H6. The greater the financial autonomy, the less the need to increase indebtedness.

The financial autonomy of the states and municipalities is conditioned by the collection of income derived from taxes, rights, products and uses to finance their spending, so that the greater the collection of these resources, the less will be the need to resort to liabilities to finance the spending.

Tax revenues reduce the need to borrow, representing a strength to meet liability commitments (Vila i Vila, 2010). In this sense, McEarchen (1978) and Brown (1996) point out that the capture of resources in relation to spending is a good indicator of financial autonomy of the entities studied.

- $\quad$ H7. Debt tends to be higher in the year prior to the elections.

This is justified by the opportunistic behaviour of the rulers when using spending variables that increase the chances that their party will remain in power.

In México, indebtedness must be justified by spending on productive public investment, a concept considered verbatim in the legal framework of the Mexican political constitution, in its article 117.

However, according to Sánchez-Mier (2011), if the level of indebtedness it contracts in the electoral period, then it could be considered a sign of good management by the ruler by decreasing this variable. 
Figure 34 Hypothesis of budgetary indebetedness

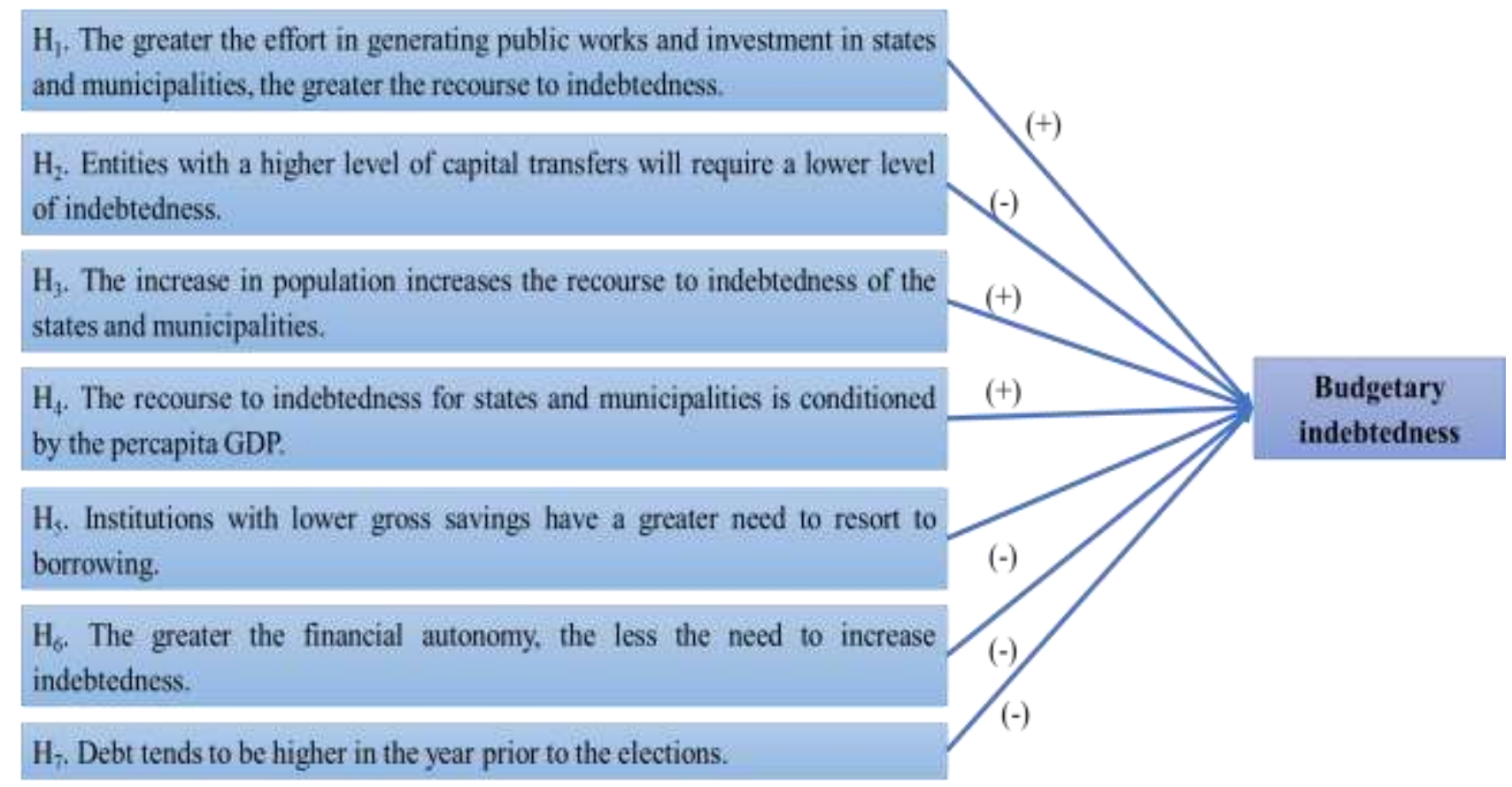

Source: Author's Own Elaboration

In this framework, Vila i Vila (2010; 2012), considers the existence of a debt cycle linked to the electoral cycle, although their results show a negative effect on debt the year before the elections. However, Brusca et al. (2010), they consider a positive effect due to the increase in investment spending in the year prior to the elections. For this reason, it is difficult to define a priori the sign in this hypothesis.

\subsection{Sample and variables}

As in the previous empirical chapters, the sample is made up of the states and municipalities of México. This analysis was carried out with two bases that integrate, on the one hand, the information from 31 states and, on the other, the 1,190 municipalities with a population of more than 2,500 inhabitants.

\subsubsection{Definition of Variables}

In the work we take as a dependent variable the budgetary indebtedness of each state and each city council of México, since in this case we only have this data, published by INEGI (2015), while we do not have information on the accumulated debt. The dependent variable used in the study are the following and are showed in the Table 22:

Budgetary indebtedness, which we are going to measure through indebtedness divided by number of habitants.

Table 22 Dependent variable used to estimate the states and municipalities

\begin{tabular}{|l|l|l|}
\hline Dependent Variable & \multicolumn{2}{|c|}{ Description } \\
\hline DEUD & Budgetary indebtedness & Resources obtained from indebtedness / Number of habitants \\
\hline
\end{tabular}

Source: Author's Own Elaboration

The independent variables used in the study are the following:

- $\quad$ Level of investment spending, which we are going to measure through capital spending per capita per year.

- Capital transfers received, obtained from federal resources transferred to states and municipalities, labelled for the generation of public works.

- $\quad$ Population Increase, which will allow us to see if the increase affects the use of debt. 
- Gross Domestic Product per capita, which refers to the economic wealth generated by each inhabitant.

- Financial autonomy variable, which includes the relationship of own income (taxes, products, rights and benefits) with respect to current spending, understood as the entity's ability to cover spending with its own income, that is, the self-sufficiency to finance its own expense and for Hence, do not depend on the recourse to indebtedness.

- Gross per capita savings, defined as the entity's own financing capacity to generate new investments or to face debt, measured by current income minus current expenditure and divided by the number of inhabitants.

- Electoral dummy variable, which collects the value 1 one year before the election and 0 otherwise, considering that in the year prior to the election, recourse to indebtedness increases.

Specifically, Table 23 shows the different variables used, their description and corresponding calculation, as well as the hypothesis with which they are related and the expected sign in the analysis.

Table 23 Variables used in the estimate for states and municipalities

\begin{tabular}{|l|l|l|}
\hline \multicolumn{1}{|c|}{ Independent Variable } & \multicolumn{1}{c|}{ Description } & \multicolumn{1}{c|}{ Calculation } \\
\hline SI_PC & Per capita Investment Spending Level & Investment Expenditure / No. of Inhabitants \\
\hline CTF & Capital transfers Federal & Contributions / No. of Inhabitants \\
\hline POP & Population increase & $\begin{array}{l}\text { Variable that represents the population increase } \\
\text { over time }\end{array}$ \\
\hline GDP_PC & GDP per capita & $\begin{array}{l}\text { GDP / Number of inhabitants } \\
\text { inhabitants }\end{array}$ \\
\hline GS_PC & Gross savings per capita & (Own income / current expense) $* 100$ \\
\hline FA & Financial autonomy & 1 one year before the election or other case \\
\hline ELEC_1 & Year before the Election & \\
\hline
\end{tabular}

Source: Author's Own Elaboration.

The following figure shows the expected signs for the variables described in the table above.

Figura 35 Expected sign of variables of PCSE model

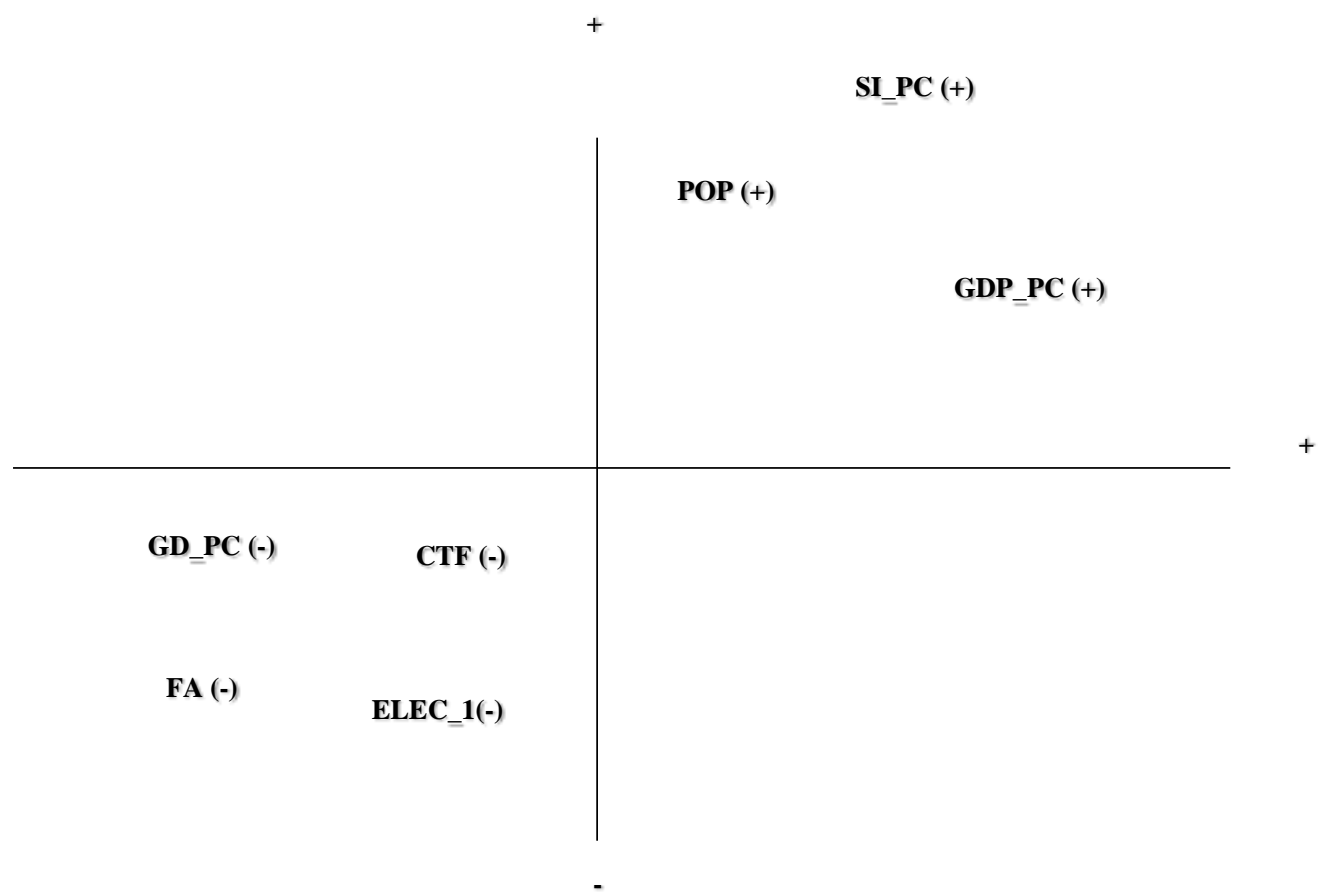

Source: Author's Own Elaboration

\subsection{Methodology}

The methodology used to estimate the statistical model, both for states and municipalities, is that of panel data, where the observation unit varies in two dimensions, in cross-section and time series. This type of model makes it possible to improve the reliability of the estimates, since it notably expands the observations when working together with the information from all the analysis entities. 
In particular, in this chapter both the fixed effects model (EF) and the random effects model (EA) were considered to shape the individual character of each state or city council. In this sense, Sosa (1999) and Hagen y Vabo (2005) highlights the importance of distinguishing between the fixed and random effects models, which is possibly the more complicated problem in implementing a panel data model.

The decision to apply one model or another can be based strictly on questions of practical convenience, performing the so-called Hausman Test, which can be interpreted as a validity test of the random effects estimator. However, if the null hypothesis is rejected, that is, the difference between the fixed and random effects coefficients is systematic, then it is advisable to use the fixed effects estimator. In addition, different tests are used that give rise to other estimators, such as the autocorrelation and heteroscedasticity test specified in the following sections.

\subsubsection{Model specification}

As we have indicated, the empirical study aims to identify the factors that determine indebtedness both in Mexican states and municipalities for the period 1996-2010. In this sense, the model we are trying to propose takes as a dependent variable the recourse to the public debt of the states and municipalities at the end of December of each year. In line with the above, the model is expressed as follows,

$\gamma_{i t}=\alpha_{i}+\beta_{i} X_{i t}+e_{i t}$

Where $i$ means the $\mathrm{i}-t h$ transversal unit (state or municipality) and $t$ the time (year). In this sense, equation (1) assumes that the intercept of the regression in general is the same for each of the states and municipalities, however, it is likely that it will be necessary to distinguish (control) the individual characteristics of Each municipality, thus, the Random Effects (EA) model assumes that each of the states and municipalities has a different intercept. The model in this case is expressed as follows:

$\gamma_{i t}=\alpha_{i}+\beta_{i} X_{l i t}+e_{i t}$

Where $\alpha i=\alpha+\mu i$ considering $\alpha$ as fixed and assuming that it is a random variable with a mean value $\alpha$ and a random deviation $\mu i$, by substituting this equation in the model we obtain:

$\gamma_{i t}=\alpha_{i}+\beta_{i} X_{l i t}+\mu i+e_{i t}$

This equation estimates the random effects model based on our variables. However, it may be necessary to models the individual character of each state through fixed effects (fixed effects), which assumes that the differences between states are not random but constant. In this case, the model is estimated using the dichotomous variables technique, expressed as follows way:

$\gamma_{i t}=v_{i}+\beta_{i} X_{l i t}+e_{i t}$

Where $v i$ is a vector of dichotomous variables for each state or city council, estimating a dummy for each entity. Now, it is important to point out that the incorporation of dichotomous variables allows modelling characteristics of the transversal units that do not change over time but do affect the result, but it is also valid to add temporary dichotomous variables to our model, that is, for each year of the sample, which transforms the equation into:

$\gamma_{i t}=v_{i}+n_{t}+\beta_{i} X_{l i t}+e_{i t}$

Where $n_{t}$ represents a vector of dichotomous variables for each year. These dichotomous variables will make it possible to control those events to which all the states were subjected each year and, like the fixed effects, can reduce important biases.

To select the best way to estimate the model, that is, to use OLS, EA or EF, various tests are performed, such as the $\mathrm{F}$ test of the fixed effects model (equation 4 ), whose value, if significant, indicates that the EF model is better than the OLS, and later we compare the OLS model vs. EA. 
In this sense, Breusch Pagan in his model propose as a null hypothesis that $\sigma_{\mu}^{2}=0$, and if the assumption is fulfilled then the test is rejected, being able to suggest that there is a difference between (1) and (3), and it is preferable to use the EA method. The Hausman test demonstrated that the difference between the fixed and random effects coefficients $\left(\beta_{e f}-\beta_{e a}\right)$ can be used to test the null hypothesis that $\mu_{i}$ and the X's (independent) variables are not correlated.

Thus, the Hausman test hypothesis considers that the estimators of EA and EF do not differ substantially. If Ho is rejected, and the estimators statistically show a difference, then it is considered more convenient to use EF compared to EA. In line with the above, the multiple regression linear model for both states and municipalities is established as follows:

$$
\begin{aligned}
& D_{E U D_{i t}}=\alpha+\beta_{1} I S_{P C i t}+\beta_{2} C T F_{i t}+\beta_{3} P O P_{l i t}+\beta_{4} G D P_{P C i t}+\beta_{5} G S_{P C i t}+\beta_{6} F A_{i t}+\beta_{7} E L E C_{1}+e_{i} \\
& ; \text { for } i=1, \ldots 30 \text { and } t=2007, \ldots, 2019 \text { for state } \\
& ; \text { for } i=1, \ldots 30 \text { and } t=2007, \ldots, 2019 \text { for municipalitis }
\end{aligned}
$$

\subsubsection{Auto correlation and Heteroscedasticity}

The Wooldridge (2010) and Modified Wald tests are tests that are used to detect and control a possible correlation and heteroscedasticity in our statistical models, even when we have modelled the temporal and spatial heterogeneity of the equation 22 .

These tests indicate and suggest, if there is a rejection of hypotheses, alternative estimators to correct the possible problems that may arise. The estimators suggested for this type of case are the panel corrected standard errors estimator (EECP) or the least squares estimator feasible generalized (MCGF). In this sense, Beck and Katz (1995) point out that EECP are more precise than MCGF, which will be considered for this work.

\subsection{Analysis of results}

To carry out our analysis we have prepared two panels, one with 464 observations corresponding to data from 31 state governments and another panel with 26,126 observations corresponding to 1,194 municipalities in the years 2007 to 2019. The use of the different tests commented on in the methodology will allow us to eliminate as far as possible the unobservable heterogeneities of each panel, trying to control the individual character of each entity and correct, if it is the case, the problems of heteroscedasticity and self-correlation that it may present. the model. In this sense, it is intended to establish the best estimator for panel data from the previous tests.

\subsubsection{Results for Municipalities}

As in the states, for the municipalities we will use the same tests to estimate the regression with panel data, trying to also identify the model that provides the best results for these entities. In line with the states, the $F$ test, the Breusch and Pagan test and for Last the Hausman test, which are presented below: As can be seen, the F test indicates that we can reject the null hypothesis of a common intercept (OLS), since the value of $\mathrm{P}$ is less than 5\%, that is, to model the individual character it is convenient to use the estimator EF versus the grouped model (OLS), which assumes that the differences between the states are constant or fixed. The next table show these statistical results.

Table 24 Statistical results on the model to be applied for municipalities

\begin{tabular}{|l|l|l|l|}
\hline \multicolumn{1}{|c|}{ Test } & \multicolumn{1}{c|}{ Null hypothesis } & \multicolumn{2}{c|}{ Pest Statistics Values } \\
\hline Test $\mathrm{F}$ & $\mathrm{H}_{\mathrm{o}}:=$ all $\mu i=0$ & $\begin{array}{l}\mathrm{F}(2007,2019) \\
=7.39\end{array}$ & Prob $>\mathrm{F}=0.0000$ \\
\hline $\begin{array}{l}\text { Multiplier Test Lagrangian de Breusch and Pay } \\
\text { for Effects Random (ER) }\end{array}$ & $\mathrm{H}_{\mathrm{o}}$ : Var $(\mathrm{u})=0$ & $\begin{array}{l}\mathrm{Chi}_{2}(1) \\
=1233.53\end{array}$ & $\begin{array}{l}\text { Prob }> \\
\mathrm{Chi}_{2}=0.0000\end{array}$ \\
\hline Hausman & $\begin{array}{l}\mathrm{H}_{\mathrm{o}} \text { : Difference in Coefficients is } \\
\text { not Systematic }\end{array}$ & $\begin{array}{l}\mathrm{Chi}_{2}(4)=29.16 \\
\text { Prob }> \\
\mathrm{Chi}_{2}=0.0000\end{array}$ \\
\hline
\end{tabular}


In this case, as we can see in the previous table, the $\mathrm{F}$ test is significant and the null hypothesis of a common intercept (OLS) must be rejected, since the value of $\mathrm{P}$ is less than 5\%, being more convenient to differentiate the individual characteristics for each municipality, that is, it is better to use an estimate from the EF model.

When applying the Breusch and Pagan test for random effects, we can observe that the null hypothesis is rejected, that is, it is significant at $1 \%$, also indicating that it is better to use the estimator of the random effects model over the pooled one.

To identify which model can give us better results, the Hausman test is applied. The result of this test indicates that it is significant at 5\%, suggesting that the hypothesis should be rejected, that is, the difference between the coefficients of random effects is systematic, for this reason, the EF estimator is better over the $\mathrm{AE}$.

However, the result of applying the fixed effects or random effects model can cause problems of self-correlation and heteroscedasticity, as was the case of the states, so it is likely that in this case the presence of these problems causes some of the variables may present weak values in their coefficients or non-significant values. In this context, the autocorrelation test and the heteroscedasticity test are carried out. The results of these tests are shown in Table 25 below:

Table 25 Statistical results of self-relationship and heteroscedasticity for municipalities

\begin{tabular}{|l|l|l|l|}
\hline \multicolumn{1}{|c|}{ Test } & \multicolumn{1}{|c|}{ Null hypothesis Pest Statistics } & \multicolumn{1}{c|}{ P Values } \\
\hline Wooldridge & $\begin{array}{l}\mathrm{H}_{\mathrm{o}}:=\text { no autocorrelation of first } \\
\text { order }\end{array}$ & $\mathrm{F}(1,1910)=3.132$ & Prob $=0.0769$ \\
\hline $\begin{array}{l}\text { Modificated Test of Wald for } \\
\text { heteroscedasticity }\end{array}$ & $\begin{array}{l}\mathrm{H}_{\mathrm{o}}: \sigma 2 i=\sigma 2 \text { for } \\
\text { all } i=1 \ldots N\end{array}$ & $\mathrm{Chi}_{2}(2007)=3.0 \mathrm{e}+09$ & Prob>chi ${ }_{2}=0.0000$ \\
\hline
\end{tabular}

Source: Author's Own Elaboration

As we can see, in this case the first test does not detect auto-correlation problems, under the assumption of Wooldridge (2010), who establishes the auto-correlation hypothesis: $\rho \neq 0$, which indicates the existence of no serial correlation. In this result, a small value is obtained, due to the size of the study base and confirming that there is no autocorrelation. To verify the presence of heteroscedasticity, the Wald test is presented, observing a significant result, for which it is concluded that the observations experience only heteroscedasticity problems.

In order to correct the heteroskedasticity problem detected in the previous tests, the estimator will be used for the Panel Corrected Standard Errors, which will allow obtaining results for the regression analysis of equation 23 for municipalities in México. The results obtained in the estimation are shown in Table 26.

Table 26 Explanatory factors of the debt resource in the municipalities

\begin{tabular}{|l|r|r|}
\hline \multicolumn{1}{|c|}{ Independent Variable } & \multicolumn{2}{c|}{ Coeficient } \\
\hline SI_PC & $0.3520 *$ & 0.0962 \\
\hline CTF & $-0.2504 * *$ & 0.1035 \\
\hline POP & $-0.0020 * *$ & 0.0010 \\
\hline GDP_PC & $36.5979 * *$ & 16.2892 \\
\hline GS_PC & $-0.2553 *$ & 0.0763 \\
\hline FA & $2.8639 * *$ & 1.1645 \\
\hline ELEC_1 & 21.5336 & 22.2404 \\
\hline Constant & $-455.2612 *$ & 154.5269 \\
\hline R-square & 0.3748 & \\
\hline Chi-square & 0.000 & \\
\hline Numbers of observations & 26126 & \\
\hline Levels of significance: & & \\
& $*$ Significant to 1\%. & \\
& $* *$ Significant to 5\% & \\
\hline
\end{tabular}


As can be seen, the results obtained in the statistical model show the significance of the variables: level of investment spending (SI_PC), transfers for public works (CTF), GDP per capita (GDP_PC), population increase (POP), savings gross generated (GS_PC) and the entity's financial autonomy (AF).

However, the electoral variable was not significant, showing a positive sign in its coefficient. In the first place, the variable of the level of investment spending (SI_PC), understood as spending on public works, is significant, and its coefficient has a positive sign as expected, which indicates the use of debt in financing for public works. This evidence confirms the hypothesis raised and coincides with the conclusions of the works of Benito and Bastida (2005), Cabasés et al. (2007), Letelier (2010), SánchezGonzález (1998), Zafra-Gómez et al. (2011) and Pérez et al. (2014), who pointed out that investment spending positively influences debt.

The variable corresponding to capital transfers (CTF), a federal resource used exclusively for public works, is also significant and with a negative sign, which confirms the hypothesis, that is, a higher level of capital transfers for public works, represents for municipalities lower financing needs, which causes less appeal to financial indebtedness, as Benito and Bastida (2005) had shown for Spanish municipalities.

The GDP per capita was significant and with a negative sign, thus confirming a negative influence on the increase in debt. This result confirms that municipalities with lower GDP resort to debt to a greater extent as financial resource, derived from a low economic level. Some works, such as that of Bahl and Duncombe (1993), point out that the economic level of the entities negatively affects indebtedness.

In the population variable (POB), the results show that its growth has a positive impact on the recourse to debt, derived from the need for municipalities to face higher expenses. Likewise, it can be commented that the result obtained in the works of Mitchell (1967), Pogue (1970), Escudero and Prior (2002), Guillamón et al. (2011) and Pérez et al. (2014), shows a certain similarity, finding a positive relationship between the number of inhabitants and indebtedness municipal.

With regard to gross savings generated by municipalities (AHB), the variable is also significant in its coefficient negative sign, which confirms what we obtained in the states, that is, the higher the expenditure generated by the municipalities, the lower your savings and therefore, the greater your increase in debt.

These results confirm those obtained in the works by Brusca and Labrador (1988) who found that gross saving influences per capita indebtedness, that is, the lower the saving, the greater its indebtedness. It also confirms what was obtained by Pérez et al. (2014) in Spanish city councils, which indicated a negative correlation of this variable with indebtedness.

For the financial autonomy variable (AF), its sign is positive and also significant, which means that municipalities with greater own resources to finance their spending have greater indebtedness. In this result we cannot confirm our hypothesis, since the variable suggests that the relation of income own / current expenditure is positive. This result indicates that own resources do not guarantee the reduction of the need to resort to more liabilities to finance their spending.

The previous result coincides with that obtained by Fernández et al. (2004) and Pascual et al. (2008), who obtain coefficients with positive signs, so that they conclude that the municipalities that make the greatest effort to collect their own income tend to increase their indebtedness. However, Benito and Bastida (2005), measuring financial autonomy only through the collection capacity of direct and indirect taxes of the local entity, obtain a result that rejects the significance of this variable.

For the dichotomous variable elections (ELEC_1), its sign is positive, but not significant, so in principle it does not confirm our hypothesis and its influence on the increase in the level of debt of the municipalities. In any case, the positive sign could indicate that the municipalities of México increase their level of indebtedness due to the generation of public works one year before the elections.

In this context, it should be noted that the results show some differences in the expected signs, which suggests that we follow the line of research in future works, adding other factors. 


\subsubsection{Results for States}

In order to identify the possible problems that the estimates may present, the tests and statistical analysis will be carried out first in order to be able to propose the model that offers the best results. The results of the corresponding tests for states are presented in the following Table 27.

Table 27 Statistical results on the model to apply for the states

\begin{tabular}{|l|l|l|l|}
\hline \multicolumn{1}{|c|}{ Test } & \multicolumn{1}{c|}{ Test Statistics hypothesis } & \multicolumn{1}{c|}{ P Values } \\
\hline Test F $(30,426)=2.84$ & Prob $>\mathrm{F}=0.0000$ \\
\hline $\begin{array}{l}\text { Multiplier Test Lagrangian de } \\
\text { Breusch and Pay for Effects } \\
\text { Random (ER) }\end{array}$ & $\mathrm{H}_{\mathrm{o}}:=0$ Var $(\mathrm{u})=0$ & $\mathrm{Chi}_{2}(1)=7.81$ & $\begin{array}{l}\text { Prob> } \\
\text { Chi }_{2}=0.0052\end{array}$ \\
\hline Hausman & $\begin{array}{l}\mathrm{H}_{\mathrm{o}}: \text { Difference in Coefficients is not } \\
\text { Systematic }\end{array}$ & Chi $_{2}(4)=5.15$ & $\begin{array}{l}\text { Prob }_{2} \\
\text { Chi }_{2}=0.0273\end{array}$ \\
\hline
\end{tabular}

Source: Author's Own Elaboration

As can be seen, the $F$ test indicates that we can reject the null hypothesis of a common intercept (OLS), since the value of $\mathrm{P}$ is less than 5\%, that is, to model the individual character it is convenient to use the estimator EF versus the grouped model (OLS), which assumes that the differences between the states are constant or fixed.

Subsequently, we apply the Lagrangian, Breusch and Pagan multiplier test for random effects, with the same objective of verifying that the estimator is appropriate and therefore we can assume it. This test, as we observe, indicates that the null hypothesis is rejected, since the P value is less than 5\% and therefore, the best estimator is the EA model on the OLS.

To compare EF and EA and which model can give us better results, the Hausman test is applied. The result of this test indicates that it is not significant, suggesting that the hypothesis should not reject, that is, the difference between the coefficients of random effects is not systematic, for this reason, the EA estimator is better over the EF.

However, the result of applying the fixed effects or random effects model can cause problems of self-correlation and heteroscedasticity, so it is likely that in this case the presence of these problems causes that some of the variables may present weak values in their values. coefficients or non-significant values.

Considering the previous argument, it is necessary to contrast by means of statistical tests the presence of autocorrelation (not independence of errors) and heteroscedasticity (non-constant variance). In this sense, the Wooldridge (2010) test will be used for the case of autocorrelation and the Modified Wald test to detect heteroscedasticity. The results of both tests are shown in the following Table 28.

Table 28 Statistical results of self-relationship and heteroscedasticity for the states

\begin{tabular}{|l|l|l|l|}
\hline \multicolumn{1}{|c|}{ Test } & \multicolumn{1}{|c|}{ Null hypothesis Pest Statistics } & \multicolumn{1}{c|}{ P Values } \\
\hline Wooldridge & $\begin{array}{l}\mathrm{H}_{\mathrm{o}}:=\text { no autocorrelation of first } \\
\text { order }\end{array}$ & $\mathrm{F}(1,30)=310$ & $\mathrm{~F}=0.5815$ \\
\hline $\begin{array}{l}\text { Modificated Test of Wald for } \\
\text { heteroscedasticity }\end{array}$ & $\begin{array}{l}\mathrm{H}_{\mathrm{o}}: \sigma 2 i=\sigma 2 \text { for } \\
\text { all } i=1 \ldots N\end{array}$ & $\mathrm{Chi}_{2}(5)=2263.92$ & Prob> chi $=0.0000$ \\
\hline
\end{tabular}

Source: Author's Own Elaboration

As can be seen, the null hypothesis of the Wooldridge (2010) test is not rejected, since its $P$ value is greater than $5 \%$, concluding that the observations do not experience serial auto-correlation problems. However, when applying the Wald test, it is rejected at 95\%, that is, the $\rho$ value is less than 5\% significant, deducing that there is a presence of heteroscedasticity between the observations. 
To correct the heteroscedasticity problem, the Correct Standard Errors for Panel (PCSE) 35 estimators will be used, trying to offer with this model a better estimator that improves the reliability of the results. This type of model was used in some works, as was the case of Beck (2001), who demonstrated that this estimator is more accurate for this type of data. Therefore, we use the EEPC estimator for the analysis of the general equation for states (6), obtaining the results that appear in Table 29.

Table 29 PCSE model of estimation of to indebtedness, results for states

\begin{tabular}{|l|r|r|}
\hline \multicolumn{1}{|c|}{ Independent Variable } & \multicolumn{1}{|c|}{ Coeficient } & Standar error \\
\hline SI_PC & $0.4679^{*}$ & 0.0728 \\
\hline CTF & -0.0353 & 0.315 \\
\hline POP & $-89.8554 * *$ & 38.598 \\
\hline GDP_PC & $0.0048^{* *}$ & 0.0019 \\
\hline GS_PC & $-0.0801^{*}$ & 0.0311 \\
\hline FA & -0.0396 & 0.1468 \\
\hline ELEC_1 & $-98.7045^{* * *}$ & 59.9159 \\
\hline Constant & $1155.11^{* *}$ & 565.9495 \\
\hline R-square & 0.2999 & \\
\hline Chi-square & 0.000 & \\
\hline Numbers of observations & 464 & \\
\hline Levels of significance: & * Significant to $1 \%$. & \\
& ** Significant to 5\% & \\
& ** Significant to 10\% & \\
\hline
\end{tabular}

Source: Author's Own Elaboration

The results show us that a of 0.2999 is obtained, indicating that the model explains $29.99 \%$ of the total variation in the dependent variable.

On the other hand, the results of the statistical model show us that the variables that were significant were the level of investment spending (GSI_PC), population increase (POP), per capita (GDP_PC), gross savings generated (GSPC) and the dichotomous variable that represents the year prior to the election (ELEC_1).

The variable of the level of investment spending (GSI_PC), understood as spending on public works, presents a high level of significance, and also presents a coefficient with a positive sign, which confirms that the debt is used to finance public works, confirming with this our hypothesis and the conclusions of the works of Montemayor (2003), Benito and Bastida (2005), Cabasés et al. (2007), Letelier (2010), Sánchez Mier (2011), Zafra Gómez (2011), Pérez (2014) and Kinto (2014), who find that investment expenses positively influence indebtedness.

The variable corresponding to capital transfers received (CTF), a resource used exclusively for public works, was not significant, so in principle we cannot confirm its influence on the increase in the level of debt, however the sign was negative, which implies a reduction in indebtedness.

Regarding the population (POP), the results show that its growth has a negative influence on the increase in debt. This result in principle does not confirm our hypothesis, stating that the growth of the population in states does not seem to affect debt in a positive way, since it has a negative sign in its coefficient.

The variable of GDP with respect to the number of inhabitants (GDP_PC), is significant and has a positive sign, which makes it possible to verify that GDP positively conditions the resource of indebtedness, allowing to verify that the states with higher GDP, they resort to debt to a greater extent. This result confirms the consideration raised by Benito and Bastida (2005), that is, the greater the wealth of an entity, the greater the population's need, and it will lead to greater indebtedness.

3 Which for its acronym in English corresponds to the Panel Corrected Standard Errors (PCSE). 
Regarding the gross savings generated by the states (GS_PC), the variable is also significant in its coefficient negative sign, confirming that the lower the savings of the states, the greater their increase in debt. These results confirm those obtained in the works of Brusca and Labrador (1988), De Mello (2001), Benito and Bastida (2004), Fernández et al. (2004), Guillamón et al. (2011) and Pérez et al. (2014), who found that gross saving has a negative influence on the level of per capita debt, that is, the lower the saving, the greater its indebtedness.

For the financial autonomy variable (AF), its sign is negative and not significant, so in principle it does not confirm our hypothesis and furthermore, we cannot confirm its influence on the increase in the level of debt in the states.

In the election dummy variable (ELEC_1), its result is significant at 10\% but presented a negative sign, which in principle does not confirm our hypothesis. This result may support that state governments prefer not to indebt their states in the year prior to the election (Sánchez Mier, 2011), turning to other financial sources, because they understand that it does not represent a good presentation credential before the election (Vila i Vila, 2010), and that obviously can reduce the acceptance of its management.

\subsection{Discussion and conclusions}

In this last empirical work, we try to offer an analysis of the factors that explain the behaviour of the resource to state and municipal debt in México. To do this, variables such as budgetary, economic, population are used and the electoral cycle in the period from 2005 to 2014.

In this context, the statistics on the increase in debt in states and municipalities were first analysed in a general way, observing that the debt variable shows a gradual increase overall of 7.30 times from 2005 to 2014. This upward behaviour indicates serious problems for its liquidation and the relevance of its transfer to future generations during several budget cycles.

The results evidenced in this last empirical chapter were deduced considering the base that integrates information from 26,126 observations for municipalities, and 464 observations for states. These two bases specifically include budget indebtedness as a dependent variable and as an independent variables: investment spending, capital transfers, population increase, GDP per capita, gross savings per capita, financial autonomy and the electoral cycle measured through the year prior to the election, as the only dichotomous variable.

Based on the analysis of the previous literature, the hypotheses to be tested have been defined, which try to answer the question to determine what factors allow us to explain and demonstrate the increase in debt in the states and municipalities of México.

The main conclusion reached is that the results for both entities show that capital expenditures are the ones that most justify Population growth generates a gradual growth in debt. This result confirms our hypothesis and confirms the results obtained by Mitchell (1967), Pogue (1970) and Balaguer y Brun (2013).

On the other hand, the variable that measures gross saving, as an alternative source of financing, appears significant and with a negative sign for the two cases analysed, confirming our hypothesis, in addition to verifying the results obtained in the work of Brusca and Labrador (1988), who point out that gross saving influences the level of per capita debt, that is, the lower the saving, the greater the need to resort to borrowing.

For the financial autonomy variable, its sign is also different in the two regressions, although it was only significant for municipalities. In this line, the results for municipalities coincided with the results obtained by Fernández et al. (2004) and Pascual et al. (2008), which conclude that the municipalities that make the greatest effort to collect their income tend to increase their indebtedness. On the other hand, in the states the coefficient of the variable presented a negative sign but was not significant. In this case, it is observed that there is no significant influence on the growth of debt, as confirmed in their study by Benito and Bastida (2005). These results indicate that in the case of the states, given that there is a greater capacity to collect income through taxation, they reduce their need to resort to debt for public works. 
Regarding the dichotomous variable ELEC_1, the results in the two cases were different, that is, for the states the coefficient was negative and significant, and for municipalities it was positive, but not significant. The result in the states could support that governments try not to borrow in the year prior to the election by resorting to other financing to generate public works, pointing out, as the literature indicates, that it is not a good presentation credential before the election (Vila i Vila, 2010; Sánchez Mier, 2011). In the specific case of municipalities, the sign of its coefficient is positive, but the variable was not significant.

The evidence from this empirical work therefore allows us to verify that investment spending, both in states and in municipalities, is the factor that most justifies the increase in debt. The study also showed that the transfer system that the federal government assigns to local public finances also influences recourse to debt.

The results obtained in the study are like those obtained by other authors for other countries, and specifically for Spain (Escudero, 2002; Fernández et al., 2004; Benito et al., 2004; Benito and Bastida, 2005; 2008). Therefore, the behaviour of the indebtedness of the Mexican municipalities does not differ significantly from the behaviour that it has in other environments, and specifically from that which has been evidenced for the Spanish municipalities.

As a general conclusion, we have obtained evidence of the factors that allow us to explain the behaviour of state and municipal budgetary indebtedness in México, in a committed and difficult period in the country. However, it is necessary to continue advancing and working on the study, so we propose in the future to analyse new approaches that allow us to conclude new factors and a greater number of years. 


\section{Conclusions}

It is important to note that the purpose of the book is to show the different methodologies that are used to generate evidence of the budget cycle, spending and public debt, so a summary of the 3 types of techniques applied in this book is given.

In chapter 4 the empirical work used the panel data methodology (OLS; EF; EA), to make estimates on investment spending and current spending; Furthermore, we introduce a dummy variable to identify the year prior to the election and to control the influence of the electoral period in each regression. Likewise, the population increase was included as a variable, which will determine whether it affects the increase in total spending and its composition due to the demand that its increase generates in services, public works and infrastructure.

In addition, the model incorporates the vector, which aims to improve the efficiency of the results and, therefore, represents the inertia in the allocation of the composition of public spending. This autoregressive model that we proposed did not present for our analysis the robustness and reliability in the results to control the individual character of each state or of each municipality, causing errors in the estimates due to the unobservable effect that the suggested model presented, due to the delays of the dependent variable. To correct this problem, Arellano and Bond (1991) propose an estimator based on the Generalized Method of Moments (GMM), which uses instrumental variables based on lags and differences of all the variables in the model.

In Chapter 5, to contrast the hypotheses, a statistical model of type data is estimated panel, which will make it possible to improve the reliability of the estimates by working together with the information from all municipalities and states over time. The program used is Stata.

At first, the statistical model applied in this work corresponds to the grouped regression method OLS (ordinary least squares), a simple approach to analyse panel-type data, omitting the space and time dimensions of the grouped data, being a methodology studied and analysed in the works of Álvarez and Delgado (2006) and Drazen and Eslava (2005; 2008). In addition, since the nature of the bias of the variables that are not identified is not known, the Breusch-Pagan / Cook-Weisberg test will be used to verify the absence of heteroscedasticity, where, if the test is significant, we will proceed to calculate the estimator of Feasible Generalized Least Squares (MCGF), an option that allows us to correct the heteroscedasticity problem of the model for states and municipalities.

In Chapter 6, the methodology used to estimate the statistical model, both for states and municipalities, was that of panel data, where the observation unit varies in two dimensions, in crosssection and time series. This type of model makes it possible to improve the reliability of the estimates, since it notably expands the observations when working together with the information from all the analysis entities.

In particular, in this exercise both the fixed effects (FE) and the random effects (EA) models were considered to shape the individual character of each state or city council. In this sense, Sosa (1999) highlights the importance of discerning between the fixed and random effects models, which is possibly the most complicated problem in the implementation of a panel data model.

The decision to apply one model or another can be based strictly on questions of practical convenience, performing the so-called Hausman Test, which can be interpreted as a validity test of the random effects estimator. However, if the null hypothesis is rejected, that is, the difference between the fixed and random effects coefficients is systematic, then it is advisable to use the fixed effects estimator. In addition, different tests are used that give rise to other estimators, such as the autocorrelation and heteroscedasticity test specified in the following sections.

The main conclusions obtained in the different chapters of this doctoral thesis are set out below, the objective of which has been to analyse the effect of elections on the management of public spending and to what extent management can influence electoral results, given the possibility of that the government in power continues or is re-elected, followed by the analysis of the factors that allow explaining and demonstrating the behaviour of the public debt, from a theoretical and empirical point of view. 
In the chapter 4, we have tried to conceptualize the particularities of the public sector in México, defining its legal framework, based on the Political Constitution of the United Mexican States. Likewise, the sources and types of financing are analysed, which, in the face of the new modernization and public management schemes, today become stricter in their management and administration.

Faced with such a scenario, within the framework of the new public management, the Ministry of Finance and Public Credit (SHCP), required to modernize and update the management processes to make the administration of the resources obtained through indebtedness transparent, trying to limit the state and local authorities to contract debt unless the financed resources are destined to productive public investment projects. The financial problems of public administrations and the international context of modernization of management within the framework of the New Public Management have served as an impetus to carry out some administrative reforms in México, although to this day they are still unfinished and this process could be said to be more rhetorical than practical, since management it remains even closer to the traditional model than to that fostered by the New Public Management.

In the chapter 5, a theoretical review of the literature that frames the explanatory theories of the Political-Economic Cycles has been presented. Within the framework of electoral systems, the Theory of Economic Political Cycles, which emerged from the 1940s, tries to explain what incidents the economic cycles can have elections on the economy, either in traditional macroeconomic models or in the microeconomic behaviour of the different public administrations.

One of its variants that emerged in the 1970s, and with much presence today, is the Budgetary Political Cycle, which is based on the manipulation of fiscal policy instruments by opportunist rulers in electoral periods that they intend to continue in the can. Both models are framed from of the School of Public Choice (Public Choice), which analyses the connection between politics and economics, from the point of view of alteration of economic variables over time, which in turn are caused by the actions of economic agents in the sector public. In short, the Budgetary Political Cycle is the periodic fluctuation in the government's fiscal policies induced by the electoral period, constituted as a tool of opportunistic behaviour by the rulers in power. It has thus served as a frame of reference for numerous empirical works whose objective was explain the behaviour of the finances of public administrations.

This framework has been studied in different scenarios, such is the case of the fiscal illusion, where an approach with few or no restrictions for public debt stands out, which can in turn suppose a generational problem that can ultimately lead to deficits mainly in developing countries development, as is the case in México and some Latin American countries.

Another theoretical framework used to explain the behaviour of public finances is the agency theory, which highlights the approaches and conflicts of interest that arise from the various agents in an entity. Under this perception, this theory is applied in the politician-voter relationship, where the politician in power seeks the maximization of his own well-being, which implies the maximization of votes to favour his re-election or, the maximization of the privileges that may result of his job, as Buchanan (1967) maintain.

Furthermore, this approach assumes that economic agents (the voter as principal and the politician as agent), are rational agents and wish to maximize their own interest (Jensen and Meckling, 1976; Zimmerman, (1997), creating a subjectivity advantage of their political position.

Creative accounting could also be applied, which maintains that managers make use of the applicable discretion and subjectivity in the preparation of financial statements, to mislead their interpretation by users (Healy and Wahlen 1999). From this perspective, politicians would try to reflect that situation that may be more favourable to achieve their legitimacy, ultimately trying to maximize them interests and intentions to stay in power.

In the chapter 6, the first empirical work is presented, which presents a debate on the interest of the ruler in the manipulation of variables and instruments of a budgetary and fiscal nature within the framework of Political Budgetary Cycles. Likewise, the chapter includes previous works in which the development of Budgetary Political Cycles is analysed, which have shown evidence of the opportunistic behaviour of the fiscal policy variables, verifying the interest of the party in the government to use the variables to try to maximize your chances of being re-elected. 
The main objective of this third chapter is to analyse the effect of elections on budget management, trying to show whether or not there is an impact of the electoral cycle on the behaviour of public spending as a consequence of the interest of the political representative to maximize the possibility that the party in state or municipal government continues or is re-elected in power.

To carry out the empirical work, the 31 states and municipalities with a population of more than 50,000 inhabitants were taken as a sample, during the period 1996-2010. For municipalities we have had to eliminate entities at the municipal level with less than 50,000 inhabitants, since an important restriction of the estimator has been detected, verified by the Arellano and Bond test and the Sargan test of overidentification of instruments used in the work de Montero (2010).

The methodology of this first empirical chapter was based on the estimation of regressions using panel data to try to control the individual character of each state and of the municipalities, using the dynamic estimator of Arellano and Bond (1991), an estimator based on the Generalized Method of Moments (GMM), which uses instrumental variables based on delays and differences that will be validated by Sargan's test.

To carry out the analysis, three regressions were used, using three dependent variables (total expenditure/no. of inhabitants, investment expenditure / total expenditure and current expenditure/total expenditure), in addition to the explanatory variables of a budgetary, electoral and economic nature. population.

The results of this first empirical work have shown the existence of budgetary political cycles for the two entities analysed. Specifically, at the state level, elections cause increases in total spending per inhabitant, as well as investment spending and a contraction of current spending with respect to total spending. For municipalities with more than 50,000 inhabitants, the evidence of the political budget cycle was like that of the states, that is, there is an increase in total spending, investment spending and a contraction in current spending.

The results suggest for the two levels analysed an expansion of total spending, of spending on public works and infrastructure and a contraction of current spending, trying to seek benefits for the operator in power, which tries to show his policies, presenting an opportunistic behaviour pattern on the myopia of voters. This indicated the preference of politicians to use investment spending over current spending to influence voter behaviour.

For the population variable, the results indicate that it has a positive and significant influence only in the case of municipalities, since in the states its coefficient is not significant, so that an increase in the population has a positive impact on expenditures. On the other hand, both in states and in municipalities, when considering the total expenditure variable, the population presents a positive and significant sign, which indicates that it has a positive impact on the composition of public spending by the municipal government, as had been verified by Brusca et al. (2010) and Vicente et al. (2013) in their works for Spain.

Therefore, this first work has allowed us to verify the existence of budgetary political cycles in México, both at the state and local levels, observing the existence of CPP in total spending, and only in the municipalities was a significant relationship and positive between investment spending and population.

In the fourth chapter, the second empirical work is presented, the objective of which was to verify whether the budget management followed by the state or municipal governments in power causes any effect on the electoral result that could justify its manipulation before each election.

In this sense, as Downs (1978) points out, the decision to vote has an eminently prospective character, and the objective of any rational voter is to maximize its utility by electing the best of the candidates, that is, that the elections not only produce a surrender of accounts, but also, they are an instrument to select the best of the candidates. The problem of this assumption is due to rational and irrational expectations of the voter, indicated in different theories of business cycles, starting from the opportunist and partisan models of the seventies and eighties. 
The rational expectations model, to explain the final decision of the voter, admits the assumption of the existence of rationality of the population, which was addressed by Peltzman (1992), pointing out that the electorate penalizes those governments that increase public spending. However, there were also positions that affirmed the opposite, for example, the works that considered that the increase in public spending before the elections increases the possibility of re-election of the rulers.

For Latin America, the studies by Drazen and Eslava (2005) and Eslava (2005) indicated that the voter values the investment spending made by the incumbent in a better way, while current spending does not seem to influence the decisions of voters, which is in line with the results of chapter three and allows us to develop this work under those circumstances.

To verify whether or not there is a result of the actions carried out, we carried out an empirical analysis taking the number of votes of the party in power as a dependent variable, considering as explanatory variables the behaviour of the budget variables of expenditure and deficit, in addition to the electoral results of the previous elections.

The results obtained at the two levels indicated that higher spending on public works and government infrastructure can have a positive effect on their ability to remain in power, thus showing that there is a positive assessment of spending on electoral results, that is, that is, the electors of the states and of city councils, they reward governments that increase investment spending and thus contract current spending before the election.

Regarding the deficit, the results of the two regressions showed a negative sign, however, not significant, confirming that the effect it represents in the two models is irrelevant, indicating that in the states and municipalities of México it seems that it does not alter the continuity of the politician at the head of the government.

The conclusion of this chapter was that both the voters of the states and those of the municipalities have a special interest in the management carried out by the ruler, so that by increasing investment spending an effect can be achieved in the elections, since it is perceived in a positive way by the population, which justifies that the increase in spending indicated by the government and valued positively by the voter, is a practice that the governments of the states and municipalities of México carry out each election period.

This second empirical work therefore allows us to assess the effect of the presence and existence of CPP at the level of investment spending observed in the first empirical chapter, showing that the spending preferred by the voter is investment spending for the two levels of government, concluding that this expense increases the probability that the ruling party remains in power.

In the third and last empirical work, the aim was to explain the behaviour of indebtedness and analyse which variables allowed to explain the increase that takes place during each year.

Previously, the general context on indebtedness was addressed as an introductory part of the chapter, trying to justify from a normative point of view the recourse to indebtedness and its relationship with budgetary variables.

Likewise, we have carried out a review of the previous literature in which the determinants of indebtedness in different environments are analysed. Some studies show, at the European level, that the increase in debt is related to the electoral year, with factors of a budgetary nature, such as the increase in investment spending, capital income, population and GDP per capita.

On the other hand, the literature reveals a debate on the efficiency of debt limits, especially in the United States, analysing their behaviour with respect to the established regulations. In other words, for some, debt limitations did not achieve the objective, as governments vary their structure to avoid it. In a study that covered both the United States and developing countries, Ratcliffe (1979) show that in the United States the debt threshold is situated at $60 \%$ in the Debt/GDP ratio, given that its adaptation structure is significant to economic circumstances, while in Latin American countries, the threshold is $90 \%$, which shows that these countries depend mostly on the recourse to debt and therefore on greater financing due to their weak economic structure. 
In México, the literature analysed shows that the level of debt is increasing in relation to partisan support, noting that the party that wins the election and coincides with the government in power, increases the tendency to resort to indebtedness. However, the literature in the country is still scarce, which represents the opportunity of our work, trying to show the factors that intervene in the increase of debt in the states and municipalities of México.

In line with the literature analysed and to demonstrate the factors that explain the behaviour of the increase in debt, we apply the most appropriate statistical model based on the Hausman test, which determines whether the differences in the Fixed Effects and Random Effects model are systematic. and significant. However, even when determining the best estimator, the literature suggested detecting and controlling, where appropriate, the correlation and heteroscedasticity of the model, using the Modified Wooldridge (2010) and Wald test, to control the problems that may arise in the same sense of Baltagi (2008).

The results of the regressions showed that both in the states and in the municipalities the presence of heteroscedasticity is verified, suggesting that for the two cases the estimator of standard errors corrected for panel (EECP), proposed by Beck (2001), was the estimator more suitable for controlling problems in this type of data.

The estimates made using this model show, for the two entities, that capital expenditures are the ones that most justify the use of debt, confirming the hypothesis and adaptation to the Constitution's regulations. These results confirm the conclusions of Benito and Bastida (2005), Cabasés et al. (2007), Letelier (2010), Brusca et al. (2010), Sánchez Mier (2011), Guillamón et al. (2011), Pérez et al. (2014) and Kinto (2014) who pointed out in their works that capital expenditures positively and significantly influence indebtedness.

Regarding the financial resources they receive from the federation, that is, resources labelled for public works, only in municipalities was their result significant, which in this case causes less appeal to the increase in debt, in line with the results of Benito and Bastida (2005).

The per capita economic level, measured in relation to the Gross Domestic Product, was significant in both cases; however, for states its sign was positive and negative for municipalities. In this sense, for the states, the result shows that those entities with the highest GDP resort more to debt as financial resource, confirming the hypothesis raised, so that the economic level is positively related to the level of indebtedness, also confirming the results of Benito and Bastida (2005).

In the case of municipalities, it was significant and with a negative sign, thus confirming an influence negative on the increase in indebtedness and therefore does not confirm the hypothesis raised.

This result shows that those entities with a lower GDP resort more to debt as a financial resource, Regarding the incidence of the population, we observe that for both cases its coefficient was significant, however, it presented different signs, that is, positive for municipalities and negative for states.

These results show that only in municipalities does population growth influence indebtedness, which shows that when increasing the need to face higher expenses is generated, confirming the results of the works of Mitchell (1967), Pogue (1970), Escudero and Prior (2002), Guillamón et al. (2011) and Pérez et al. (2014).

The result of the gross savings variable confirms our hypothesis for both cases, that is, the lower the savings, the greater the need to resort to borrowing. These results are in line with what was obtained in Brusca and Labrador (1998), De Mello (2001), Benito and Bastida (2004), Fernández et al. (2004), Guillamón et al. (2011), Pérez et al. (2014) who found that gross saving has a negative influence on the level of per capita debt.

Regarding financial autonomy, its sign is positive and also significant, which suggests that municipalities with greater own resources to finance their spending have higher indebtedness. Along these lines, the results for municipalities coincided with the results obtained by Fernández et al. (2004) and Pascual et al.(2008), which conclude that the municipalities that make the greatest effort to collect their income tend to increase their indebtedness. 
On the other hand, in the states the coefficient of the variable presented a negative sign but was not significant. In that case, it is observed that there is no influence on the growth of the debt, as confirmed in their study by Benito and Bastida (2005). This may indicate that in the case of states, given that there is a greater capacity to collect income through taxation, they reduce their need to resort to debt for public works, situation contrary to that manifested by the municipalities.

Finally, regarding the behaviour of indebtedness in the electoral cycle, the results in the two cases were different, that is, for the states the coefficient was negative and significant, and for municipalities it was positive, but not significant. The result in the states could support that governments try not to borrow in the year prior to the election by resorting to other financial sources to generate public works, understanding as the literature indicates, that it is not a good presentation credential before the election (Vila i Vila, 2010; Sánchez Mier, 2011).

As we have indicated, the results we obtained in this study were generally like those obtained in some studies from other countries and specifically for Spain (Escudero, 2002 and 2003; Fernández et al., 2004; Benito et al., 2004; Benito and Bastida, 2005; 2008), which were a reference for our last empirical chapter.

Therefore, the behaviour of the indebtedness of the Mexican states and municipalities does not differ significantly from the behaviour that it has in other environments, and specifically from that which has been evidenced for the Spanish municipalities. The results provide us with an opportunity to add other factors in future research, which will allow us to determine new statistical models as far as possible, to improve the evidence regarding the explanatory factors for the increase in public debt in the state and municipal governments of México.

To finalize the conclusions, we would like to point out that this work constitutes a small contribution in the field of the behaviour of public finances supported by the theory of Budgetary Political Cycles and shows that even today politicians introduce opportunistic behaviours in the management of administrations to try to maximize their own interest, such as the number of votes obtained in elections.

In fact, our results show that there may be positive effects of these behaviours, which can be an incentive for policy makers to act. An important recommendation to reduce the size of political cycles and its effect is the implementation of management systems that are transparent and provide citizens with all kinds of information so that they can make informed decisions, a recommendation already collected in the literature in numerous studies, such as Caba et al. (2014).

This information should be considered both the positive and the negative of the public actions, and of the investments in public works that the government carries out, insofar as it is verified in the work, they are the main cause of the increase in indebtedness, which requires a strict control of the adequacy of the principles of economy, efficiency and effectiveness to the time to carry them out. 


\section{References}

Aghion, P., y Bolton, P. P. (1990). Government domestic debt and the risk of default: A politicaleconomic model of the strategic role of government debt. Public Debt Management: Theory and History. Cambridge University Press, NY.

Aidt, T. S., Veiga, F. J., y Veiga, L. G. (2011). Election results and opportunistic policies: a new test of the rational political business cycle model. Public choice, 148(1-2), 21-44.

Akhmedov, A., Ravichev, A., y Zhuravskaya, E. (2002). Regional Political Cycles in Russia. Center for Economic and Financial Research. http://pdc.ceu.hu/archive/00001617/

Akhmedov, A., y Zhuravskaya, E. (2004). Opportunistic political cycles: test in a young democracy setting. The quarterly journal of economics, 119(4), 1301-1338.

Alesina, A. (1987). Macroeconomic policy in a two-party system as a repeated game. The Quarterly Journal of Economics, 1(2), 651-678.

Alesina, A., Cohen, G. D., y Roubini, N. (1992). Macroeconomic policy and elections in OECD democracies. Economics y Politics, 4(1), 1-30.

Alesina, A. y Sachs, J. (1988). Political parties and the business cycle in the United States, 1948-1984. Journal of money, credit and bankin, political parties and the business cycle in the USA 1948-1984, $1(20)$.

Alesina, A., y Tabellini, G. (1988). Voting on the budget deficit. American Economic Review, 1(80), 3749.

Alesina, A., Perotti, R., Tavares, J., Obstfeld, M., y Eichengreen, B. (1998). The political economy of fiscal adjustments.Brookings Papers on Economic Activity, 1(2), 197-266.

Alesina, A., Ardagna, S., Perotti, R., y Schiantarelli, F. (1999). Fiscal policy, profits, and investment National Bureau of Economic. Research working papers. 7207.

Allers, M., De Haan, J., y Sterks, C. (2001). Partisan influence on the local tax burden in the Netherlands. Public Choice, 106(3-4), 351-363.

Álvarez, A. y Delgado, M. (2006). Manipulación Electoral del gasto público. Evidencia empírica de las provincias argentinas (1983-2002). Anales de la XLI Reunión Anual de la AAEP (Asociación Argentina de Economía Política), 15, 16 y 17 de noviembre de 2006, Ciudad de Salta, editado por la AAEP.

Arellano, M., y Bond, S. (1991). Some tests of specification for panel data: Monte Carlo evidence and an application to employment equations. The review of economic studies, 58(2), 277-297.

Arellano, M., y Bover, O. (1990). La econometría de datos de panel. Investigaciones Económicas (segunda época), 14(1), 3-45.

Arrow, K. (1951). Social choice and individual values. New York: Ed. Wiley.

Arvate, P. R., Avelino, G., y Tavares, J. (2009). Fiscal conservatism in a new democracy: "sophisticated" versus "naïve" voters. Economics Letters, 102(2), 125-127.

ASF. (2012). Análisis de la Deuda Pública de las Entidades Federativas y Municipios. Cámara de Diputados.

(2011). Análisis de Deuda Pública de las Entidades Federativas y Municipios, 2000-2011. Auditoría Superior de la Federación, Cámara de Diputados. 
Ayala, J. (2001). Economía del Sector Público Mexicano. México, Facultad de Economía, UNAM: Ed. Esfinge S. de R. L. de C. V.

Barber, W. R., y Sen, P. (1986). The political process and the use of debt financing by state governments. Public Choice, 48(3), 201-215.

Baker, S. H. (1983). The determinants of median voter tax liability: an empirical test of the fiscal illusion hypothesis. Public Finance Quartely, 1(11), pp. 95-108.

Balaguer, M., y Brun, M. (2013). El gasto público como determinante de la reelección de los gobiernos locales. Revista de Contabilidad-Spanish Accounting Review 1(16), 74-80.

Baltagi, B. (2008). Econometric analysis of panel data. Paperback.

Bahl, R., y Duncombe, W. (1993). State and local debt burdens in the 1980s: a study in contrast. Public Administration Review, 1(1),31-40.

Barro, R. J. (1979). On the determination of the public debt. The Journal of Political Economy, 1(1), 940-971.

Benito, B., y Bastida, F. (2004). The determinants of the municipal debt policy in Spain. Journal of Public Budgeting, Accounting and Financial Management, 16(4), 525-558.

(2005). Análisis del endeudamiento en los Ayuntamientos: un Estudio Empírico. Revista Española de Financiación y Contabilidad, 126(1), 613-636.

(2008). Política y gestión financiera municipal. Spanish Accounting Review, 11(2), 43-66.

Benito, L. B., Brusca, I. y Montesinos, V. J. (2004). Análisis del endeudamiento en las comunidades autónomas. Revista de contabilidad, 7(13), 85-112.

Benito, B., Vicente, C. y Bastida, F. (2013). Transparency and political budget cycles at municipal level. Swiss Political Science Review, 19(2), 139-156.

Bennett, J. T., y DiLorenzo, T. J. (1982). Off-budget activities of local government: the bane of the tax revolt. Public Choice, 39(3), 333-342.

Beck, N. (2001). Time-series-cross-section data: What have we learned in the past few years? Annual review of political science, 4(1), 271-293.

Beck, N. y Katz, J. (1995). What to do (and not to do) with time-series cross-section data, The American Political Science Review, 89(1), 634-647.

Black, D. (1948). On the rationale of group decision-making. The Journal of Political Economy, 1(2): 23-34.

(1958). The Theory of Committees and Elections, Cambridge: University Press.

Blasco, J. (1998). De la contabilidad creativa al delito contable. Partida Doble, (85), 33-39.

Blaug, M. (1985). Teoría económica en retrospección. México D.C.: Fondo de Cultura Económica.

Blewett, R. (1984). Off-budget activities of local government: comment. Public Choice, 42(2), 205-211.

Block, S. A. (2002). Political business cycles, democratization, and economic reform: the case of Africa. Journal of Development Economics, 67(1), 205-228.

Breeden, C. H., y Hunter, W. J. (1985). Tax revenue and tax structure. Public Finance Review, 13(2), 16-224. 
Brender, A. (2003). The effect of fiscal performance on local government election results in Israel: 1989998. Journal of Public Economics, 87(9), 2187-2205.

Brender, A., y Drazen, A. (2003). Where does the political budget cycle really come from? Social Science Research Network. CEPR Discussion Paper No. 4049.

(2005). Political budget cycles in new versus established democracies. Journal of monetary Economics, 52(7), 1271-1295.

(2008). How do budget deficits and economic growth affect re-election prospects? evidence from a large panel of countries. The American Economic Review, 2203-2220.

Brennan, G. y Buchanan, J. (1980). The power to tax: Analytical foundations of a fiscal constitution. NY. EEUU: Cambridge University Press.

Brown, K. W. (1996). Trends in key ratios using the GFOA financial indicators databases 1989-1993. Government Finance Review, 12(1), 30-34.

Brusca, I., y Labrador, M. (1998). Análisis del endeudamiento en las Corporaciones Locales. Revista de Hacienda Local, 28(84), 581-596.

Brusca, I., Montesinos, V. y Mora, L. (2012). El Endeudamiento como factor explicativo de la descentralización de servicios en los ayuntamientos españoles. Spanish Journal of Finance and Accounting/Revista Española de Financiación y Contabilidad, 41(153), 143-162.

Brusca, I., Labrador, M., y Montesinos, V. (2010). Elections and local government management. 33rd European Accounting Association Annual Congress, Istanbul (Turquois).

Brusca, I., y Montesinos, V. (2006). Are citizens significant users of government financial information? Public Money and Management, 26(4), 205-209.

------- (2005). The usefulness of local government financial reporting for citizens. Workshop of the CIGAR, St. Gallén.

Buchanan, J. M., y Wagner, R. E. (1977). Democracy in deficit. New York: Academic Press.

Buchanan, J. M. (1967). La Hacienda Pública en un contexto democrático. Ed. Aguilar, Madrid.

Buchanan, J. M., y Tullock, G. (1962). The calculus of consent: Logical Foundations of Constitutional democracy. Michigan: Press.

Bunch, B. S. (1991). The effect of constitutional debt limits on state governments uses of public authorities. Public Choice, 68(1-3), 57-69.

Caba, M., Rodríguez, M., y López, A. (2014). The determinants of government financial reports online. Transylvanian Review of Administrative Sciences, 1(42), 5-31.

(2010). Transparency and E-government in developing countries: The case of latinamerican municipalities. In C.G. Reddick (Ed.), Citizens and E-government: Evaluating Policy and Management: Evaluating Policy and Management. Herhsey, PA: Information Science Reference (IGI Glonal).

Caba, M y Hernández, A. (2007). Latin-American public financial reporting: recent and future development. Public administration and development, 27(2), 139-157.

Cabasés, F., Pascual, P., y Vallés, J. (2007). The effectiveness of institutional borrowing restrictions: empirical evidence from Spanish municipalities. Public Choice, 131(3-4), 293-313.

Calderón, J., Orozco, M. y Villegas, A. (2002). Situación Económica y política en México. 1er Foro de dialogo con la Sociedad Civil México-Unión Europea, 15-20. 
Cano, M. (2001). Análisis de la fiabilidad de la información contable: La contabilidad creativa. España: Prentice Hall.

Carpizo, C. (2012). Los efectos cruzados de la competencia política sobre el endeudamiento: un análisis empírico de la deuda estatal en México, 2003-2010. Revista de Finanzas Públicas. 4(8), 181-220.

Carrasco, D.; Buendía, D. y Navarro, A. (2011): El papel de la contabilidad analítica en el buen gobierno de la administración municipal. AECA: Revista de la Asociación Española de Contabilidad y Administración de Empresas, 1(95), 10-11.

Carrasco, D., Buendía, D., Navarro, A., Valencia, M., y Llorente, V. (2006). La evaluación de la eficiencia de los servicios públicos deportivos a través de modelos de cálculo de costes e indicadores de gestión. Revista de Administração e Contabilidade da Unisinos, 3(3), 311-320.

Carrasco, C. (2011). Inflation Targeting and Economic Performance: The Case of México. Panoeconomicus, 5(Special Issue), 675-692. Doi:10.2298/PAN1105675C

CEFP. (11 de junio de 2019). Obligaciones Financieras de las Entidades Federativas de México rimer Trimestre de 2019. Obtenido de Centro de estudios de las Finanzas Públicas: https://cefp.gob.mx/publicaciones/documento/2019/cefp0212019.pdf

Cerda, R., y Vergara, R. (2007). Business Cycle and Political Election Outcomes: New Evidence from the Chilean Democracy. Public Choice. 132(1 y 2), 125-136.

--------(2005). Government subsidies and political elections: evidence for Chile. Universidad Católica de Chile, No. 294, PUC.

CFI. (02 de september de 2021). What is the Economic Cycle? The fluctuating state of an economy from periods of economic expansion and contraction. Obtenido de Corporate Finance Institute: https://corporatefinanceinstitute.com/resources/knowledge/economics/economic-cycle/

Cioffi, M., Messina, G., y Tommasino, P. (2012). Parties, institutions and political budget cycles at the municipal level. Bank of Italy Temi di Discussione (Working Paper), 885, 38.

Clotfelter, C. T. (1976). Public spending for higher education: an empirical test of two hypotheses. Public Finance, 31(2), 177-95.

Cortés, J. (2003). El presupuesto como instrumento de gestión pública: del presupuesto por objetivos al presupuesto de recursos. Instituto Andaluz de Administración Pública. Tesis Doctoral. Palma de Mallorca, Universitat de las Illes Balears, España.

CONAPO. (2015). Consejo Nacional de Población. Recuperado el 20 de mayo de 2015, de http://www.conapo.gob.mx/

Consejo Nacional de Evaluacion de la Politica de Desarrollo Social [CONEVAL] (2018). Diagnóstico de objetivos e indicadores de los programas del ámbito social derivados del Plan Nacional de Desarrollo 2013-2018: estructuras de medición y vinculación con derechos y programas sociales. Consultado el 16 de junio de 2018. https://www.coneval.org.mx/informespublicaciones/documents/diagnostico-yobjetivos-pnd-2013-18.pdf

Coutino, A. (13 de september de 2018). The Political-Transition Business Cycle in México. Obtenido de Moody's Analitycs: www.alfredocoutino.com

Cukierman, A., y Meltzer, A. H. (1986). A theory of ambiguity, credibility, and inflation under discretion and asymmetric information. Econometrica: journal of the econometric society, 54(5), 1099-1128.

de la Cruz, C. (2004). La nueva gestión pública en México: un enfoque prospectivo para la toma de decisiones y la planeación estratégica del gobierno. Revista de Administración Pública, 1(110), 246-277. 
De Mello, L. R. (2001). Fiscal decentralization and borrowing costs: the case of local governments. Public Finance Review, 29(2), 108-138.

Diario Oficial de la Federación [DOF] (2018a). Ley de Coordinación Fiscal. Consultado el 25 de enero de 2015. http://www.diputados.gob.mx/LeyesBiblio/pdf/31_300118.pdf

------ (2018b). Leyes de Deuda Pública. Consultado el 25 de enero de 2015. http://www.diputados.gob.mx/LeyesBiblio/pdf/136_300118.pdf

(2018c). Ley general de contabilidad gubernamental. Consultado el 25 de enero de 2015. http://www.diputados.gob.mx/LeyesBiblio/pdf/LGCG_300118.pdf

------ (2013a). Programa para un Gobierno Cercano y Moderno, 2013 - 2018. Consultado el 25 de enero de 2015. http://www.dof.gob.mx/nota_detalle.php?codigo=5312420\&fecha=30/08/2013

------- (2013b). Plan nacional de desarrollo 2013-2018. Consultado el 25 de enero de 2015. http://www.dof.gob.mx/nota_detalle.php?codigo $=5299465 \&$ fecha $=20 / 05 / 2013$

Dornbusch, R., Fischer, S. y Startz, R. (1988). Macroeconomía. México: McGraw-Hill.

Downs, A. (1957a). Teoría económica de la democracia. Madrid: Aguilar.

(1978). Teoría económica de la acción política en una democracia. Revista Española de Economía, 8(2), 403-427.

Drazen, A. y Eslava, M. (2008). Electoral manipulation via voter-friendly spending: Theory and evidence. Journal of Development Economics, 92(1), 39-52.

(2005). Electoral manipulation via expenditure composition: theory and evidence. NBER Working Paper, 11085.

(2003). The political business cycle in Colombia on the National and Regional level, Archivos de Economía, No. 215. DNP.

Drazen, A. (2000). The political business cycle after 25 years. In NBER Macroeconomics Annual 2000, $1(15), 75-138$.

Dye, R. A. (1988). Earnings management in an overlapping generations model. Journal of Accounting Research, 26(2), 195-235. https://doi.org/10.2307/2491102

Escudero, P. (2002). Endeudamiento, descentralización de servicios y ciclos políticos presupuestarios: el caso de los ayuntamientos catalanes (Doctoral dissertation, Universitat Autònoma de Barcelona).

Escudero, P. y Prior, D. (2002). Endeudamiento y ciclos políticos presupuestarios: el caso de los ayuntamientos catalanes. Documents de Treball (Universitat Autònoma de Barcelona. Departament d'Economia de l'Empresa), (10), 10.

(2003). Análisis del Endeudamiento y Efectos de su Control en las Corporaciones Locales. IX Encuentro de Economía Pública, 7.

Eslava, M. (2017). Ciclos políticos de la política fiscal con votantes opuestos al déficit: el caso colombiano. El Trimestre Económico, 73(290), 289-336. https://doi.org/10.20430/ete.v73i290.546

-(2006). The political economy of fiscal policy: survey. Inter-American Development Bank, Working Paper 583.

(2005). Political budget cycles or voters as fiscal conservatives? Evidence from Colombia (No. 003343). Universidad de los Andes-CEDE. 
Farías, L. (2009). Normativa emitida por el Consejo Nacional de Armonización Contable (CONAC). Saltillo, Coahuila.

Farnham, P. (1985). Re-examining local debt limits: A disaggregated analysis. Southern Economic Journal, 51(4),1186-1201.

Fearon, J. (1999). Electoral accountability and the control of politicians: selecting good types versus sanctioning poor performance. In: A. Przeworski, S. C. Stokes, and B. Manin (Coord.). Democracy, accountability, and representation (page. 364). New York: Cambridge University Press.

Feld, L. P., y Kirchgässner, G. (2001a). Does Direct Democracy Reduce Public Debt Evidence from Swiss Municipalities. Public Choice, 109(3-4), 347-370.

(2001b). The political economy of direct legislation: direct democracy and local decisionmaking. Economic Policy, 16(33), 329-367.

Fernández de Mantilla, L., y Flores Pinilla, K. (2008). ¿Qué evalúa el ciudadano al momento de votar? Algunas apreciaciones desde el enfoque racional. Reflexión política, 10(19), 196-204.

Fernández-Llera, R., Cantarero Prieto, D., García Valiñas, M. y Pascual Sáez, M. (2004). Factores determinantes del endeudamiento de los Entes Locales: Una aplicación al caso español. In XI Encuentro de Economía Pública: [los retos de la descentralización fiscal ante la globalización] (p. 13).

Fitch. (5 de october de 2021). Decentralized Federalism' Supports Canadian Subnational Ratings. Obtenido de Fitch Ratings: https://www.fitchratings.com/research/international-publicfinance/decentralized-federalism-supports-canadian-subnational-ratings-05-10-2021

Fitch. (22 de junio de 2015). Fitch Ratings. Recuperado el 22 de junio de 2015, de http://www.fitchratings.mx/default.aspx

Frey, B., y Schneider, F. (1988). Politico-economic Models of Macroeconomic Policy: A Review of the Empirical Evidence', in Thomas D. Willett (ed.), Political Business Cycles.

(1981). The Political Economy of Money, Inflation and Unemployment, Chapter 9, Durham and London: Duke University Press, 239-75. International Library of Critical Writings in Economics, 79, 339.

(1978). A politico-economic model of the United Kingdom. The Economic Journal, 243-253.

Galli, E., y Rossi, S. P. (2002). Political budget cycles: the case of the Western German Länder. Public Choice, 110(3-4), 283-303.

Galli, E. y Villani, M. (2011). Public spending and budget cycles in the Italian regions: an empirical analysis. Journal of public finance and public choice.1(28), 167-177.

Gámez, C. (2006). The political cycle and the mexican economy (Doctoral dissertation, disertación doctoral, Monterrey, egade).

--------- (2010). El ciclo político y la economía mexicana. Universidad Autónoma de Nuevo León. ISBN 978-607-433-342-8. Volumen: I.

Gámez, C., y Amarillas, V. A. (2011). Política económica o economía política: el ciclo político presupuestal en México. Cofactor, II (3), 71-96.

Gámez, C., y Botello, J. (1987). La influencia del ciclo presidencial en la economía mexicana: un ejercicio econométrico con variables dummy. El dilema de la economía mexicana: Ensayos de interpretación, Ediciones de Cultura Popular-Universidad Autónoma Metropolitana, México, 215-232. 
Gámez, C., y Ibarra-Yúnez, A. (2009). El ciclo político oportunista y el gasto de los estados mexicanos. Gestión y política pública, 18(1), 39-65.

García, I., Prado, J. y Cuadrado, B. (2011). Do progressive goverments undertake different debt burdens? partisan vs. electoral cycles. Revista de Contabilidad, 14(1), 29-57.

García, R. and García, M. (2010). Managing for Development. Results at the InterAmerican. Development Bank. Consultado el 15 de febrero de 2014. https://publications.iadb.org/publications/english/document/Managing-for-Development-ResultsProgress-and-Challenges-in-Latin-America-and-the-Caribbean.pdf

Gemmell, N., Morrissey, O., y Pinar, A. (1999). Fiscal illusion and the demand for government expenditures in the UK. European journal of political economy, 15(4), 687-704.

González, I. (2012). Gasto y deuda pública en América Latina: Indicadores del sector público. Santiago de Chile: CEPAL.

González, M. (2002). Do changes in democracy affect the political budget cycle? Evidence from México. Review of Development Economics, 6(2), 204-224.

(2000). On elections, democracy and macroeconomic policy cycles. Department of Economics, Princeton University, Working Paper.

Griffiths, I. (1988). Contabilidad Creativa: cómo hacer que los beneficios aparezcan del modo más favorable. Ediciones Deusto.

Guillamón, M. D., Benito, B., y Bastida, F. (2011). Evaluación de la deuda pública local en España. Spanish Journal of Finance and Accounting/Revista Española de Financiación y Contabilidad, 40(150), 251-285.

Hagen, T. P., y Vabo, S. I. (2005). Political characteristics, institutional procedures and fiscal performance: Panel data analyses of Norwegian local governments, 1991-1998. European Journal of Political Research, 44(1), 43-64.

Healy, P. M., y Wahlen, J. M. (1999). A review of the earnings management literature and its implications for standard setting. Accounting horizons, 13(4), 365-383.

Hernández, J. (2011). Déficit público e incertidumbre: ¿causa, consecuencia o remedio de la inestabilidad financiera? Economía Informa, No. 369.

Hibbs, D. (1992). Partisan theory after fifteen years. European Journal of Political Economy, 8(3), 361373.

(1989). The political economy of industrial democracies. In: J. H. Nagel, Policy Analysis and Management (pp. 57-61). Pennsylvania, Maureen Pirog.

(1987). The american political economy: macroeconomics and electoral politics in the United States. Boston: Harvard University Press.

---------(1977). Political parties and macroeconomic policy. American political science review, 71(04), 1467-1487.

Instituto Mexicano para la Competitividad [IMCO]. (2021a). Índice de Competitividad Estatal 2021. Consultado el 20 de mayo de 2021. https://imco.org.mx/indices/

Instituto Nacional de Estadística y Geografía. [INEGI]. (2015). Consultado el 15 de mayo de 2015. http://www.inegi.org.mx/ 
Institute for Economic and Social Planning [ILPES] (2004). Las innovaciones en materia presupuestaria. Panorama de la Gestión Pública en América Latina. (LC/IP/L.243).

International Monetary Fund [IMF], (2012a). A survey of experiences with emerging market sovereign debt restructurings. Prepared by the Monetary and Capital Markets Department.

(2012b). Modernizing the Framework for Fiscal Policy and Public Debt Sustainability Analysis. prepared by the fiscal affairs department and the strategy, policy, and review department.

Jensen, M. C., y Meckling, W. H. (1976). Theory of the firm: managerial behavior, agency costs and ownership structure. Journal of financial economics, 3(4), 305-360.

Kalecki, M. (1943). Political aspects of full employment. The Political Quarterly, 14(4), 322-330.

Kalendiene, J., \& Petreikyte, R. (2013). Political budget cycles in EU. En E. Rennes (Ed.), The 7 th International Days of Statistics and Economics, (págs. 541-550). Prague. Obtenido de https://www.researchgate.net/publication/320839893_Political_budget_cycles_in_EU

Katsimi, M., y Sarantides, V. (2012). Do elections affect the composition of fiscal policy in developed, established democracies. Public Choice, 151(1-2), 325-362.

Khemani, S. (2004). The Political Economy of Equalization Transfers. International Center for Public Policy, Andrew Young School of Policy Studies, Georgia State University in its series International Center for Public Policy Working Paper Series, at AYSPS, GSU with number paper 413, pp. 15.

Kiewiet, D. R., y Szakaly, K. (1996). Constitutional limitations on borrowing: An analysis of state bonded indebtedness. Journal of Law, Economic and Organization, 12(1), 62-97.

Kinto, M. (2014). ¿Por qué se endeudan los gobiernos estatales en México? Centro de Estudios de las Finanzas Públicas. Recuperado el 30 de octubre de 2014. http://www.cefp.gob.mx/portal_archivos/convocatoria/pnfp2014/segundolugarpnfp2014.pdf

Klomp, J., y de Haan, J. (2009). Political budget cycles and election outcomes. Paper to the EEA-ESEM 2009. In www.eea-esem.com.

Kneebone, R. D., y McKenzie, K. J. (2001). Electoral and partisan cycles in fiscal policy: An examination of Canadian provinces. International Tax and Public Finance, 8(5-6), 753-774.

Kraemer, M. (1997). Electoral Budget Cycles in Latin America and the Caribbean: Incidence, Causes, and Political Futility (No. 4084). Inter-American Development Bank, Research Department.

Kuklinski, J. H., y West, D. M. (1981). Economic expectations and voting behavior in United States House and Senate elections. American Political Science Review, 75(02), 436-447.

Lago-Peñas, I., y Lago-Peñas, S. (2008). Explaining budgetary indiscipline: evidence from Spanish municipalities. Public Finance and Management, 8(1), 1-18.

Letelier, L. (2010). Theory and evidence of municipal borrowing in Chile. Public Choice, 146, 395-411.

Levaggi, R., y Zanola, R. (2003). Flypaper effect and sluggishness: evidence from regional health expenditure in Italy. International Tax and Public Finance, 10(5), 535-547.

Levitt, S. D. y Snyder, J. M. (1997). The impact of federal spending on House election outcomes. The Journal of Political Economy, 105(1) 30-53.

Lewis-Beck, M. S., y Skalaban, A. (1989). Citizen forecasting: can voters see into the future? British Journal of Political Science, 19(01), 146-153. 
Lindbeck, A. (1976). Stabilization policy in open economies with endogenous politicians. The American Economic Review, 66(2), 1-19.

López Uribe, M. D. (2013). Roads or Schools? Political Budget Cycles with different types of voters, MPRA Paper, No. 50529, University Library of Munich, Germany.

Losada, C. (1997). Procesos de modernización de las Administraciones Públicas: contenidos y estrategias de reforma. Gestión y Análisis de Políticas Públicas, 1(7), 95-102.

Lucas, R. E., y Stokey, N. L. (1983). Optimal fiscal and monetary policy in an economy without capital. Journal of monetary Economics, 12(1), 55-93.

MacRae, C. (1977). A political model of the business cycle. The Journal of Political Economy, 85(29, 239-263.

Magaloni, B. (2000). Institutions, Political Opportunism and Macroeconomic Cycles: México 19701998. Working Paper, Stanford University.

Manjhi, G., \& Mehra, M. (2019). Political transfer cycles from the centre to the states. Ensayos sobre política económica, 36(86), 207-241. Doi:https://doi.org/10.32468/espe.8604

McEachern, W. (1978). Collective decision rules and local debt choice: a test of the median-voter hypothesis. National Tax Journal, 31(2), 129-136.

Meltzer, A. H., y Richard, S. F. (1981). A rational theory of the size of government. The Journal of Political Economy, 914-927.

Metcalf, G. (1991). The role of federal taxation in the supply of municipal bonds: evidence from municipal governments. National Tax Journal, XLIV(4).

Metheny, N. (17 de octubre de 2021). Endgame: The Long-Term Debt Cycle. Obtenido de Wealthrise: https://www.wealthrisecapital.com/insights/endgame-is-a-name-depicting-the-end-of-this-most-recent

Milesi-Ferreti, G. (1995). Do good or do well? Public debt management in a twoparty economy. Economics and Politics, 7(1), 59-78.

Milesi-Ferretti, G. M., y Spolaore, E. (1994). How cynical can an incumbent be? strategic policy in a model of government spending. Journal of Public Economics, 55(1), 121-140.

Misiolek, W. S., y Elder, H. W. (1988). Tax structure and the size of government: An empirical analysis of the fiscal illusion and fiscal stress arguments. Public Choice, 57(3), 233-245.

Mitchell, W. (1967). The effectiveness of debt limits on state and local government borrowing The Bulletin, No. 45, New York University: Institute of Finance.

Montemayor, G. (2003). Determinantes del endeudamiento subnacional. Un estudio para los estados y municipios de México, 1993-1999. Ensayos Revista de Economía, 22(1), 35-88.

Montero, R. (2010). Panel dinámico. Documentos de Trabajo en Economía Aplicada. Universidad de Granada, España.

Monterrey, J. (1997). Entre la Contabilidad Creativa y el delito contable: la visión de la Contabilidad privada. Trabajo presentado en el V Seminario Carlos Cubillo, U. Autónoma de Madrid.

Moreno, J. (2007). Gasto público y elecciones: una explicación política de la asignación de los presupuestos municipales en México. Foro Internacional, 408-434.

Mueller, D. (1976). Public choice: A survey. Journal of Economic Literature, 14(2), 395-433. 
Musgrave, R. (1966). Principles of budget determination. In: Cameron, H. and Henderson, W (Eds), Public Finance Selected Readings. New York: Random House.

Naser, K. (1993). Creative financial accounting: its nature and use. Prentice Hall.

Nelder, J. and Wedderburn, R. (1972). Generalized Linear Models (GLM). Journal of the Royal Statistical Society: Series A (General). 135(3), 370-384.

Nordhaus, W. (1975). The political business cycle. The review of economic studies, 42(2), 169-190.

Nordhaus, W. D., Alesina, A., y Schultze, C. L. (1989). Alternative approaches to the political business cycle. Brookings papers on economic activity, 1(2), 1-68.

OECD. (2011). Estudios económicos de la OCDE: México 2011. Recuperado el 3 de julio de 2012, de OECD, publishing: http://dx.doi.org/10.1787/9789264115934-es

-------- (2015). Estudios económicos de la OCDE: México 2015. Recuperado el 18 de junio de 2015, de http://www.oecd.org/economy/surveys/MéxicoOverview-2015\%20Spanish.pdf.

Oszlak, O. (1999). Quemar las naves (o cómo lograr reformas estatales irreversibles). In Trabajo presentado al IV Congreso Internacional del CLAD, México (p. 7).

Pacto por México (2013). Adéndum al Pacto por México. Recuperado el 3 de diciembre de 2014, de http://pactoporMéxico.org/adendum-al-pacto-por-México/

Pascual, P., Cabasés, F., y Roberto, R. (2008). Financiación, restricciones institucionales y endeudamiento: Un análisis con microdatos de los municipios de Navarra. XV Encuentro de economía pública, 7.

Peacock, A. T., y Wiseman, J. (1979). Approaches to the analysis of government expenditure growth. Public Finance Review, 7(1), 3-23.

Peltzman, S. (1992). Voters as fiscal conservatives. The Quarterly Journal of Economics, 327-361.

Pérez, G., Plata, A. M., Zafra, J. y López, A. M. (2013). Municipal debt within a situation of economic crisis: key factors and management methods. Spanish Journal of Finance and Accounting, 16(2). 83-93.

(2014). Operaciones fuera de presupuesto (off budget), factores políticos y deuda municipal: Un estudio empírico aplicando una metodología de datos de panel. Gestión y política pública, 23(1), 185218.

Pérez-Cruz, O., Nande-Vázquez, E., \& Martínez-Verdugo, J. (2021). Public Expenditure Management and Political Budget Cycles: The Case of Colima City Council 2009-2018. International Journal of Economics and Finance, 13(4), 40-46. doi:https://doi.org/10.5539/ijef.v13n4p40.

Perez-Cruz, O., Nande-Vazquez, \& Martines-Verdugo. (2020). The economic policy cycle and public debt in México. A retrospective analysis of 2012-2016 period. Journal of Social Researches, 6(17), 2231. doi:10.35429/JSR.2020.17.6.22.31

Pérez-Cruz, O. (2018). Gobernanza y gobierno electrónico. Análisis del ciclo de integración en el H. Congreso del Estado de Colima. Revista de Estudios en Contaduría, Administración e Informática, RECAI, 7(18), 1-21. Obtenido de https://recai.uaemex.mx/article/view/9244

Perez-Cruz, O. (2016). Procesos de desarrollo económico y sociocultural en México durante el siglo XX. Colima: U de C. Obtenido de http://ww.ucol.mx/content/publicacionesenlinea/adjuntos/Procesos-dedesarrollo-(ISBN)_430.pdf 
Pérez-Cruz, O. (2015). PyME’s Mexicanas: Impacto de la Primera Crisis Global del Siglo XXI. RECAI Revista de Estudios en Contaduría, Administración e Informática. 4(9): 1-4. https://recai.uaemex.mx/article/view/8902

Persson, T., y Svensson, L. E. (1989). Why a stubborn conservative would run a deficit: Policy with time-inconsistent preferences. The Quarterly Journal of Economics, 325-345.

Persson, T., y Tabellini, G. E. (1990). Macroeconomic policy, credibility and politics (Vol. 38). Taylor y Francis.

(2002). Do electoral cycles differ across political systems? Stockholm University.

Piñeiro, A. (2019). Política y economía: Un análisis del caso español para el período democrático 9772017. Coruña: Universidad de Coruña.

Poghosyan , T., \& Akitoby, B. (2015). How Do Public Debt Cycles Interact with Financial Cycles? nternational Monetary Fund, 248(1), 1-33. doi:https://doi.org/10.5089/9781513511641.001

Pogue, T. (1970). The effect of debt limits: some new evidence. National Tax Journal, 23(1), 36-49.

Pommerehne, W. y Schneider, F. (1978). Fiscal illusion, political institutions, and local public spending. Kyklos, 31(3), 381-408.

Pollitt, C. (2002). Convergence: The Useful Myth? Public Administration, 79(4), 933-947.

Price, S. (1997). Political business cycles and macroeconomic credibility: a survey. Public Choice, 92(34), 407-427.

Przeworski, A. (1998). Acerca del diseño del Estado: una perspectiva principalagente. Lecturas sobre el Estado y las políticas públicas: Retomando el debate de ayer para fortalecer el actual, 143.

Przeworski, A. y Stokes, S. (1995). Citizen information and government accountability: what must citizens know to control politicians? Paper prepared for delivery at the 1995 Annual Meeting of the American Political Association, The Chicago Hilton, August 31-September 1.

Ramírez, A. (2003). Evidencia empírica acerca de los determinantes políticos e institucionales del endeudamiento municipal en México. Gaceta de Economía, 9(17), 119-139.

Ramírez, R. y Erquizio, E. A. (2012). Análisis del ciclo político electoral a partir de variables de gasto público por entidad federativa en México, 1993-2009. Revista de Economía Regional y Sectorial. 4(2), 5-27.

Ratcliffe, T. (1979). Financial reporting framework for accounting in the public sector. The Government Accountants Journal, 44-52.

Rogoff, K. (1990). Equilibrium political budget cycles. American Economic Review, 80 (1), 21-36.

Rogoff, K., y Sibert, A. (1988). Elections and Macroeconomic Policy Cycles. The Review of Economic Studies, 55(1), 1-16.

Rosenberg, J. (1992). Rationality and the political business cycle: The case of local government. Public choice, 73(1), 71-81.

Sakurai, S. N., y Menezes-Filho, N. A. (2008). Fiscal policy and re-election in Brazilian municipalities. Public Choice, 137(1-2), 301-314.

(2011). Opportunistic and partisan election cycles in Brazil: new evidence at the municipal level.

Public Choice, 148(1-2), 233-247. 
Samuelson, P., y Nordhaus, W. (1992). Economía, Centro de Investigación y Docencia Económicas (CIDE): McGraw-Hill.

Sánchez-González, J. (1998). Administración pública y reforma del Estado en México. México: Instituto Nacional de Administración Pública (INAP).

Sánchez-Mier, M. (2011). Endeudamiento y ciclo político-presupuestario: aplicación a los municipios asturianos. Presupuesto y Gasto Público, 65(1), 75-96.

Sargan, J. (1964). Wages and prices in the United Kingdom: a study in econometric methodology. Econometric analysis for national economic planning, 16(1), 25-54.

Shadbegian, R. J. (1999). The effect of tax and expenditure limitations on the revenue structure of local government, 1962-87. National Tax Journal, 1(2)221-237.

Schipper, K. (1989). Commentary on earnings management. Accounting horizons, 3(4), 91-102.

Schneider, J. S. (2003). Competencia electoral con dos niveles de gobierno. Un rol activo para la oposición. Universidad del Cema, Buenos Aires, Argentina.

Schuknecht, L. (1996). Political business cycles and fiscal policies in developing countries. Kyklos, 49(2), 155-170.

Sedmihradská, L., Kubík, R., y Haas, J. (2011). Political business cycle in Czech municipalities. Prague Economic Papers, 1(2), 59-70.

Seitz, H. (2000). Fiscal policy, deficits and politics of subnational governments: The case of the German Laender. Public Choice, 102(3-4), 183-218.

Selume, N. (2007). Ciclos en la composición del gasto municipal y retorno electoral. PUC. Tesis de Magíster en Economía. Chile.

Shi, M., y Svensson, J. (2000). Political business cycles in developed and developing countries. The World Bank Working Paper.

-------- (2003). Political budget cycles: a review of recent developments. Nordic Journal of Political Economy, 29(1), 67-76.

(2006). Political budget cycles: do they differ across countries and why? Journal of public economics, 90(8), 1367-1389.

Smith, H. (2015). Now for Public Debt in México: Policy Lessons for the Effective Oversight of State and Municipal Government Finances. Obtenido de Wilson Center. México Institute: https://www.wilsoncenter.org/sites/default/files/media/documents/publication/now_for_public_debt_in _México_policy_lessons_for_the_effective_oversight_of_state_and_municipal_government_finances.p $\overline{\mathrm{df}}$

Sosa, E. W. (1999). Tópicos de econometría aplicada (Notas de Clase). Trabajo Docente No. 2, Universidad Nacional de La Plata, 1-78.

Standard and Poor's (2018). Standard and Poor's, rating services. Recuperado el 27 de marzo de 2015, spglobal.com/ratings/es/pdf-articles/2019-01-22-documento-de-orientacion-criterios-gobiernossoberanos-metodologia-de-calificaciones-soberanas

Suharnoko, B., Kis-Katos, K., y Schulze, G. (2013). Political budget cycles in local Indonesia. Economics Letters, 120(2), 342-345.

Suleiman, E. (2000). ¿Es Max Weber realmente irrelevante? Gestión y Análisis de Políticas Públicas, 1(17-18), 3-17. 
Tellier, G. (2006). Public expenditures in Canadian provinces: an empirical study of politico-economic interactions. Public Choice, 126(3-4), 367-385.

Tufte, E. R. (1980). Political control of the economy. Princeton University Press.

Vallés, J. (2002). Un modelo explicativo de las causas del endeudamiento autonómico. El impacto de los límites de la ley orgánica de financiación de las comunidades autónomas. Revista Galega de Economía, $11(1), 1-18$.

Vallés, J., Cabasés, F., y Pascual, P. (2005). Un análisis con microdatos de la normativa de control del endeudamiento local. Papeles de trabajo del Instituto de Estudios Fiscales, Serie Economía, 1(8), 5-51.

Vargas, H. J. (2005). Teoría de la agencia. Revista Digital Universitaria, UNAM, 6(8).

Vásquez Ruíz, H. A., Rivas Cueto, R., y Díaz Hernández, R. (2013). Evidencia sobre el ciclo políticoeconómico en la República Dominicana. Ciencia y Sociedad, 38(2), 293-320.

Veiga, L., y Veiga, F. (2007). Political business cycles at the municipal level. Public Choice, 131(1-2), 45-64.

(2007b). Does opportunism pay off? Economics Letters, 96(2), 177-182.

Vergne, C. (2009). Democracy, elections and allocation of public expenditures in developing countries. European Journal of Political Economy, 25(1), 63-77.

Vicente, C., Ríos, A., y Guillamón, M. (2013). Voting behavior and budget stability. Revista de Contabilidad, 16(1), 46-52.

Vila i Vila, J. (2010). Endeudamiento, gastos de inversión, y ciclo político presupuestario en las haciendas locales: el caso de los ayuntamientos valencianos. In XVII Encuentro de Economía Pública: Políticas públicas ante la crisis (p. 82).

(2012). El endeudamiento de los municipios ¿Una cuestión de comportamiento político? Presupuesto y Gasto Público, 1(66), 199-216.

Von Hagen, J. (1991). A note on the empirical effectiveness of formal fiscal restraints. Journal of Public Economics, 44(2), 199-210.

Wagner, R. E. (1976). Revenue structure, fiscal illusion, and budgetary choice. Public choice, 25(1), 4561.

Watts, R. L., y Zimmerman, J. L. (1986). Positive accounting theory. Prentice Hall.

(1978). Towards a positive theory of the determination of accounting standards. Accounting review, 1(53), 112-134.

Wicksell, K. (1964). A new principle of just taxation. En R. Musgrave, y R. Peacock, Classics in the Theory of Public Finance (págs. pp. 72-18). NY. EEUU: St. Martin's Press.

Wooldridge, J. M. (2010). Econometric Analysis of Cross Section and Panel Data. The MIT Press.

Zafra-Gómez, J. L., López-Hernández, A. M., y Hernández-Bastida, A. (2009). Developing an alert system for local governments in financial crisis. Public Money y Management, 29(3), 175-181.

(2010). Factores Determinantes de la deuda viva en los ayuntamientos. Una aplicación al caso español. Asociacion Española de Contabilidad y Administracion de Empresas, 129F, pp. 18. 
(2011). Influencia de los factores económico-financieros, políticos y de las formas de gestión sobre el nivel de la deuda viva en las entidades locales usando una metodología de datos de panel. XVIII Encuentro de Economía Pública, Málaga.

Zimmerman, J. L. (1977). The municipal accounting maze: An analysis of political incentives. Journal of Accounting Research, 1(2), 107-144. 


\section{[[Title in Times New Roman and Bold No. 14 in English and Spanish]}

Surname (IN UPPERCASE), Name $1^{\text {st }}$ Author ${ }^{*}$, Surname (IN UPPERCASE), Name $1^{\text {st }}$ Coauthor, Surname (IN UPPERCASE), Name $2^{\text {nd }}$ Coauthor and Surname (IN UPPERCASE), Name $3^{\text {rd }}$ Coauthor

Institution of Affiliation of the Author including dependency (in Times New Roman No.10 and Italics)

$\underline{\text { International Identification of Science - Technology and Innovation }}$

ID $1^{\text {st }}$ Author: (ORC ID - Researcher ID Thomson, arXiv Author ID - PubMed Author ID - Open ID) and CVU $1^{\text {st }}$ author: (Scholar-PNPC or SNI-CONACYT) (No.10 Times New Roman)

ID $1^{\text {st }}$ Coauthor: (ORC ID - Researcher ID Thomson, arXiv Author ID - PubMed Author ID - Open ID) and CVU $1^{\text {st }}$ coauthor: (Scholar or SNI) (No.10 Times New Roman)

ID $2^{\text {nd }}$ Coauthor: (ORC ID - Researcher ID Thomson, arXiv Author ID - PubMed Author ID - Open ID) and CVU $2^{\text {nd }}$ coauthor: (Scholar or SNI) (No.10 Times New Roman)

ID $3^{\text {rd }}$ Coauthor: (ORC ID - Researcher ID Thomson, arXiv Author ID - PubMed Author ID - Open ID) and CVU $3^{\text {rd }}$ coauthor: (Scholar or SNI) (No.10 Times New Roman)

(Report Submission Date: Month, Day, and Year); Accepted (Insert date of Acceptance: Use Only ECORFAN)

Citation: First letter (IN UPPERCASE) of the Name of the 1st Author. Surname, First letter (IN UPPERCASE) of the First Coauthor's Name. Surname, First letter (IN UPPERCASE) of the Name of the 2nd Co-author. Surname, First letter (IN UPPERCASE) of the Name of the 3rd Co-author. Last name

Institutional mail [Times New Roman No.10]

First letter (IN UPPERCASE) of the Name Publishers. Surnames (eds.) Title of the Books [Times New Roman No.10], Selected Topics of the corresponding area (C ECORFAN- Subsidiary, Year. 


\section{Abstract (In English, 150-200 words)}

Text written in Times New Roman No.12, single space

\section{Keywords (In English)}

Indicate 3 keywords in Times New Roman and Bold No. 12

\section{Introduction}

Text in Times New Roman No.12, single space.

General explanation of the subject and explain why it is important.

What is your added value with respect to other techniques?

Clearly focus each of its features

Clearly explain the problem to be solved and the central hypothesis.

Explanation of sections Chapter.

\section{Development of headings and subheadings of the chapter with subsequent numbers}

[Title No.12 in Times New Roman, single spaced and bold]

Products in development No.12 Times New Roman, single spaced.

\section{Including graphs, figures and tables-Editable}

In the Chapter content any graphic, table and figure should be editable formats that can change size, type and number of letter, for the purposes of edition, these must be high quality, not pixelated and should be noticeable even reducing image scale.

[Indicating the title at the bottom with No.10 and Times New Roman Bold]

Table 1.1 Title

\begin{tabular}{|l|l|l|}
\hline Variable & Descripción & Valor \\
\hline $\mathrm{V}_{\mathrm{V}}$ & Volumen de Venta & 20000 \\
\hline $\mathrm{P}_{\mathrm{V}}$ & Postura de venta & 490.61 \\
\hline $\mathrm{V}_{\mathrm{C}}$ & Volumen de Compra & 20000 \\
\hline $\mathrm{P}_{\mathrm{c}}$ & Postura de Compra & 485.39 \\
\hline $\mathrm{P}^{\mathrm{Uh}}$ & Precio último Hecho & 491.61 \\
\hline $\mathrm{V}_{\mathrm{O}}$ & Volumen Operado & 1241979 \\
\hline $\mathrm{P}_{\mathrm{u}}$ & Precio/Utilidad & 0 \\
\hline $\mathrm{P}^{\mathrm{VL}}$ & Precio/Valor Libro & 0 \\
\hline $\mathrm{U}_{\mathrm{a}}$ & Utilidad p/Acción & 0 \\
\hline $\mathrm{V}^{\mathrm{La}}$ & Valor Libro p/Acción & 0 \\
\hline
\end{tabular}

Source (in italics)

Should not be images-everything must be editable. 
Figure 1.1 Title

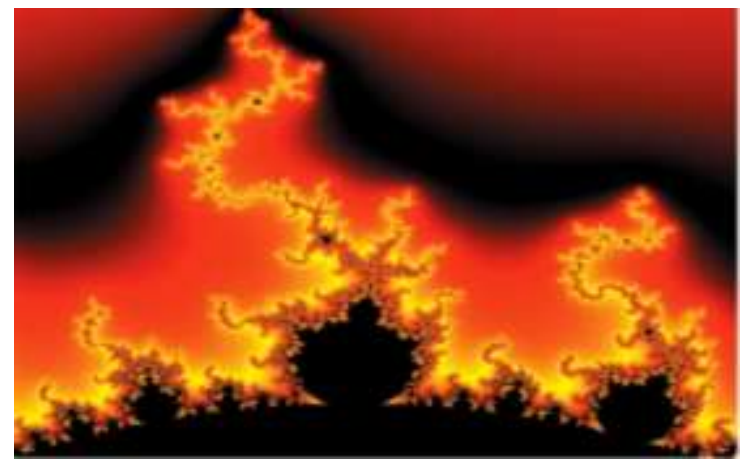

Source (in italics)

Should not be images-everything must be editable.

Graphic 1.1 Title

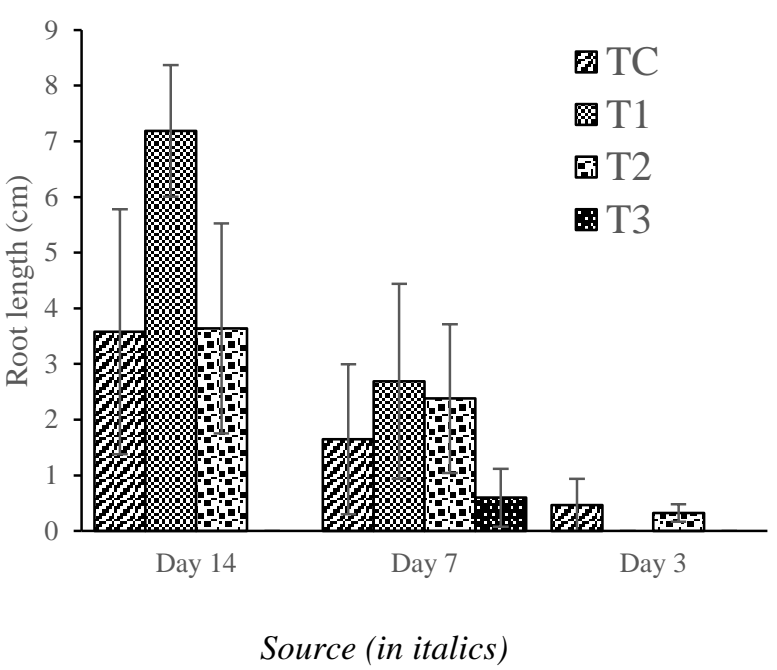

Should not be images-everything must be editable.

Each chapter shall present separately in $\mathbf{3}$ folders: a) Figures, b) Charts and c) Tables in .JPG format, indicating the number and sequential Bold Title.

For the use of equations, noted as follows:

$\int_{\lim ^{-1}}^{l i m^{1}}=\int \frac{\lim ^{1}}{\lim ^{-1}}=\left[\frac{1(-1)}{\lim }\right]^{2}=\frac{(0)^{2}}{\lim }=\sqrt{\lim }=0=0 \rightarrow \propto$

Must be editable and number aligned on the right side.

\section{Methodology}

Develop give the meaning of the variables in linear writing and important is the comparison of the used criteria.

\section{Results}

The results shall be by section of the Chapter.

\section{Annexes}

Tables and adequate sources 


\section{Thanks}

Indicate if they were financed by any institution, University or company.

\section{Conclusions}

Explain clearly the results and possibilities of improvement.

\section{References}

Use APA system. Should not be numbered, nor with bullets, however if necessary numbering will be because reference or mention is made somewhere in the Chapter.

Use Roman Alphabet, all references you have used must be in the Roman Alphabet, even if you have quoted an Chapter, book in any of the official languages of the United Nations (English, French, German, Chinese, Russian, Portuguese, Italian, Spanish, Arabic), you must write the reference in Roman script and not in any of the official languages.

\section{Technical Specifications}

Each chapter must submit your dates into a Word document (.docx):

Books title

Chapter title

Abstract

Keywords

Proceedings sections, for example:

\section{Introduction}

2. Description of the method

3. Analysis from the regression demand curve

4. Results

5. Thanks

6. Conclusions

7. References

Author Name (s)

Email Correspondence to Author

References

\section{Intellectual Property Requirements for editing:}

- $\quad$ Authentic Signature in Color of Originality Format Author and Coauthors

- Authentic Signature in Color of the Acceptance Format of Author and Coauthors 


\section{Reservation of Editorial Policy}

ECORFAN Books reserves the right to make the editorial changes required to adapt the Scientific Work to the Editorial Policy of ECORFAN Books. Once the Scientific Work is accepted in its final version, ECORFAN Books will send the author the proofs for its revision. ECORFAN® will only accept the correction of errata and errors or omissions arising from the publication process of the journal, reserving in its entirety the copyright and content dissemination. No deletions, substitutions or additions that alter the formation of the Scientific Work will be accepted.

\section{Code of Ethics - Good Practices and Declaration of Solution to Editorial Conflicts}

Declaration of Originality and unpublished character of the Scientific Work, of Authorship, on the obtaining of data and interpretation of results, Acknowledgments, Conflict of interests, Assignment of rights and distribution.

The ECORFAN-Mexico, S.C Directorate asserts to the Authors of the Scientific Work that its content must be original, unpublished and of Scientific, Technological and Innovation content to be submitted for evaluation.

The Authors signing the Scientific Work must be the same that have contributed to its conception, realization and development, as well as the obtaining of data, interpretation of the results, its writing and revision. The Correspondent Author of the proposed Scientific Work will request the form that follows. Title of the Scientific Work:

- $\quad$ The sending of a Scientific Work to ECORFAN Books emanates the commitment of the author not to submit it simultaneously to the consideration of other serial publications for it must complement the Format of Originality for its Scientific Work, unless it is rejected by the Arbitration Committee, may be withdrawn.

- $\quad$ None of the data presented in this Scientific Work has been plagiarized or invented. The original data are clearly distinguishable from those already published. And you have knowledge of the test in PLAGSCAN if a level of plagiarism is detected Positive will not proceed to arbitrate.

- $\quad$ References are cited on which the information contained in the Scientific Work is based, as well as theories and data from other previously published Scientific Works.

- $\quad$ The authors sign the Authorization Form for their Scientific Work to be disseminated by means that ECORFAN-Mexico, S.C. in its Holding Mexico consider relevant for the dissemination and dissemination of its Scientific Work by giving up its Scientific Work Rights.

- $\quad$ The consent of those who have provided unpublished data obtained by verbal or written communication has been obtained, and such communication and authorship are adequately identified.

- $\quad$ The Author and Co-Authors who sign this work have participated in its planning, design and execution, as well as in the interpretation of the results. They also critically reviewed the paper, approved its final version and agreed with its publication.

- No signature responsible for the work has been omitted and the criteria of Scientific Authorization are satisfied.

- $\quad$ The results of this Scientific Work have been interpreted objectively. Any result contrary to the point of view of those who sign is exposed and discussed in the Scientific Work. 


\section{Copyright and Access}

The publication of this Scientific Work entails the transfer of the copyright to ECORFAN-Mexico, SC in its Mexico Holding for its ECORFAN Books, which reserves the right to distribute on the Web the published version of the Scientific Work and the making available of the Scientific Work in this format supposes for its Authors the fulfillment of what is established in the Law of Science and Technology of the United States of Mexico, regarding the obligation to allow access to the results of Scientific Research.

Title of the Scientific Work:

\begin{tabular}{|l|l|}
\hline Name and surnames of the Contact Author and the Coauthors & Signature \\
\hline 1. & \\
\hline 2. & \\
\hline 3. & \\
\hline 4. & \\
\hline
\end{tabular}

\section{Principles of Ethics and Declaration of Solution to Editorial Conflicts}

\section{Publisher Responsibilities}

The Publisher undertakes to guarantee the confidentiality of the evaluation process, it may not disclose to the Arbitrators the identity of the Authors, nor may it reveal the identity of the Arbitrators at any time.

The Editor assumes the responsibility of properly informing the Author of the phase of the editorial process in which the text is sent, as well as the resolutions of Double Blind Arbitration.

The Editor must evaluate the manuscripts and their intellectual content without distinction of race, gender, sexual orientation, religious beliefs, ethnicity, nationality, or the political philosophy of the Authors.

The Editor and his editing team of ECORFAN $®$ Holdings will not disclose any information about the Scientific Work sent to anyone other than the corresponding Author.

The Editor must make fair and impartial decisions and ensure a fair peer arbitration process.

\section{Responsibilities of the Editorial Board}

The description of the processes of peer review is made known by the Editorial Board in order that the Authors know the evaluation criteria and will always be willing to justify any controversy in the evaluation process. In case of Detection of Plagiarism to the Scientific Work the Committee notifies the Authors for Violation to the Right of Scientific, Technological and Innovation Authorization.

\section{Responsibilities of the Arbitration Committee}

The Arbitrators undertake to notify about any unethical conduct by the Authors and to indicate all the information that may be reason to reject the publication of the Scientific Work. In addition, they must commit to keep confidential information related to the Scientific Work that they evaluate.

Any manuscript received for your arbitration must be treated as confidential, must not be displayed or discussed with other experts, except with the permission of the Editor.

The Referees should conduct themselves objectively, any personal criticism of the Author is inappropriate.

The Arbitrators must express their points of view with clear and valid arguments that contribute to the Scientific, Technological and Innovation of the Author.

The Arbitrators should not evaluate the manuscripts in which they have conflicts of interest and that they have been notified to the Editor before submitting the Scientific Work to evaluation. 


\section{Responsibilities of Authors}

Authors must ensure that their Scientific Works are the product of their original work and that the data have been obtained in an ethical manner.

Authors must ensure they have not been previously published or are not being considered in another serial publication.

Authors must strictly follow the rules for the publication of Scientific Works defined by the Editorial Board.

Authors should consider that plagiarism in all its forms constitutes unethical editorial conduct and is unacceptable, consequently any manuscript that incurs plagiarism will be removed and not considered for publication.

Authors should cite publications that have been influential in the nature of the Scientific Work submitted to arbitration.

\section{Information services}

\section{Indexing - Bases and Repositories}

RESEARCH GATE (Germany)

MENDELEY (Bibliographic References Manager)

GOOGLE SCHOLAR (Citation indices-Google)

REDIB Ibero-American Network of Innovation and Scientific Knowledge-CSIC

\section{Publishing Services}

Citation and Index Identification $\mathrm{H}$

Management of Originality Format and Authorization

Testing of Books with PLAGSCAN

Evaluation of Scientific Work

Issuance of Certificate of Arbitration

Edition of Scientific Work

Web layout

Indexing and Repository

Publication of Scientific Work

Certificate of Scientific Work

Editing Service Billing

\section{Editorial Policy and Management}

143 - 50 Itzopan, Ecatepec de Morelos-Mexico. Phones: +52 1556159 2296, +52 1551260 0355, +52 1556034 9181; Email: contact@ecorfan.org www.ecorfan.org 


\title{
ECORFAN®
}

\section{Chief Editor}

VARGAS-DELGADO, Oscar. PhD

\author{
Executive Director \\ RAMOS-ESCAMILLA, María. PhD \\ Editorial Director \\ PERALTA-CASTRO, Enrique. MsC
}

\section{Web Designer}

ESCAMILLA-BOUCHAN, Imelda. PhD

\author{
Web Diagrammer \\ LUNA-SOTO, Vladimir. PhD
}

Editorial Assistant

REYES-VILLAO, Angélica. BsC

\section{Translator}

DÍAZ-OCAMPO, Javier. BsC

\author{
Philologist \\ RAMOS-ARANCIBIA, Alejandra. BsC
}

\section{Advertising \& Sponsorship}

(ECORFAN ${ }^{\circledR}$-Mexico - Bolivia - Spain - Ecuador - Cameroon - Colombia - El Salvador - Guatemala -Nicaragua-Peru-Paraguay-Democratic Republic of The Congo, Taiwan), sponsorships@ecorfan.org

\section{Site Licences}

03-2010-032610094200-01-For printed material ,03-2010-031613323600-01-For Electronic material,03-2010-032610105200-01-For Photographic material,03-2010-032610115700-14-For the facts Compilation,04-2010-031613323600-01-For its Web page,19502-For the Iberoamerican and Caribbean Indexation,20-281 HB9-For its indexation in Latin-American in Social Sciences and Humanities,671-For its indexing in Electronic Scientific Journals Spanish and Latin-America,7045008For its divulgation and edition in the Ministry of Education and Culture-Spain,25409-For its repository in the Biblioteca Universitaria-Madrid,16258-For its indexing in the Dialnet,20589-For its indexing in the edited Journals in the countries of Iberian-America and the Caribbean, 15048-For the international registration of Congress and Colloquiums. financingprograms@ecorfan.org

\section{Management Offices}

143 - 50 Itzopan, Ecatepec de Morelos-México.

21 Santa Lucía, CP-5220. Libertadores -Sucre-Bolivia.

38 Matacerquillas, CP-28411. Moralzarzal -Madrid-España.

18 Marcial Romero, CP-241550. Avenue, Salinas 1 - Santa Elena-Ecuador.

1047 La Raza Avenue -Santa Ana, Cusco-Peru.

Boulevard de la Liberté, Immeuble Kassap, CP-5963.Akwa- Douala-Cameroon.

Southwest Avenue, San Sebastian - León-Nicaragua.

31 Kinshasa 6593 - Republique Démocratique du Congo.

San Quentin Avenue, R 1-17 Miralvalle - San Salvador-El Salvador.

16 Kilometro, American Highway, House Terra Alta, D7 Mixco Zona 1-Guatemala.

105 Alberdi Rivarola Captain, CP-2060. Luque City- Paraguay.

69 Street. YongHe district, ZhongXin. Taipei-Taiwan.

43 Street \# 30 -90 B. El Triunfo CP.50001. Bogota Colombia. 


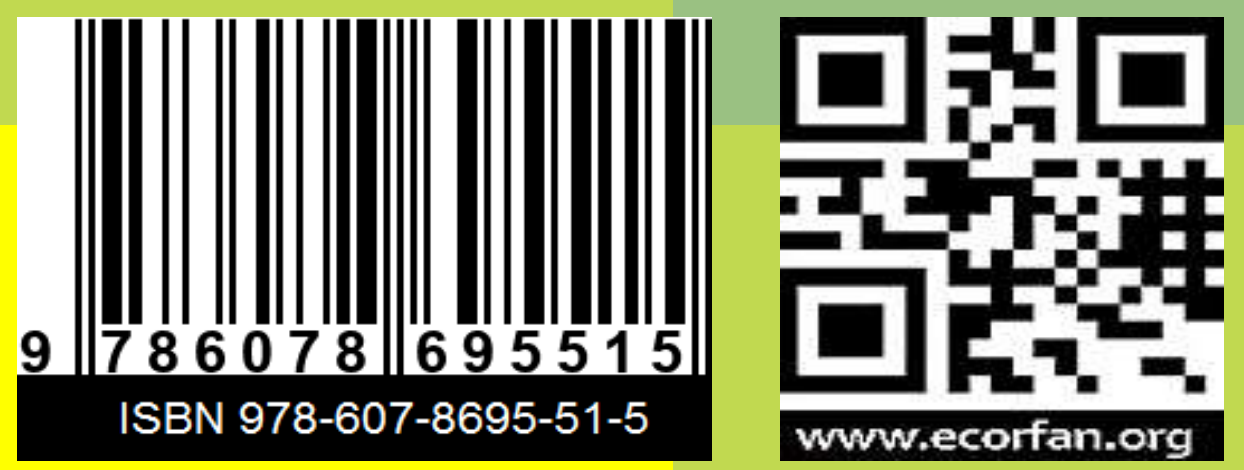

